\title{
The validation of bio-electrical impedance spectroscopy (BIS) for measuring body composition in patients
}

\author{
Citation for published version (APA):
}

Cox-Reijven, P. L. (2002). The validation of bio-electrical impedance spectroscopy (BIS) for measuring body composition in patients. [Doctoral Thesis, Maastricht University]. Universiteit Maastricht. https://doi.org/10.26481/dis.20021114pc

Document status and date:

Published: 01/01/2002

DOI:

10.26481/dis.20021114pc

Document Version:

Publisher's PDF, also known as Version of record

\section{Please check the document version of this publication:}

- A submitted manuscript is the version of the article upon submission and before peer-review. There can be important differences between the submitted version and the official published version of record. People interested in the research are advised to contact the author for the final version of the publication, or visit the DOI to the publisher's website.

- The final author version and the galley proof are versions of the publication after peer review.

- The final published version features the final layout of the paper including the volume, issue and page numbers.

Link to publication

\footnotetext{
General rights rights.

- You may freely distribute the URL identifying the publication in the public portal. please follow below link for the End User Agreement:

www.umlib.nl/taverne-license

Take down policy

If you believe that this document breaches copyright please contact us at:

repository@maastrichtuniversity.nl

providing details and we will investigate your claim.
}

Copyright and moral rights for the publications made accessible in the public portal are retained by the authors and/or other copyright owners and it is a condition of accessing publications that users recognise and abide by the legal requirements associated with these

- Users may download and print one copy of any publication from the public portal for the purpose of private study or research.

- You may not further distribute the material or use it for any profit-making activity or commercial gain

If the publication is distributed under the terms of Article $25 \mathrm{fa}$ of the Dutch Copyright Act, indicated by the "Taverne" license above, 
The validation of Bio-electrical Impedance Spectroscopy (BIS) for measuring body composition in patients 
O Nel Cox-Reijven, Maastricht 2002

ISBN 90-5681-147-9

Druk: Unigraphic, Maastricht

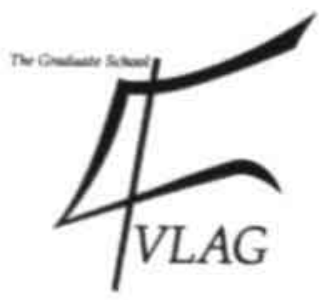

The study presented in this thesis was performed at the Nutrition and Toxicology Research Institute Maastricht (NUTRIM) which participates in the Graduate School VAG (Food Technology. Agrobiotechnology. Nutrition and Health Sciences), accredited by the Royal Netherlands Academy of Arts and Sciences. 


\title{
The validation of Bio-electrical Impedance
}

\section{Spectroscopy (BIS) for measuring body}

\section{composition in patients}

\author{
Proefschrift \\ ter verkrijging van de graad van doctor \\ aan de Universiteit Maastricht, \\ op gezag van de Rector Magnificus, \\ Prof. Dr. A.C. Nieuwenhuijzen Kruseman \\ volgens het besluit van het College van Decanen \\ in het openbaar te verdedigen \\ op donderdag 14 november 2002 om 14:00 uur \\ door
}

Petronella Lucia Martha Cox-Reijven 


\section{Promotor}

Prof. Dr. P.B. Soeters

\section{Co-promotor}

Dr. B. van Kreel

\section{Beoordelingscommissie}

Prof. Dr. K.M.A. Leunissen (voorzitter)

Dr. R.J. Brummer

Dr. P. Deurenberg (Consultant Visiting Professor University "Tor Vergata", Rome, Italië)

Prof. dr. C. Pichard (University Hospital, Geneva, Zwitserland)

Prof. Dr. K. Westerterp

The publication of this thesis was financially supporten by Nutricia Nederland. 
Aan Henk, Marco,

Robbert en Laura 



\section{Contents}

Chapter 1 Introduction and outline of thesis.

Chapter 2 Validation of bio-impedance spectroscopy:

Effect of degree of obesity and ways of caiculating volumes from measured resistance values.

Chapter 3 Accuracy of bio-electrical impedance spectroscopy in measuring changes in body composition during severe weight loss.

Chapter 4 Bio-electrical impedance analysis during severe weight loss.

Comparison of the regression and mixture approach for measuring changes in body fluid compartments.

Chapter 5 Role of bio-impedance spectroscopy in assessment of body water compartments in hemodialysis patients.

Chapter 6 Bio-electrical impedance spectroscopy:

Alternatives for the conventional hand-to-foot measurements.

Chapter 7 Bio-electrical impedance spectroscopy and skinfold measurements for monitoring body composition in children with cystic fibrosis.

Chapter 8 Bio-electrical impedance measurements in patients with gastrointestinal disease. Validation of the spectrum approach and a comparison of different methods for screening nutritional depletion.

Chapter 9 General discussion

Summary

Samenvatting

Appendix I

Appendix II

Appendix III

Nawoord

Curriculum Vitae

Publicaties 



\title{
CHAPTER 1
}

\author{
Introduction and outline of thesis
}




\section{Body composition and nutritional assessment}

During illness body composition can change in relatively short time. The changes depend on the art and severity of the underlying disease. Due to the catabolic influence of disease, patients lose body cell mass, the metabolically active part of the organism. Especially in septic patients these changes are accompanied by fluid shifts leading to overexpansion of $\mathrm{ECW}^{1,2}$ and shrinkage of intracellular mass and water (ICW). Loss of cell mass and ICW lead to depletion of this compartment and to deterioration of nutritional status, which in turn increase complication rates and mortality of disease and treatment of disease ${ }^{3,4,5}$. Nutritional management aims at minimizing loss of body cell mass and at restoring body composition. During this process the monitoring of changes in body composition is essential for screening, diagnostic and therapeutic purposes.

The need for a safe, noninvasive technique that is rapid and convenient and provides reliable and sufficiently accurate estimates of human body composition is great. Most methods to assess body composition, that are currently available are not applicable for routine clinical use by practical constraints. Laboratory methods such as indicator dilution methods, computer tomography, whole-body counting of ${ }^{40} \mathrm{~K}$ and neutron activation analysis for total body nitrogen are very accurate but also expensive, cumbersome, and require sophisticated instrumentation and highly trained technicians ${ }^{6}$. Densitometry, underwater weighing, is less expensive but not suited for patients. Techniques based on anthropometry and skinfold thickness measurements are not reliable enough for use in the individual patient. Furthermore, many indirect methods rely on assumptions, which are not valid during disease states. Changes in fluid balance leading to over- or underhydration will change the density of the fat free mass. In these situations hydrodensitometry and skinfold measurements are not applicable.

For routine clinical use the ideal body composition method should be able to measure body cell mass, or intracellular water, and extracellular water separately with acceptable accuracy. Furthermore the method should be noninvasive and simple to perform at the bedside or in the outpatient clinic. Bioelectrical impedance analysis (BIA), which has proven to be sufficiently accurate to measure total body water in healthy persons? clinical use.

\section{Principles and applications of BIA}

BIA measurements are based on the conduction of an alternating electrical current applied to the human body. This conductivity is largely determined by the amount of body water and the dissolved electrolytes. The body contains intra- and extracellular fluids that behave as electrical conductors and cell membranes that act as capacitors. At low frequencies the current mainly passes through extracellular fluids, whereas at higher frequencies it penetrates the cellular membrane and gets access to intracellular fluid. Impedance $(Z)$ is the frequency-dependent opposition of a conductor to the flow of an alternating electric current and is a function of resistance $(R)$ and reactance $(X c)$, such that:

$$
Z^{2}=R^{2}+X c^{2}
$$

$R$ is equal to the pure opposition to flow of an alternating current, $X c$ is the opposition to flow of electric current caused by capacitance produced by tissue interfaces and cell membranes. Reactance is the reciprocal of capacitance, or the storage of voltage by a condenser for a brief moment in time ${ }^{6}$. At very low and very high frequencies the measured impedance is almost purely resistive. Resistance values measured at different frequencies have been used to predict body composition.

The relationship between total body water and body impedance was first described by Thomassett $^{3}$ and Hoffer, For an aqueous solution of known ionic properties placed in a cylinder of uniform dimensions the volume $(V)$ can be described as: 


$$
V=\rho L^{2} / R
$$

in which $\rho$ is the specific resistivity (ohm.cm), $L$ the conductor length (cm), $R$ the resistance (ohm).

Although there are difficulties in applying this general principle in a system with complex geometry and bioelectrical characteristics like the human body, this relationship has been used to derive models for the prediction of TBW. FFM, ECW and ICW. Usually the impedance is measured from hand to foot and the subjects height is used as surrogate for conductor length. In the human body other factors besides the volume of the conductor influence the measured resistance, such as body temperature ${ }^{10,11}$, body positioning ${ }^{12,13}$, body geometry ${ }^{14-16}$, specific resistivity of different body fluids ${ }^{17.21}$. Standard measurement conditions have been described to control some of these variables (Appendix I).

It is important to realize that different models are currently in use to predict body composition based on BIA measurements. The first generation of instruments measured impedance at one frequency, usually $50 \mathrm{kHz}$. These so-called single-frequency measurements (SF-BIA) led to the publication of prediction equations for TBW or fat free mass, usually based on the resistance index $\left(\mathrm{L}^{2} / \mathrm{R} 50\right)$ with or without inclusion of other variables like gender, weight and other anthropometric measures ${ }^{22.24}$. It was assumed that at $50 \mathrm{kHz}$ the current was conducted by both the ECW and ICW. Although SF-BIA gave acceptable results in healthy subjects with normal body composition, in very lean ${ }^{25.27}$ or obese subjects ${ }^{26-30}$ results were less accurate and for these groups specific equations were developed ${ }^{24,31,32}$. Furthermore, in patients the relationship between R50 and TBW was found to differ from the relationship in healthy individuals. This explains the lower predictive capacity in conditions of dehydration ${ }^{33}$, in patients after cardiac surgery ${ }^{34}$, or overhydration ${ }^{35.36}$ and in dialysis patients ${ }^{37}$, patients with multiple organ failure ${ }^{30}$ and patients with liver disease ${ }^{30}$. Equations developed in healthy individuals were not considered suitable to measure TBW or fat free mass in patients, which lead to publications of disease specific prediction equations ${ }^{40}$. Theoretically SF-BIA is unable to measure fluid compartments separately because at a given frequency the conduction of current by ECW and ICW is individually determined as it is influenced by the fluid distribution between both compartments, the relative conductivity of the compartments and membrane properties. A panel of experts concluded that SF-BIA was not yet useful for clinical applications especially if patients are likely to have an altered body water distribution? ${ }^{7}$. For clinical application it is essential to measure both compartments separately because during fluid imbalance TBW gives no precise information regarding the volume of body cell mass. Newer impedance analyzers made it possible to measure impedance at multiple frequencies. This multi-frequency (MF-BIA) approach resulted in the publication of prediction equations for ECW based on the resistance index at a low frequency ${ }^{14}$, and for TBW based on the results at a high frequencies ${ }^{42.46}$ calibrated against fluid volumes measured by indicator dilution methods. It is not convincingly proven that this last approach yielded better results for predicting TBW than SF-BIA method ${ }^{47}$. In surgical patients ${ }^{46}$, in patients with cirrhosis ${ }^{45}$ and with pulmonary disease ${ }^{40}$ the MF-BIA results were comparable with SF-BIA results.

A more theoretical approach is the bioelectrical impedance spectroscopy (BIS) which uses extrapolated resistance values at zero and infinite frequency (Rinf) by use of the Cole-Cole model ${ }^{50}$. The model assumes a parallel arrangement of the ECW and ICW. The R at zero frequency is called Recw. Rinf is set to be the parallel sum of Recw and the resistance of intracellular water $(\mathrm{RiCW})(1 / \mathrm{Rinf}=1 / \mathrm{Recw}+1 / \mathrm{RicW})$. Fitting the complex impedance data to this biophysical model eliminates any further discussion regarding which frequency to use. This approach resulted in prediction equations based on regression analysis of the resistance index of RecW and Ricw for ECW and ICW respectively ${ }^{40.51}$. Although not in accordance with the BIS theory several TBW predictions based on Rinf have been published $^{52}$. Opponents of this approach claim that no single frequency, including Rinf is theoretically able to predict TBW because TBW is the sum of ECW and ICW. which have different electrical properties like different specific resistivities. The relatively good results obtained by this approach can be explained by the constant relationship between the two fluid volumes in normal healthy conditions, but in cases of disturbed fluid balance or when 
the specific resistivity of one compartment is altered, this approach is likely to fail similarly as the SF-BIA.

The most recent model uses the extrapolated $R$ values in equations based on emulsion sciences and is called the mixing model, often referred to as the Hanai model. Hanai described the resistance of conducting solutions corrected for the concentration of nonconducting particles ${ }^{53}$. Variables in the model include body volume, calculated from body weight and density, height and Recw and Ricw. The specific resistivity of the fluid compartments are included as constants. A detailed description of these equations is presented in appendix III. Theoretically this model should be less population specific than equations developed by regression analysis since it is based on a fundamental approach. The advantage of mixture equations over regressions based on Ricw and Recw has not been studied thoroughly yet. Both improvement ${ }^{7.54,55}$ and no improvement ${ }^{56-56}$ or even worsening ${ }^{43.51}$ of estimations of body compartments by application of mixture equations have been described. Several studies suggest that the resistivity coefficient used should be adjusted for the population measured ${ }^{50-02}$. This implies that also the mixture equation approach fails to assess body composition reliably in different populations.

Compared with the numerous studies in various populations for measuring body composition there has been minimal investigation of the reliability of different BIA approaches for measuring changes in body composition ${ }^{10,63,64}$. Results differ, depending on different comnartments (ECW. fat free mass or fat mass) and the used anoroach. It can be concluded that at present no general accepted procedure is available although several approaches are being used not only for research purposes but also in daily clinical practice.

To study the validity of different BIA approaches comparison with a gold standard is needed. The dilution of compartment specific indicators or tracers is often used as the gold standard for the measurement of the volume of different body compartments. Deuterium dilution is used as reference method for $\mathrm{TBW}^{\mathrm{65}}$ and Bromide dilution for $\mathrm{ECW}^{66}$. At present these dilution methods are the best methods available yielding acceptable accuracies in clinical studies $^{51,56,66}$. Other methods are either not applicable in patients or rely on assumptions not valid during disease states. Furthermore, both the dilution methods and BIS primarily measure the volume of fluid compartments.

\section{Aim of the thesis}

The diversity of BIA models currently in use complicate the clinical application of impedance measurements. From a large number of population and disease specific prediction equations the most appropriate one has to be used. Such choices are very difficult in clinical practice due to the fact that often more than one illness is present. Furthermore, monitoring the body composition during a phase of recovery or during deterioration of the condition of the patient inevitably leads to the question when to apply which specific equation. The ideal approach should be universally applicable and be able to measure fluid compartments separately, with an acceptable accuracy. The indroduction of BIS was one step in the development of such method because a discussion about the optimal frequency to use became unnecessary. For the calculation of fluid compartments from the extrapolated Recw and Ricw values, a model based on physical laws. like the Hanai derived equations, seems to be an attractive alternative for empiric equations. At present, the validity of this approach for clinical application is not clear.

Aim of the present thesis was to assess the validity of BIS in different patient groups and to study if the method is able to measure clinically relevant changes in body composition. Because most body compartments are intercorrelated, the true merit of a body composition assessment method becomes clear in situations where the normal relationship between body compartments is altered. Therefore, the study was performed in different patient groups with alterations in specific body compartments. These included obese subjects with extreme 
amounts of fat mass, dialysis patients with excess ECW, children with cystic fibrosis and patients with gastrointestinal disease susceptible for developing clinical depletion. The following sub-aims can be defined:

1. To study the validity of mixture equations in different populations.

2. To identify in different populations the presence of confounding factors.

3. To assess the accuracy of different BIS approaches (mixture equations and resistance index at different frequencies) for measuring changes in body composition.

\section{Outline of the thesis}

In chapter 2 the validity of BIS with mixture equations was compared with the regression approach in a population with differing degrees of overweight. Also, the effect of the degree of overweight on the prediction errors of mixture equations was studied. Chapter $\mathbf{3}$ describes the accuracy of mixture equations for measuring changes in body composition during severe weight loss in patients undergoing gastric reduction surgery. In chapter $\mathbf{4}$ a comparison of the regression approach and the mixture approach for measuring changes in body composition in obese subjects is presented. Chapter $\mathbf{5}$ describes the results of BIS measurements in hemodialysis patients. The effect of the relative magnitude of the fluid compartments on the agreement between BIS and the dilution method was studied and the accuracy of BIS for measuring changes in fluid compartments was assessed. In chapter 6 results of alternatives for the traditional hand-foot measurements are presented. A comparison of the validity of BIS and of skinfold measurements for monitoring body composition in children with cystic fibrosis is presented in chapter 7. Chapter 8 describes results of BIS measurements in patients with gastrointestinal diseases. The effects of weight loss and the presence of clinical depletion on the accuracy of BIS were studied. Also, the applicability of different approaches for screening of clinical depletion based on BIS measurements was tested. Finally, the results of these studies are discussed and implications for the clinical use of BIS and for future research are described in chapter 9.

\section{References}

1. Finn PJ, Plank LD, Clark MA, Connolly AB, Hill GL. Progressive cellular dehydration and proteolysis in critically ill patients. Lancet. 1996;347:654-656.

2. Cheng AT, Plank L.D. Hill GL.Prolonged overexpansion of extracellular water in elderly patients with sepsis. Arch Surg 1998;133:745-751.

3. Heymsfield SB, Mcmanus C, Stevens V. Smith J. Muscle mass: a reliable indicator of protein energy malnutrition severity and outcome. Am J Clin Nutr 1982;35:1192-1199.

4. Gariballa SE, Parker SG, Taub N, Castleden CM. The influence of nutritional status on clinical outcome after acute ischaemic stroke. Am J Clin Nutr 1998; 68:275-281.

5. Green CJ. Existence, causes and consequences of disease-related malnutrition in the hospital and the community, and clinical and financial benefits of nutritional intervention. Clin Nutr 1999;18(Suppl 2):3-28.

6. Baumgartner RN, Chumlea WC, Roche AF, Bioelectric impedance for body composition. In: Paudolf K, Holloszy J (eds) 1990. Exercise and sport sciences reveiws Vol 18 Chapter 6:193-224.

7. Ellis KJ, Bell SJ, Chertow GM, Chumlea WC, Knox TA, Kotler DP, Lukaski HC, Schoelier DA. Bioelectrical impedance methods in clinical research: a follow-up to the NIH technology assessment conference. Nutrition $1999 ; 15: 874-880$.

8. Thomassett A. Bio-electrical properties of tissue impedance measurements. Lyon Med 1962:207:107-118.

9. Hoffer EC, Meador CK, Simpson DC. Correlation of whole body impedance with total body water volume. J Appl Physiol 1969:27 531-534. 
10. Asselin MC, Kriemler S, Chettle DR, Webber CE, Bar-Or O. Mcneill FE. Hydration status assessed by multi-frequency bioimpedance analysis. Appl Radiat isot 1998;49:495-497.

11. Cornish BH, Thomas BJ, Ward LC. Effect of temperature and sweating on bioimpedance measurements. Appl Radiat Isot 1998:49:475-476.

12. Thomas BJ, Cornish BH, Ward LC, Patterson MA. A comparison of segmental and wrist-to-ankle methodologies of bioimpedance analysis. Appl Radiat Isot 1998;49:477-478.

13. Scharfetter $H$, Monif M, Laszlo Z, Lambauer T, Hutten $H$, Hinghofer-Szalkay $H$. Effect of postural changes on the reliability of volume estimations from bioimpedance spectroscopy data. Kidney Int 1997;51:1078-1087.

14. Foster KR, Lukaski HC. Whole-body impedance--what does it measure? Am J Clin Nutr 1996;64(3 Suppl):388S-396S.

15. Valentinuzzi ME, Morucci JP, Felice CJ. Bioelectrical impedance techniques in medicine. Part II: Monitoring of physiological events by impedance. Crit Rev Biomed Eng 1996;24:353-466.

16. Roos AN, Westendorp RG, Frolich M, Meinders AE. Tetrapolar body impedance is influenced by body posture and plasma sodium concentration. Eur J Clin Nutr 1992;46:53-60.

17. Rees AE, Ward LC, Cornish BH. Thomas BJ. Sensitivity of multiple frequency bioelectrical impedance analysis to changes in ion status. Physiol Meas 1999;20:349-362.

18. Ward LC, Elia M, Cornish B. Potential errors in the application of mixture theory to multifrequency bioelectrical impedance analysis. Physiol Meas 1998;19:53-60.

19. Berneis $\mathrm{K}$, Keller U. Bioelectrical impedance analysis during acute changes of extracellular osmolality in man. Clin Nutr $2000 ; 19: 361-366$.

20. Scharfetter $\mathrm{H}$, Wirnsberger $\mathrm{GH}$, Holzer $\mathrm{H}$, Hutten $\mathrm{H}$. Influence of ionic shifts during dialysis on volume estimations with multifrequency impedance analysis. Med Biol Eng Comput 1997;35:96102

21. Azcue M, Wesson D, Neuman M, Pencharz P. What does bioelectrical impedance spectroscopy (BIS) measure? In: Ellis KJ, Eastman JD (eds). Human body composition: In vivo methods models and assessment. Plenum: New York, 1993 pp:67-70.

22. Lukaski HC,Johnson P, Bolonchuk W, Lykken G. Assessment of fat-free mass using bioelectrical impedance measurements of the human body. Am J clin Nutr 1985;41;810-817.

23. Deurenberg P, Van der Kooij K, Evers P, Hulshof T. Assessment of body composition by bioelectrical impedance in a population aged > 60 y. Am J Clin Nutr 1990; 51:3-6.

24. Segal KR, Van Loan M, Fitzgerald PI, Hodgdon JA, Van Itallie TB. Lean body mass estimation by bioelectrical impedance analysis: a four-site cross-validation study. Am J Clin Nutr 1988;47:7-14.

25. Haderslev KV, Staun M. Comparison of dual-energy X-ray absorptiometry to four other methods to determine body composition in underweight patients with chronic gastrointestinal disease. Metabolism 2000;49:360-6.

26. Simons JP, Schois AM, Westerterp KR, ten Velde GP, Wouters EF. The use of bioelectrical impedance analysis to predict total body water in patients with cancer cachexia. Am J Clin Nutr 1995;61:741-745.

27. Scalf L, Bedogni G, Marra M, Di Biase G, Caldara A, Severi S, Contaldo F, Battistini N. The prediction of total body water from bioelectrical impedance in patients with anorexia nervosa. $\mathrm{Br} \mathrm{J}$ Nutr 1997;78:357-365

28. Hodgdon JA, Fitzgerald PI. Validity of impedance predictions at various levels of fatness. Hum Biol 1987;59:281-98.

29. Segal KR, Gutin B, Presta E, Wang J. Van Itallie TB. Estimation of human body composition by electrical impedance methods: a comparative study. J Appl Physiol 1985;58:1565-1571.

30. Carella MJ, Rodgers CD, Anderson D, Gossain W. Serial measurements of body composition in obese subjects during a very-low-energy diet (VLED) comparing bioelectrical impedance with hydrodensitometry. Obes Res 1997;5:250-256.

31. Gray DS, Bray GA, Gemayel N, Kaplan K. Effect of obesity on bioelectrical impedance. Am J Clin Nutr 1989;50:255-260.

32. Battistini N, Brambilla P, Virgili F, Simone P, Bedogni G, Morini P, Chiumello G. The prediction of total body water from body impedance in young obese subjects. Int J Obes 1992:16:207-212.

33. De Lorenzo A, Barra PFA, Sasso G, Battistini NC, Deurenberg P. Body impedance measurements during dialysis Eur J Clin Nutr 1991;45:321-325.

34. Yamaguchi H, Yamauchi H. Hazama S, Hamamoto $H$. Evaluation of body fluid status after cardiac surgery using bioelectrical impedance analysis. J Cardiovasc Surg (Torino) 2000;41:559-566.

35. Deurenberg $P$. Weststrate JA. Hautvast JGAJ. Changes in fat free mass during weight loss measured by bioelectric impedance and by densitometry. Am J Clin Nutr 1989;49:33-36. 
36. De Lorenzo A, Deurenberg P, Andreoli A, Sasso GF, Palestini M, Docimo R. Multifrequency impedance in the assessment of body water losses during dialysis. Renal Physiol Biochem 1994:17:326-332.

37. Kurtin PS, Shapiro AC, Tomita H. Raizman D. Volume status and body composition of chronic dialysis patients: utility of bioelectric impedance plethysmography. Am J Nephrol 1990;10:363367.

38. Foley K, Keegan M, Campbell I. Murby B, Hancox D. Pollard B. Use of single-frequency bioimpedance at $50 \mathrm{kHz}$ to estimate total body water in patients with multiple organ failure and fluid overload. Crit Care Med 1999,27:1472-1477.

39. Schloerb PR, Forster J, Delcore R. Kindscher JD. Bioelectrical impedance in the clinical evaluation of liver disease. Am J Clin Nutr 1996;64(3 Suppl):510S-514S.

40. Pencharz PB, Azcue M. Use of bioelectrical impedance analysis measurements in the clinical management of malnutrition. Am J Clin Nutr 1996;64(3 Suppi):485S-488S.

41. Marx G, Vangerow B, Burczyk C. Gratz KF. Maassen N, Cobas Meyer M, Leuwer M. Kuse E, Rueckholdt. Evaluation of noninvasive determinants for capillary leakage syndrome in septic shock patients. Intensive Care Med 2000;26:1252-1258.

42. Ritz P. Bioelectrical impedance analysis estimation of water compartments in elderly diseased patients: the source study. J Gerontol A Biol Sci Med Sci 2001;56:M344-M348.

43. Hannan WJ, Cowen S.J, Plester C. Fearon KC. Proximal and distal measurements of extracellular and total body water by multi-frequency bio-impedance analysis in surgical patients. Appl Radiat isot 1998; $49: 621-622$.

44. Deurenberg P. Tagliabue A, Schouten FJ. Multi-frequency impedance for the prediction of extracellular water and total body water. Br J Nutr 1995;73:349-358.

45. Lehnert ME, Clarke DD, Gibbons JG, Ward LC, Golding SM, Shepherd RW, Cornish BH, Crawford $\mathrm{DH}$. Estimation of body water compartments in cirrhosis by multiple-frequency bioelectrical-impedance analysis. Nutrition 2001:17:31-34.

46. De Lorenzo A, Sasso GF, Andreoli A, Sorge R, Candeloro N, Cairella M. Improved prediction formula for total body water assessment in obese women. Int $\mathrm{J}$ Obes Relat Metab Disord 1995; 19:535-538.

47. Simpson JA, Lobo DN, Anderson JA, Macdonald IA, Perkins AC, Neal KR, Allison SP, Rowlands BJ. Body water compartment measurements: a comparison of bioelectrical impedance analysis with tritium and sodium bromide dilution techniques. Clin Nutr 2001;20:339-343.

48. Hannan WJ, Cowen SJ, Fearon KC, Plester CE, Falconer JS, Richardson RA. Evaluation of multifrequency bio-impedance analysis for the assessment of extracellular and total body water in surgical patients. Clin Sci (Lond) 1994;86(4):479-485.

49. Baarends EM, van Marken Lichtenbelt WD, Wouters EF, Schols AM. Body-water compartments measured by bio-electrical impedance spectroscopy in patients with chronic obstructive pulmonary disease. Clin Nutr 1998;17:15-22.

50. Cole KS. Membranes, Ions and Impulses: A Chapter of Classical Biophysics. Berkeley, CA: Univ. of Calif. Press. 1972.

51. Gudivaka R, Schoeller DA, Kushner RF, Bolt MJ. Single- and multifrequency models for bioelectrical impedance analysis of body water compartments. J Appl Physiol 1999;87:1087-1096.

52. van Marken Lichtenbelt WD, Westerterp KR, Wouters L, Luijendijk SC. Validation of bioelectricalimpedance measurements as a method to estimate body-water compartments. Am J Clin Nutr $1994 ; 60: 159-166$.

53. Hanai T. Electrical properties of emulsions. In: Sherman PH (ed). Emulsion science. Academic: Londodn, 1968, pp 354-477.

54. Bradbury MG, Smye SW, Brocklebank JT. Measurement of intercompartmental fluid shifts during haemodialysis in children. Physiol Meas 2001:22:351-363.

55. Earthman CP. Matthie JR, Reid PM, Harper IT, Ravussin E, Howell WH. A comparison of bioimpedance methods for detection of body cell mass change in HIV infection. J Appl Physiol $2000 ; 88: 944-956$.

56. Chumlea WC, Guo SS, Baumgartner RN, Siervogel RM. Determination of body fluid compartments with multiple frequency bioelectric impedance In: Ellis KJ, Eastman JD (eds) Human body composition: In Vivo Methods, Models and Assessment. Plenum: New York, 1993, pp23-26.

57. Sodenberg M, Hahn RG, Cederholm T. Bioelectric impedance analysis of acute body water changes in congestive heart failure. Scand J Clin Lab Invest 2001;61:89-94.

58. Ho LT, Kushner RF, Schoeller DA, Gudivaka R, Spiegel DM. Bioimpedance analysis of total body water in hemodialysis patients. Kidney int 1994;46:1438-1442. 
59. Van Loan MD, Kopp LE, King JC, Wong WW, Mayclin PL. Fluid changes during pregnancy: use of bioimpedance spectroscopy. J Appl Physiol 1995;78:1037-1042.

60. van Marken Lichtenbelt WD, Snel YE, Brummer RJ, Koppeschaar HP. Deuterium and bromide dilution, and bioimpedance spectrometry independently show that growth hormone-deficient adults have an enlarged extracellular water compartment related to intracellular water. J Clin Endocrinol Metab 1997;82:907-911.

61. Ellis KJ, Wong WW. Human hydrometry: comparison of multifrequency bioelectrical impedance with $2 \mathrm{H} 2 \mathrm{O}$ and bromine dilution. J Appl Physiol 1998:85:1056-1062.

62. De Lorenzo A, Andreoli A, Matthie J, Withers P. Predicting body cell mass with bioimpedance by using theoretical methods: a technological review. J Appl Physiol 1997;82:1542-1558.

63. Simons JP, Schols AM, Westerterp KR, Ten Velde GP, Wouters EF. Bioelectrical impedance analysis to assess changes in total body water in patients with cancer. Clin Nutr 1999;18:35-39.

64. Plank LD, Monk DN, Woollard GA, Hill GL. Evaluation of multifrequency bioimpedance spectroscopy for measurement of the extracellular water space in critically ill patients. Appl Radiat Isot 1998;49:481-483.

65. Westerterp KR, Wouters L, Van Marken Lichtenbelt WD. The Maastricht protocol for the measurement of body composition and energy expenditure with labeled water. Obes Res 1995;3(Suppl 1):49-57.

66. Van Kreel BK. An improved bromide assay for the estimation of extracellular water volume by capillary gas chromatography, Clin Chim Acta 1994;231:117-128. 


\section{CHAPTER 2}

\section{Validation of bio-impedance spectroscopy: \\ Effects of degree of obesity and ways of calculating \\ volumes from measured resistance values}

PLM Cox-Reijven' and PB Soeters ${ }^{2}$.

Departments of 'Dietetics and ${ }^{2}$ Surgery.

University Hospital Maastricht, Netherlands.

Int J Obes 2000; 24:172-280 


\begin{abstract}
Background:

Bioelectrical-impedance spectroscopy (BIS) is a very attractive method for body composition measurements in a clinical setting. However, validation studies often yield different results. This can partly be explained by the different approaches used to transform measured resistance values into body compartments.

Objective:

Aim of this study was to compare the linear regression (LR) method with the Hanai mixture theory (HM). Secondly, the effect of degree of overweight on the accuracy of BIS was analysed.

Design:

In 90 persons (10 M, $80 \mathrm{~F}$; body mass index (BMI) $23-62 \mathrm{~kg} / \mathrm{m}^{2}$ ) total body water (TBW) and extracellular water (ECW) were measured by deuterium and $\mathrm{NaBr}$ dilution methods, respectively and by BIS. Resistance values of ECW (Recw) and TBW (Rtbw) were used for volume calculations. Data of half the group were used for $L R$ based on $L^{2} / R$ ( $L=$ length, $R=$ resistance) to predict TBW and ECW and to calculate the constants used in the HM (kecw, kp). Prediction equations and constants were cross validated in group 2.

Results:

Bland and Altman analysis showed that the LR method underestimated TBW by $1.1 \mathrm{~L}$ $(P<0.005)$ and $E C W$ by $1.1 \mathrm{~L}(P<0.005)$. The $\mathrm{HM}$ approach underestimated $\mathrm{ECW}$ by $0.8 \mathrm{~L}$ $(\mathrm{P}<0.005)$. The correlations with the dilution methods and the SEEs for TBW and ECW were comparable for the two approaches. The prediction error of BIS for TBW and ECW correlated with BMI. The constant kecW, and the specific resistivities of the ECW and intracellular water (ICW) pecw and picw were also correlated with BMI.

Conclusions:

The mixture approach is slightly more accurate than linear regression, but not sensitive enough for clinical use. The constants used in the HM model are not constants in a population with a wide variation in degree of overweight. The physical causes of the correlation between BMI and constants used in the model should be studied further in order to optimize the mixture model.
\end{abstract}




\section{Introduction}

There is a great need for a simple, non-invasive method to measure body composition in a clinical setting. Until now no suitable methods have been available. Most techniques are too invasive, too expensive or not accurate enough because they rely on assumptions which are not valid in ill patients. Furthermore, most methods can not be used for repeated measurements, which are necessary for monitoring changes in body composition.

Bio-electrical impedance analysis (BIA) is a simple, non-invasive method which can be performed repeatedly. However, the underlying physical principles are poorly understood'. BIA measures the resistance of the body to an alternating current. Until a decade ago a current of $800 \mu \mathrm{A}, 50 \mathrm{kHz}$ was used. Measured resistance was used as a measure for total body water (TBW). It was thought that at this frequency the current was conducted by all conducting material in the body, based on measurements in muscie ${ }^{2}$. In the last 10 years numerous regression equations were published. These equations used measured resistance or impedance together with anthropometric variables to predict TBW or fat free mass (FFM). For clinical use this single-frequency BIA is not applicable because of the population specific approach and because the accuracy, as expressed by the reported standard error of estimation (SEE), varies from 1.4 to $3.5 \mathrm{~L}$ for $\mathrm{TBW}^{3}$. This is insufficient for use in individual patients. Furthermore, as fluid shifts are often present in patients, TBW is not a good measure for nutritional status, because it includes besides intracellar water also extracellular water, which may be expanded in depletion and disease $e^{4.5}$. Intracellular water (ICW) or body cell mass (BCM) would therefore be more appropriate for nutritional assessment, as this compartment represents the active living part of the body.

The development of new impedance analysers made it possible to measure impedance at different frequencies. This technique is called bio-electrical impedance spectroscopy (BIS). At low frequencies the current is conducted by ECW because cell walls and tissue interfaces act as condensers. At higher frequencies this capacitive effect is lost and the current will pass through all conducting material. Theoretically, this property makes it possible to measure ECW as well as ICW, based on their relative resistivities, and thus also TBW. Furthermore, it was shown that at $50 \mathrm{kHz}$ the current is often not completely conducted by TBW. making the use of single frequency BIA questionable ${ }^{6}$.

This newer technique led to a new series of population specific equations, either based on resistance values at single frequencies ${ }^{6-11}$ or on extrapolated resistances at 0 (Recw) and infinite frequency (Rtbw), reflective of ECW and TBW respectively ${ }^{12,13}$. Another approach is based on a theoretical equation developed by $\mathrm{Hanai}^{14}$, which describes the conductivity of suspensions. Because this method is based on a fundamental approach it might be immune to inter-subject variability. Therefore, the model could theoretically be used in all patients. assuming certain constants are indeed constant. The number of papers describing the results of this approach is growing ${ }^{12,15-21}$. While some investigators report very promising results $^{19.21}$, others claim that BIS based on emulsion sciences or on regression analysis does not improve the results of single frequency measurements ${ }^{7.8 .9 .12 .13}$. One assumption in the emulsion science derived equations is that the specific resistivities (p) of ECW (pecw) and ICW (picw) are constants. However, more research is needed to determine appropriate resistivity coefficients and whether population -or patient specific values are necessary.

In this study we will compare the results of (BIS) with indicator dilution methods for measuring TBW and ECW in a population with differing degrees of overweight. The regression approach on Rtbw and Recw as used in many published studies, was compared with the Hanai-derived predictions of fluid volumes. The constants used in this model were analysed. 


\section{Theoretical description}

\section{General principles}

Bioelectrical impedance analysis (BIA) measures tissue conductivity. Under stable conditions the conductivity of a body is directly proportional to the amount of electrolyte-rich fluid present. BIA can therefore be used to measure several fluid compartments, including TBW, ECW and ICW. Fat is anhydrous and thus all body fluids, including the water present in adipose tissue, reside in the fat-free mass component ${ }^{22}$.

Impedance ( $\mathrm{Z})$ is the frequency-dependent opposition of a conductor to the flow of an administered alternating current. This opposition has two components or vectors, termed resistance $(R)$ and reactance $(X c)$, which are linked mathematically as $^{23}$ :

$$
Z^{2}=R^{2}+X c^{2}
$$

$R$ is the pure opposition of the conductor to the flow of current. Reactance is related to capacitance produced by tissue interfaces and by cell membranes. Capacitance causes the administered current to lag behind the voltage and creates a phase shift that is represented geometrically as the phase angle or arc tangent of the ratio $\mathrm{Xc} / \mathrm{R}^{24}$.

The impedance of tissues is strongly dependent on frequency. At low frequencies the impedance of the cell membranes and tissue interfaces is too large for conduction of current within the cells to occur. As a result the current is conducted only through the extracellular fluid. Thus the measured impedance is considered resistive with no reactive component ${ }^{24}$. As frequency increases reactance increases because the capacitive properties start to retard the current, and resistance decreases. At a critical frequency the reactance is maximal. At frequencies exceeding this critical frequency the current flow in the intracellular route will increase, as cell membranes and tissue interfaces start to lose their capacitive ability ${ }^{24}$. This frequency dependence can be modeled empirically by a function. The most widely used model is the Cole-Cole equation. A plot of reactance versus the resistance at different frequencies results in a semicircular arc, the center of which is depressed below the real axis 1. Fitting the measured impedance data to this model the resistance at zero and at infinite frequency can be extrapolated which are the resistances of ECW and TBW respectively. The resistance of ICW can be calculated from the electrical circuit model of a parallel combination of a resistor and capacitor:

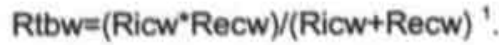

\section{Volume equations}

The resistance of a component with a homogeneous cross-sectional area and homogeneous resistivity can be described as:

$$
V=p\left(L^{2} / R\right)
$$

where $V=$ volume $(\mathrm{L}), p=$ specific resistivity (ohm. $\mathrm{cm}$ ), $\mathrm{L}=$ lenght $(\mathrm{cm}) \mathrm{R}=$ measured resistance. To calculate volumes from measured impedance investigators have followed different procedures. The older single-frequency BIA data were used to develop population specific equations to calculate TBW. These equations had as dependent variables $L^{2} / R_{s o}$ with or without weight, gender and age. Multi-frequency BIA generated new equations for ECW and TBW with regression equations based on $L^{2} / R_{x}$ at fixed frequencies $(x)$, in which $x$ was low $(1-5 \mathrm{kHz})$ for $\mathrm{ECW}^{7.216}$ and high $(>50 \mathrm{kHz})$ for TBW predictions ${ }^{7.216,17}$, or with the extrapolated resistances Recw and Rtbw ${ }^{12.13}$. The software of the Xitron $4000 \mathrm{~B}$ model we used, contains volume prediction equations based emulsion sciences, a theory developed by 
Hanai $^{14}$. This theory describes the effect of a concentration of nonconductive material on the apparent resistivity $(p)$ of the surrounding conductive fluid, and is

$p=p_{0} d\left((1-C)^{32}\right)$

$p_{0}=$ the actual resistivity of a conductive material;

$\mathrm{C}=$ volumetric concentration of the nonconductive material contained in the mixture.

The volumetric concentration of nonconductive elements in the body at low frequencies is:

\section{1-(Vecw/Ntot)}

where Vtot $=$ the total body volume.

At high frequencies this is:

\section{1-(Vecw+Vicw) Ntot}

From the Hanai equation the following set of equations were derived:

$$
\begin{aligned}
& V e c w=k e c w\left(L^{2} W t^{1 / 2} / R e\right)^{23} \\
& \text { kecw }=(1 / 1000)\left(\left(\mathrm{Kb}^{2} \text { pecw }{ }^{2}\right) / \mathrm{Db}\right)^{1 / 3} \\
& \mathrm{~Kb}=\left(1 / \mathrm{L}^{2}\right)\left(\left(\left(\mathrm{Ll} / \mathrm{Cl}^{2}\right)+\left(\mathrm{LVCt}^{2}\right)+\left(\mathrm{La} / \mathrm{Ca}^{2}\right)\right)\left(2 \mathrm{LaCa}^{2}+2 \mathrm{LICl}{ }^{2}+\mathrm{LtCt}^{2}\right)\right) \\
& (1+V i c w / N e c w)^{5 / 2}=((\operatorname{Re}+R i) / R i)(1+(k p V i c w / N e c w)) \\
& k p=p i c w / p e c w \\
& \text { VecW }=\text { the predicted ECW }(\mathrm{L}) ; \text { VicW }=\text { the predicted ICW } \\
& \mathrm{Wt}=\text { weight }(\mathrm{kg}) \text {; } \\
& \mathrm{L}=\text { Length }(\mathrm{cm}) \text {; } \\
& \mathrm{Re}=\text { resistance of extracellular water }(\mathrm{ohm}) \text { from model fitting; } \mathrm{Ri}=\text { resistance of } \\
& \text { intracellular water (ohm) from model fitting. } \\
& \mathrm{Db}=\text { body density }\left(\mathrm{kg} / \mathrm{cm}^{3}\right) \text {; } \\
& \mathrm{La}, \mathrm{LI} \text { and } \mathrm{Lt} \text { are the length respectively of an arm, leg and trunk }(\mathrm{cm}) \text {; } \\
& \mathrm{Ca}, \mathrm{Cl} \text { and } \mathrm{Lt} \text { are the circumference, respectively of an arm, leg and trunk }(\mathrm{cm}) \text {. }
\end{aligned}
$$

Kecw is considered a constant.

$\mathrm{Kb}$ is a factor correcting for a whole body measurement between wrist and ankle, relating the relative proportions of the leg, arm, trunk and height.

With equations 1 and 4 , ECW and ICW can be calculated from the Re and Ri values obtained from fitting the data to the Cole-Cole model, and from measured length and weight. Kecw is a constant, set at a different value for man and women.

TBW is calculated as the sum of ECW and ICW. For an extensive explanation of the equations used by the Xitron $4000 \mathrm{~B}$ software, and the assumptions used, we refer to the paper of De Lorenzo et al $^{19}$.

\section{Subjects and methods}

In a group of subjects with varying degree of overweight body composition was measured by indicator dilution methods and by BIS using the manufacturer's software.

In Part I two ways of calculating fluid volumes from extrapolated resistances of extracellularand total body water were compared by dividing the total group into two comparable subgroups. From the data of the first group constants used in the software of the manufacturer for calculating TBW and ECW were derived. Secondly, prediction equations were derived in 
this group based on linear regression using the dilution values as dependent variable and the resistance values, body weight and length as independent variables. The accuracy of both approaches were compared by predicting TBW and ECW in the second group.

In Part II the effect of the degree of overweight, using the independent variable body mass index (BMl: $\mathrm{kg} / \mathrm{m}^{2}$ ), on the difference between the two methods was studied using data of all measurements (group 1 and group 2). The equations for calculating body fluid volumes were further analysed by calculating the constants used in the model. The effect of the degree of overweight on the values of these constants was evaluated.

\section{Population}

The population consisted 90 of people, 10 males, 80 females. Their body mass index (BMI) varied from 23 to $56 \mathrm{~kg} / \mathrm{m}^{2}$. Written informed consent was obtained from all participants. The study was approved by the Medical Ethical Committee of the University Hospital Maastricht. The group was divided into two comparable subgroups (table 1).

Table 1. Physical characteristics of the subjects'

\begin{tabular}{lccc}
\hline & Group 1 & Group 2 & Total \\
\hline Number & 45 & 45 & 90 \\
M/F & $5 / 40$ & $5 / 40$ & $10 / 80$ \\
Age (years) & $34.6(9.5)$ & $37.5(8.9)$ & $36.0(9.2)$ \\
Weight (kg) & $118.2(24.9)$ & $105.6(25.2)$ & $111.9(25.0)$ \\
Length (cm) & $165.8(9.9)$ & $164.4(7.1)$ & $165.1(8.5)$ \\
BMI (kg/m $\left.{ }^{2}\right)$ & $40.5(8.9)$ & $38.9(8.2)$ & $39.7(8.5)$ \\
TBW (L) & $41.0(6.4)$ & $40.0(6.8)$ & $40.5(6.6)$ \\
ECW (L) & $19.9(4.1)$ & $19.4(3.1)$ & $19.6(3.6)$ \\
\hline 'Mean values, SD in parentheses. TBW, total body water (Deuterium dilution); & \\
ECW, extracellutar water (Br dilution) &
\end{tabular}

\section{Body composition}

Anthropometric measurements were performed in the morning after an overnight fast. Weight was measured to the nearest $0.1 \mathrm{~kg}$ and length to the nearest $0.1 \mathrm{~cm}$. For the calculation of constants used in the Xitron software the following lengths and circumferences were also measured in a subgroup of 56 persons: shoulder height, length of arm, leg and trunk, circumference of wrist, upper arm, ankle, upper leg, hip and waist. From these values the mean circumferences of arm, leg and trunk were calculated. Length and mean circumferences of arm, leg and trunk were used for calculation of $\mathrm{Kb}$ according to equation 3 . Total body water and extracellular water were measured by deuterium oxide dilution and $\mathrm{NaBr}$ dilution respectively. In the morning, fasted patients drank a mixture of $5 \mathrm{~g}$ deuterium labelled water $\left(\mathrm{D}_{2} \mathrm{O}: 99.84\right.$ atom percentage excess) and $30 \mathrm{ml} 150 \mathrm{mM} \mathrm{NaBr}$. Before and 4 hours after ingestion of the indicators saliva and blood samples were obtained for deuterium and bromide analysis respectively. During the 4 hour interval people stayed in the hospital. They were allowed to move freely and to drink $200 \mathrm{ml}$ water during the first 2 hours. Eating 
was not allowed. Deuterium was analysed with an isotope ratio mass spectroscope ${ }^{25}$. Bromide was analysed by ion chromatography as described by Wong ${ }^{20}$. Plasma was not deproteinized by the use of a filter, but by acetonitrile.

TBW was calculated by correcting the Deu-dilution space with $4 \%$ for exchange of labile hydrogen. ECW was calculated by correcting the Br-dilution space with 0.90 for nonextracellular distribution of $\mathrm{Br}$ and with 0.95 for the Donnan equilibrium.

\section{Bio-electrical impedance spectroscopy (B/S)}

BIS measurements were performed just before subjects drank the indicator mixture. Subjects lay on a bed with legs separated and arms abducted from the body. A tetra-polar electrode (3M red Dot $\mathrm{Ag} / \mathrm{AgCl}$ ) arrangement as described by Lukaski et al. was used ${ }^{23}$. Impedance was measured with a Xitron $4000 \mathrm{~B}$ bio-electrical impedance spectrometer (Xitron technologies, San Diego, California) using 48 frequencies, ranging from 5 to $500 \mathrm{kHz}$. Measurements were done at the right and left side of the body. Mean values of resistances and fluid volumes were used for analysis of the data. From all 48 measured resistance and reactance values the resistance of the extracellular (Recw) and intracellular (Ricw) fluid was extrapolated by using the Xitron curve-fit software. All fits were classified as "good" or "excellent". Recw and Ricw were used in equations based on Hanai mixture theory for calculating body fluid comparments. Resistance of total body water (Rtbw) was calculated as:

Rtbw=(Ricw* Recw) / (Ricw + Recw) '

\section{Statistical analysis}

Statistical evaluation was performed with SPSS PC program for Windows. Regression analysis was performed in group 1 with the body fluids measured by the dilution methods as dependent, and $L^{2} / R e c w$ or $L^{2} / R$ tbw as independent variables. Body fluids were calculated with these equations in group 2 and compared, using the method described by Bland and Altman $^{27}$, with values obtained using the Hanai mixture theory. Differences between values obtained by different methods were statistically tested by paired $t$-test. Correlation coefficient analysis was performed to test the linear relationship between BMI and other variables.

\section{Results}

\section{Part I}

From the results of the measurements in group 1 the following regression equations were derived:

$T B W=0.458\left(L^{2} / R\right.$ tbW $)+0.06^{\circ} W t+0.08 \quad\left(R^{2}=0.914 ; S E E=1.91\right)$

$E C W=0.351\left(L^{2} / R e c W\right)+0.05^{\circ} W t-3.511\left(R^{2}=0.769 ; S E E=2.00\right)$

$\mathrm{L}=$ length $(\mathrm{cm})$;

Wt $=$ weight $(\mathrm{kg})$;

Rtbw= extrapolated resistance of total body water (ohm);

Recw= extrapolated resistance of extracellular water (ohm).

The constants used in the Hanai model were calculated and were Kecw= 0.3003 $(S D=0.0297)$ for females and $0.3304(S D=0.0257)$ for males and $K p=3.026(S D=0.3601)$ for females and $2.827(S D=0.3513)$ for males. These values were different from those used in the Xitron's software ( $k e c w=0.338, K p=2.968$ ). 
With these results the fluid volumes in group 2 were calculated. Figure 1 shows the results of both caiculations. Results are summarized in table 2. For TBW, use of the regression equation underestimated the volume significantly by $1.1 \mathrm{~L}$. The $95 \%$ limits of agreement were -3.7 and $+5.9 \mathrm{~L}$. Predicting TBW with the Hanai based equation using the old as well as the new constant did not lead to systematic over- or under estimation. Use of the new constant however improved the accuracy as the mean difference decreased from 0.5 to $0.3 \mathrm{~L}$ and the SD of the difference decreased from 2.3 to $2.1 \mathrm{~L}$. The $95 \%$ limits of agreement were -4.1 and +5.1 for the old constants and -3.9 and 4.5 for the new constants. Correlation between the dilution method and the prediction based on the mixture theory only slightly improved by the use of new constants.

Calculation of ECW by the regression equation resulted in a significant underestimation of $1.1 \mathrm{~L}$. The $95 \%$ limits of agreement were -2.5 and 4.7 . Use of the old constant in the BIS model significantly overestimated ECW by $1.8 \mathrm{~L}$ ( $95 \%$ limits of agreement -5.4 and 1.8 ) and with the use of the new constant this changed in a slight, but significant underestimation of $0.8 \mathrm{~L}(95 \%$ limits of agreement -2.6 and 4.2 ). The correlation between the methods did not improve.

A

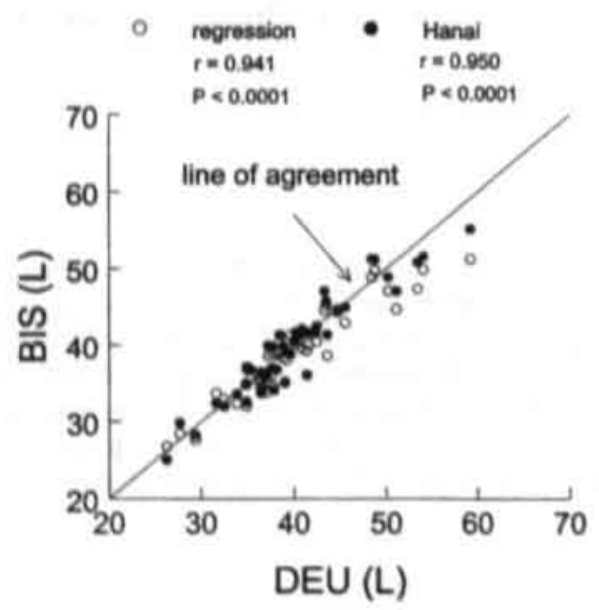

B

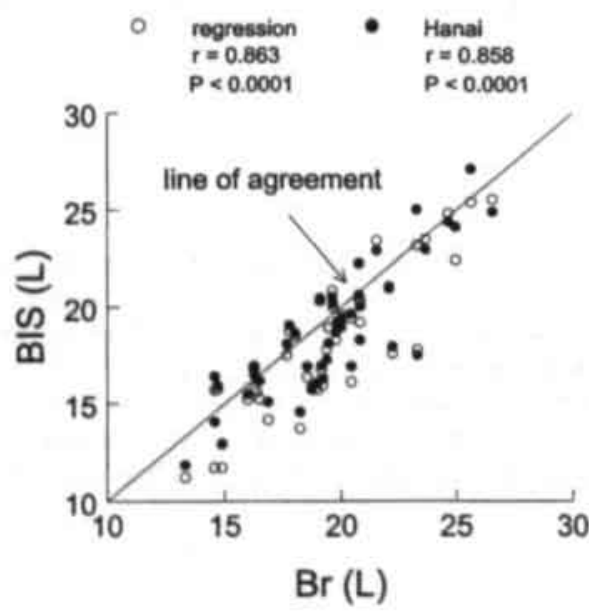

Figure 1. Body water compartments in group 2 predicted by BIS using the linear regression approach and the Hanai mixture approach against values from the indicator dilution methods. A: Total body water. B: Extracellular water.

\section{Part 2}

For all measurements fluid volumes measured by dilution methods were compared with results of BIS using the manufacturers software (old constants). Bland and Altmann analysis (fig. 2 and 3) did not yield systematic differences between BIS and Deu-dilution. The SEE was 2.26 for TBW. No correlation between the difference of the methods and their mean value was found. For ECW BIS overestimated ECW with a mean value of $2.27 \mathrm{~L}$, but the size of the fluid compartment did not correlate with the difference between the methods. SEE for ECW was $1.9 \mathrm{~L}$. 
Table 2. Comparison of body fluid compartments in group 2 measured with dilution techniques and bioelectrical impedance spectroscopy (BIS).'

\begin{tabular}{|c|c|c|c|}
\hline & Volume (L) & $\begin{array}{l}\text { Difference } \\
\text { (dilution - } \\
\text { calculation) }\end{array}$ & $\begin{array}{l}\text { Correlation } \\
\text { with } \\
\text { dilution }\end{array}$ \\
\hline \multicolumn{4}{|l|}{ TBW } \\
\hline dilution & $40.0(6.8)$ & & \\
\hline \multicolumn{4}{|l|}{ calculations: } \\
\hline regression & $38.9(5.8)^{\circ}$ & $1.1(2.4)$ & 0.941 \\
\hline BIS (old constants) & $39.6(6.5)$ & $0.5(2.3)$ & 0.943 \\
\hline BIS (new constants) & $39.7(6.7)$ & $0.3(2.1)$ & 0.950 \\
\hline \multicolumn{4}{|l|}{ ECW } \\
\hline dilution & $19.4(3.1)$ & & \\
\hline calculations: & $18.3(3.5)^{\circ}$ & $1.1(1.8)$ & 0.863 \\
\hline BIS (old constants) & $21.2(3.4)^{\circ}$ & $-1.8(1.8)$ & 0.863 \\
\hline BIS (new constants) & $18.6(3.3)^{*}$ & $0.8(1.7)$ & 0.858 \\
\hline
\end{tabular}

\footnotetext{
'Mean values, SD in parentheses. Volumes were calculated from the extrapolated resistance values of ECW (extracellular water) and TBW (total body water) using linear regression analysis or the Hanai mixture theory with constants provided by the software (old constants) or with newly derived constants (new constant).

•Significant different from dilution value, paired T-test (P<0.005).
}
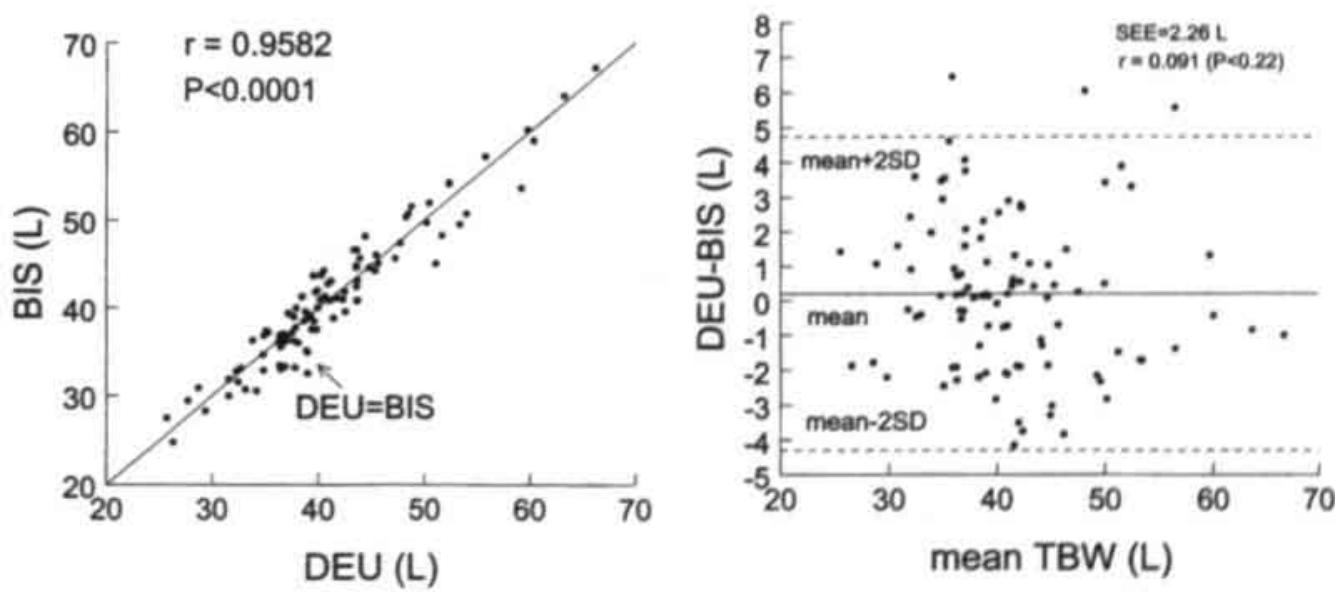

Figure 2. Comparison of total body water (TBW) measured with deuterium dilution (DEU) and bioelectrical impedance spectroscopy (BIS) in the total population. A: The correlation between the two methods. B: Difference between the two methods against their mean value. The horizontal line indicates the mean difference (bias) and the dotted lines indicate the $95 \%$ limits of agreement. Mean difference was not significantly different from 0 . 
The error for predicting TBW as well as for ECW was correlated with the degree of overweight, expressed as BMI (fig. 4). Correlation coefficients were -0.4721 for ECW $(P<0.0001)$, and -0.4607 for TBW ( $<<0.0001)$.

The calculated Kecw also correlated with BMI $(r=-0.352, \mathrm{P}<0.001)$ (fig.5). This constant for calculating ECW volumes incorporates three factors which are considered constant: the body density (Db), the specific resistivity of ECW (pecw) and a correction factor for a whole body measurement between wrist and ankle, relating the relative proportions of the leg, arm, trunk, and height $(\mathrm{Kb})$. However, in very obese people $\mathrm{Db}$ and $\mathrm{Kb}$ can deviate from normal values which were set at $1.05 \mathrm{~kg} / \mathrm{L}$ and 4.3 respectively in the BIS software. The anthropometric data of 56 persons were used to calculate the $\mathrm{Kb}$ factor used in the model. The body density was derived by calculating the amount of fat based on the TBW values from Deu-dilution. The mean value for $\mathrm{Kb}$ was 4.9 in our population, ranging from 3.5 to 6.5 . The $\mathrm{Kb}$ factor increased with increasing BMI $(r=0.432, \mathrm{P}<0.0001)$ and consequently was not responsible for the negative correlation between Kecw and BMI. The body density (Db) decreased with increasing $\mathrm{BMI}(r=-0.5617, \mathrm{P}<0.0001)$. Substituting $\mathrm{Kb}$ and $\mathrm{Db}$ in the equation describing Kecw resulted in values for pecw, the specific resistivity. Figure 6 shows the values of pecw plotted against the corresponding BMI of the subjects. Pecw was more strongly correlated with BMI than Kecw $(r=-0.641, \mathrm{P}<0.0001)$. The mean value for $\mathrm{kp}$ (picw/pecw) was 2.935 $(\mathrm{SD}=0.367)$. $\mathrm{kp}$ was not correlated with the BMI $(r=0.094)$. The specific resistivity of the intracellular fluid (picw) ranged from 81 to $157 \mathrm{ohm} . \mathrm{cm}$ (mean 108, SD 18), and correlated with BMI $(r=-0.683, \mathrm{P}<0.0001)$.

A

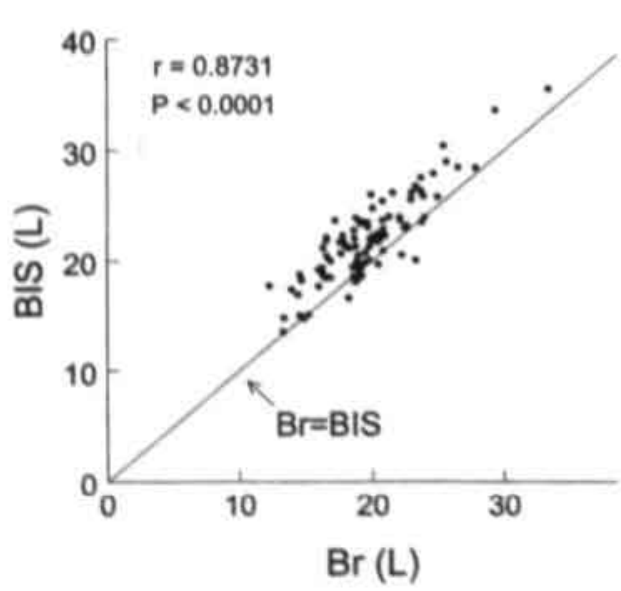

B

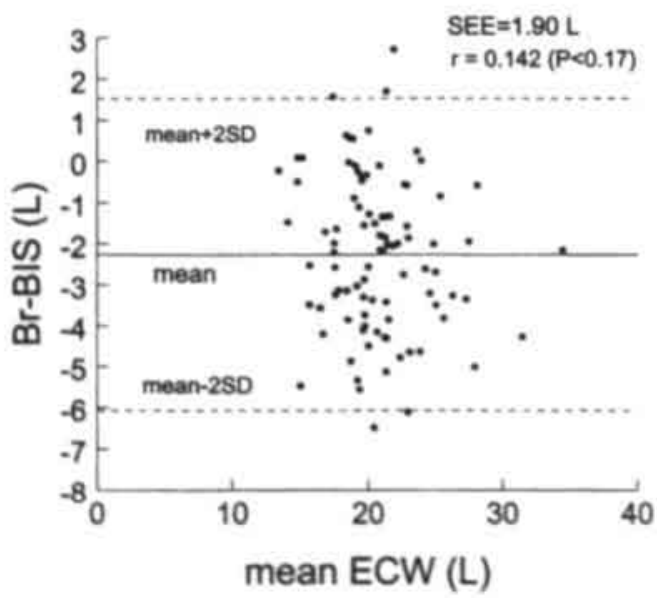

Figure 3. Comparison of extracellular water (ECW) measured with $\mathrm{Br}$ dilution $(\mathrm{Br})$ and bioelectrical impedance spectroscopy (BIS) in the total population. A: The correlation between the two methods. B: Difference between the two methods against their mean value. The horizontal line indicates the mean difference (bias) and the dotted lines indicate the $95 \%$ limits of agreement. Mean difference was -2.27 $\mathrm{L}$ ( (significantly different from $0, P<0.005$ ). 
A

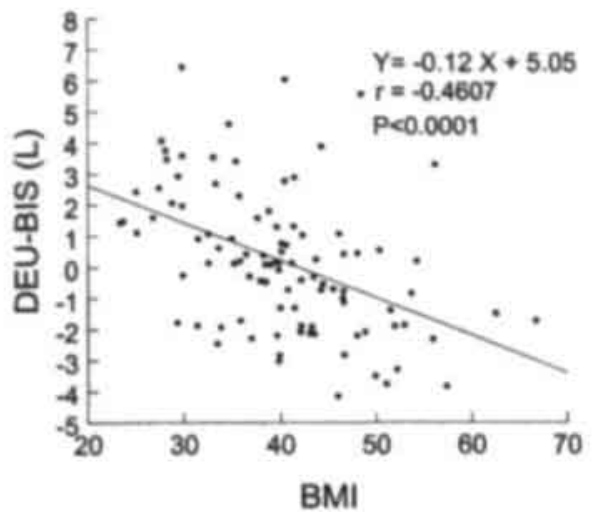

B

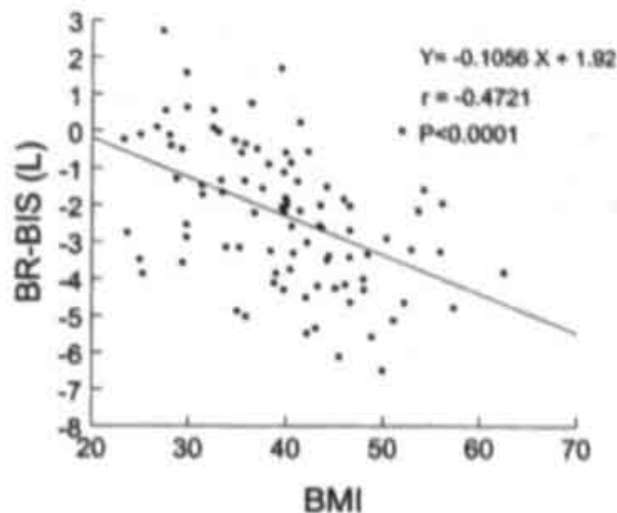

Figure 4. Correlation of the differences between body water compartments measured with the dilution methods and bio-electrical impedance spectroscopy (BIS) with body mass index (BMI). A: Total body water (TBW), deuterium dilution minus BIS values (DEU-BIS) against BMI. B:Extracellular water (ECW), bromide dilution values minus BIS (Br-BIS) against BMI.

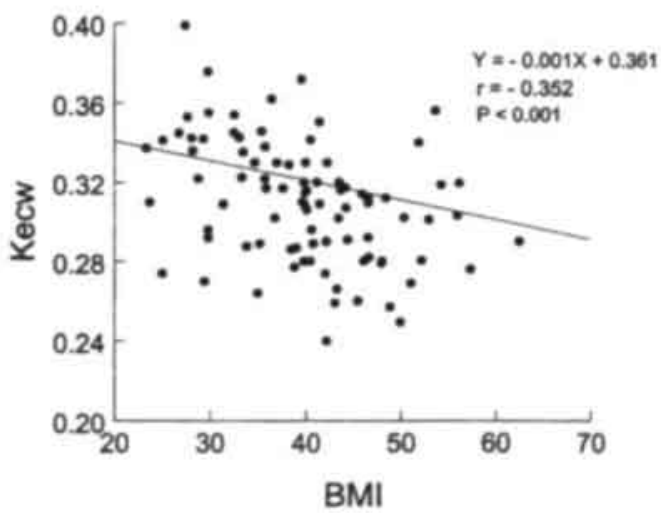

Figure 5. Correlation between Kecw, the constant used in the Hanai mixture theory for calculation of extracellular water ECW) and the BMI

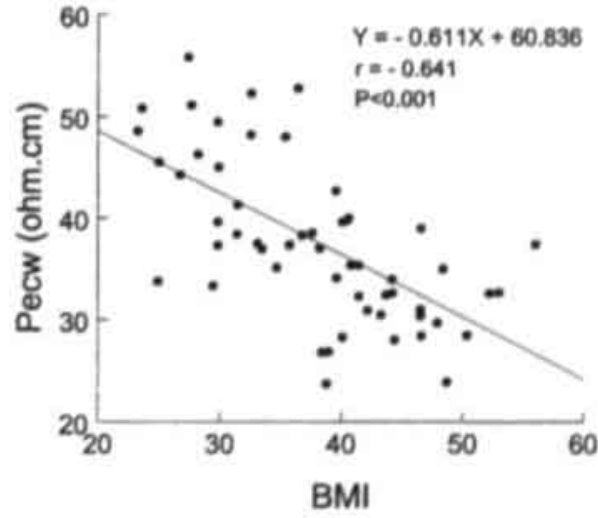

Figure 6. Correlation between the specific resistivity of the extracellular fluid (pecw) and BMI. 


\section{Discussion}

In this study we compared the accuracy of BIS using linear regression or the Hanai mixture theory in a heterogeneous population with differing degrees of overweight. Results show that the Hanai mixture theory gives slightly better results than regression analysis. Systematic differences between the dilution techniques and BIS can be minimized by adjusting the constants used in the model. These differences are caused by the specific reference method used which can vary between laboratories. Adjusting the constants does not improve the correlation or SEE. These constants act as scalars. The fact that Kecw, and the specific resistivities of ECW and ICW correlate with the degree of overweight is a new finding and may be a reason why BIS gives only slightly better results than linear regression.

In the literature impedance measurement at different frequencies has led to several ways of calculating fluid volumes from measured resistances. Stepwise regression resulted in predictions based on $L^{2} / Z_{x}, L^{2} / R_{x}, L^{2} / X c_{x}$ or $L^{2} / Z c$, in which $Z_{x}, R_{x,} X c_{x}$ are the impedance, resistance and reactance at a frequency $x$, and $Z c$ is the impedance at the critical frequency. For TBW prediction equations with $L^{2} / Z 100, L^{2} / Z 50^{8.11} L^{2} / R 500$ and $L^{2} / X c 500^{7} L^{2} / Z c^{28}$ were published. The reported correlations with the reference method, using this approach, varied from $0.927^{10}$ to $0.975^{8}$ and the SEE from $1.6^{11}$ to $3.6 \mathrm{~L}^{10}$ respectively. For ECW prediction equations based on $L^{2} / R 224^{10} L^{2} / Z 0^{34}, L^{2} / Z 1^{11} L^{2} / R 5$ and $L^{2} / X c 50$ were published with correlations ranging from ranging from $0.883^{6}$ to $0.961^{10}$ and SEE from 0.93 to $1.73 \mathrm{~L}$. Use of the Cole-Cole model for extrapolation of the resistance of extracellular- (Recw) and total body water (Rtbw), using the results of impedance measures at a range of frequencies, precluded the discussion regarding which frequency should be used. However, the question whether volumes should be calculated based on the resistivity index of these resistances or on emulsion sciences continues in the literature. The number of studies using the Hanai approach is growing ${ }^{12.15-21}$. In healthy persons SEE for TBW of $1.33^{19}, 2.27^{20}$ and $1.26^{18}$ were found and for ECW $0.9,0.89$ and 1.14. In COPD patients SEE for TBW and ECW were respectively 2.3 and 1.4 when using the emulsion science approach. These results were only a slight improvement compared with the use of regression analysis based on resistivity index ${ }^{12}$. In growth hormone deficient adults promising results were found, with an SEE for TBW of $1.6 \mathrm{~L}$ and for ECW of $0.8 \mathrm{~L}^{21}$. Van Loan et al. studied the accuracy of BIS during pregnancy and found SEE for TBW ranging from 1.6 to $3 \mathrm{~L}$ and for ECW from 1.2 to $3.4 \mathrm{~L}$, depending on the stage of pregnancy ${ }^{15}$. They calculated volumes with newly derived resistivity constants. The authors stated that this was necessary and appropriate because changes in conductivity occur with fluid and/or electrolyte concentration changes.

The accuracy of BIS that was found in this study is comparable with the results described in the literature. However, in contrast with previous reports we studied a heterogeneous population with regard to body composition. The finding that the accuracy of BIS is influenced by the degree of overweight is not new. The effect of obesity on the accuracy of SF-BIA has been described extensively ${ }^{20}$. In the very obese TBW was generally overestimated. These findings resulted in obesity specific prediction equations. Several explanations for this finding were described, including an increased relative TBW, an increased ECW/TBW ratio and a different body geometry. Changes in fluid distribution may have resulted in an incomplete conduction of the current at $50 \mathrm{kHz}$. With the use of BIS, this explanation is not valid anymore because a wide range of frequencies is used, measuring TBW as well as ECW. In this study the mean ECW/TBW ratio, measured with the dilution techniques, was $0.48(\mathrm{SD}=0.04)$ and did not correlate with $\mathrm{BMI}(r=-0.100, \mathrm{P}<0.347)$. The effect of body geometry can be explained by the fact that the trunk contributes only $12-15 \%$ of the total resistance, due to the large diameter and relatively short length ${ }^{30}$. There is no disagreement that the limbs account for most of the whole-body impedance but only for a minor fraction of the body volume'

This problem is not restricted to SF-BIA. In the case of BIS the geometry constant $\mathrm{Kb}$ is incorporated in the equation for calculating kecw. This $\mathrm{Kb}$ factor was used to remove the 
geometry effect on $p$, and was set at a value of 4.3 in the software ${ }^{10}$. Our study shows that this factor is not constant but increases with overweight. Correcting the measured resistances for the geometry effect by a fixed factor does not seem to be appropriate in the case of different levels of adiposity. As body proportions are also influenced by ethnicity effects. application of the volume equations in different races should include calculation of the appropriate $\mathrm{Kb}$ factor ${ }^{3 !}$.

There are several possible explanations for the negative correlation between the bias (dilution method minus BIS) and the degree of overweight. The dilution methods are unlikely to be responsible for this effect. We used an equilibration time of 4 hours. It can be argued whether this is long enough for very obese people. However, if the indicators would not have been fully equilibrated, we should have found an overestimation of the fluid volumes by the dilution methods. We found an underestimation compared with BIS, which increased with overweight.

A practical problem during the performing of BIS measurements in very obese subjects is the separation of legs and the positioning of the arms, not touching the trunk. It has been described in normal weight individuals that the greater the separation of the limbs from the trunk, the higher the resistance ${ }^{32}$. Although great care was taken to avoid this, it might have affected the results in the very obese persons. The current path will decrease in cases where legs or arms are not fully separated, resulting in a decreased resistance and consequently an overestimation of the fluid volumes.

It is very likely that the constants used in the Xitron model are influenced by the degree of overweight. In several studies these constants were derived and deviated from those provided by the software $12,10,21,15$. Differences in the reference methods used might be responsible. Adjusting the constants will not influence the SEE or correlation, but only corrects for the systematic difference between BIS and reference method ${ }^{19}$. The finding that the kecw correlates with $\mathrm{BMI}$ is new. The effect of overweight on the $\mathrm{Kb}$ factor and on $\mathrm{Db}$ can not explain this negative correlation, as both these factors would result in an increase of kecw with increasing BMI. In the equations used, the only factors left to be responsible for this effect, are the specific resistivities of ECW and ICW. The high correlations we found between pecw, picw and BMI suggests that both pecw and picw vary with changes in body composition. It is not clear whether there is a true effect on specific resistivity or whether other confounding factors associated with overweight are responsible.

The specific resistivity is an electrical property particular to the conducting material and independent of its size or shape ${ }^{33}$. For the whole body it is assumed to be a constant at each frequency, but each tissue has a characteristic specific resistivity and the absolute $p$ of the whole body is the mean $p$ of all conducting tissues. The resistivity of a tissue will vary depending upon its microstructure, level of hydration, and the concentration and types of electrolytic ions ${ }^{32}$. Fuller and Elia found a positive correlation between the specific resistivity at $50 \mathrm{kHz}$ of body segments and the percentage fat derived from skinfold thicknesses ${ }^{34}$. At very low frequencies ECW is the only conducting material. Changes in the $p$ of ECW have been reported by Azcue et $\mathrm{al}^{35}$. They found changes in $p$ at low frequencies during infusion of solutions with different electro-osmotic properties. They concluded that the technique measures principally the electro-ionic state of the body. Van Loan et al ${ }^{15}$ performed BIS measurements in pregnant women. They stated that changes in plasma volume, hematocrit and serum electrolytes can have effects on resitivity. In obese persons changes in fluid distribution, like the described expansion of the ECW, may be associated with changes in the resistivity of the fluids. It has been described that the extracellular fluid content of subcutaneous adipose tissue varies among individuals and increases with the amount of adipose tissue ${ }^{36}$. Changes in picw with overweight are also likely, but have not been described yet. At high frequencies the overall picw is determined by the mean picw of all cells. With increasing adiposity not only the amount of intracellular fat increases, which would increase the intracellular resistance, but also the amount of intracellular water located in fat cells increases. Both factors possibly affect the overall picw. Based on a theoretical analysis of the volume equations Ward et al. concluded that a change in the assumed value for $p$ will 
markedly alter the precision of the estimated volumes ${ }^{31}$. A change in pecw of $10 \%$ will predict changes of $4.9,-1.3$ and $1.2 \%$ in ECW, ICW and TBW respectively. A similar $10 \%$ change in picw will cause 7.0 and $4.2 \%$ change in ICW and TBW. Scharfetter et al. studied the changes in resistivities due to ionic shifts during dialysis and concluded that the relative resistivity changes remained within $4 \%$. The corresponding volume estimation errors were < $2 \%$ in ECW and $<2.2 \%$ in ICW ${ }^{37}$. However, the \% error for measuring changes in ECW and ICW were $<15 \%$ for ECW and > $20 \%$ for ICW change. They concluded that correction of the model is necessary to obtain more reliable ICW values.

The accuracy of BIS may be improved by adjusting the Kecw and $\mathrm{kp}$ constants in the model according to the BMI, or by calculating the $\mathrm{Kb}$ factor with the use of anthropometric data, and use of the empirical relationship between the specific resistivities and the BMI. Ellis et al. tested the assumptions associated with the Hanai model used in BIS methodology in a group of 387 children and 82 young adults ${ }^{30}$. In this population a wide variation in body size, shape and composition was present. Adjusting the constants $\mathrm{Ke}$ and $\mathrm{Kp}$ eliminated the systematic differences between the dilution method and BIS, but did not change the SD of the difference between the two methods. They concluded that refinement of the constants used in the BIS analysis is needed as Kecw may not be constant among individuals for the full age range examined. From our results the same conclusion can be made with respect to a wide range of overweight. The accuracy can only be improved if the constants are adjusted for the degree of overweight. Use of the relationship we found between $\mathrm{Ke}$ and BMI (fig 5) is a simple way of refinement. However, only when the physical causes of the effects of obesity on BIS, found in this study, are identified, such a procedure appears to be justified. Preliminary results show that recalculation of ECW in group 2 with the kecw adjusted for BMI (fig.5) yielded a slight improvement of the accuracy. The mean difference with $\mathrm{Br}$ dilution was $-0.28 \mathrm{~L}(\mathrm{SD}=1.52)$ and did not correlate with the BMI. The correlation with $\mathrm{Br}$ dilution was 0.873. Use of specific resistivities corrected for BMI and of a measured $\mathrm{Kb}$ factor instead of a constant value, yielded no improvement of the accuracy for ECW and TBW calculations. However, the difference with the dilution methods did not correlate with BMI anymore. Excluding the confounding effect of BMI is important for the use of BIS in epidemiologic studies and for monitoring changes in body composition.

We prefer the use of emulsion sciences rather than regression analysis for the calculation of fluid volumes. Especially for clinical application, population specific regression equations are not suitable. However, for the development of a general applicable equation, more clinical research is needed to study the effects of illness associated phenomena on the specific resistivities. Although the physical mechanisms responsible for the results we found are not identified yet, we advice that for the time being the constants used in the model should be adjusted for very obese subjects with the use of the empirical equations presented here.

BIS is very attractive for clinical use because it is cheap, easy to perform, not invasive and because it can measure ECW as well as TBW. This makes it possible to monitoring changes in ICW, or body cell mass, nececcary for nutritional assessment. However, the accuracy of BIS as applied in this study and reported by others, is not high enough for routine clinical use. Before all possible confounding factors are identified, BIS should be used with caution in clinical practice.

In summary, this study shows that in obese people the Hanai mixture theory gives slightly better results for the calculation of fluid volumes than regression equations. The accuracy of BIS might be improved by adjusting the constants used in the mixture theory for the degree of overweight. However, such adjustments are only valid if the physical principles of the effects of adiposity on BIS are identified. Especially for the clinical application of BIS, more research is needed to identify factors which may affect the specific resistivity of the body fluids. Eventually, this should lead to a general applicable equation, obeying physical laws. 


\section{References}

1. Foster KR, Lukaski HC. Whole-body impedance-what does it measure ? Am J Clin Nutr 1996; 64(suppl): 388S-96S.

2. Nyboer J. Electrorheometric properties of tissues and fluids. Ann NY Acad Scl 1970; 170: 410420.

3. Kushner RF Bioelectrical impedance analysis:a review of principles and applications. J Am Col Nutr 1992; 11: 199-209.

4. Brodie D, Moscrip V, Hutcheon R. Body composition measurements: A review of hydrodensitometry, anthropometry and impedance methods. Nutrition 1998; 14:296-310.

5. Plank LD, Monk DN, Woollard GA, Hill GL. Evaluation of multifrequency bioimpedance spectroscopy for measurement of the extracellular water space in critically ili patients. Appl Radiat Isot 1998; 49:481-483.

6. Deurenberg P. Schouten FJM, Andreoli A, de Lorenzo A. Assessment of changes in extra-cellutar water and total body water using multi-frequency bio-electrical impedance. In: Ellis KJ. Eastman JD (eds). Human Body Composition: Vivo Methods, Models and Assessment. Plenum: New York, 1993, pp 129-132.

7. Hannan WJ, Cowen SJ, Fearon KCH, Plester CE, Falconer JS, Richardson RA. Evaluation of multi-frequency bio-impedance analysis for the assessment of extracellular and total body water in surgical patients. Clin Sci 1994; 86: 479-485.

8. Deurenberg P, Tagliabue A, Schouten FJM. Multi-frequency impedance for the prediction of extracellular water and total body water. Br J Nutr 1995; 73; 349-358.

9. Chumlea WC, Guo SS, Baumgartner RN, Siervogel RM. Determination of body fluid compartments with multiple frequency bioelectric impedance In: Ellis KJ, Eastman JD (eds). Human Body Composition: Vivo Methods, Models and Assessment. Plenum: New York, 1993, pp 23-26.

10. Van Loan MD, Mayclin PL. Use of multi-frequency bioelectrical impedance analysis for the estimation of extracellular fluid. Eur J Clin Nutr 1992; 46: 117-124.

11. Deurenberg P, Schouten FJM 92. Loss of total body water and extracellular water assessed by multifrequency impedance. Eur J Clin Nutr 1992; 46: 247-255.

12. Baarends EM, WD Van Marken Lichrenbelt, EFM Wouters, AMWJ Schols. Body_water compartments measured by bio-electrical impedance spectroscopy in patients with chronic obstructive pulmonary disease. Eur J Clin Nutr 1998; 17: 15-22.

13. Van Marken Lichtenbelt W, Westerterp KR, Wouters L, Luijendijk SCM. Validation of bioelectricalimpedance measurements as a method to estimate body-water compartments. Am J Clin Nutr 1994: 60: 159-166.

14. Hanai T. Electrical properties of emulsions. In: Sherman PH (ed). Emulsion science. Academic: London, 1968, pp 354-477.

15. Van Loan MD, Kopp LE, King JC, Wong WW, Mayclin PL. Fluid changes during pregnancy: use of bioimpedance spectroscopy. J Appl Physiol 1995; 78(3): 1037-1042.

16. Jaffrin MY, Maasrani M, Le Gourrier A, Boudailliez B. Extra- and intracellular volume monitoring by impedance during haemodialysis using Cole-Cole extrapolation. Med Biol Eng Comput 1997; 35: 266-270.

17. Ho LT, Kushner RF, Schoeller DA, Gudivaka R, Spiegel DM. Bioimpedance analysis of total body water in hemodialysis petients. Kidney Int 1994; 46: 1438-1442.

18. Patel RV, Matthie JR, Withers PO, Peterson EL, Zarowitz BJ. Estimation of total and extracellular water using single-and multiple-frequency bioimpedance. Ann Pharmacother 1994; 28: 565-569.

19. Lorenzo de A, Andreoli A, Matthie J, Withers P. Predicting body cell mass with bioimpedance methods: a technological review. J Appl Physiol 1997; 82(5): 1542-1558.

20. Van Loan MD, Withhers P, Matthie J, Mayclin PL. Use of bioimpedance spectroscopy to determine extracellular fluid, total body water, and fat-free. In: Ellis KJ, Eastman JD (eds). Human Body Composition: In Vivo Methods, Models and Assessment. Plenum: New York, 1993, pp 67. 70.

21. van Marken Lichtenbelt WD, Snel YEM, Brummer RJM, Koppeschaar HPF. Deuterium and Bromide Dilution, and Bioimpedance Spectrometry independently show that growth hormonedeficient adults have an enlarged extracellular water compartment related to intracellular water. $J$ Clin Endocrinol Metab 1997; 82: 907-911. 
22. Heymsfield SB,Wang Z, Visser M, Gallagher D, Pierson RN. Techniques used in the measurement of body composition: an overview with emphasis on bioelectrical impedance analysis. Am J Clin Nutr 1996; 64(suppl): 478S-84S).

23. Lukaski HC, Johnson PE, Bolonchuk WW, Lykken GI. Assessment of fat free mass using bioelectrical impedance measurement of human body. Am J Clin Nutr 1985; 41: 810-817.

24. Lukaski HC.Biological indexes considered in the derivation of the bioelectrical impedance analysis. Am J Clin Nutr 1996; 64(suppl): 397S-404S.

25. Westerterp KR, Wouters L, van Marken Lichtenbelt WD. The Maastricht protocol for the measurement of body composition and energy expenditure with labeled water. Obes Res 1995; 3(suppl 1): 49-57.

26. Wong WW, Sheng HP, Morkeberg JC, Kosanovich JL, Clarke LL, Klein PD. Measurement of extracellular water volume by bromide ion chromatography. Am J Clin Nutr 1989; 50: 1290-1294.

27. Bland JM, Altman DG. Statistical methods for assessing agreement between two methods of clinical measurements. Lancet 1986; 1: 307-310.

28. Cornish BH, Ward LC Thomas BJ. Measurement of extracellular and total body water of rays using multiple frequency bioelectrical impedance analysis. Nutr Res 1992; 12: 657-666.

29. Deurenberg P. Limitations of the bioelectrical impedance method for the assessment of body fat in severe obesity. Am J Clin Nutr 1996; 64(suppl); 449S-52S.

30. Heitman BL. Impedance: A vallid method in assessment of body composition? Eur J Clin Nutr 1994: 48: 228-240.

31. Ward LC. Elia M, Cornish BH. Potential errors in the application of mixture theory to multifrequency bioelectrical impedance analysis. Physiol Meas 1998; 19: 53-60.

32. Chumlea WC, Baumgartner RN. Bioelectrical impedance methods for the estimation of body composition. Can J Spt Sci 1990; 15(3): 172-179.

33. chumlea WC, Shumei SG. Bioelectrical impedance and body composition:Present status and future directions. Nutr Rev 1994; 52: 123-131.

34. Fuller NJ, Elia M. Potential use of bioelectrical impedance of the whole body and of body segments for the assessment of body composition: comparison with densitometry and anthropometry. Eur J Clin Nutr 1989; 43: 779-791.

35. Azcue $M$, Wesson D, Neuman M, Pencharz P. What does bioelectrical impedance spectroscopy (BIS) measure? In: Ellis KJ, Eastman JD (eds). Human Body Composition: Vivo Methods, Models and Assessment. Plenum: New York, 1993, pp 67-70.

36. Pierson RN, Wang J, Colt EW, Neumann P. Body composition measurements in normal man: The potassium, sodium, sulfate and tritium spaces in 58 adults. J Chronic Dis 1982; 35: 419.

37. Scharfetter $\mathrm{H}$, Wirnsberger $\mathrm{GH}$. Holzer $\mathrm{H}$, Hutten $\mathrm{H}$. Influence of ionic shifts during dialysis on volume estimations with multifrequency impedance analysis. Med \& Biol Eng \& Coput 1997; 35:96-102.

38. Ellis KJ, Wong WW. Human hydrometry: comparison of multifrequency bioelectrical impedance with ${ }^{2} \mathrm{H}_{2} \mathrm{O}$ and bromide dilution. J Appl Physiol 1998; 85:1056-1062. 


\section{CHAPTER 3}

\section{Accuracy of bioelectrical impedance spectroscopy in measuring changes in body composition during severe weight loss.}

PLM. Cox-Reijven ${ }^{1}$, B van Kreel $^{2}$, PB Soeters ${ }^{3}$ Departments of 'Dietetics, ${ }^{2}$ Clinical Chemistry and ${ }^{3}$ Surgery, University Hospital Maastricht, Netherlands

JPEN 2002; 26:120-127 


\begin{abstract}
Background:

Bioelectrical impedance spectroscopy (BIS) is an attractive method for measuring body composition because it is non-invasive, simple and cheap. The effect of obesity on the accuracy of impedance measurements has been recognized for some time but no conclusive explanations or ways to correct the measurement errors have been published. We studied the effect of the composition of weight loss on the accuracy of BIS to measure changes in body fluid volumes during severe weight loss. Within subjects the effect of variable losses of fat mass was studied.

Design:

In ten morbidly obese female subject who underwent gastric reduction surgery changes in total body water (TBW) and extracellular water (ECW) were monitored for one year by Deuterium (Deu) and Bromide (Br) dilution and by BIS. Measurements were performed before operation, after 2 weeks, 3 months and 1 year. Extrapolated resistance values of extracellular (Recw) and intracellular water (Ricw) were used in mixture equations for calculation of the corresponding fluid volumes.

Results:

After one year weight decreased by $53 \mathrm{~kg}$. TBW (Deu) loss was $8.7 \mathrm{~L}$ and ECW (Br) loss 4.3 $\mathrm{L}$. Comparison of BIS with reference methods for measuring all possible changes over 6 time intervals revealed a mean overestimation of TBW $(2.4 \mathrm{~L}, \mathrm{SD}=2.9)$ and $\mathrm{ECW}(0.74 \mathrm{~L}, \mathrm{SD}=2.6)$ losses by BIS. Overestimation increased significantly with increasing fat losses, expressed as \% fat the weight loss and as change in triceps skinfolds. Measured changes in Recw and Ricw were less than expected for an ideal agreement between dilution methods and mixture equations.

Conclusions:

BIS with the use of mixture equations overestimates fluid losses during weight loss. The error is associated with the amount of fat loss. The large contribution of the factor weight in the mixture equations is likely to be responsible. The assumptions of mixture theory are not valid in obesity.
\end{abstract}




\section{Introduction}

Bioelectrical impedance spectroscopy (BIS) is an easy, portable, noninvasive method for measuring body composition. The method is based on the conductivity of the body to an alternating current. The main conductors of the body are the electrolyte rich fluids. Basically, fluid volumes are measured by means of BIS. From these volumes fat mass and fat free mass are derived'. Validation studies have indicated that obesity affects the accuracy of the method $^{2-8}$. Empirical prediction equations based on measured resistance $(R)$ values differ for obese and non-obese. The different body geometry and changes in the fluid distribution between extracellular (ECW) and intracellular water (ICW) have been put forward as possible causes for this finding ${ }^{5,7.9}$. Although the method is becoming increasingly popular for monitoring the changes in body composition during weight loss programs, only few studies address the question how accurate these measures are. If the degree of obesity affects the accuracy of the method the question arises how accurate changes in body fluid volumes can be measured during weight loss and if the composition of the weight loss, e.g. the contribution of fat, influences this accuracy. Answers to these questions may broaden our insight in the effect of obesity on impedance measurements and can have implications for the applicability of the method.

BIS is based on the impedance measurement of the body to an alternating current at different frequencies. At low frequencies the extracellular water will conduct the current because cell membranes and tissue interfaces act as capacitors. This capacitive property is lost at high frequencies, resulting in conduction of the current by both ECW and intracellular water (ICW $)^{1}$. These physical characteristics are used to extrapolate the resistance of ECW (Recw) and ICW (RicW), which are related to the fluid volumes. Prediction equations for fluid volumes are based on the relation between $L^{2} / R$ and volume. Two main approaches are used: the regression approach which relates the fluid volumes as measured by gold standards to $L^{2} / R$ and body weight, and the mixture approach, which uses $R$, length and weight in equations bases on emulsion sciences'.

Theoretically the mixture approach can be used in obese as well as in non-obese subjects. However, in a previous study we found that the values of the 'constants' used in this model were correlated with the body mass index $(\mathrm{BMI})^{10}$. The present study was performed in morbidly obese subjects undergoing gastric reduction surgery. Short-term as well as longterm changes in fluid compartments were monitored with indicator dilution methods and BIS.

The aim of the study was to analyze the errors of BIS with use of the mixture equations for measuring changes in fluid compartments during weight loss. The study design offered the possibility to study the accuracy of BIS to measure changes in fluid compartments during variable losses of fat mass within the same individual. During the early postoperative period fluid losses are expected to contribute substantially to the weight loss while during the later stages fat losses will dominate. The effect of this composition of the weight loss on the accuracy for measuring changes in fluid volumes was studied. The effect of the size of fluid loss was also analyzed. In search for possible causative factors for the errors found, the actual measured changes in resistance values were compared with expected changes according to the mixture equations.

\section{Subjects and methods}

\section{Population}

Ten morbidly obese female patients undergoing vertical banded gastroplasty, according to Mason, were included in the study. Their physical characteristics are described in table 1. Written informed consent was obtained from all participants. The study was approved by the Medical Ethical Committee of the University Hospital Maastricht. Anthropometric measurements, bio-electrical impedance analysis (BIA) and body fluid compartments (TBW 
and ECW) were measured 3 to 7 days before operation, 2 weeks after, 3 months and 1 year after operation. Measurements were performed in the morning after an overnight 8-hour fast.

Table 1. subject characteristics, fluid volumes measured by dilution methods (dil) and BIS and resistance of ECW (RecW) and ICW (RiCW) before and after operation.

\begin{tabular}{lllll}
\hline & Before & 2 weeks & 3 months & 1 year \\
\hline & & & & \\
Age & $33.9(8,1)$ & $33.9(8.1)$ & $34,2(8,1)$ & $34,9(8,1)$ \\
Length (cm) & $165,3(7,2)$ & $165,3(7,2)$ & $165,3(7,2)$ & $165,3(7,2)$ \\
Weight $(\mathrm{kg})$ & $133.3(17,0)$ & $122.8(16,3)^{\mathrm{b}}$ & $105,6(16,5)^{\mathrm{w}}$ & $80,3(9,2)^{\mathrm{m}}$ \\
BMI (kg/m2) & $49,0(7,1)$ & $45,1(6,8)^{\mathrm{b}}$ & $38,9(7,1)^{\mathrm{w}}$ & $29,6(4,5)^{\mathrm{m}}$ \\
TBWdil(L) & $45,4(3,7)$ & $40,6(2,9)^{\mathrm{b}}$ & $38,8(3,0)^{\mathrm{w}}$ & $36,7(2,7)^{\mathrm{m}}$ \\
ECWdil (L) & $21,9(2,4)$ & $18,5(1,7)^{\mathrm{b}}$ & $19,4(2,1)$ & $17,6(2,3)^{\mathrm{m}}$ \\
Recw & $512,3(55,4)$ & $583,3(78,0)^{\mathrm{b}}$ & $558,7(71,6)^{\mathrm{w}}$ & $565,5(39,0)$ \\
Ricw & $1018,9(108,0)$ & $1086,8(95,1)^{\mathrm{b}}$ & $1248,5(101,9)^{\mathrm{w}}$ & $1363,8(175,5)$ \\
TBWbis & $46,31(4,07)$ & $42,53(3,63)^{\mathrm{b}}$ & $38,49(3,53)^{\mathrm{w}}$ & $33,83(2,77)^{\mathrm{m}}$ \\
ECWbis & $24,92(2,13)$ & $22,32(2,09)^{\mathrm{b}}$ & $21,78(2,29)^{\mathrm{w}}$ & $19,61(1,69)^{\mathrm{m}}$ \\
\hline
\end{tabular}

Values are mean (SD).

Paired student T-test (two-tailed $P<0,05$ ): b, w and $m$ indicate significant difference compared with values before operation (b), after 2 weeks ( $w$ ) or after 3 months ( $m)$.

\section{Anthropometric measurements}

Weight was measured to the nearest $0.1 \mathrm{~kg}$ and length to the nearest $0.1 \mathrm{~cm}$ after subjects had voided. Triceps skinfolds were measured with a caliper to the nearest $0.1 \mathrm{~mm}$.

\section{Body fluid compartments}

Total body water (TBW) and extracellular water (ECW) were measured by deuterium oxide dilution and $\mathrm{NaBr}$ dilution respectively. In the morning, fasted patients drank a mixture of $5 \mathrm{~g}$ deuterium labeled water ( $\mathrm{D}_{2} \mathrm{O}: 99.84$ atom percentage excess) and $30 \mathrm{ml} 150 \mathrm{mM} \mathrm{NaBr}$. Before and 4 hours after ingestion of the indicators saliva and blood samples were obtained for deuterium and bromide analysis respectively. During the 4 hour interval people stayed in the hospital. They were allowed to move freely and to drink $200 \mathrm{ml}$ of water the first 2 hours. Eating was not allowed. Deuterium was analyzed with an isotope ratio mass spectrometer". Bromide was analyzed by ion chromatography as described by Wong ${ }^{12}$. Plasma was not deproteinized by the use of a filter, but by acetonitrile.

TBWdil was calculated by correcting the Deu-dilution space with $4 \%$ for exchange of labile

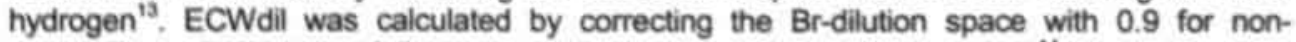
extracellular distribution of $\mathrm{Br}$ and with 0.95 for the Donnan equilibrium ${ }^{14}$. The $\mathrm{Br}$-dilution method for ECW is estimated to have an accuracy of $5 \%$ 15, 16. The accuracy of TBW measurements by Deu-dilution has been reported to be $1.5 \%{ }^{16.17}$. 


\section{Bio-electrical impedance measurements}

Impedance measurements were performed just before the subjects drank the indicator mixture. Subjects were lying on a bed with legs separated and arms abducted from the body. A tetrapolar electrode (3M red Dot $\mathrm{Ag} / \mathrm{AgCl}$ ) arrangement as described by Lukaski et al, was used ${ }^{16}$. impedance was measured with a Xitron $4000 \mathrm{~B}$ bio-electrical impedance spectrometer (Xitron technologies. San Diego, California) using 48 frequencies ranging from 5 to $500 \mathrm{kHz}$. From all 48 measured resistance and reactance values the resistance of the extracellular (Recw) and intracellular fluid (Ricw) were extrapolated by using the Xitron curve-fit software. All fits were classified as "good" or "excellent". Recw and Ricw were used in equations based on Hanai mixture theory for calculating body fluid compartments.

The volume equations provided by the Xitron software were used to calculate TBWbis . ECWbis. For a detailed description of the derivation of these equations and their undertying physical assumption based on the Hanai mixture theory, we refer to the article of de Lorenzo et al."

\section{Calculations}

The percent contribution of fat to the weight loss between two time points $t_{1}$ and $t_{2}$ was calculated as:

$$
\% F M=[\Delta W-\Delta(\text { TBWdivo.73) }] \cdot 100 / \Delta W
$$

The expected, calculated values of Recw (Recwcal) and Ricw (Ricwcal) at each of the time points were calculated by applying the mixture equations as described in the manual of the Xitron and by de Lorenzo et al.'.

From the equation:

$$
E C W=k e c w\left(L^{2} W^{1 / 2} / \operatorname{RecW}\right)^{2 / 3}
$$

in which kecw is a constant, L is length in cm, W is weight in $\mathrm{kg}$. Recwcal was calculated as:

$$
\text { Recwcal }=\left(\text { kecw }^{3 / 2} \cdot L^{2} \cdot W^{1 / 2}\right) /\left(E C W^{3 / 2}\right)
$$

in which ECW is measured by $\mathrm{Br}$ dilution.

Ricwcal was derived from:

$$
(1+I C W / E C W)^{5 / 2}=((\text { ReCW }+ \text { RiCW }) / \text { RiCW })(1+k p(I C W / E C W))
$$

in which ICW and ECW are the dilution derived fluid volumes (L) and $\mathrm{kp}$ a constant, as:

$$
\text { RicWcal }=[(1+k p(I C W / E C W)) \text { ReCW }] /\left[(1+I C W / E C W)^{52}-(1+k p(I C W / E C W))\right]
$$

For the constants kecw and $\mathrm{kp}$ values of 0.338 and 2.968 (Xitron manual) were used respectively.

Changes in the calculated $R$ values (Ricwcal and Recwcal) between two time points were compared with measured changes in $R$ values. 


\section{Statistical analysis}

Results are expressed as mean (SD) unless indicated otherwise.

Absolute values of variables at different time points as well as changes over time intervals were compared between methods by paired Student $t$-tests.

From the measured fluid volumes at each of the 4 time points all pairwise changes over periods were calculated: before vs 2 weeks $(0-2 w)$, before vs 3 months $(0-3 \mathrm{~m})$, before vs 1 year $(0-1 y), 2$ weeks vs 3 months $(2 w-3 m), 2$ weeks vs 1 year $(2 w-1 y)$ and 3 months vs 1 year $(3 m-1 y)$.

For the 10 subjects a total of 60 measured changes in TBW and ECW as measured by BIS were compared with the corresponding changes measured by the dilution methods by Bland and Altman analysis ${ }^{19}$.

Linear regression analysis was used to relate the BIS prediction errors for changes in TBW and ECW to the percentage fat of the weight loss and to changes in triceps skinfold thickness.

Pearson's product moment correlations ( $r$ ) between calculated and measured Recw and Ricw and between changes in these calculated and measured resistance values were computed.

Statistical analysis was performed by SPSS-pc, version 8.0 .

\section{Results}

After 2 weeks subjects had lost $10.5 \mathrm{~kg}$ body weight of which $4.8 \mathrm{~L}$ was water according to deuterium dilution (table 1). Between 2 weeks and 3 months $17.2 \mathrm{~kg}$ weight was lost with a contribution of $1.8 \mathrm{~L}$ water. During the next 9 months body weight decreased by $25.3 \mathrm{~kg}$ and TBW by $2.1 \mathrm{~L}$. The decreasing contribution of water to the weight loss, from $46 \%$ (before-2 weeks) to $10 \%$ ( 2 weeks-3 months) and $8 \%$ ( 3 months- 1 year), indicates that early weight losses differ in composition from long-term losses. The contribution of ECW to TBW losses ranged from $50 \%$ ( 2 weeks- 3 months) to $71 \%$ (before- 2 weeks) and $86 \%$ (( 3 months-1 year).

TBW and ECW measured by BIS decreased significantly during each phase (table 1). The corresponding measured Recw and Ricw values increased significantly during the first 3 months but not between 3 months and 1 year (table 1).

Comparison of the methods for the changes over 6 time intervals revealed that most TBW losses were overestimated by BIS, except the early loss after 2 weeks which was significantly underestimated by $1 \mathrm{~L}$, and the loss 3 months after operation which was comparable with the reference method (fig. 1). The overestimation of the TBW loss was most pronounced during long term losses and reached mean values of $5 \mathrm{~L}$. Overestimations of ECW losses were smaller, mean values up to $1.7 \mathrm{~L}$, and were significant during 2 periods $(2 w-1 y, 2 w-3 m)$.

Bland Altman analysis of measured changes in TBW and ECW including 60 measurement points (all possible time intervals in 10 patients) showed that the correlation between methods was better for TBW ( $r=0.689)$ (fig. 2) than for ECW ( $r=0.535)$ (fig. 3). For TBW the mean difference between methods was $-2.4 \mathrm{~L}$ and the $95 \%$ limits of agreement ranged from -8.07 to $3.37 \mathrm{~L}$. No correlation between the absolute change in TBW and the difference between methods for measuring change was found. The mean ECW change was overpredicted by BIS with $0.74 \mathrm{~L}$. The $95 \%$ limits of agreement for ECW changes were -5.3 and $3.9 \mathrm{~L}$. A strong correlation between the difference of the methods and the true change in ECW was present $(r=0.689)$. 


\section{TBW changes}

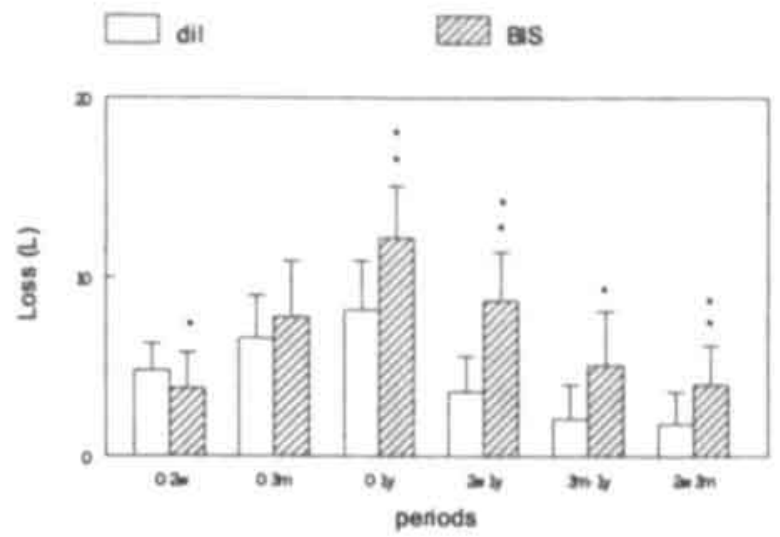

\section{ECW changes}

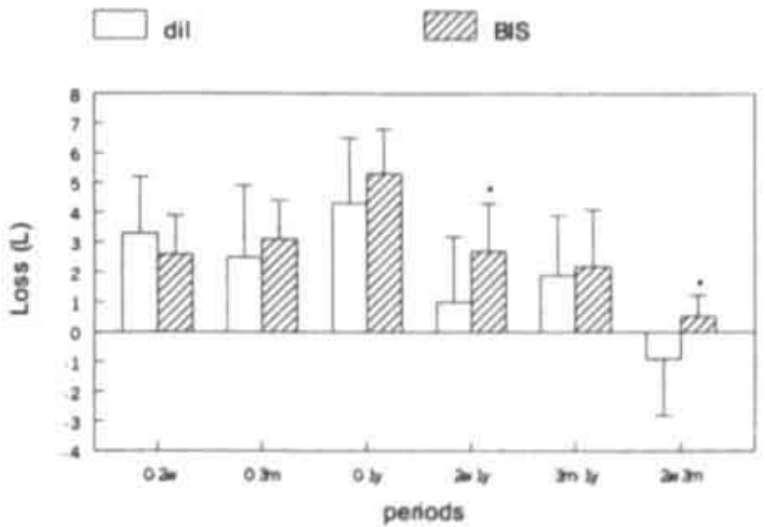

Figure 1. Changes in TBW and ECW during different periods after operation measured by dilution techniques (dil) and BIS. Different time points are indicated by 0 (before operation), $2 w$ ( 2 weeks after operation), $3 \mathrm{~m}$ ( 3 months after operation) and $1 \mathrm{y}$ ( 1 year after operation). Paired $t$-tests results: * $(\mathrm{P}<0,05), \cdots(\mathrm{P}<0,0005)$.

A strong negative correlation between the error of BIS for measuring changes in TBW (dilution - BIS) and the change in body weight was found $(r=-0.642, \mathrm{P}<0.0001)$. For ECW this error was also correlated with the change in body weight $(r=-0.283, P<0.03)$. These results indicate that not the fluid loss but weight loss is responsible for the overestimation of TBW and ECW changes by BIS.

To test if the composition of the weight loss influences the accuracy of BIS for measuring changes in ECW and TBW, the difference between dilution and BIS was plotted against the percentage fat of the weight loss (fig. 4) and against the change in triceps skinfold (fig. 5). The higher the fat percentage of the weight loss, the more BIS overestimated the losses of TBW 
$(r=-0.664, P<0.0001)$ and to a lesser extent this was also found for ECW $(r=-0.415$, $\mathrm{P}<0.001$ ). The same results were obtained when relating the error of BIS measured changes to changes in triceps skinfolds. These results indicate that the overestimation of TBW and ECW losses by BIS increases when these losses are accompanied by fat losses.

TBW changes, BIS against dilution

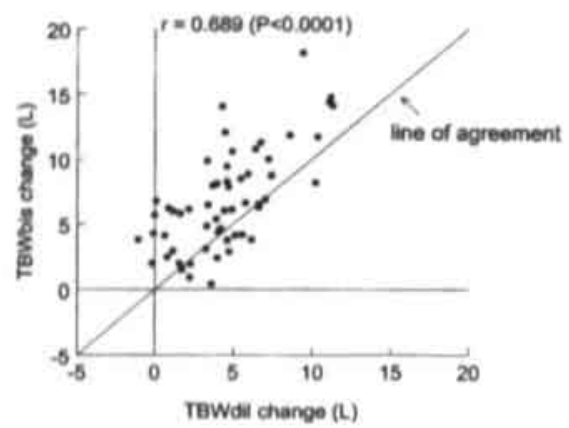

difference in measured changes of TBW against TBWdil

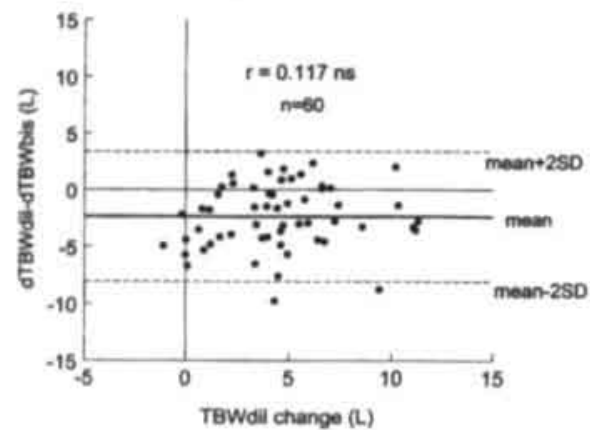

Figure 2. Comparison between BIS and deuterium dilution method for measuring changes in TBW by Bland Altman analysis. Correlation between methods (left) and difference between methods against changes measured by deuterium dilution (right).

ECW changes, BIS against dilution

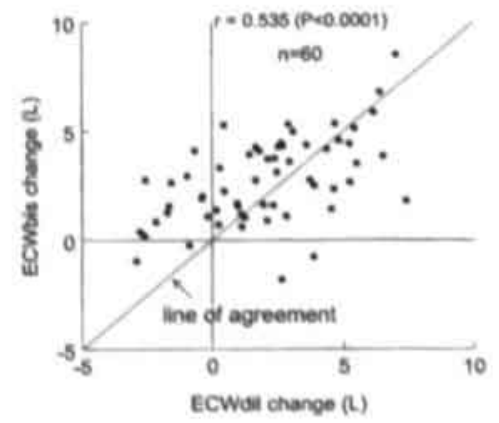

difterence in measured changes of ECW against ECW changes

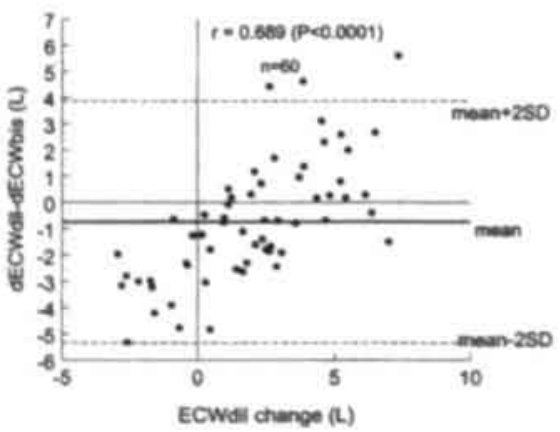

Figure 3. Comparison between BIS and bromide dilution method for measuring changes in ECW by Bland Altman analysis. Correiation between methods (left) and difference between methods against changes measured by bromide dilution (right). 

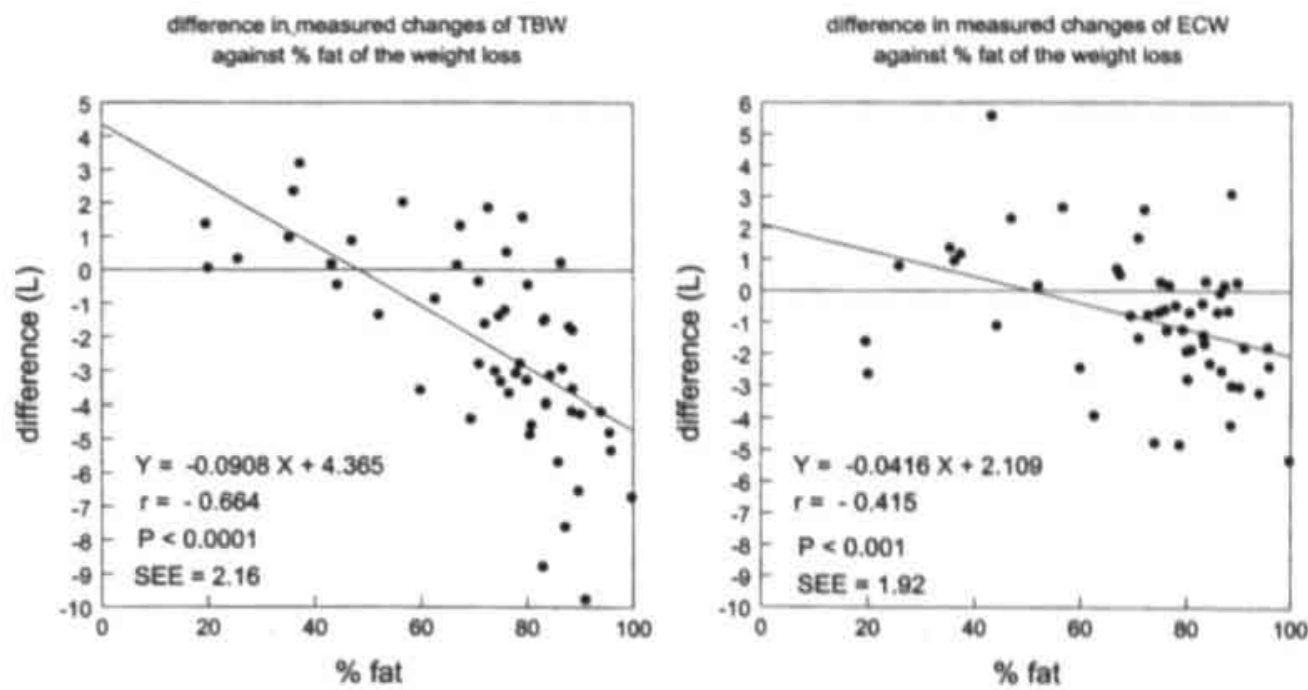

Figure 4. The differences between the reference methods and BIS (error) for measuring changes in TBW and ECW against the contribution of fat $(\%)$ to the weight loss.
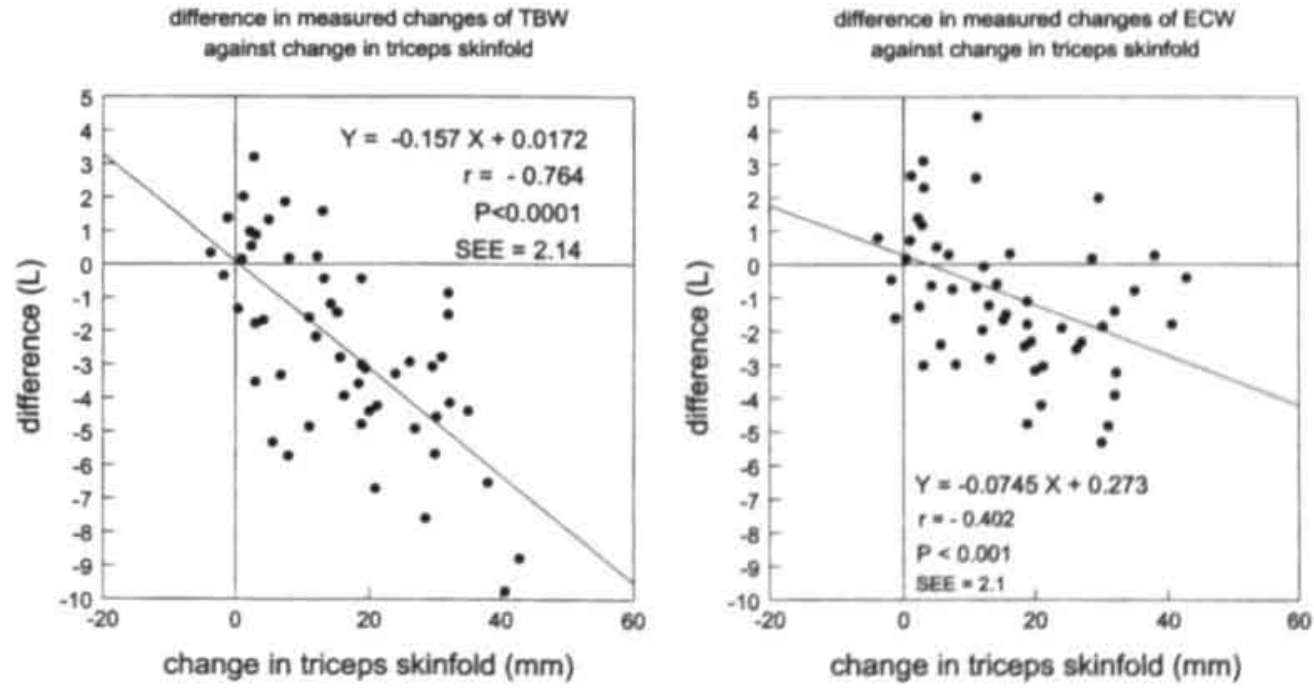

Figure 5. The differences between the reference methods and BIS (error) for measuring changes in TBW and ECW against the changes in triceps skinfold thickness. 
Comparing calculated Recw and Ricw values with measured values showed that Recw measured was smaller than Recw calculated. The correlation between the Recw calculated and measured was not strong $(r=0.351, \mathrm{P}<.0 .03)$. Ricw values measured were also lower that calculated values. No correlation between Ricw calculated and Ricw measured was found (fig. 6). Comparing changes in the measured and calculated $R$ values showed that measured changes of Recw and Ricw were smaller than calculated changes and that measured changes in Ricw did not correlate with calculated changes (fig. 6).

Recw

measured against calculated values

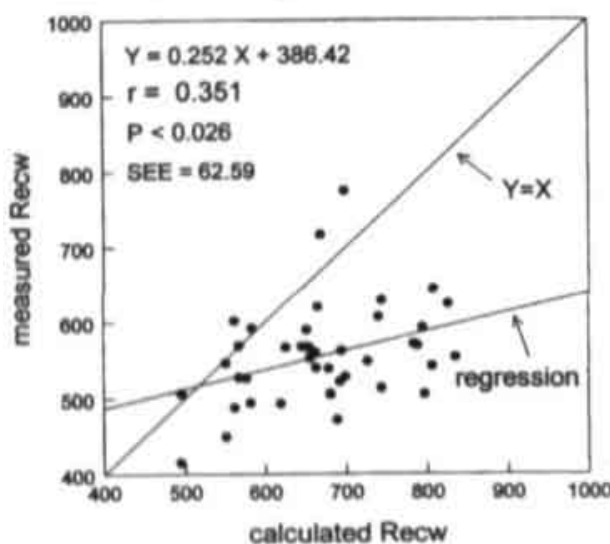

changes in Recw

measured against calcuiated

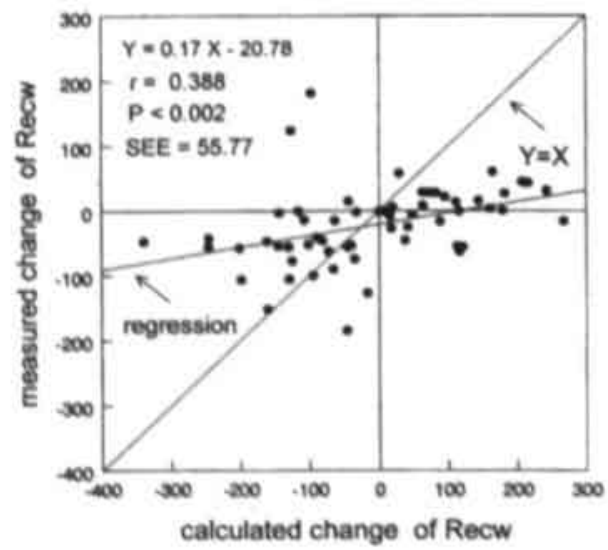

Ricw

measured against calculated values

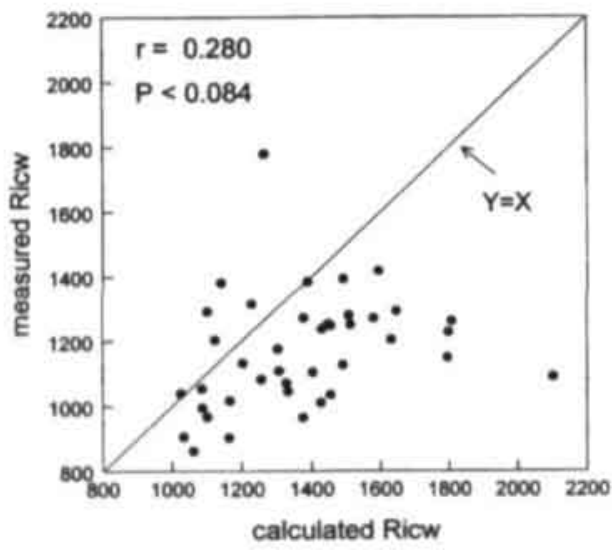

changes in Ricw measured against calculated

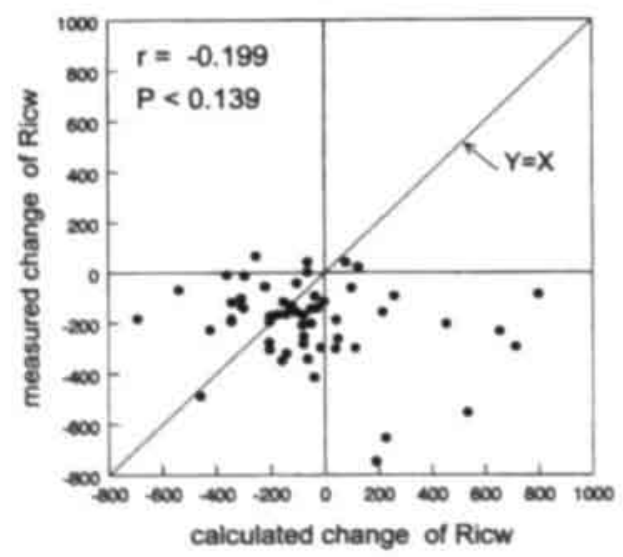

Figure 6. Measured values of Recw and Ricw plotted against predicted values in case of an ideal agreement between BIS and the reference methods (above) and changes in these $R$ values plotted against their predicted changes (below). Recw and Ricw were calculated with equations based on emulsion sciences 


\section{Discussion}

The results of the present study show that the degree of fat loss is associated with systematic overestimation of fluid losses as measured by BIS with use of mixture equations. According to these equations much larger changes in Recw and Ricw should be measured for an ideal agreement with the reference method.

Errors in the dilution methods are unlikely to be responsible for the differences in measured changes between BIS and the reference methods. It can be argued whether an equilibration time of 4 hours is long enough for very obese subjects. However, an uncompleted equilibration of the indicators would have resulted in an overestimation of the fluid volumes in obese compared with non-obese subjects. This would result in an overestimation of fluid losses during weight loss by dilution methods compared with BIS. The opposite was found, BIS overpredicted fluid losses compared with the dilution methods.

It seems logical to assume that the magnitude of changes in $R$ values is related to the absolute amount of fluid lost. However, the changes in TBW and ECW as measured by BIS were overestimated instead of underestimated. These findings seem to be contradictory, but can be explained by the contribution of body weight in the equations. To apply mixture theory, total volume must be known and is provided by $\mathrm{W} / \mathrm{Db}$. Db varies between individuals but the maximal error caused by variations in $\mathrm{Db}$ is about $2.5 \%{ }^{20}$. In the equations $\mathrm{ECW}$ is proportional to $W^{1 / 3}$ and $R e c W^{-23}$. This implies that for a reduction in $W$ from 130 to $80 \mathrm{~kg}$ a decrease in $R$ from 500 to 392 is necessary if ECW is constant. A decrease in ECW is calculated when W decreases although Recw is constant. This explains why fluid volumes changes are overestimated by BIS while R values change less than they should, according to the used equations.

Changes in calculated volumes are partly caused by changes in body weight. This can best be illustrated by the changes between 2 weeks and 3 months after operation. During this period Recw significantly decreased. It seems logical to assume that this decrease reflects an increase in ECW. $\mathrm{Br}$-dilution indeed measured a mean increase of $0.9 \mathrm{~L}$. but the BIS mixture equations calculated an ECW decrease of $0.5 \mathrm{~L}$. These results indicate that large changes in weight overrule the change in R. Between 3 months and 1 year no significant changes in Recw or Ricw were measured but BIS mixture equations calculated a loss of $4.7 \mathrm{~L} \mathrm{TBW}$ and $2.2 \mathrm{~L}$ ECW.

Several studies of single-frequency BIA have shown a systematic error in the calculation of body composition in individuals with obesity. The used equations usually overpredicted FFM and $\mathrm{TBW}^{24,6}$. Consequently, reported changes in FFM and TBW during weight loss were usually overestimated by $\mathrm{BIA}^{7,8}$. These findings lead to the development of obese specific prediction equations based on $\mathrm{L}^{2} / \mathrm{R} 50$ and weight $\mathrm{t}^{3.21 .22}$. In the literature two main factors that may affect the validity of BIA in obese states have been described. First, the hydration and/or fluid distribution in either non-adipose or adipose tissue is altered in obesity and secondly differences in the body geometry affect the measurement ${ }^{5.7-9}$. The first hypothesis does not hold for BIS because ICW and ECW are measured separately. However, the effect of changes in body geometry is not limited to SF-BIA but will also influence BIS measurements. Because the trunk contains about one half of the conductive mass but contributes only $10-20$ $\%$ of total body impedance, fluid changes in the trunk will have less effect on measured resistance than comparable changes in the limbs 2.23 . In the mixture equations a factor based on anthropometry $(\mathrm{Kb})$ is used to remove the geometry effect on the specific resistivity, and is set at 4.3 in the BIS software. However, as geometry changes during weight loss, Kb will decrease. We have reported $\mathrm{Kb}$ values ranging from 3.5 to 6.5 in a population varying in the degree of overweight. Furthermore, a positive correlation between $\mathrm{Kb}$ and $\mathrm{BMI}$ was found ${ }^{10}$. However, adjusting this constant does not improve the measured change in fluid volumes, as $\mathrm{ECW}$ is proportional to $\mathrm{Kb}^{23}$ a decrease of $\mathrm{Kb}$ would result in a larger loss of ECW. The 
overprediction of fluid losses will be larger due to this correction. The use of segmental BIS may overcome the limitations caused by geometry changes. Studies in patients on peritoneal dialysis showed that whole body BIS was unable to detect changes in trunk water while segmental measurements could detect regional changes ${ }^{24}$.

Baumgartner et al. hypothesized that the increased fat in obese subjects directly affects the measured $\mathrm{R}$ at $50 \mathrm{kHz}^{3}$. They compared whole body and segmental BIA measurements with MRI measurements. It was found that subcutaneous adipose tissue had a slight but statistically significant effect in women, primarily for the leg, suggesting that adipose tissue can affect measured $\mathrm{R}$ when the volume of adipose tissue is greater than muscle volume. This effect resulted in a slight overestimation of FFM $(3 \mathrm{~kg})$ when a BIA equation calibrated for nonobese female subjects was applied.

The mixture equations used are based on Hanai's theory which describes the effect that a concentration of nonconducting material has on the apparent resistivity of the surrounding conductive fluid $^{25}$. For application to the human body total body volume must be known and the volumetric concentration of nonconducting material is calculated at low and high frequency assuming ECW is the conducting volume at low frequencies and TBW at high frequency. The Hanai model was validated in vitro with suspensions of spherical nonconducting particles in a conducting medium. As pointed out by Schoeller ${ }^{26}$ in the human body the body cell mass, especially muscle mass, constitutes the major current path. These cells are not spherical but rather eytindrinal, arranged langitudinally along the ourrent's path. Ho opooulatod that the difference in geometry accounts for the reduction in the mixture effect and thus, failure of the mixing effect. In several studies the accuracy of the mixture equations was compared with the regression approach on modeled resistance values in which fluid volumes are described as a function of $L^{2} / R$. Improvement of the accuracy ${ }^{10,27.28}$ as well as no improvement ${ }^{17.20}$ and worsening ${ }^{16}$ were found by application of the mixture equations.

The present study differs from previous ones by the extreme changes in fat mass and by the fact that variable changes of fluid volumes and fat mass could be measured within the same individual. Limitations of the mixture equations may become apparent during extreme changes in body composition. The impact of changes in fat mass on fluid loss calculations by mixture equations is evident in this study. We agree with Schoeller that geometry factors may be responsible for the errors found ${ }^{20}$. Compared with suspensions the situation in obese subjects differs in the location of the nonconducting material as a large portion, the subcutaneous fat layer, is not suspended but rather surrounds the mixture of conducting and non-conducting material. Adjustment of the mixture equations for this effect seems necessary in very obese subjects. Therefore, future research should focus on the effect of obesity in general and subcutaneous fat mass in particular on the physical characteristics of BIS measurements. More insight in the physical effects of body fat mass on impedance measurements may lead to adjusted mixture equations based on physical laws.

In conclusion, the errors for measuring changes in TBW and ECW volumes during weight reduction were correlated with the change in triceps skinfold and with the contribution of fat to weight loss. This implies that BIS with mixture equations can measure changes in body fluids with greater accuracy if these changes are not accompanied by large changes in body fat. Contribution of the variable weight in the used equations combined with the large weight changes may be responsible for this finding. Adjustrnent of the equations for degree of obesity seems necessary for application of BIS during weight-reduction programs.

\section{References}

1. Lorenzo de A. Andreoli A. Matthie J, et al: Predicting body cell mass with bioimpedance methods: a technological review. J Appl Physiol 82:1542-1558, 1997

2. Segal KR, Gutin B, Presta E, etal: Estimation of human body composition by electrical impedance methods: A comparative study. J Appl Physiol 58:1565-1571, 1985 
3. Segal KR, Van Loan M, Fitzgerald PI, et al: Lean body mass estimation by bioelctrical impedance analysis: A four-site cross-validation study. Am J Clin Nutr 47:7-14, 1988

4. Deurenberg P. Weststrate JA. Hautvast JG: Changes in fat-free mass during weight loss measured by bioelectrical impedance and by densitometry. Eur J Clin Nutr 49:33-36, 1988

5. Baumgartner RN, Ross R, Heymsfield SB: Does adipose tissue influence bioelectrical impedance in obese men and women? J Appl Physiol 84:257-262, 1998

6. Lukaski HC, Johnson PE, Bolonchuk WW, et al: Assessment of tat-free mass using bioelectrical impedance measurements of the human body. Am J Clin Nutr 41:810-817, 1985

7. Fogelhoim GM, Sievanen HT, Van Marken Lichtenbelt WD, et al: Assessment of Fat-mass loss durinm weight reduction in obese women. Metabolism 46:968-975, 1997

8. Carella MJ: Serial measurements of body composition in obese subjects during a very-tow-energy diet (vied) comparing bioelectrical impedance with hydrodensitometry. Obes Res 5:250-256, 1997

9. Deurenberg P: Limitations of the bioelectrical impedance method for the assessment of body fat in severe obesity. Am J Clin Nutr 64(suppl):449S-452S, 1996

10. Cox-Reijven PL, Soeters PB: Validation of bio-impedance spectroscopy: effects of degree of obesity and ways of calculating volumes from measured resistance values. Int J obes 24:271-280, 2000

11. Westerterp KR, Wouters L, van Marken Lichtenbelt WD: The Maastricht protocol for the measurement of body composition and energy expenditure with labeled water. Obes Res 3(suppl 1):49-57, 1995

12. Wong WW, Sheng HP, Morkeberg JC, et al: Measurement of extracellular water by bromide ion chromatography. Am J Clin Nutr 50:1290-1294. 1989

13. Schoeller DA: Isotope dilution metheods. IN Obesity, Bjontrop P, Brodoff BN (eds). JB Lippecott Company, Philadelphia, 1992, pp 80-88

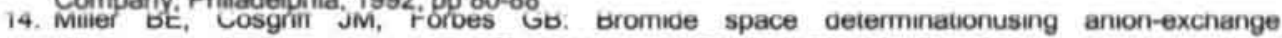
chromatography for measurement of bromide. Am J Clin Nutr 50:168-171. 1989

15. Van Kreel BK: An improved bromide assay for the estimation of extracellular water volume by capillary gas chromatography. Clin Chim Acta 231:117-128, 1994

16. Gudivaka R, Schoeller DA, Kushner RF, et al: Single-and multifrequency models for bioelectrical impedance analysis of body water compartments. J Appl Physiol 87:1087-1096, 1999

17. Ho LT, Kushner R, Schoeller DA, et al: Bioimpedance analysis of total body water in hemodialysis patients. Kidney Int 46:1438-1442, 1994

18. Lukaski HC, Johnson PE, Bolonchuk WW, et al: Assessment of fat free mass using bioelectrical imoedance measurement of human body. Am J Clin Nutr 41: 810-817, 1985

19. Bland JM, Altman DG: Statistical methods for assessing agreement between two methods of clinical measurements. Lancet 1:307-310, 1986

20. Ward LC, Elia M, Comish BH: Potential errors in the application of mixture theory to multifrequency bioelectrical impedance analysis. Physiol Meas 19:53-60, 1998

21. Gray DS, Bray GA, Gemayel N, et al: Effect of obesity on bioelectrical impedance. Am J Clin Nutr 50:255-260, 1989

22. De Lorenzo A, Sasso GF, Andreoli A, et al: Improved prediction formula for total body water assessment in obese women. Int J Obes 19:535-538, 1995

23. Foster KR, Lukaski HC. Whole body impedance. What does it measure? Am J Clin Nutr, 64 (suppl): 388S-396S, 1996

24. Zhu F, Schneditz D, Kaufman AM, et al: Estimation of body fluid changes during peritoneal dialysis by segmental bioimpedance analysis. Kidney int 57:299-306, 2000

25. Hanai T. Electrical properties of emulsions. IN: Emulsion science, Sherman PH (ed). Academic, London, 1968, pp 354-477

26. Schoeller DA: Bioelectricalimpedance Analysis. What does it measure? Ann N Y Acad Sci 904:159162,2000

27. Hannan WJ, Cowen SJ, Plester C, et al: Proximal and distal measurements of extracellular and total body water by multi-frequency bio-impedance analysis in surgical patients. Appl Radiat isot 49:621622, 1998

28. Earthman CP, Matthie JR, Reid PM, et al: A comparison of bioimpedance methods for detection of body cell mass change in HIV infection. J Appl Physiol 88:944-956, 2000

29. Baarends EM, Van Marken Lichtenbelt WD, Wouters EFM, et al: Body water compartments measured by bio-electrical impedance spectroscopy in patients with chronic obstructive pulmonary disease. Eur J Clin Nutr 17:15-22, 1998 
Chapter 3

46 


\section{CHAPTER 4}

Bio-electrical impedance analysis during severe weight loss. Comparison of the regression and mixture approach for measuring changes in body fluid compartments.

P.L.M. Cox-Reijven', B. van Kreel', P.B. Soeters ${ }^{3}$. Departments of 'Dietetics, ${ }^{2} \mathrm{Clinical}$ Chemistry and ${ }^{3}$ Surgery, University Hospital Maastricht, Netherlands

Submitted for publication 


\title{
Chapter 4
}

\begin{abstract}
Background:

At present no simple non-invasive methods are available for monitoring changes in body composition. Bio-electical impedance analysis (BIA) is attractive for clinical use because it is a bedside method, easy to perform and non-invasive.

Objective:

We studied the accuracy of BIA for measuring changes in total body water (TBW), extracellular water (ECW) and intracellular water (ICW) during severe weight loss.

Design:

In 23 morbidly obese patients undergoing vertical banded gastroplasty according to Mason, BIA measurements at 50 frequencies were performed before operation $(0)$ and 2 weeks $(2 w)$, 3 months $(3 \mathrm{~m})$ and 1 year $(1 \mathrm{y})$ after operation. Changes in the extrapolated resistance values of ICW (Ricw), ECW (RecW) and at infinite frequency Rinf) were related to changes in body fluids measured by $\mathrm{D}_{2} \mathrm{O}$ and $\mathrm{Br}$ dilution. The spectroscopy approach (BIS) with the use of mixture equations was compared with the regression approach for measuring changes in fluid compartments over different time intervals.
\end{abstract}

Results:

Ricw and Rinf increased during the first 3 months but not between 3 months and 1 year after operation. Recw was increased 2 weeks after operation without further increase thereafter. BIS with mixture equations systematically overestimated long-term losses of ECW, TBW and ICW, while relative changes in $L^{2} /$ Recw, $L^{2} / R i c w$ and $L^{2} / R$ inf were in the same order as relative changes in ECW, ICW and TBW.

Conclusions:

The accuracy of the mixture approach of BIS for measuring changes in TBW and ECW is not high enough for clinical use. Systematic overestimation of fluid losses during weight reduction is indicative for the presence of a confounder. Possible responsible factors are changes in the specific resistivities of ECW and ICW and/or overestimation of the change in conductive body volume during severe weight loss. 


\section{Introduction}

Bioelectrical impedance analysis (BIA) is a non-invasive bedside method for measuring body composition. BIA measurements are easy to perform and suited for repeated measurements. These features make the method very attractive for clinical use. Furthermore, BIA is theoretically able to measure extracellular water (ECW) as well as intracellular water (ICW). which makes it possible to monitor changes in body cell mass (BCM). Evaluating the nutritional status of patients by measuring the fat free mass (FFM) is inadequate because changes in the hydration of the FFM, caused by ECW fluctuations, are often present. Therefore, monitoring ICW as a measure of BCM is theoretically the preferred method for nutritional assessment in patients.

For clinical application a method for measuring body composition should be sensitive enough to measure clinically relevant changes. Single-frequency BIA (SF-BIA) measures the impedance of the body to an alternating current of $50 \mathrm{kHz}$. Many validation studies of SF-BIA have been published with standard errors of estimation (SEE) for measured TBW ranging from 1.4 to $3.5 \mathrm{~L}^{1,2}$. Some studies addressed the accuracy of SF-BIA to measure changes in TBW ${ }^{3}$ ${ }^{10}$. Most of these studies yielded disappointing results ${ }^{6-10}$. In most cases it was hypothesized that the disability of SF-BIA to measure accurately changes in TBW may be caused by changes in the fluid distribution between intracellular (ICW) and extracellular water (ECW). At the frequency used during SF-BIA, usually $50 \mathrm{kHz}$, the current is conducted by ECW and only partly by ICW. Because the resistance of ICW is higher than of ECW, selective loss of ECW during weight loss would increase the specific resistivity at $50 \mathrm{kHz}$, resulting in an underestimation of absolute TBW values and an overestimation of TBW losses ${ }^{3,11.12}$. Changes in the geometry of the body may also explain the lack of sensitivity for measuring changes during weight loss because BIA is relatively insensitive for measuring changes in the trunk ${ }^{13}$.

Impedance measurements at a range of frequencies could theoretically overcome some limitations of SF-BIA because theoretically both ECW and ICW can be measured. From resistance and reactance values at different frequencies the resistance at zero $\left(R_{0}\right)$ and infinite frequency (Rinf, can be extrapolated. $R_{0}$ represents the resistance of the extracellular fluid (Recw) and Rinf of the parallel sum of the resistance of intracellular fluid (Ricw) and Recw $(1 /$ Rinf $=1 /$ Recw $+1 /$ Ricw). Usually the electrical Cole-Cole model is used (14) According to the bioelectrical impedance spectroscopy (BIS) theory RicW and RecW are used to predict ICW and ECW and TBW is calculated as the sum of ICW and ECW. Because Rinf is the result of the resistance of two different fluid compartments which can change independently, Rinf or any resistance at high frequency is theoretically unable to measure TBW if changes in fluid distribution are present ${ }^{14}$. However, besides regression equations for ECW and ICW based on $\mathrm{L}^{2} /$ RecW and $\mathrm{L}^{2} /$ Ricw, equations based on $\mathrm{L}^{2} /$ Rinf for TBW or FFM predictions have been published ${ }^{15,16}$. Besides this regression approach the use of equations based on emulsion sciences to calculate fluid volumes from measured $R$ values has been described ${ }^{17}$. The extrapolated Recw and Ricw values are used in equations derived from Hanai mixture theory to predict ECW and ICW. TBW is calculated as the sum of ECW and ICW. Validation studies of both the regression and mixture approach have been published for different populations. The reported SEEs were comparable with SF-BIA ${ }^{15,16,16-20}$.

The advantage of the mixture theory over the regression approach has not been convincingly proven yet. However, measuring changes in body composition makes it difficult to use the regression approach because for obese subjects prediction equations are advised that differ from those for normal weight individuals ${ }^{12}$. The question arises which equation should be used when during the course of weight loss quantification of the changes is desired.

Until now no studies describing the accuracy of BIS to measure changes in body composition during severe weight loss have been published. For the clinical application of BIS this is however of major importance. We therefore measured the changes in body fluid volumes in morbidly obese subjects after gastric reduction surgery. Aim of the study was to compare the mixture approach and the regression approach for their sensitivity to predict changes in fluid compartments. Deuterium and bromide dilution were used as reference methods. Short term, as well as long term changes were monitored. 


\section{Subjects and methods}

In a group of morbidly obese subjects undergoing gastroplasty body fluids compartments were measured before and 3 times after surgery (at 2 weeks, 3 months and 1 year) by indicator dilution methods and by bio-electrical impedance measurements. Changes in fluid compartments as measured by the dilution methods were compared with changes measured by BIS with the use of equations based on mixture theory and with absolute as well as relative changes in $L^{2} / R e c w$ and $L^{2} / R i c w$. Not in accordance with BIS theory, but in order to compare results with previously published studies, the correlation between changes in $L^{2} / R$ inf and changes in TBW was caiculated.

\section{Population}

Twenty-three morbidly obese patients undergoing vertical banded gastroplasty, according to Mason, were included in the study. Their physical characteristics are described in table 1.

Table 1. Population characteristics.

\begin{tabular}{lllll}
\hline & $\begin{array}{l}\text { before } \\
\text { operation }\end{array}$ & 2 weeks & 3 months & 1 year \\
\hline number $(\mathrm{m} / \mathrm{f})$ & $23(4 / 19)$ & $17(1 / 16)$ & $23(3 / 20)$ & $18(3 / 15)$ \\
age (years) & $34.2(8.4)$ & $34.8(9.5)$ & $35.8(8.2)$ & $35.0(7.3)$ \\
height (cm) & $165.7(9.3)$ & $164.6(7.8)$ & $165.7(9.3)$ & $166.4(9.9)$ \\
BMI $\left(\mathrm{kg} / \mathrm{m}^{2}\right)$ & $47.3(7.2)$ & $43.4(6.0)$ & $37.37(6.9)$ & $29.7(5.1)$ \\
weight $(\mathrm{kg})$ & $131.2(23.8)$ & $117.6(17.8)$ & $102.1(19.8)$ & $81.3(13.1)$ \\
TBWdil (L) & $45.6(7.8)$ & $40.3(5.7)$ & $38.8(6.1)$ & $37.7(5.9)$ \\
ECWdil (L) & $20.5(3.6)$ & $18.8(2.2)$ & $19.5(2.9)$ & $18.5(3.9)$ \\
ECWdilTBWdil & $0.47(0.05)$ & $0.45(0.03)$ & $0.51(0.04)$ & $0.49(0.05)$ \\
\hline
\end{tabular}

Values are mean (SD), TBWdil is total body water measured by Deuterium ditution;

ECWdil is extracellular water measured by Bromide dilution

Written informed consent was obtained from all participants. The study was approved by the Medical Ethical Committee of the University Hospital Maastricht. Anthropometric measurements, bio-electrical impedance analysis (BIA) and body fluid compartments (TBW and ECW) were measured 3 to 7 days before operation, 2 weeks after, 3 months and 1 year after operation. Measurements were performed in the morning after an ovemight 8-hour fast.

\section{Anthropometric measurements}

Weight was measured to the nearest $0.1 \mathrm{~kg}$ and length to the nearest $0.1 \mathrm{~cm}$ after subjects had voided. 


\section{Body fluid compartments}

Total body water (TBW) and extracellular water (ECW) were measured by deuterium oxide dilution and $\mathrm{NaBr}$ dilution respectively. In the moming, fasted patients drank a mixture of $5 \mathrm{~g}$ deuterium labeled water ( $D_{2} \mathrm{O}: 99.84$ atom percentage excess) and $30 \mathrm{ml} 150 \mathrm{mM} \mathrm{NaBr}$. Before and 4 hours after ingestion of the indicators saliva and blood samples were obtained for deuterium and bromide analysis respectively. During the 4 hour interval people stayed in the hospital. They were allowed to move freely and to drink $200 \mathrm{ml}$ of water the first 2 hours. Eating was not allowed. Deuterium was analyzed with an isotope ratio mass spectrometer" $r^{2}$. Bromide was analyzed by ion chromatography as described by Wong ${ }^{2}$. Plasma was not deproteinized by the use of a filter, but by acetonitrile.

TBWdil was calculated by correcting the Deu-dilution space with $4 \%$ for exchange of labile hydrogen ${ }^{2}$. ECWdil was calculated by correcting the Br-dilution space with 0.9 for nonextracellular distribution of $\mathrm{Br}$ and with 0.95 for the Donnan equilibrium ${ }^{24}$. The Br-dilution method for ECW is estimated to have an accuracy of $5 \%{ }^{2 \mathrm{a} . \mathrm{n}}$. The accuracy of TBW measurements by Deu-dilution has been reported to be $1.5 \%{ }^{2 x z}$, ICWdil was calculated as TBWdil-ECWdil,

\section{Bio-electrical impedance measurements}

Impedance measurements were performed just before the subjects drank the indicator mixture. Subjects were lying on a bed with legs separated and arms abducted from the body. A tetrapolar electrode (3M red Dot $\mathrm{Ag} / \mathrm{AgCl}$ ) arrangement as described by Lukaski et al. was used ${ }^{20}$. Impedance was measured with a Xitron $4000 \mathrm{~B}$ bio-electrical impedance spectrometer (Xitron technologies, San Diego, California) using 48 frequencies ranging from 5 to $500 \mathrm{kHz}$. From all 48 measured resistance and reactance values the resistance of the extracellular (Recw) and intracellular fluid (Ricw) were extrapolated by using the Xitron curve-fit software. All fits were classified as "good" or "excellent". Recw and Ricw were used in equations based on Hanai mixture theory for calculating body fluid compartments. Resistance at infinite frequency (Rinf) is related to Recw and Ricw as:

Rinf $=\left(\right.$ Ricw*Recw)/(Ricw+Recw) ${ }^{20}$.

The volume equations provided by the Xitron software were used to calculate TBWbis , ECWbis and ICWbis. For a detailed description of the derivation of these equations and their undertying physical assumption based on the Hanai mixture theory, we refer to the article of de Lorenzo et al. ${ }^{14}$.

Besides the equations based on mixture theory, changes ECW, ICW and TBW were related to absolute as well as to relative changes in $\mathrm{L}^{2} / R e c w, \mathrm{~L}^{2} / R i c w$ and $\mathrm{L}^{2} / R$ inf.

\section{Statistical analysis}

Results are expressed as mean (SD) unless indicated otherwise.

From the measured fluid volumes at each of the 4 time points all pairwise changes over periods were calculated: before verses 2 weeks $(0-2 w)$, before verses 3 months $(0-3 m)$, before verses 1 year $(0-1 y), 2$ weeks verses 3 months $(2 w-3 m), 2$ weeks verses 1 year $(2 w-1 y)$ and 3 months verses 1 year $(3 m-1 y)$. Because the number of subjects was not equal for all 6 periods, data of each period were treated as a separate experiments.

The measured Recw. Ricw and Rinf at each test session were compared within individuals by 2 -tailed paired $t$-test. Absolute values as well as changes in fluid volumes measured by the dilution methods (ICWdil, ECWdil and TBWdii) were compared with fluid volumes measured by BIS with paired t-tests. Aiso Pearson's product moment correlations (r) 
between changes in $\mathrm{L}^{2} /$ Ricw, $\mathrm{L}^{2} /$ Recw or $\mathrm{L}^{2} / \mathrm{Rinf}$ and changes in ICWdil, ECWdil or TBWdil were computed.

\section{Results}

Of the 23 subjects included only 10 completed all 4 test sessions. Measurements after 2 weeks and 1 year were not performed in 6 and 5 patients respectively. Tests were missed because of iliness, vomiting, technical problems or other unforeseen circumstances or because of noncompliance. Bromide analysis were not performed in 3 patients before operation, in 2 patients at 2 weeks after and in 1 patient 3 months after operation because of problems with blood sampling caused by the thick subcutaneous fat layer, or because of abnormal high baseline levels of bromide. Deuterium analysis of one patient was not performed 1 year after operation because of dilution of the saliva sample caused by accidentally drinking of water just before sampling.

Population characteristics are presented in table 1 . The mean weight loss after one year was $53.7 \mathrm{~kg}(\mathrm{SD}=14.1)$. During the first 2 weeks a loss of $10.1 \mathrm{~kg}(\mathrm{SD}=2.7)$ was measured, between 2 weeks and 3 months $17.1 \mathrm{~kg}(S D=4.7)$ and between 3 months and 1 year $24.9 \mathrm{~kg}$ $(S D=12.0)$. The mean BMI decreased in one year from 47.3 to $29.7 \mathrm{~kg} / \mathrm{m}^{2}$. Mean TBW and ECW volumes decreased. The major losses occurred in the first 2 weeks. While ECW stayed stable after 2 weeks, TBW continued to decrease. The ECW/TBW ratio did not significantly decrease after weight loss, but an increase at 3 months after operation was measured (Paired $t$-test, $P<0.005$ ).

Comparison of ECW and TBW values measured by the two methods at each test session are presented in table 2. TBW was significantly overestimated by BIS by $1.3 \mathrm{~L}$ at 2 weeks and underestimated 1 year after operation by $2.7 \mathrm{~L}$. The correlation between the two methods for TBW ranged from 0.927 at 3 months to 0.976 before operation. ECW was consistently overestimated by BIS. This overestimation was $3 \mathrm{~L}$ before operation, $3.6 \mathrm{~L}$ after 2 weeks and decreased to $1.6 \mathrm{~L}$ and $1.3 \mathrm{~L}$ after 3 months and 1 year respectively. Correlations between the two methods for ECW were generally lower than for TBW and ranged from 0.769 at 2 weeks to 0.911 before operation.

Table 2. Body fluid compartments (mean (SD)) before and after operation, measured with dilution methods and BIS.

\begin{tabular}{|c|c|c|c|c|c|c|c|}
\hline & & $T B W$ & & & $E C W$ & & \\
\hline & & number & volume (L) & correlation & number & volume (L) & correlation \\
\hline & & & & coefficient & & & coefficient \\
\hline \multirow[t]{2}{*}{ betore } & dilution & 23 & $45.7(7.8)$ & & 20 & $20.5(3.6)$ & \\
\hline & Bis & & $45.9(7.8)$ & $0.976^{\mu}$ & & $23.5(3.2)^{*}$ & $0.911 \mu$ \\
\hline \multirow[t]{2}{*}{2 weeks } & dilution & 17 & $40.3(5.7)$ & & 15 & $18.8(2.2)$ & \\
\hline & Bis & & $41.6(5.6)^{*}$ & $0.947^{M}$ & & $22.4(2.9)^{\prime \prime}$ & $0.769^{m}$ \\
\hline \multirow[t]{2}{*}{3 months } & dilution & 23 & $38.8(6.1)$ & 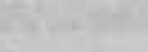 & 22 & $19.5(2.9)$ & \\
\hline & BIS & & 38.2 (5.9) & $0.927 \mu$ & & $21.1(3.7)^{*}$ & $0.823^{m}$ \\
\hline \multirow[t]{2}{*}{1 year } & dilution & 17 & $37.8(5.9)$ & & 18 & 18.5 (3.9) & \\
\hline & BIS & & $35.1(5.8)^{* *}$ & $0.974^{\mu}$ & & $19.8(3.5)^{*}$ & $0.865 \mathrm{~m}$ \\
\hline
\end{tabular}

Paired Ftest P values (2-tailed) $<0.01(\%),<0.05(\%)$. Significant comelation: P<0.01 (M). 
Comparison of $\mathbf{R}$ values at different times (table 3 ) revealed that most changes took place during the first 3 months. No significant changes between 3 months and 1 year were measured. Rinf and Ricw increased during each of the other 5 time intervals. Recw was increased after 2 weeks, but no further increase between 2 weeks and 3 months and between 3 months and 1 year was seen.

Table 3. Comparison of BIS variables at different time points with paired T-test. Mean values (SD) are presented.

\begin{tabular}{|c|c|c|c|}
\hline Pair & Ricw & Recw & Rint \\
\hline $\begin{array}{l}\text { Before } \\
2 \text { weeks } \\
(n=16)\end{array}$ & $\begin{array}{l}1020(117) \\
1095(110)^{* *}\end{array}$ & $\begin{array}{l}521(56) \\
587(74)^{k *}\end{array}$ & $\begin{array}{l}344(33) \\
380(36)^{* *}\end{array}$ \\
\hline $\begin{array}{l}\text { before } \\
3 \text { months } \\
(n=22)\end{array}$ & $\begin{array}{l}1018(121) \\
1232(98)^{* *}\end{array}$ & $\begin{array}{l}524(68) \\
582(68)^{* *}\end{array}$ & $\begin{array}{l}345(40) \\
394(36)^{* 0}\end{array}$ \\
\hline $\begin{array}{l}\text { before } \\
1 \text { year } \\
(n=16)\end{array}$ & $\begin{array}{l}1029(122) \\
1311(161)^{* *}\end{array}$ & $\begin{array}{l}526(76) \\
584(72)^{* *}\end{array}$ & $\begin{array}{l}347(43) \\
402(36)^{* *}\end{array}$ \\
\hline $\begin{array}{l}2 \text { weeks } \\
3 \text { months } \\
(n=15)\end{array}$ & $\begin{array}{l}1088(102) \\
1240(115)^{* *}\end{array}$ & $\begin{array}{l}587(73) \\
574(67)\end{array}$ & $\begin{array}{l}379(35) \\
391(38)^{* *}\end{array}$ \\
\hline $\begin{array}{l}2 \text { weeks } \\
1 \text { year } \\
(n=11)\end{array}$ & $\begin{array}{l}1100(91) \\
1348(162)^{* *}\end{array}$ & $\begin{array}{l}594(75) \\
584(60)\end{array}$ & $\begin{array}{l}383(32) \\
405(28)^{* *}\end{array}$ \\
\hline $\begin{array}{l}3 \text { months } \\
1 \text { year } \\
(n=17)\end{array}$ & $\begin{array}{l}1251(98) \\
1307(156)\end{array}$ & $\begin{array}{l}580(72) \\
593(77)\end{array}$ & $\begin{array}{l}395(38) \\
405(38)\end{array}$ \\
\hline
\end{tabular}

Values are mean (SD). Ricw = extrapolated resistance of intracellular fluid. Recw = extrapolated resistance of extracellular fluid, Rinf $=$ extrapolated resistance at infinite frequency. Paired $t$-test :P values $(2-t a i l e d)<0.01(")$ ), $\left.\propto 0.05()^{\circ}\right)$.

The calculated changes in fluid volumes as measured by dilution methods and by BIS with the use of mixture equations were compared for the 6 time intervals (table 4). BIS overestimated ECW losses in 4 of the 6 time intervals and overestimated ICW losses in 2 periods. BIS underestimated the short-term TBW loss after 2 weeks and overestimated the long term TBW losses. The correlations between the methods for measuring changes (table 5) were weak. The ICW changes were not correlated and ECW changes were only significantly correlated in 3 of the 6 periods. TBW changes were better correlated, $r$ ranged from 0.588 to 0.776 and was significant in all cases.

In order to compare the predictive capacity of changes in $L^{2} / R$ without use of mixture equations, relative changes in fluid compartments as measured by the dilution method and by BIS (with mixture equations) were compared with relative changes in $L^{2} / R$ (fig. 1 ). For ECW and ICW the \% change in $L^{2} / R e c W$ or $L^{2} / R i c W$ was not different from the \% Loss of ECW and ICW respectively as measured by the dilution methods, while the use of mixture equations (ECWbis and ICWbis) significantly overestimated the relative losses in 4 of the 6 periods. Most pronounced were the differences for the relative changes in TBW. In contrast 
to the overestimation of \%TBW losses in 4 of the 6 periods by mixture equations , relative changes in $L^{2} /$ Rinf were not larger than $\%$ changes in TBW. In 2 of the periods the relative change in $L^{2} /$ Rinf was smaller than the relative TBW loss. The correlations between the relative changes and the \% changes measured by the reference method were weak (table 5). For ICW no significant correlations between methods were found and for ECW only during one period ( 3 months -1 year). Relative TBW losses were significantly correlated in 3 of the 6 periods. These results indicate that not the measured change in $R$ values, but the use of mixture equations is responsible for the overestimation of fluid losses.

Table 4. Comparison of BIS with the dilution method for measuring changes in fluid compartments (L) over 6 time periods.

\begin{tabular}{lllllll}
\hline Period & AECWdil & $\Delta E C W b i s$ & $\Delta I C W d i l$ & $\Delta I C W b i s$ & $\Delta T B W d i l$ & $\Delta T B W b i s$ \\
\hline & & & & & & \\
$0-2 w$ & $3.2(2.0)$ & $2.5(1.2)$ & $1.4(2.3)$ & $1.3(0.9)$ & $4.7(1.4)$ & $3.8(1.9)^{*}$ \\
$0-3 m$ & $1.6(2.5)$ & $3.1(1.3)^{*}$ & $4.9(2.9)$ & $4.1(2.1)$ & $6.4(2.3)$ & $7.2(3.2)$ \\
$0-1 y$ & $3.2(2.7)$ & $5.2(1.3)^{* *}$ & $4.6(2.3)$ & $5.9(2.2)$ & $7.8(2.4)$ & $11.1(3.1)^{* *}$ \\
$2 w-1 y$ & $0.6(2.1)$ & $3.1(1.1)^{* *}$ & $2.9(1.5)$ & $5.6(2.0)^{*}$ & $3.6(2.0)$ & $8.7(2.7)^{* *}$ \\
$3 m-1 y$ & $2.0(2.6)$ & $2.6(1.7)$ & $0.0(2.2)$ & $2.4(1.7)^{*}$ & $1.9(2.1)$ & $5.0(2.8)^{* *}$ \\
$2 w-3 m$ & $-0.7(1.9)$ & $0.9(0.9)^{* *}$ & $2.5(1.1)$ & $3.3(1.8)$ & $1.8(1.7)$ & $4.2(2.0)^{* *}$ \\
\hline
\end{tabular}

Values are mean (SD). Paired T-test: $P$ values (2-tailed) $<0.005\left({ }^{* *}\right), P<0.05\left({ }^{*}\right)$

Table 5. Correlation coefficients $(r)$ between absolute $(L)$ or relative $(\%)$ changes in fluid volumes measured by the dilution methods and absolute and relative changes in BiS calculated fluid volumes or absolute and relative changes in $\mathrm{L}^{2} /$ Recw, $\mathrm{L}^{2} /$ Ricw and $\mathrm{L}^{2} /$ Rint.

Absolute changes

\begin{tabular}{|c|c|c|c|c|c|}
\hline \multicolumn{6}{|l|}{ ECW } \\
\hline & Period & $\triangle$ ECWbis & $\Delta\left(\mathrm{L}^{2} / \mathrm{Rec} w\right)$ & $\%$ ECWbis & $\%\left(\mathrm{~L}^{2} / \mathrm{Rec} w\right)$ \\
\hline & $0-2 w$ & 0.255 & 0.206 & 0.247 & 0.211 \\
\hline & $0-3 m$ & 0.295 & 0.256 & 0.124 & 0.124 \\
\hline & $0-1 y$ & $0.686^{\mathrm{M}}$ & 0.528 & 0.462 & 0.464 \\
\hline & $2 w-1 y$ & 0.548 & 0.503 & 0.550 & 0.509 \\
\hline & $3 m-1 y$ & $0.541^{\wedge}$ & $0.605^{\wedge}$ & $0.540^{4}$ & $0.652^{\wedge}$ \\
\hline & $2 w \cdot 3 m$ & $0.642^{\wedge}$ & $0.533^{n}$ & $0.611^{\wedge}$ & 0.486 \\
\hline \multicolumn{6}{|l|}{ ICW } \\
\hline & Period & $\triangle$ ICWDis & $\Delta\left(L^{2} / R i c W\right)$ & \% ICWbis & $\%\left(L^{2} / R i c w\right)$ \\
\hline & $0.2 \mathrm{w}$ & -0.032 & 0.139 & -0.165 & -0.015 \\
\hline & $0-3 m$ & 0.214 & 0.178 & 0.170 & 0.069 \\
\hline & $0-1 y$ & -0.241 & -0.364 & -0.292 & -0.447 \\
\hline & $2 w-1 y$ & -0.085 & -0.385 & -0.275 & -0.566 \\
\hline & $3 m-1 y$ & -0.308 & -0.499 & -0.326 & -0.482 \\
\hline & $2 w-3 m$ & 0.279 & 0.269 & 0.234 & 0.195 \\
\hline \multicolumn{6}{|l|}{ TBW } \\
\hline & Period & $\triangle T$ TBWbis & $\Delta\left(\mathrm{L}^{2} /\right.$ Rint $)$ & $\%$ TBWbis & $\%\left(\mathrm{~L}^{2} /\right.$ Rinf $)$ \\
\hline & $0-2 w$ & $0.776 \mu$ & $0.809 n$ & $0.780^{M}$ & $0.853^{\mu}$ \\
\hline & $0-3 m$ & $0.655^{\mathrm{M}}$ & $0.564^{\wedge}$ & $0.609 \mathrm{~m}$ & $0.482^{\star}$ \\
\hline & $0-1 y$ & $0.724^{M}$ & $0.572^{\star}$ & $0.648 \mathrm{M}$ & 0.467 \\
\hline & $2 w-1 y$ & $0.674^{x}$ & 0.476 & $0.659^{\wedge}$ & 0.442 \\
\hline & $3 m-1 y$ & $0.594^{\wedge}$ & 0.360 & 0.513 & 0.425 \\
\hline & $2 w-3 m$ & $0.588^{\wedge}$ & $0.670^{4}$ & 0.523 & $0.634^{\wedge}$ \\
\hline
\end{tabular}

Significant correlations: $P<0.05\left({ }^{\wedge}\right), P<0.005\left(^{(\mathcal{M})}\right.$. 
$\%$ loss ECW

dil

bis DIA

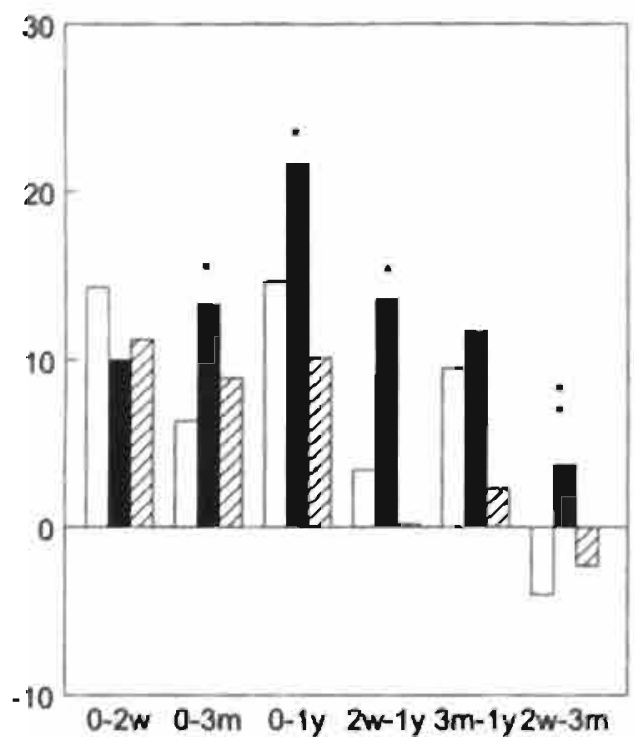

$\%$ loss ICW

bis UTA regr

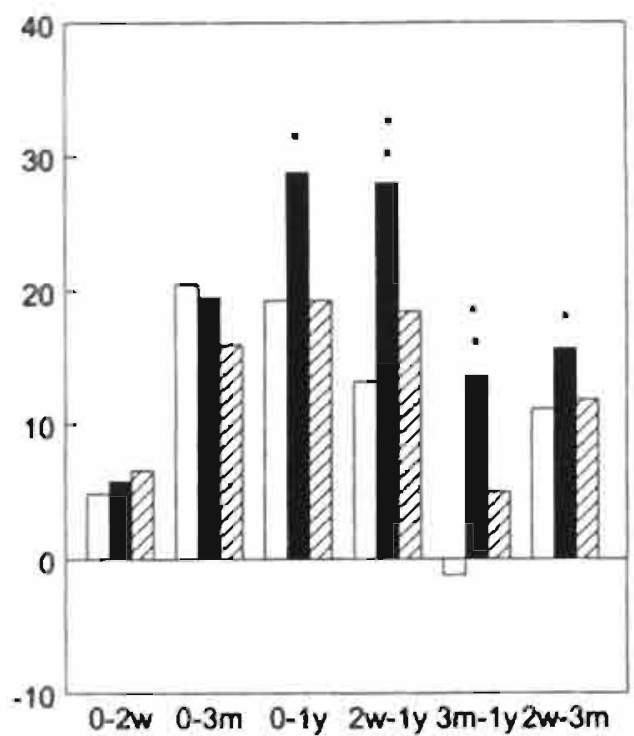

$\%$ loss TBW

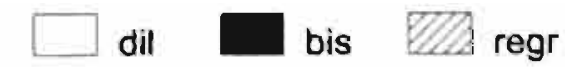

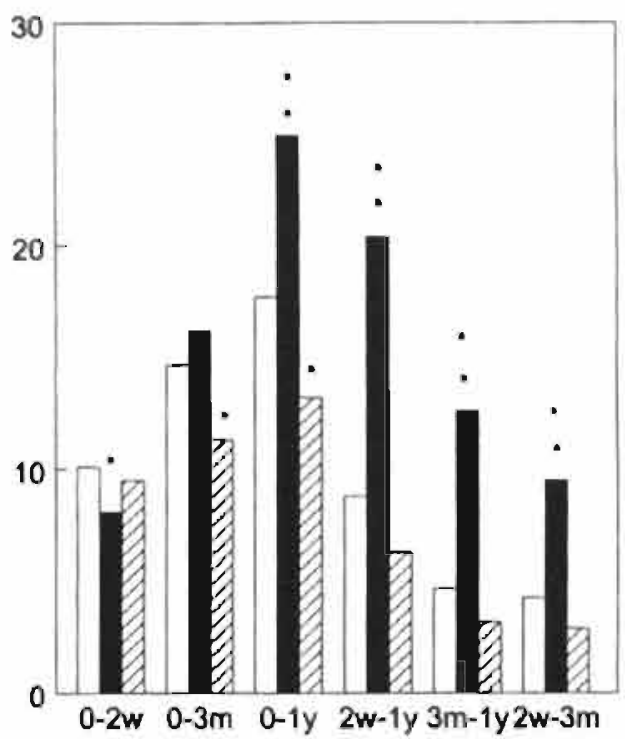

Figure 1. Comparison of the mixture (bis) and regression approach (reg) with the dilution method (dil) for measuring relative changes in fluid volumes during weight loss over different time intervals. For the regression approach $\%$ changes in $L^{2} / R e c w, L^{2} / R i c w$ and $L^{2} / R i n f$ as measures for $\%$ change in $E C W$, ICW and

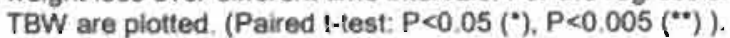




\section{Discussion}

In this study the results of serial bioelectrical impedance measurements during weight loss are described. Short-term as well as long term changes in body fluid compartments were measured with dilution methods and BIA. Relative changes in $L^{2} / R e c w, L^{2} / R i c w$ and $L^{2} / R$ inf were more in agreement with changes in fluid volumes than relative changes in ECW, ICW and TBW as calculated with the use of mixture equations.

\section{General considerations}

In this study we limited the comparison between body composition methods to fluid volumes because both the dilution method and BIA primarily measure fluid volumes. Fat- and fat free mass are derived from these fluid volumes with the use of assumptions that are probably not valid during each phase of the weight loss period studied.

The correlation between absolute values of fluid volumes measured by BIS using mixture equations and dilution methods were comparable with results of previous studies ${ }^{15,16,18-20}$. The consistent overestimation of absolute ECW values by BIS can be explained by differences in the reference methods used. A consistent overestimation can be mathematically corrected by adjusting the constant kecw, used in the volume equations. For measuring changes in ECW, the absolute value of this constant, if it is indeed constant, is not relevant because it only acts as a scalar ${ }^{14}$. Changing the value of kecw can reduce the systematic difference between ECW measured by BIS and the reference method, but the correlation between the two methods and the SEE will not be altered.

The small but significant increase in the ECW/TBW ratio after 3 months may be caused by the fact that during the first 3 months relatively more body cell mass is lost than during the last 9 months. Comparing the ICW and ECW losses during these two periods reveals that more ICW is lost during the first 3 months than during the next 9 months, 4.9 versus $0 \mathrm{~L}$, while the corresponding ECW losses were 1.6 and $1.8 \mathrm{~L}$. The large loss of ICW compared with the ECW loss during the early period is responsible for the measured changes in the ECW/TBW ratio. The rapid weight loss during the early post-operative period is associated with a substantial loss of body cell mass while after 3 months the decrease in body weight is mainly caused by a decrease in fat mass.

Weak correlations between methods for measuring changes can partly be explained by the accuracy of the reference methods. Based on an accuracy of respectively 5 and $1.5 \%$ of the $\mathrm{NaBr}$ and D2O dilution methods it can be calculated that the accuracy for measuring changes in TBW, ECW and ICW are in the order of $0.8 \mathrm{~L}, 1.1 \mathrm{~L}$ and $1.5 \mathrm{~L}$ respectively in normal individuals ${ }^{26,30}$. For a comparison between methods changes have to be larger than these values. This was true for TBW changes, but ECW and ICW changes were in 2 of the 6 time intervals smaller that the required minimal change.

\section{The ability of BIA to measure changes}

The ability of SF-BIA to measure changes in body composition has been questioned. Forbes analyzed data of 7 studies and concluded that only in 2 studies a significant weak negative correlation could be found between changes in lean body mass and changes in R at $50 \mathrm{kHz}$. Weight change appeared to be a more reliable predictor of LBM change than was body resistance ${ }^{10}$. Studies in weight losing obese subjects yielded conflicting results. Carella et al. found an overestimation of fat free mass (FFM) loss with increasing obesity ${ }^{3}$. Fogelholm et al. also found an overestimation of TBW loss $^{6}$. In this study the R increased during weight loss while TBW according to $\mathrm{D}_{2} \mathrm{O}$ dilution did not change. They discussed as possible causes for these findings small changes in the geometry of distal parts of legs and arms, or variations in the intra-abdominal fatness which can not be accurately measured by BIA. Van der Kooy et al. also concluded that SF- BIA overestimated the decrease in LBM during weight loss ${ }^{31}$. In 
their study no correlation was found between change in FFM by densitometry and change in resistance measured at $50 \mathrm{kHz}$. Wabitsch et al. measured TBW changes in 146 obese children and adolescents and found only a weak correlation $(r=0.21)$ between individual changes in TBW measured by $\mathrm{D}_{2} \mathrm{O}$ dilution and $\mathrm{SF}-\mathrm{BI} \mathrm{A}^{32}$. They concluded that prediction of small individual changes in TBW during weight loss is not possible by BIA. Results of other studies were promising. Kushner et al. found in 12 obese weight losing patients that changes in FFM could be measured by SF-BIA with an accuracy of $0.4 \mathrm{~kg}$ and precision of $1.28 \mathrm{~kg}$. Evans et al. measured an SEE for changes in \% fat mass of $2.1 \%$. Individual differences with the reference method ranged from $-3.6 \%$ to $4.8 \%$.

The inability of SF-BIA to measure accurately changes in body composition during weight loss was often explained by changes in the fluid distribution between ICW and ECW combined with the incomplete penetration of the current at $50 \mathrm{kHz}$ through the cell membranes. In contrast to other studies, in the present study we did not find an expanded ECW space in the obese patients before operation. Instead of a decrease in the ECW/TBW ratio after weight reduction a small but statistically significant increase of this ratio during 3 of the 6 time intervals $(0-3 \mathrm{~m}$, $2 \mathrm{w}-3 \mathrm{~m}, 2 \mathrm{w}-1 \mathrm{y}$ ) studied was measured. The hypothesis of selective ECW losses causing an increase in the specific resistivity and thus a larger than expected $\mathrm{R}$ at $50 \mathrm{kHz}$ resulting in underestimation of TBW by SF-BIA in obese subjects, is not supported by the present study.

Measuring ECW and ICW separately using BIS should theoretically give better results than SFBIA. However, no studies using BIS and the mixture approach during weight reduction have been published yet. The only studies published using BIS and the mixture approach for measuring changes were studies with acute changes in fluid volumes ${ }^{26,34,35}$. Plank et al. reported that BIS, using the same approach as in the present study, can reliably monitor the extracellular fluid changes in a group of critically ill patients undergoing large changes in hydration status. ECW changes measured by BIS were compared with $\mathrm{Br}$-dilution. The mean ECW loss measured by BIS did not differ from $\mathrm{Br}$ dilution and was $4.4 \mathrm{~L}$ during a period of 10 days. However, a considerable discrepancy between bromide and BIS estimates of up to $5 \mathrm{~L}$ can occur for individual patients ${ }^{34}$. Gudivaka et al. compared 7 BIA models, by validating them against a within-individual change in water compartementalisation. ECW was expanded by infusion of lactate Ringer solution or reduced by administration of a potent diuretic drug in 19 subjects $^{26}$. The reference methods used were $\mathrm{D}_{2} \mathrm{O}$ and $\mathrm{NaBr}$ dilution. Most models overestimated the change in fluid compartments. They concluded that SF-BIA (at $50 \mathrm{Khz}$ ) becomes invalid when the ECW/ICW ratio is altered. Results of the dual frequency approach, using $R$ values at 5 and $500 \mathrm{kHz}$, were less accurate than use of the extrapolated resistance values Recw and Ricw (Cole-Cole model) in a parallel model. Compared with the regression model , use of the Hanai mixture model did not improve the predictions based on Recw and RicW. The accuracy for measuring changes in TBW and ECW were 0.1 and $0.2 \mathrm{~L}$ and the precision 0.7 and $0.4 \mathrm{~L}$ respectively.

\section{Explanations for overestimation of fluid losses}

The present study gives better correlations between BIS and the dilution method for the measured changes in TBW compared with the SF-BIA studies. However, the changes in TBW and ECW were significantly overestimated by BIS with the use of mixture equations. For ECW and ICW changes the correlations between methods was much poorer than for TBW, probably caused by the low precision of the $\mathrm{Br}$-dilution method compared with the $\mathrm{D}_{2} \mathrm{O}$-dilution and by the fact that ICW is calculated as the difference between TBW and ECW. Relative changes in $L^{2} / R$ did not overestimate the relative changes in fluid volumes. Possible explanations for these findings are the assumptions used in the mixture equations:

(1) For predicting ECW a constant, kecw is included in the equation: $E C W=\operatorname{kecw}\left(\mathrm{L}^{2} \mathrm{~W}^{1 / 2} / \mathrm{RecW}\right)^{2 / 3}$. This kecw can be described as:

Kecw $=(1 / 1000)\left(\left(K^{2} b^{2} p e c w^{2}\right) / D b\right)^{1 / 3}$ 
in which $\mathrm{Kb}$ is a factor correcting for a whole body measurement between wrist and ankle, relating the relative proportions of the leg, arm, trunk and height, pecw is the specific resistivity of the ECW and $\mathrm{Db}$ is the body density. All these factors are assumed to be constant. However, $\mathrm{Kb}$ and $\mathrm{Db}$ are likely to change during severe weight loss. The $\mathrm{Kb}$ is used to remove the geometry effect on the specific resistivity, and is set at 4.3 in the BIS software. However, as geometry changes during weight loss, $\mathrm{Kb}$ will decrease. We have reported $\mathrm{Kb}$ values ranging from 3.5 to 6.5 in a population varying in the degree of overweight. Furthermore, a positive correlation between $\mathrm{Kb}$ and BMI was found ${ }^{36}$.

The density of the body will increase when fat mass is lost. A decrease of the body fat percentage from 50 to 20 will theoretically increase the density from 1.00 to $1.06 \mathrm{~kg} / \mathrm{L}$. The overall effect of changes in these variables on the predicted ECW depends on their relative contribution and direction of the change. It can be calculated that the decrease in $\mathrm{Kb}$ combined with the increase in Db would result in a $35 \%$ decrease of the calculated kecw and thus of ECW, when pecw is kept constant. Adjusting kecw, with a decrease during weight loss, would result in a decrease of measured ECW after weight loss. The calculated ECW loss would be larger due to this correction. Therefore, the overestimation of ECW loss found in this study can not be explained by changes in $\mathrm{Kb}$ and $\mathrm{Db}$.

(2) The other assumed constant pecw may be responsible for the overestimation of fluid loss, or other assumptions in the mixture theory are not valid. The effect of obesity on the pecw is not known. The measurement of resistivity of biological materials in vivo is extremely difficult and the published data on the resistivity of body tissues are widely variant ${ }^{37}$. Recently we reported data of calculated values of pecw based on the mixture equations ${ }^{36}$. A negative correlation between $\mathrm{BMI}$ and pecw was found in a population with differing degrees of overweight $(r=-641)$. Theoretically an increase in pecw during weight loss could explain the overestimation of fluid losses. However, it seems unlikely that large changes in electrolyte concentrations were present in these patients because they were healthy, showed no visible signs of fluid imbalance and had normal fluid intake. It has been reported that significant changes in ion concentrations during dialysis resulted in resistivity changes of $<4 \%$. The corresponding volume estimation errors did not exceed $2.1 \%$.

(3) The most plausible explanation for the overestimation of fluid losses by mixture equations is the contribution of body weight in the equations. To apply mixture theory, total volume must be known and is provided by W/Db. Db varies between individuals as described above. In the equations ECW is proportional to $\mathrm{W}^{1 / 3}$ and $R$ RecW ${ }^{2 / 3}$. This implies that for a reduction in $W$ from 130 to $80 \mathrm{~kg}$ a decrease in R from 500 to 392 is necessary if ECW is constant. A decrease in ECW is calculated when W decreases although Recw is constant. This explains why fluid volumes changes are overestimated by BIS although $\mathbf{R}$ values did not change between 3 months and 1 year. Changes in calculated volumes are partly caused by changes in body weight. It should be questioned whether W/Db is the best approximation of the total body volume especially if fat losses are large and $\mathrm{Db}$ increases. Measurements of body volume, although cumbersome, could improve the prediction of body fluids by BIS. Furthermore, parts of the body like the head, hands and feet are not measured as they are not located within the current path over which the voltage drop is measured. This fact is the same for all people and is accounted for in the constants used. It is not likely that large parts of the measured fluid changes take place in hands, feet or head. Theoretically however, it can be argued that structures like fat lobes and breasts are not measured as well, because the current will take the easiest, shortest path. During severe weight loss this error will decrease and the actual conducting volume will approach the calculated one. Overestimation of the change in the conducting body volume during weight loss may be responsible for the overestimation of fluid losses by mixture equations. The fact that relative changes in $L^{2} / R$ without inclusion of the factor W did not overestimate fluid losses further supports this hypothesis.

Changes in the body geometry may also affect the sensitivity of BIA to measure changes during severe weight loss. The trunk contributes only $12-15 \%$ to the total resistance due to the 
large diameter and relatively short length ${ }^{20}$. Therefore, a decrease in the fluid volume of the extremities will result in a larger increase of measured $R$ values than an equal amount of fluid removed from the trunk. Previous reports have demonstrated that impedance measurements are insensitive to significant changes in abdomen and trunk fluid volumes ${ }^{30.40}$. The magnitude of this effect on the results of the present study is unclear because use of dilution techniques as gold standard is not suited for studying regional changes. However, the difference between the regression and mixture approach can not be explained by this effect because both approaches are whole body measurements and will be affected in the same way.

\section{Conclusion}

In conclusion, short-term changes in body fluid volumes during weight loss are equally well predicted by regression and mixture approach but long-term losses associated with massive fat losses are largely overestimated by mixture equations but not by the regression approach. Overestimation of changes in the conducting volume by the mixture approach may be responsible for these findings.

\section{References}

1. Kushner RF. Bio-electrical impedance analysis: a review of principles and applications. J Am Col Nutr 1992; 11: 199-209.

2. Houtkooper LB, Lohman TG, Going SB, Howell WH. Why bioelectrical impedance analysis should be used for estimating adiposity. Am J Clin Nutr 1996; 64(suppl): 436S-448S.

3. Simons JPFHA, Schols AMWJ, Westerterp KR, Ten Velde GPM, Wouters EFM. Bioelectrical impedance analysis to assess changes in total body water in patients with cancer. Clin Nutr 1999; 18: 35-39.

4. Pencharz PB, Azcue M. Use of bioelectrical impedance analysis measurements in the clinical manegement of malnutrition. Am J Clin Nutr 1996; 64(suppl): 485S-488S.

5. Carella MJ. Serial measurements of body composition in obese subjects during a very-low-energy diet (vied) comparing bioelectrical impedance with hydrodensitometry. Obes Res 1997; 5: 250-256.

6. Fogelholm GM, Sievanen HT, Van Marken Lichtenbelt WD, Westerterp KR. Assessment of Fatmass loss durinmg weight reduction in obese women. Metabolism 1997; 46: 968-975.

7. Kushner RF,Kunigk A, Alspaugh M, Andronis PT, Leitch CA, Schoeller DA. Validation of bioelectrical-impedance analysis as a measurement of change in body composition in obesity. Am $J$ clin Nutr 1990; 52: 219-223.

8. Deurenberg P. Weststrate JA, Hautvast JGAJ. Changes in fat-free mass during weight loss measured by bioelectricasl impedance and by densitometry. Am J Clin Nutr 1989; 49: 33-36.

9. Vazquez JA, Janosky JE. Validation of bioelectrical-impedance analysis in measuring changes in lean body mass during weight reduction. Am J Clin Nutr 1991; 54: 970-975.

10. Forbes GB, Simon W. Amatruda JM. Is bioimpedance a good predictor of body-composition change? Am J Clin Nutr 1992; 56: 4-6.

11. Deurenberg P. Schouten FJM. Loss of total body water and extracellular water assessed by multifrequency impedance. Eur J Clin Nutr 1992; 46: 247-255.

12. Deurenberg $P$. Limitations of the bioelectrical impedance method for the assessment of body fat in severe obesity. Am J Clin Nutr 1996; 64(suppl): 449S-452S.

13. Thomas BJ, Comish BH, Ward LC, Jacobs A. Bioimpedance: is it a predictor of true water volume? Ann N Y Acad Sci 1999; 873: 89-93.

14. Lorenzo de A, Andreoli A, Matthie J. Withers P. Predicting body cell masswith bioimpedance methods: a technological review. J Appl Physiol 1997; 82: 1542-1558.

15. Baarends EM, Van Marken Lichtenbelt WD, Wouters EFMm, Schols AMWJ. Body water compartments measured by bio-electrical impedance spectroscopy in patients with chronic obstructive pulmonary disease. Eur J Clin Nutr 1998; 17: 15-22.

16. Van Marken Lichtenbelt W, Westerterp KR, Wouters L, Luyendijk SCM. Validation of bioelectricalimpedance measurements as a method to estimate body-water compartments. Am. J Clin Nutr 1994; 60: 159-166. 
17. Hanai T. Electrical properties of emulsions. In: Sherman PH (ed).Emulsion science.Academic: London, 1968, pp 354-477.

18. Chumlea WC, Guo SS, Baumgartner RN, Siervogel RM. Determination of body fluid compartments with multiple frequency bioelectrical imoedance . In: Ellis KJ, Eastman JD (eds). Human Body Composition: Vivo Methods, Models and Assessment. Plenum: New York, 1993, pp 23-26.

19. Hannan WJ, Cowen SJ, Fearon KCH, Plester CE, Falconer JS. Evaluation of multi-frequency bioimpedance analysis for the assessment of extracellular and total body water in surgical patients. Clin Sci 1994; 86: 479-485.

20. Thomas BJ, Ward LC, Comish BH. Bioimpedance spectrometry in the determination of body water compartments: accuracy and clinical significance. Appl Radiat Isot 1998; 49: 447-455.

21. Westerterp KR,Wouters L, van Marken Lichtenbelt WD. The Maastricht protocol for the measurement of body composition and energy expenditure with labeled water. Obes Res 1995; 3(suppl 1 ): 49-57.

22. Wong WW, Sheng HP, Morkeberg JC, Kosanovich JL, Clarke LL, Klein PD. Measurement of extracellular water by bromide ion chromatography. Am J Clin Nutr 1989; 50: 1290-1294.

23. Schoeller DA. Isotope dilution metheods. In:Bjöntröp P, Brodoff BN (Eds) Obesity. JB Lippecott Company: Philadelphia 1992, pp 80-88.

24. Miller BE,Cosgriff JM, Forbes GB. Bromide space determinationusing anion-exchange chromatography for measurement of bromide. Am J Clin Nutr 1989; 50: 168-171.

25. Van Kreel BK. An improved bromide assay for the estimation of extracellular water volume by capillary gas chromatography. Clin Chim Acta 1994; 231:117-128.

26. Gudivaka R, Schoeller DA, Kushner RF, Bolt MJG. Single-and multifrequency models for

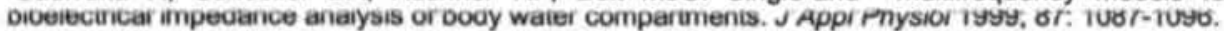

27. Ho LT, Kushner R, Schoeller DA, Gudivaka R, Spiegel DM. Bioimpedance analysis of total body water in hemodialysis patients. Kidney Int 1994; 46:1438-1442.

28. Lukaski HC, Johnson PE, Bolonchuk WW, Lykken GI. Assessment of fat free mass using bioelectrical imoedance measurement of human body. Am J Clin Nutr 1985; 41: 810-817.

29. Foster KR, Lukaski HC. Whole body impedance. What does it measure ? Am J Clin Nutr 1996; 64 (suppl): 388 S-396S.

30. Earthman CP, Matthie JR, Reid PM, Harper IT, Ravussin E, Howell WH. A comparison of bioimpedance methods for detection of body cell mass change in HIV infection. J Appl Physiol 2000: 88: 944-956.

31. Van der Kooy K, Leenen R, Deurenberg P, Seidell JC, Westerterp KR, Hautvast JGAJ. Changes in fat-free mass in obese subjects after weight loss: A comparison of body composition measures. Int $J$ Obes 1992; 16: 675-683.

32. Wabitsch M, Braun U, Heinze E Mucher R, Mayer H, Teller W, Fusch C. Body composition in 5-18year-old children and adolescents before and after weight reduction as assessed by deuterium dilution and bioelectrical impedance analysis. Am J Clin Nutr 1996; 64: 1-6.

33. Evans EM, Saunders MJ, Spano MA, Arngrimsson SA, Lewis RD, Cureton KJ. Body-composition changes with diet and exercise in obese women: a comparison of astimates from clinical methods and a 4-component model. Am J Clin Nutr 1999; 70: 5-12.

34. Plank LD, Monk DN, Woollard GA, Hill GL. Evaluation of multifrequency bioimpedance spectroscopy for measurement of the extracellular water space in critically ili patients. Appl Radiat Isot 1998; 49: 481-483.

35. Meyer A, Mazariegos M, Solomons NW, Furst P. The use of bioimpedance spectropscopy to monitor water changes induced by rehydration in young children with abnormal water disturbances associated with diarneal disease. Appl Radiat isot 1998; 49: 607-610.

36. Cox-Reijven PL, Soeters PB. Validation of bio-impedance spectroscopy: effects of degree of obesity and ways of calculating volumes from measured resistance values. Int $J$ obes 2000; 24:271-280.

37. Ward LC, Elia M, Cornish BH. Potential errors in the application of mixture theory to multifrequency bioelectrical impedance analysis. Physiol Meas 1998;19: 53-60.

38. Scharfetter $\mathrm{H}$, Wirnsberger $\mathrm{GH}$, Holzer $\mathrm{H}$, Hutten $\mathrm{H}$. Influence of ionic shifts during dialysis on volume estimations with multifrequency impedance analysis. Med \& Biol Eng \& Comput 1997; 35:96-102.

39. Thompson CM, Kong CH, Lewis CA, Hill PD, Thompson FD. Can bioelectrical impedance be used to measure total body water in dialysis patients ? Physiol Meas 1993; 14:455-461.

40. Kong $\mathrm{CH}$, Thompson CM, Lewis CA. Hill PD, Thompson FD. Determination of total body water in uraemic patients by bio-electrical impedance. Nephrol Dial Transplant 1993; 8:716-719. 


\section{CHAPTER 5}

\section{The role of bio-impedance spectroscopy in the assessment of body water compartments in hemodialysis patients}

PLM Cox-Reijven ' , JP Kooman ${ }^{2}$, PB Soeters ${ }^{3}$, FM van der Sande ${ }^{2}$, KML Leunissen ${ }^{2}$

'Department of Dietetics, ${ }^{2}$ Department of Internal Medicine, ${ }^{3}$ Department of Surgery, University Hospital Maastricht, Netherlands

Am. J. of Kidney Dis. 2001; 38:832-838. 


\begin{abstract}
Bio-impedance spectroscopy (BIS) has been advocated as a tool to assess fluid status in hemodialysis (HD) patients. However, uncertainty remains about the reliability of BIS in patients with abnormalities in fluid status. Aims of the study were to assess the agreement between total body water (TBW) and extracellular volume (ECW), measured by BIS and tracer dilution (deuterium oxide $\left(\mathrm{D}_{2} \mathrm{O}\right)$ and sodium bromide $(\mathrm{NaBr})$ ), the influence of the relative magnitude of water compartments (expressed as $\mathrm{TBW}_{\mathrm{D} 2 \mathrm{O}}$ and $\mathrm{ECW}_{\mathrm{NaBr}}$ :body weight) on the agreement between BIS and tracer dilution, and the ability of BIS to predict acute changes in fluid status. BIS and tracer dilution techniques were performed in $17 \mathrm{HD}$ patients before a dialysis session. Moreover, the relation between BIS and gravimetric weight changes were assessed both during isolated ultrafiltration and hemodialysis. The correlation coefficiënt between TBW and ECW measured by BIS and tracer dilution was $r=0.71$ and $r$ $=0.71$; resp. Mean difference (tracer-BIS) for TBW was $6.9 \mathrm{~L}$ (limits of agreement -1.5 to $21.6 \mathrm{~L}$ ) and $2.3 \mathrm{~L}$ for ECW (limits of agreement -1.7 to $9.7 \mathrm{~L}$ ). There was a significant relationship between the relative magnitude of TBW and ECW compartments and the disagreement between BIS and tracer dilution $(r=0.65$ and $0.77 ; \mathrm{P}<0.05)$. Both during isolated ultrafiltration and hemodialysis, there was a significant relation between gravimetric changes and the change in $\mathrm{ECW}_{\text {Bis }}(r=0.83$ and $r=0.76 ; \mathrm{P}<0.05)$, but not with the change in TBW BIS.

In conclusion, in hemodialysis patients, the agreement between BIS and tracer dilution techniques in the assessment of TBW and ECW is unsatisfactory. The discrepancy between BIS and dilution techniques is related to the relative magnitude of body water compartments. Nevertheless, BIS predicted acute changes in ECW during isolated ultrafiltration and hemodialysis adequately, in contrast to changes in TBW.
\end{abstract}




\section{Introduction}

An adequate assessment of body water compartments is of utmost importance in hemodialysis (HD) patients, firstly because over- and underhydration are often difficult to detect by clinical means and may have severe consequences in this population ${ }^{1}$ and because total body water $(\mathrm{V})$ is a very important determinant for $\mathrm{Kt} N$, the most commonly used parameter for dialysis adequacy. $y^{2}$. Bio-impedance analysis, a simple and reproducible method, has been advocated widely in the literature to serve as a tool for the assessment of body water compartments in dialysis patients ${ }^{26}$. Bio-impedance analysis is based on the conductive properties of biologic tissues. The volume of conductive tissues can be deduced from the measurements of their resistance. Tissues that contain a combination of water and electrolytes are basically more conductive than bone, air-filled spaces, and fat, which cannot be measured directly by this method ${ }^{\text {? }}$.

Multifrequency bio-impedance analysis, or bio-impedance spectroscopy (BIS) has been introduced somewhat recently for use in dialysis patients ${ }^{4.8}$. Because of the use of multiple frequencies, BIS is able to discriminate between intracellular (ICW) and extracellular water (ECW) compartments. At low frequencies, the cell membrane acts as a capacitor and blocks the flow of the current through the cell, whereas at higher frequencies the current flows both through the intra- and extracellular space ${ }^{0.9 .10}$. Although reliable measurements of the extracellular space would have enormous advantages in dialysis patients, uncertainty remains regarding the agreement of BIS in hemodialysis (HD) patients with tracer dilution techniques, which are considered gold standard methods. One reason may be that the reliability of BIS might be impaired because of the abnormal water distribution in this population. Also the reliability of both single-frequency bioimpedance and BIS in the detection of rapid volume changes has been questioned in HD patients ${ }^{11-13}$, e.g., because rapid ionic shifts during a dialysis session may interfere with the capacitance of the cell membrane ${ }^{14}$.

Therefore, aims of the present study are to assess:

1. The relationship between total body water (TBW) and extracellular water (ECW) measured by BIS and tracer dilution techniques.

2. The influence of the relative magnitude of these body water compartments (water compartment corrected for body weight) on the relationship between BIS and tracer dilution techniques.

3. The relationship between gravimetric weight changes and the change in body water compartments, assessed by BIS both during isotonic fluid removal (isolated ultrafiltration) as well as during hemodialysis (HD).

\section{Patients and methods}

\section{Patients}

Seventeen stable hemodialysis patients were included. Patients with metal implants, recent complications (e.g. malignancy or surgery) diabetes mellitus, and congestive or coronary heart disease of New York Heart Association class III and higher were excluded. Informed consent was obtained from each patient, and the study was approved by the Ethics Committee of the Maastricht University Hospital. Mean patient age was $59.2 \pm 12.5$ years (range 35-78). Mean height was $1.73 \pm 0.77 \mathrm{~m}$ (range 1.63-1.87 m) and mean dry weight was $77.6 \pm 11.6 \mathrm{~kg}$ (range 63.2-95.7 kg). 


\section{Study protocol}

Body water compartments were assessed by BIS and tracer dilution (deuterium $\left(\mathrm{D}_{2} \mathrm{O}\right.$ ) and sodium bromide ( $\mathrm{NaBr}$ ). In the early morning after an overnight fast, patients were administered an oral dose of $\mathrm{D}_{2} \mathrm{O}$ and $\mathrm{NaBr}$ (discussed next). Immediately before the oral intake, a (background) blood sample was obtained. After a period of 4 hours, needed for equilibration of $\mathrm{NaBr}$ and $\mathrm{D}_{2} \mathrm{O}$, a second blood sample was collected and $\mathrm{BIS}$ measurements were performed. Hereafter, patients were treated with isolated ultrafiltration until their dry weight, which was assessed on clinical grounds, was reached. After the session with isolated ultrafiltration, BIS was performed.

On the second day of the study, patients underwent a session with combined hemodialysis and ultrafiltration until dry weight was reached. BIS measurements were performed before and after the hemodialysis session. Dialysis was performed using hemophane membranes. Dialysate sodium concentration was $140 \mathrm{mmol} / \mathrm{L}$; potassium, $2 \mathrm{mmol} / \mathrm{L}$; and bicarbonate, 34 $\mathrm{mmol} / \mathrm{L}$.

\section{Tracer dilution}

Patients were administered an oral dose of $20 \mathrm{~mL}$ of $\mathrm{D}_{2} \mathrm{O}(99 \%$, Sigma Chemicals, St. Louis, USA) and $\mathrm{NaBr}$ of $30 \mathrm{~mL}$ (150 mmol/L). Dose bottles were rinsed and the resulting water was also ingested by the patients to ensure that all $\mathrm{D}_{2} \mathrm{O}$ and $\mathrm{NaBr}$ was consumed. Enrichments of $\mathrm{D}_{2} \mathrm{O}$ and $\mathrm{NaBr}$ were measured in saliva and in serum, respectively. Immediately before $\mathrm{D}_{2} \mathrm{O}$ and $\mathrm{NaBr}$ intake, a (background) saliva and blood sample was obtained. After an equilibration time of 4 hours, a second blood sample was collected. Food and fluid intake were not allowed until the second saliva and blood sample were obtained.

Concentrations of $\mathrm{D}_{2} \mathrm{O}$ and bromide in serum were determined by tracer ratio mass spectrometry and ion chromatography respectively ${ }^{15,16}, \mathrm{D}_{2} \mathrm{O}$ and bromide dilution spaces were calculated from the enrichment of $\mathrm{D}_{2} \mathrm{O}$ and $\mathrm{NaBr}$ after 4 hours, respectively ${ }^{17}$. TBW was calculated as the $\mathrm{D}_{2} \mathrm{O}$ dilution space corrected for the exchange of $\mathrm{D}_{2} \mathrm{O}$ with nonaquaous compartments by dividing the dilution space by $1.04{ }^{17,18}$. The ECW compartment was calculated as the bromide dilution space corrected for intracellular penetration of bromide in erythrocytes, leukocytes and secretory cells, for unequal bromide concentrations in the extracellular fluids (Gibbs-Donnan effect); therefore, bromide dilution space was multiplied by $0.90^{*} 0.95$ respectively ${ }^{17,12,21}$.

The accuracy of the $\mathrm{D}_{2} \mathrm{O}$ and $\mathrm{NaBr}$ methods to assess TBW and ECW are $1.5 \%$ and $5 \%$, respectively ${ }^{15,16}$,

\section{Multifrequency bio-electrical impedance analysis:}

Bio-electrical impedance measurements were performed in a standard fashion while the patient was lying supine on a flat, nonconductive bed. Multifrequency $(5-500 \mathrm{KHz})$, alternating currents were introduced at distal electrodes on the hands fiust proximal to the phalangeal-metacarpal joint in the middle of the dorsal side of the hand) and the feet (proximal to the transverse (metatarsal) arch on the superior side of the foot), and resistance were measured by proximal electrodes (to the wrist midway between the styloid process, to the ankle midway between the malleoli). TBW and ECW were predicted from a general mixture theory (Cole-Cole model) ${ }^{22.23}$ : water compartments were directly calculated from resistance values, assuming specific resistances of ECW and ICW. Specific resistances of $E C W$ and ICW are provided by the manufacturer (for men: $\rho E C W=215.0, \rho I C W=824.0$, for women $\rho E C W=206.0$, $\rho I C W=797.0)^{24}$. TBW was calculated as the sum of ICW and ECW. The bio-electrical impedance analyzer used in this study was the Xitron $4000 \mathrm{~B}$ (Xitron Technologies Inc, San Diego, USA). Moreover, critical frequency and membrane capacitance were assessed during all measurements. 


\section{Statistical analysis}

Data are expressed as mean \pm standard deviation (SD). Correlations between body water compartments measured by the different methods were estimated by the use of Pearson product -moment correlations. P-values of less than 0.05 were considered significant. Bland and Altman plots ${ }^{25}$ were used to visually assess agreement between the different methods to measure TBW and ECW. Statistical analysis was performed by SPSSIPC for windows, version 10.0 .

\section{Results}

Inter-day reproducibility of BIS measurements

The correlation between TBW and ECW measurements by BIS, performed on the first and second day of the study (assessed before isolated ultrafiltration and before hemodialysis) was 0.95 and $0.95(\mathrm{P}<0.05)$ respectively.

\section{Relation between BIS and tracer dilution techniques}

Data for absolute and relative magnitude of the body water compartments assessed by BIS and tracer dilution techniques, are listed in table 1. With regard to TBW, the correlation coefficient between $\mathrm{BIS}$ and $\mathrm{D}_{2} \mathrm{O}$ was $0.71(P<0.05)$. The mean difference between $\mathrm{D}_{2} \mathrm{O}$ and BIS (BIS- $\mathrm{D}_{2} \mathrm{O}$ ) was $6.9 \mathrm{~L}$ (limits of agreement -1.5 to $21.6 \mathrm{~L}$; fig. 1).

Regarding ECW, the correlation coefficient between BIS and $\mathrm{NaBr}$ was $0.71(\mathrm{P}<0.05)$. The mean difference between $\mathrm{NaBr}$ and $\mathrm{BIS}(\mathrm{NaBr}$ - $\mathrm{BIS}$ ) was $2.3 \mathrm{~L}$ (limits of agreement -1.7 to $9.7 \mathrm{~L} ;$ fig.2). In the single patient with concomitant liver cirrhosis, the difference between TBW measured by $\mathrm{D}_{2} \mathrm{O}$ and $\mathrm{BIS}$ was $21.6 \mathrm{~L}$ whereas the difference in ECW measured by $\mathrm{NaBr}$ and $\mathrm{BIS}$ was $6.9 \mathrm{~L}$.

Table 1: Body water compartments measured by the different techniques in hemodialysis patients (mean, standard deviation and range)
Mean
SD
Range

\begin{tabular}{|c|c|c|c|}
\hline $\mathrm{TBW}_{020}$ (L) & 44.2 & 8.5 & $34.7-60.4$ \\
\hline TBW $_{\text {bis }}(\mathrm{L})$ & 38.2 & 5.9 & $29.7-47.7$ \\
\hline$E C W_{\text {Nato }}$ (L) & 23.9 & 4.4 & $18.1-33.3$ \\
\hline$E C W_{\text {th }}(L)$ & 21.6 & 2.7 & $17.2-26.2$ \\
\hline $\mathrm{TBW}_{020} / \mathrm{BW}(\%)$ & 56 & 6 & $38-68$ \\
\hline $\mathrm{ECW}_{\text {Natr } / \mathrm{BW}(\%)}$ & 30 & 5 & $20-39$ \\
\hline $\mathrm{ECW}_{\text {bis }} / \mathrm{TBW}_{\text {bis }}$ & 0.57 & 0.05 & $0.47-0.67$ \\
\hline
\end{tabular}

$\mathrm{TBW}_{\mathrm{O} 20}=$ total body water measured by deuterium dilution; $\mathrm{TBW}_{\mathrm{Ba}}=$ total body water measured by $\mathrm{BIS} ; \mathrm{ECW}_{\mathrm{Mab}}=$ extracellular water measured by sodium bromide dilution; $\mathrm{ECW}_{\mathrm{bes}}=$ extracellular water measured by BIS. BW = body weight $(\mathrm{kg})$ measured before isolated ultrafiltration. 


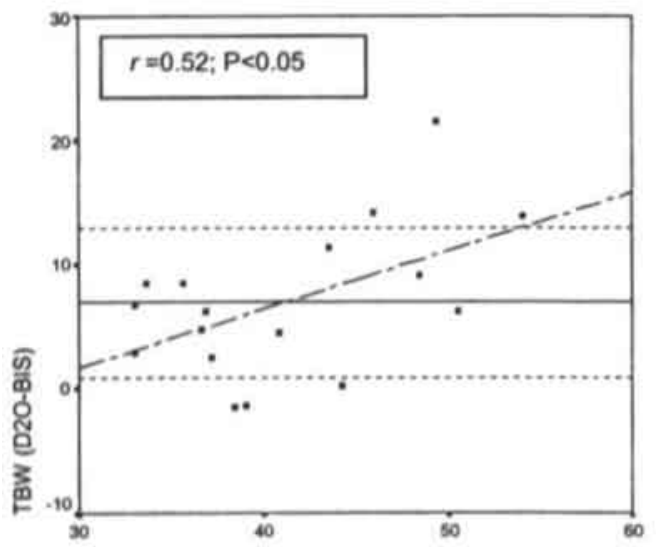

Average of TBW (D20 and BiS)

Figure 1. Agreement between TBW On the $x$-axis, the average of TBW assessed by $\mathrm{D}_{2} \mathrm{O}$ and $\mathrm{BIS}$ is shown. On the $\mathrm{y}$-axis, the difference between $\mathrm{D}_{2} \mathrm{O}$ and $\mathrm{BIS}$ is shown. Indicated horizontal lines are mean and SD. The regression line indicates the relation between the absolute magnitude of the TBW compartment (mean of $\mathrm{D}_{2} \mathrm{O}$ and BIS) and the difference between D2O and BIS.

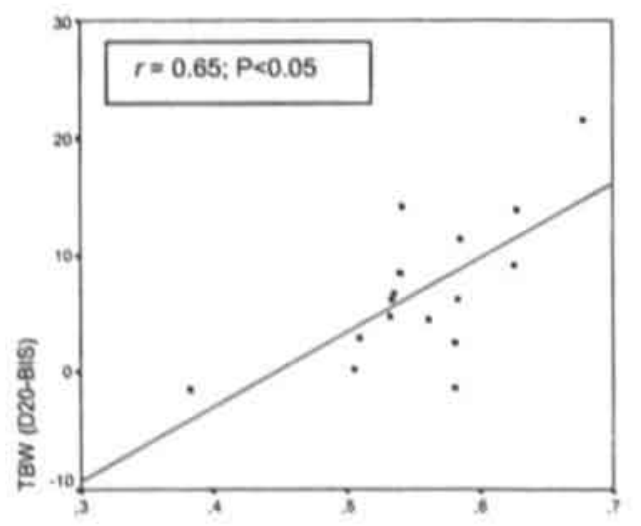

TEW: body weight

Figure 3. Relation between the relative magnitude of TBW (TBW crobody weight) and difference between TBW oso and TBWes. Body weight was measured before isolated ultrafiltration. $r=0.65$; $P<$ 0.05 .

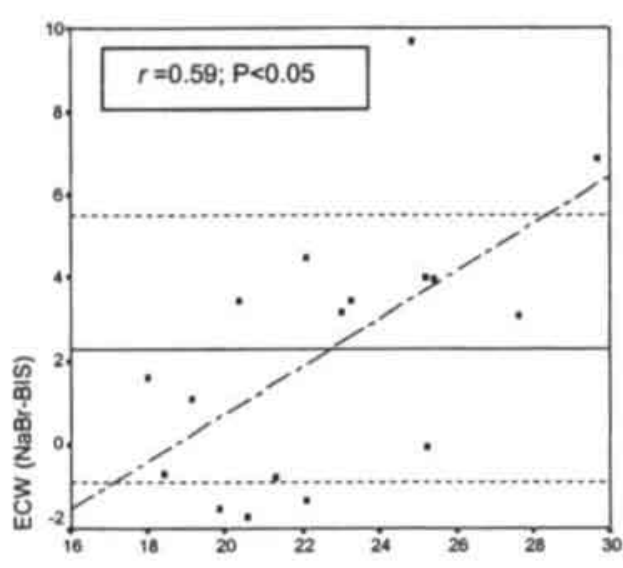

Average of ECW ( $\mathrm{NaBr}$ and BIS)

Figure 2. Agreement between ECW vabr and $E_{\text {ais }}$ On the $x$-axis, the average of ECW assessed by $\mathrm{NaBr}$ and BIS is shown. On the y-axis, the difference between $\mathrm{NaBr}$ and $\mathrm{BIS}$ is shown. Indicated horizontal lines are mean and SD. The regression line indicates the relation between the absolute magnitude of the ECW compartment (mean of $\mathrm{NaBr}$ and BIS) and the difference between ECW Nat and BIS.

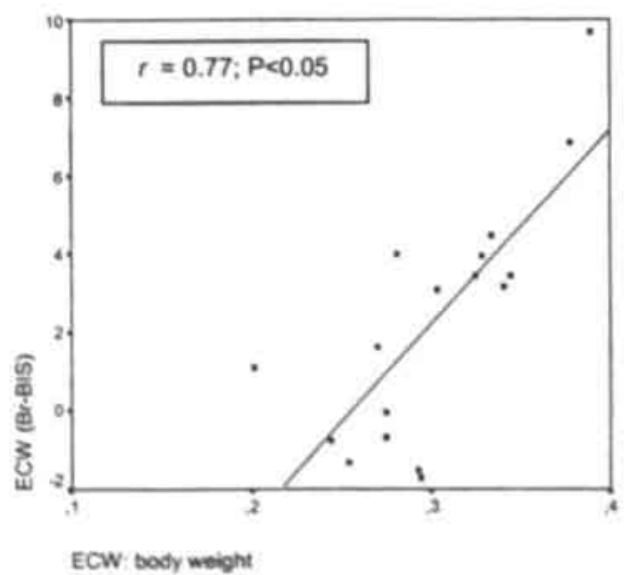

Figure 4. Relation between the relative magnitude of ECW (ECWwosbody weight) and difference between ECW and ECW ass. Body weight was measured before isolated ultrafiltration. $r=0.77 ; \mathrm{P}<$ 0.05 . 
Influence of the absolute and relative magnitude of body water compartments on agreement between BIS and tracer dilution techniques

There was a significant relation between the absolute magnitude of the TBW compartment (expressed as the average of $\mathrm{D}_{2} \mathrm{O}$ and BIS) and the difference between TBW measured by the dilution method and BIS $(r=0.52 ; \mathrm{P}<0.05$; fig. 1), whereas the relation between the relative magnitude of the TBW compartment (TBW $\mathrm{Dr}_{0}$ : body weight) and difference between TBW measured by $\mathrm{D}_{2} \mathrm{O}$ and BIS was even more pronounced ( $r=0.65 ; \mathrm{P}<0.05 ;$ fig. 3 ). Also the relation between both the absolute (fig. 2) and the relative magnitude of the ECW compartment (fig.4) was highly significant ( $r=0.57$ and $r=0.77$, respectively).

\section{Changes in BIS measurements duning isolated ultrafiltration and during hemodialysis}

As listed in table 2, during both isolated ultrafiltration and hemodialysis, resistance, as well as calculated volume of TBW and ECW, decreased significantly. During isolated ultrafiltration, the resistance of the ICW compartments changed significantly, whereas ICW resistance did not change significantly during hemodialysis. Both during isolated ultrafiltration and hemodialysis, membrane capacitance, as well as critical frequency changed significantly.

Table 2. Changes in BIS measurements during isolated ultrafiltration and hemodialysis. Values are mean \pm SD.

\begin{tabular}{lccc}
\hline & Before & After & $P$ \\
\hline Isolated ultrafiltration & & & \\
Body weight & $79.6 \pm 11.6$ & $77.6 \pm 11.6$ & $<0.05$ \\
TBW & $38.2 \pm 5.9$ & $37.3 \pm 5.8$ & $<0.05$ \\
ECW $_{\text {Bis }}$ & $21.6 \pm 2.7$ & $19.2 \pm 2.8$ & $<0.05$ \\
Rtbw (Ohm) & $385.4 \pm 50.9$ & $421.3 \pm 53.3$ & $<0.05$ \\
Recw (Ohm) & $607.4 \pm 78.0$ & $668.5 \pm 89.6$ & $<0.05$ \\
Ricw (Ohm) & $1287.6 \pm 307.1$ & $1200.5 \pm 267.1$ & $<0.05$ \\
Critical frequency (kHz) & $111.9 \pm 87.6$ & $91.0 \pm 74.4$ & $<0.05$ \\
Membrane capacitance (nF) & $1.49 \pm 0.76$ & $1.91 \pm 0.95$ & $<0.05$ \\
Hemodialysis & & & \\
Body weight & $78.0 \pm 11.7$ & $77.4 \pm 11.6$ & $<0.05$ \\
TBW & $37.3 \pm 6.2$ & $36.9 \pm 6.4$ & $\mathrm{NS}$ \\
ECW & $20.3 \pm 3.0$ & $18.9 \pm 3.1$ & $<0.05$ \\
Rtbw (Ohm) & $406.9 \pm 55.8$ & $428.6 \pm 63.4$ & $<0.05$ \\
Recw (Ohm) & $607.4 \pm 78.0$ & $668.5 \pm 89.6$ & $<0.05$ \\
Ricw (Ohm) & $1279.5 \pm 329.9$ & $1230.8 \pm 322.2$ & $\mathrm{NS}$ \\
Critical frequency (kHz) & $107.0 \pm 83.1$ & $91.9 \pm 20.6$ & $<0.05$ \\
Membrane capacitance (nF) & $1.52 \pm 0.73$ & $1.88 \pm 0.93$ & $<0.05$ \\
\hline
\end{tabular}

Abbreviations : $R$, resistance, $N S$, not significant, $n F$, nano Farad. 
The relation between gravimetric weight changes during isolated ultrafiltration and hemodialysis and the change in body water compartments, assessed by BIS

On the first day before the study, the mean weight before isolated ultrafiltration was $79.6 \pm$ $11.6 \mathrm{~kg}$ (range 65 to $98 \mathrm{~kg}$ ). Mean ultrafiltration volume during isolated ultrafiltration was 2.2 $\pm 1.0 \mathrm{~L}$ (range 0.3 to $4.5 \mathrm{~L}$ ) whereas the main difference in gravimetric weight before and after isolated ultrafiltration was $2.0 \pm 0.9 \mathrm{~kg}$ (range, 0.3 to $4.5 \mathrm{~kg}$ ). There was a highly significant relation between gravimetric weight change and changes in both extracellular resistance $(r=0.75 ; \mathrm{P}<0.05)$ and ECW, assessed by BIS $(r=0.83 ; \mathrm{P}<0.05 ;$ fig. 5$)$. Conversely, neither the relation between gravimetric weight changes and change in TBW assessed by BIS $(r=-0.24)$ nor the relation between resistance of the TBW compartment and weight change $(r=0.44)$ was significant.

On the second day of the study, mean body weight before hemodialysis was $78.0 \pm 11.7 \mathrm{~kg}$ (range, 64 to $96 \mathrm{~kg}$ ). Mean ultrafiltration volume during hemodialysis was $0.7 \pm 0.5 \mathrm{~L}$ (range, 0.3 to $2.1 \mathrm{~L}$ ) whereas the main difference in gravimetric weight before and after hemodialysis was $0.6 \pm 0.5 \mathrm{~kg}$ (rang. -0.1 to $2.1 \mathrm{~kg}$ ). Also during hemodialysis, the relation between the gravimetric weight change and the change in ECW assessed by BIS, was highly significant ( $r$ $=0.76 ; \mathrm{P}<0.05)$, whereas the relation between gravimetric weight change and changes in TBW was not $(r=0.45)$.

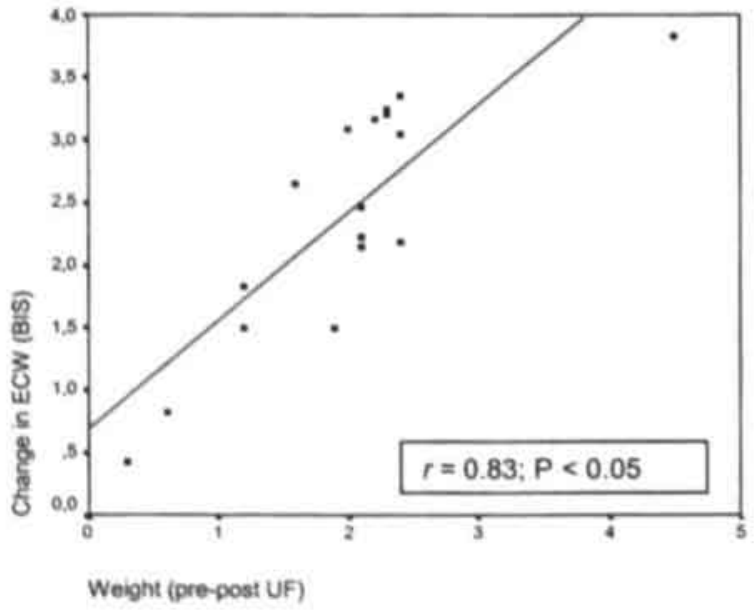

Figure 5. Relation between gravimetric weight change during isolated ultrafiltration (UF) and change in $\mathrm{ECW}_{\mathrm{Bis}} \mathrm{R}=0.83 ; \mathrm{P}<0.05$.

\section{Discussion}

In this study, we assessed first the relation between TBW and ECW measured by BIS and tracer dilution techniques; second, the influence of the relative magnitude of these body water compartments on the relation between BIS and tracer dilution techniques; and last, 
the relation between gravimetric weight changes during isolated ultrafiltration and hemodialysis and the change in body water compartments, predicted by BIS.

The agreement between BIS and tracer dilution techniques was unsatisfactory for both TBW and ECW. The limits of agreement between BIS and tracer dilution were wide. These disappointing results are in contrast with the good agreement between TBW measured by BIS and $\mathrm{D}_{2} \mathrm{O}$ in non-renal patients ${ }^{10}$, and in renal transplant recipients previously reported by our group ${ }^{20}$. Moreover, with regard to TBW, a reasonable agreement with tracer dilution techniques was reported for single frequency and triple-frequency bioimpedance measurements, although also in these studies, the limits of agreement were wide ${ }^{5.27 .28}$. Other authors found a reduced accuracy of (single frequency) bioimpedance methods in renal patients compared with controls ${ }^{20}$ and unacceptable wide limits of agreement between bioimpedance and tracer dilution techniques ${ }^{30}$.

Nevertheless, when studying the agreement between BIS and tracer dilution, also the limitations of tracer dilution techniques have to be taken into account. Whereas the accuracy of deuterium oxide by continuous flow tracer ratio mass spectroscopy is excellent with regard to the measurements of TBW $(1.6 \%)$ and is dependent mainly on the uncertainty of the estimate of nonaqueous exchange $( \pm 1 \%)^{15,17}$, accuracy for the assessment of ECW by bromide space is somewhat less $( \pm 5 \%)^{16}$. Moreover, especially in patients with abnormal ECW, some errors with the bromide technique cannot be excluded, for instance due to the uncertainty of the correction constants for plasma water and the Gibbs-Donnan equilibrium as well as penetration into the intracellular space due to changes in plasma protein concentration and hematocrit ${ }^{17}$.

However, these limitations of the tracer dilution techniques are unlikely to account for all of the discrepancy. One explanations for the lack of a satisfactory agreement between BIS and tracer dilution techniques is the fact that BIS (as with single-frequency bio-impedance) considers the body as five conductive cylinders (arms, legs, and trunk), connected in series. In conductors connected in series, the conductors with the smallest cross-sectional area (the extremities) will determine most of the resistance whereas the part with the largest crosssectional area (trunk) will contribute little to the resistance although it contains a significant amount of body water ${ }^{7.931}$. This explanation is supported by the fact that the disagreement between BIS and tracer dilution techniques was augmented in the patients with the largest relative magnitude of the body water compartments. Also, a large difference in hydration state, expressed as ECW: body weight (measured before dialysis) was observed between $\mathrm{HD}$ patients and the renal transplant patients in our former study $(30 \pm 5 \%$ before isolated ultrafiltration versus $22 \pm 4 \%$ in renal transplant patients ${ }^{8}$ ). In addition, the disagreement between BIS and dilution techniques was very large in the patient with concomitant liver cirrhosis and ascites. The inability of BIS to measure trunk water adequately was further supported by the study of Zhu et al, who showed that changes in trunk water by infusion of peritoneal dialysate in continuous ambulatory peritoneal dialysis patients were not detected adequately by standard BIS measurements ${ }^{32}$. Conversely, assessment of the sum of segmental BIA measurements, which takes into account the resistance of the extremities and the trunk independently, was able to detect these changes in trunk water more adequately. Whether this approach, which is far more complicated than standard BIS measurements, is able to yield better agreement with tracer dilution techniques with regard to the assessment of the absolute magnitude of body water compartments in dialysis patients has not been studied to date.

With regard to the different relations between bio-impedance and tracer dilution methods observed in the few studies that addressed this topic, it is important to note that prediction of body fluid volumes is different between the single-frequency and the multifrequency approach. The single frequency approach often uses empirically derived (regression) formula in order to assess TBW, whereas BIS predicts the volume of TBW and ECW from a general 
mixture theory, assuming specific resistance values for ECW and intracellular water 9.22 .23 . Moreover, the contribution of body weight, which is strongly related to ECW and TBW, is greater in the regression approach compared to the mixture approach. In addition, differences in hydration state, which appeared to be a pivotal factor in the agreement between BIS and tracer dilution in the present study, also may explain the somewhat different findings between the various studies. In this study, agreement between BIS and tracer dilution methods was assessed before ultrafiltration, thus in a state of relative overhydration.

With regard to the ability of BIS to predict acute changes in volume status, gravimetric weight changes and the change in ECW, assessed by BIS, were reasonably well related both during isolated ultrafiltration and during hemodialysis, in contrast to the change in TBW. Interestingly, membrane capacitance and critical frequency also changed during both isolated ultrafiltration and hemodialysis, perhaps pointing towards changes in cell-volume or cell-membrane characteristics. It is tempting to speculate that rapid changes in cellmembrane characteristics during fluid removal might partly explain the lack of agreement between changes in TBW and gravimetric weight ${ }^{23}$.

In conclusion, agreement between BIS and tracer dilution techniques in the assessment of TBW and ECW in hemodialysis patients is unsatisfactory. The discrepancy between BIS and dilution techniques is related to the relative magnitude of body water compartments, possibly caused by inadequate measurement of trunk volume by BIS. Nevertheless, BIS adequately predicted acute changes in ECW during isolated ultrafiltration and hemodialysis, in contrast to changes in TBW.

\section{References}

1. Jaeger JQ, Mehta RL. Assessment of dry weight in hemodialysis: an overview. J Am Soc Nephrol. 10:392-403, 1999.

2. Chertow GM, Owen WF, Lazarus JM, Lew NL, Lowrie EG. Exploring the reverse J-shaped curve between urea reduction ratio and mortality.. Kidney Int 56:1872-8, 1999

3. Pupim LB, Kent P. Ikizler TA. Bioelectrical impedance analysis in dialysis patients. Miner Electrolyte Metab 24: 400-406, 1999

4. Katzarski K, Charra B, Laurent G, Lopot F. Divino-Filho JC, Nisell J, Bergstrom J, Multifrequency bioimpedance in assessment of dry weight in haemodialysis. Nephrol Dial Transplant. 11 Suppl 2:20-3, 1996.

5. Cooper BA, Aslani A, Ryan M, Zhu FY, Ibeis LS, Allen BJ, Pollock CA. Comparing different methods of assessing body composition in end-stage renal failure. Kidney Int 58:408-416, 2000.

6. Dumler $F$ Use of bioelectric impedance analysis and dual-energy $X$-ray absorptiometry for monitoring the nutritional status of dialysis patients: ASAIO J 43:256-60, 1997.

7. Baumgartner RN: Electrical impedance and total body electrical conductivity. In: Human body composition. 1st ed., edited by Roche AF. Heymsfield SB, Lohman TG. Champaign, Human Kinetics, 1996, pp 79-107

8. Matthie J, Zarowitz B, De Lorenzo A, Andreoli A, Katzarski K, Pan G, Withers PJ. Analytic assessment of the various bioimpedance methods used to estimate body water. Appl Physiol ;84:1801-16, 1998.

9. Ellis KJ, Bell SJ, Chertow GM, Chumlea WC, Knox TA, Kotler DP, Lukaski HC, Schoeller DA. Bioelectrical impedance methods in clinical research: a follow-up to the NIH Technology Assessment Conference. Nutrition 15:874-80, 1999.

10. Hannan WJ, Cowen SJ, Plester CE. Fearon KCH, DeBeau A: Comparison of bio-impedance spectroscopy and multi-frequency bio-impedance analysis for the assessment of extracellular and total body water in surgical patients. Clinical Science 89.651-658, 1995

11. Abrahamsen B, Hansen TB, Hogsberg IM, Pedersen FB, Beck-Nielsen H Impact of hemodialysis on dual X-ray absorptiometry, bioelectrical impedance measurements, and anthropometry. Am J Clin Nutr. 63:80-6, 1996. 
12. Zaluska WT, Schneditz D, Kaufman AM, Morris AT, Levin NW. Relative underestimation of fluid removal during hemodialysis hypotension measured by whole body bioimpedance. ASAIO J. 44:823-7, 1998.

13. Johnson DW. Thomas BJ. Fleming SJ, Westhuyzen J, Moran D, Ward LC. Monitoring of extracellular and total body water during haemodialysis using multifrequency bio-electrical impedance analysis.. Kidney Blood Press Res. 19:94-99, 1996.

14. Scharfetter $\mathrm{H}$, Wirnsberger $\mathrm{GH}$, Holzer $\mathrm{H}$, Hutten $\mathrm{H}$. Influence of ionic shifts during dialysis on volume estimations with multifrequency impedance analysis. Med Biol Eng Comput. 35:96-102. 1997.

15. Van Kreel BK, Van der Vegt F, Meers M: Determination of total body water by a simple and rapid mass spectrometric method. J Mass Spectrom 31:108-111, 1996

16. Van Kreel BK: An improved bromide assay for the estimation of extracellular water volume by capillary gas chromatography. Clin Chim Acta 231:117-128, 1994

17. Schoeller DA: Hydrometry. In: Human body composition, 1st ed., edited by Roche AF, Heymsfield SB, Lohman TG, Champaign, Human Kinetics, 1996, pp 25-44

18. Schoeller DA, Van Santen E, Peterson DW, Dietz W, Jaspen J, Klein PD: Total body water measurements in humans with ${ }^{18} \mathrm{O}$ and ${ }^{2} \mathrm{H}$ labeled water. Am J Clin Nutr 33:2686-2693, 1980

19. Edeiman IS, Leibman J: Anatomy of body water and electrolytes. Am J Med 27:256-277, 1959

20. Donnan FG, Allmand AJ: Ionic equilibration across semi-permeable membranes. J Chem Soc 105:1941-1963, 1914

21. Miller ME, Cosgriff JM, Forbes GB: Bromide space determination using anion-exchange chromatography for measurement of bromide. Am J Clin Nutr 50:168-171, 1989

22. De Lorenzo A, Andreoli A, Matthie J, Withers P: Predicting body cell mass with bioimpedance by using theoretical methods: a technological review. J Appl Physiol 82:1542-1558, 1997

23. Ward LC, Elia M, Cornish BH Potential errors in the application of mixture theory to multifrequency bioelectrical impedance analysis. Physiol Meas. 19:53-60, 1998.

24. Operating manual Xitron $4000 \mathrm{~B}$ bio-impedance spectrum analyser system. Xitron Technologies INC, San Diego CA, USA

25. Bland JM, Altman DG: Statistical methods for assessing agreement between two methods of clinical measurement. The Lancet 1:307-310, 1986

26. van den Ham EC, Kooman JP, Christiaans MH, Nieman FH, Van Kreel BK, Heidendal GA, Van Hooff JP. Body composition in renal transplant patients: bioimpedance analysis compared to isotope dilution, dual energy $X$-ray absorptiometry, and anthropometry. J Am Soc Nephrol. 10:1067-79, 1999.

27. Ho LT, Kushner RF, Schoeller DA, Gudivaka R, Spiegel DM. Bioimpedance analysis of total body water in hemodialysis patients. Kidney Int. 46:1438-1442, 1994.

28. Chertow GM, Lowrie EG, Wilmore DW, Gonzalez J, Lew NL, Ling J, Leboff MS, Gottlieb MN, Huang W, Zebrowski B, et al. Nutritional assessment with bioelectrical impedance analysis in maintenance hemodialysis patients. J Am Soc Nephrol 6:75-81, 1995.

29. Woodrow G, Oldroyd B, Turney JH, Davies PS, Day JM, Smith MA. Measurement of total body water by bioelectrical impedance in chronic renal failure. Eur J Clin Nutr 50:676-681, 1996.

30. Arkouche W, Fouque D, Pachiaudi C, Normand S, Laville M, Delawari E, Riou JP. Traeger J, La Ville M. Total body water and body composition in chronic peritoneal dialysis patients. J Am Soc Nephrol 8:1906-1914, 1997.

31. Di lorio BR, Terracciano V, Bellizzi V. Bioelectrical impedance measurement: errors and artifacts. J Ren Nutr 9:192-7, 1999.

32. Zhu F, Schneditz D, Kaufman AM, Levin NW. Estimation of body fluid changes during peritoneal dialysis by segmental bioimpedance analysis. Kidney int. 57:299-306, 2000. 
Chapter 5 


\section{CHAPTER 6}

\section{Bio-electrical impedance spectroscopy. Alternatives for the conventional hand- to-foot measurements.}

PLM Cox-Reijven ${ }^{1}$, B van Kreel ${ }^{2}$, PB Soeters ${ }^{3}$ 'Department of Dietetics, ${ }^{2}$ Clinical Chemistry and ${ }^{3}$ Surgery, University Hospital Maastricht, The Netherlands 


\section{Abstract}

Background and aim:

Bio-impedance spectroscopy (BIS) is a very attractive method for measuring body composition. The standard method measures impedance from hand to foot. However, in patients a hand or foot is not always accessible. In these cases alternative methods would be helpful. The objective of this study was to compare BIS measurements from hand to foot (HF) with foot to foot (FF) and hand to hand $(\mathrm{HH})$ measurements as alternatives. Aims were firstly, to assess the relationship between resistance $(R)$ values measured by the different methods, secondly, to study the influence of body geometry on this relationship and lastly, to assess the predictive capacity of the methods for measuring body fluid volumes.

Methods:

In 53 subjects with different degrees of overweight (mean BMI $=38, \mathrm{SD}=9 \mathrm{~kg} / \mathrm{m}^{2}$ ) three BIS measurements were performed from HF, HH and FF with a Xitron 4000B machine. Resistances of extracellular (Recw) and intracellular water (Ricw) were extrapolated by fitting the data to a Cole-Cole plot. Total body water (TBW) and extracellular water (ECW) were measured by deuterium and bromide dilution respectively. Intracellular water (ICW) was calculated as TBW-ECW. Anthropometric measurements, including length and circumference of limbs and trunk, were performed as measures for body geometry.

Results:

The Recw, Ricw and R50 values of HF measurements could be accurately described as a function of the Recw, Ricw and R50 values of HH or FF measurements. The relative circumference of arms and legs and the length of the trunk influenced the relationship between $R$ values of the three different measurements. The degree of overweight did not affect this relationship. The precision of the predictions of TBW, ECW and ICW based on R values of the $\mathrm{HH}$ measurements were comparable with the traditional $\mathrm{HF}$ measurements while the FF measurements gave slightly less accurate results.

Conclusions:

Under circumstances where total body BIS measurements can not be performed, FF or $\mathrm{HH}$ measurements may be used as alternatives. However, for clinical use the effect of changes in fluid distribution on the accuracy of these methods needs to be studied further. 


\section{Introduction.}

Bio-electrical impedance spectroscopy (BIS) is increasingly used to measure body composition. BIS is a very attractive method because it is non-invasive and simple to perform. The first impedance analysers measured the impedance of the body from hand to foot to an alternating current of $50 \mathrm{kHz}$. This approach is called the single frequency bioelectrical impedance analysis (SF-BIA). Newer devices made it possible to measure at a range of frequencies from which the resistance of extracellular (Recw) and intracellular water (Ricw) can be extrapolated', called bioelectrical impedance spectroscopy (BIS). This BIS procedure allows the measurement of separate fluid compartments and is in principle an important improvement because fluid shifts are often present during severe illness.

In a clinical setting the standard method is not always applicable because a hand or a foot is not always accessible. Correct electrode placement is often not possible due to the presence of bandages or infusion systems. In these cases alternative methods are required. Because the extremities account for 85 to $88 \%$ of the total body impedance ${ }^{2}$, measuring legs or arms instead of the traditional hand to foot measurement may also be of value for predicting total body composition. Furthermore, for monitoring the nutritional status of patients, measurements of the limbs could be of value. As Ricw is related to ICW, changes in Ricw of the extremities may be a measure of changes in skeletal muscle mass.

Recently, new devices measuring impedance from foot to foot or from hand to hand instead of the standard hand to foot measurement have become available. These devices are attractive because they are very easy to use. However, they only measure at a frequency of $50 \mathrm{kHz}$, and only part of the body is measured. Several studies showed that a frequency of $50 \mathrm{kHz}$ is too low for full penetration of the current through the cell ${ }^{3}$. Theoretically these devices are unable to discriminate between ECW and ICW. Therefore, the use of these new devices is not recommended in cases of disturbed fluid distribution. BIS measurements, which are theoretically able to measure ECW and intracellular water (ICW) separately, could overcome this limitation. In the literature several approaches for the calculation of fluid volumes from $\mathrm{R}$-values derived from modelling are described. Comparing different models revealed that predictions based on Recw and Ricw (the $0 / \infty \mathrm{kHz}$ parallel model) gave the best results 4.5 .

Besides the facts that only the upper or lower part of the body is measured and that measurements are performed at one frequency, these new systems also differ from the traditional systems in the way the current injection takes place and the voltage drop is measured. The traditional gel electrodes are replaced by either four metallic footplates integrated into a conventional electronic weighing scale or by four metallic cylinders incorporated into two handles. Several validation studies of the new devices have been published $d^{6,7.9 .10}$. Because their use is increasing, it is necessary to compare results of these alternative methods with the traditional hand to foot measurements and with the BIS approach.

Measuring from arm to arm or from leg to leg to assess total body composition is only justified if a fixed relationship exists between the composition of these extremities and total body composition. In the case of obesity the geometry of the body is changed and the question arises whether there still is a fixed relationship. This is especially important when these alternative measurements are used during weight loss programs or during repletion of depleted patients.

The aim of the present study was threefold. Firstly, to study the relationship between measured resistance (R) values of hand to hand $(\mathrm{HH})$, foot to foot (FF) and the traditional hand to foot (HF) measurements performed with a BIS system, secondly, to assess the influence of body geometry on the relationship between $R$ values of the different measurements and lastly, to compare the precision of the three methods for predicting TBW. ECW and ICW by regression equations.

In order to test the influence of body geometry on the relationship between R-values measured with the three different methods, a population varying substantially in degree of overweight was investigated. 


\section{Subjects and methods}

\section{Subjects}

Measurements were performed in 53 white females with varying degrees of overweight. Physical characteristics are shown in table 1. Measurements were performed in the morning after an overnight fast and after emptying the bladder.

\section{Anthropometric measurements}

Weight of the subjects wearing only underwear was measured to the nearest $0.1 \mathrm{~kg}$ with a digital scale. Stature and acromial heights were measured to the nearest $0.1 \mathrm{~cm}$ with a wallmounted stadiometer. Length of the left arm (La) and leg (LI) as well as the circumference of upper arm (Ca1), wrist (Ca2), upper leg (Cl1), ankle ( $\mathrm{Cl} 2)$, waist (Ct1) and hip (Ct2) were measured to the nearest $0.1 \mathrm{~cm}$ with a metal tape to the nearest $0.1 \mathrm{~cm}$. La was measured from acromion to wrist and $\mathrm{LI}$ from the buttock to ankle. Ca1 and $\mathrm{Cl} 1$ were measured at the most proximal position of the limbs. Mean circumference of the arm (Ca), leg ( $\mathrm{Cl}$ ) and trunk (Ct) were calculated as the mean values from $\mathrm{Ca} 1$ and $\mathrm{Ca} 2, \mathrm{Cl} 1$ and $\mathrm{Cl}_{2}, \mathrm{Ct} 1$ and $\mathrm{Ct} 2$ respectively. Trunk length (Lt) was calculated as the acromial height minus leg length.

\section{Bio-electrical impedance measurements}

BIS measurements were performed just before the subjects drank the indicator mixture. Subjects were lying on a bed with legs separated and arms abducted from the body. A tetrapolar electrode $(3 \mathrm{M}$ red Dot $\mathrm{Ag} / \mathrm{AgCl}$ ) arrangement as described by Lukaski et al. was used . with one set of electrodes on the hand and one on the foot ${ }^{11}$. Electrodes were placed on the right and left side of the body using identical landmarks. Impedance was measured with a Xitron $4000 B$ bioelectrical impedance spectrometer (Xitron technologies, San Diego, California) using 48 frequencies ranging from 5 to $500 \mathrm{kHz}$. From all 48 measured resistance and reactance values the resistance of the extracellular (Recw) and intracellular fluid (Ricw) were extrapolated by using the Xitron curve-fit software.

Each subject underwent 4 BIS measurements: from hand to foot (HF) at the left side and at the right side of the body, from hand to hand $(\mathrm{HH})$ and from foot to foot (FF). Resistance values measured at $50 \mathrm{kHz}$ were recorded for the 4 measurements.

The mean of the measurements at the right and left side of the body was used for further analysis of the data and is referred to as the traditional hand-to-foot (HF) measurement. Results of resistance measured with the $\mathrm{HH}$ and FF configuration were compared with $\mathrm{HF}$ measurements.

\section{Dilution methods}

Total body water (TBW) and extracellular water (ECW) were measured by deuterium oxide dilution and $\mathrm{NaBr}$ dilution respectively. In the moming, fasted patients drank a mixture of $5 \mathrm{~g}$ deuterium labelled water $\left(\mathrm{D}_{2} \mathrm{O}: 99.84\right.$ atom percentage excess) and $30 \mathrm{ml} 150 \mathrm{mM} \mathrm{NaBr}$. Before and 4 hours after ingestion of the indicators saliva and blood samples were obtained for deuterium and bromide analysis respectively. During the 4 hour interval people stayed in the hospital. They were allowed to move freely and to drink $200 \mathrm{ml}$ of water during the first 2 hours. Consumption of food was not allowed. Deuterium was analysed with an isotope ratio mass spectrometer $^{12}$. Bromide was analysed by ion chromatography as described by Wong ${ }^{13}$. Plasma was deproteinized by acetonitrile. 
TBW was calculated by correcting the Deu-dilution space with $4 \%$ for exchange of labile hydrogen. ECWdil was calculated by correcting the Br-dilution space with 0.9 for nonextracellular distribution of $\mathrm{Br}$ and with 0.95 for the Donnan equilibrium.

ICW was calculated as the difference between TBW and ECW as measured with the dilution techniques.

\section{Statistics}

Statistical analysis was performed by SPSS-pc, version 8.0 .

Correlation coefficient analysis was performed to test the linear relationship between measured anthropometric variables and to test the effect of overweight on these relationships.

Linear regression analysis was performed to describe the resistance values measured with the traditional HF method as a function of the resistance measured with the two alternative methods. To test the influence of body geometry on the relationship between R-values measured by the different methods, correlations between the ratios of these R-values (e.g. RecwHH/RecwHF) and anthropometric variables were calculated.

Stepwise linear regression was performed to study the contribution of anthropometric parameters to the prediction equations for the resistance values measured with the traditional HF method as a function of the resistance measured with the two alternative methods.

Prediction equations for TBW, ECW and ICW were constructed by linear regression analysis with the TBW. ECW and ICW volumes measured by the dilution methods as dependent variables and $L^{2} / R 50, L^{2} / R e c w$ and $L^{2} / R i c w$ values of the three different methods $(H F, H H$ and FF) as independent variables. This regression analysis was performed with and without inclusion of body weight as independent variable.

Table 1 Physical characteristics of the study population $(\mathrm{N}=53)$.

\begin{tabular}{lllll}
\hline & Minimum & Maximum & Mean & SD \\
\hline Weight $(\mathrm{kg})$ & 51,0 & 201,4 & 104,5 & 27,5 \\
Length $(\mathrm{cm})$ & 147,9 & 189,5 & 164,5 & 8,1 \\
BMI (kg/m 2 $^{2}$ & 23,3 & 66,8 & 38,5 & 9,2 \\
TBW (dilution) & 25,6 & 59,2 & 39,8 & 6,9 \\
ECW (dilution) & 13,3 & 27,9 & 19,3 & 3,3 \\
ICW (dilution) & 12,3 & 33,6 & 20,5 & 4,2 \\
\hline
\end{tabular}

\section{Results}

\section{Relationship between $R$ values}

In figure 1 the linear relationships between resistances measured from hand to foot are described as functions of the two alternative measurements. In general, the FF and $\mathrm{HH}$ measurements could predict the corresponding R values of the HF measurement with the same accuracy. The Ricw predictions of the HF measurement with Ricw of FF or HH measurements were less precise than the Recw and R50 predictions. For RecwHF and 
R50HF correlation coefficients $(r)$ ranged from 0.902 to 0.933 while for RicwHF the correlations with RicwFF or RicwHH were 0.786 and 0.858 respectively.

We tested if the relationship between resistance values from the alternative measurements and from the traditional HF measurements was influenced by anthropometric variables. No significant correlations between BMI and the ratio's RecwHH/RecwHF or RecwFF/RecwHF, R50HH/R50HF or R50FF/R50HF and RicwHH/RicwHF or RicwFF/RicwHF were found. Also, absolute and relative measures of body length or length of limbs did not influence these ratios. The only anthropometric variables that were highly significantly correlated with these ratios were the relative circumferences of the limbs, expressed as circumference arm / circumference leg (Carm/Cleg) (fig. 2), and to a lesser extent length of trunk (table 2). For Ricw ratio's, no correlation with the length of the trunk was found, indicating a non-significant contribution of the trunk to the Ricw values.

Table 2. Correlation coefficients $(r)$ between the ratio's of resistance values (R) and length of trunk or the ratio circumference arm / circumference leg (Carm/Cleg).

\begin{tabular}{|c|c|c|c|c|}
\hline & \multicolumn{2}{|c|}{ Carm / Cleg } & \multicolumn{2}{|c|}{ length trunk } \\
\hline & $r$ & $P$ & $r$ & $P$ \\
\hline R50HH/R50HF & -0.489 & 0.000 & -0.312 & 0.018 \\
\hline R50FF/R50HF & 0.544 & 0.000 & 0.330 & 0.011 \\
\hline RecwHH/RecwHF & -0.419 & 0.001 & -0.296 & 0.025 \\
\hline RecwFF/RecwHF & 0.486 & 0.000 & 0.288 & 0.03 \\
\hline RicwHH/RicWHF & -0.291 & 0.029 & -0.202 & 0.135 \\
\hline RicwFF/RicwHF & 0.301 & 0.023 & 0.137 & 0.308 \\
\hline
\end{tabular}

$\mathrm{HH}, \mathrm{FF}$ and HF measurements stand for hand-to-hand, foot-to-foot and hand to foot measurements respectively

To test the effect of obesity on the relative circumference of the extremities and trunk the correlations between $\mathrm{BMI}$ and the ratios $\mathrm{Ca} / \mathrm{Ct}, \mathrm{Cl} / \mathrm{Ct}$ and $\mathrm{Ca} / \mathrm{Cl}$ were calculated. These were $-0.558(\mathrm{P}<0.01),-0.344(\mathrm{P}<0.01)$ and -0.122 (not significant) respectively. This means that with increasing obesity the circumference of the trunk is relatively more increased than the circumference of the extremities. Circumferences of arms and legs increase to the same extent when overweight is increasing. These data indicate that not the degree of overweight itself, but the relative distribution of the excess fat mass over arms and legs may influence the accuracy of the alternative measurements.

Stepwise linear regression with the anthropometric variables L, La, LI, Lt, Ca, Cl, Ct revealed that prediction equations for $\mathrm{R}$ values measured from hand to foot as a function of the corresponding $R$ values of the alternative methods could be improved (table 3 ). Describing R50HF or RecwHF as a function of R50FF or RecwFF respectively was improved by inclusion of the length of trunk $(\mathrm{Lt})$ and circumference of arm $(\mathrm{Ca})$ in the regression equation. The accuracy of the prediction equation describing the resistance values of $\mathrm{HF}$ measurements as function of $\mathrm{HH}$ measurements was improved by inclusion of leg circumference $(\mathrm{Cl})$ and am circumference $(\mathrm{Ca})$. The mean increase in the correlation coefficient was 0.025 and the mean decrease in SEE 3.5 ohms. For Ricw only a slight improvement of inclusion of $\mathrm{Cl}$ was found. These data indicate that inclusions of anthropometric data of the part of the body not measured, improves the relationship between the conventional and alternative measurements. 
R50 (ohm)

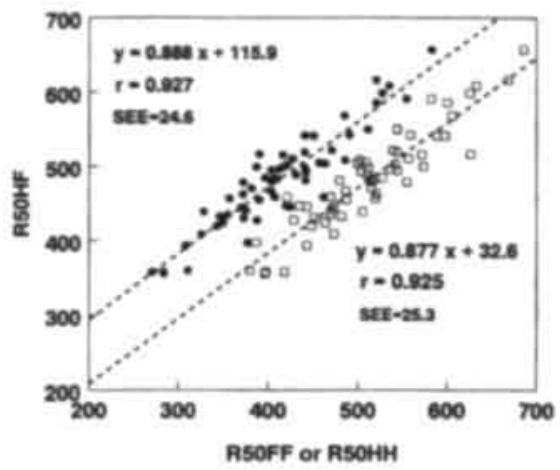

Recw (ohm)

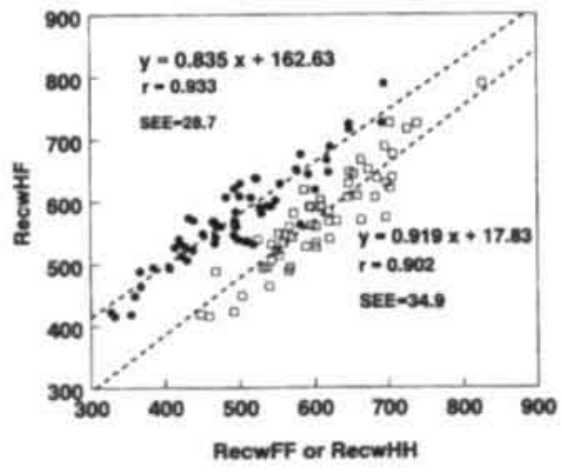

Ricw (ohm)

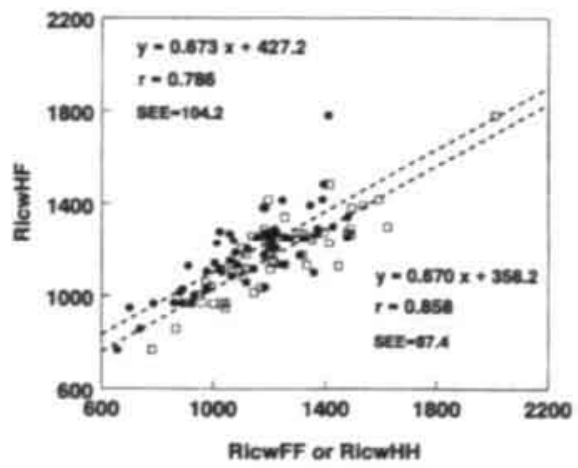

Figure 1. Resistance values R50, Recw or Ricw (ohms) measured from hand to foot (HF) as a function of these resistances measured from hand to hand $(\mathrm{HH})$ or from foot to foot (FF). $\square \mathrm{HH}$, 9 FF
A

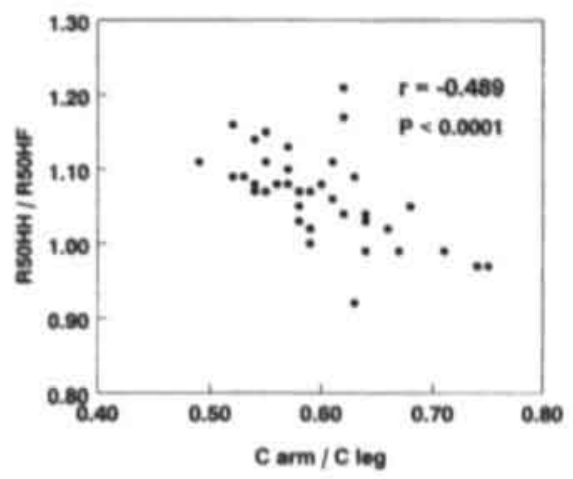

B

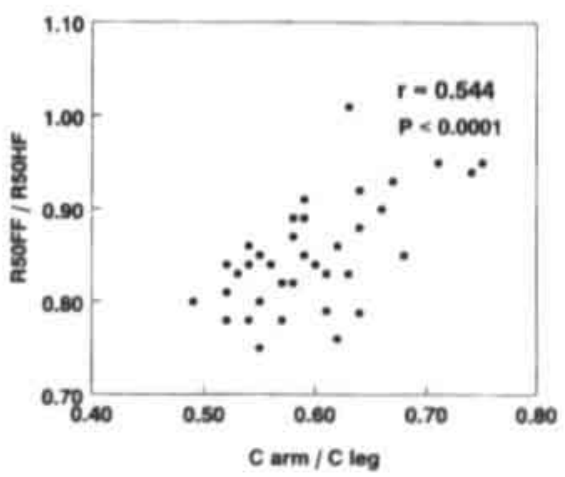

Figure 2. Correlation between the ratio circumference arm / circumference leg (Carm iCleg) and

A: the ratio of the resistance at $50 \mathrm{kHz}$ (ohms) measured from hand to hand $(\mathrm{HH}) /$ resistance at $50 \mathrm{kHz}$ measured from hand to foot (HF) or B: the ratio of the resistance at $50 \mathrm{kHz}$ measured from foot to foot (FF) / resistance at $50 \mathrm{kHz}$ measured from hand to foot (HF). 
Table 3. Stepwise regression analysis to describe $R$ values measured from hand to foot as a function of the $R$ values measured from hand to hand $(\mathrm{HH})$ or from foot to foot (FF) and of anthropometric variables:

\begin{tabular}{llll}
\hline Equation & $r$ & SEE & P \\
\hline R5OHF $=0.835^{\circ}$ R5OHH $-2.804^{\circ} \mathrm{Cl}+2.797^{\circ} \mathrm{Ca}+110.46$ & 0.947 & 21.9 & $<0.0001$ \\
R50HF $=0.874^{\circ} \mathrm{R} 50 \mathrm{FF}-1.878^{\circ} \mathrm{Lt}-4.290^{\circ} \mathrm{Ca}+1.628^{\circ} \mathrm{Cl}+296.49$ & 0.958 & 19.7 & $<0.0001$ \\
RecwHF $=0.928^{\circ} \mathrm{ReCWHH}-3.063^{\circ} \mathrm{Cl}+4.14^{\circ} \mathrm{Ca}+1.14^{\circ} \mathrm{L}-146.6$ & 0.928 & 31.2 & $<0.0001$ \\
RecwHF $=0.783^{\circ}$ RecwFF $-2.53^{\circ} \mathrm{Lt}-2.953^{\circ} \mathrm{Ca}+447.78$ & 0.955 & 24.3 & $<0.0001$ \\
RicwHF $=0.599^{\circ}$ RicwHH $-6.476^{\circ} \mathrm{Cl}+758.67$ & 0.889 & 79.4 & $<0.0001$ \\
RicwHF $=0.673^{\circ}$ RicwFF +427.2 & 0.786 & 104.2 & $<0.0001$ \\
\hline
\end{tabular}

The anthropometric variables tested for their significant $(P<0.05)$ contribution to the prediction equations were body lenght (L), Length of arm (La), Leg (L) and trunk (Lt), circumference of arm (Ca), leg (CI) and trunk (Ct). R50, Recw and Ricw stand for the resistance at $50 \mathrm{kHz}$, at zero frequency, modeled resistance of ICW respectively.

\section{Prediction equations for TBW and ECW volumes}

Prediction equations based on regression analysis were constructed for TBW, based on $L^{2} / R 50$, for ECW based on $L^{2} / R e c W$ and for ICW based on $L^{2} / R i c W$ with $R$-values of the three different measurements (table 4). The analysis was performed with and without inclusion of the factor body weight. Prediction of TBW based on R50 of the FF measurements was less accurate than predictions based on R50 of the $\mathrm{HH}$ or $\mathrm{HF}$ measurements. Predictions of ECW and ICW were less accurate than predictions of TBW for all three measurements. Again the $\mathrm{HH}$ measurements gave the same results as HF measurements, while the regressions based on FF measurements were less precise. Compared with ECW and TBW, ICW predictions were less precise, with again the FF measurement showing the weakest correlation. Adding body weight as an independent variable increased the $r$, and decreased the SEE of all the prediction equations. The SEE decreased by about $0.3 \mathrm{~L}$ and the $r$ increased by about 0.042 .

\section{Discussion}

In contrast to most validation studies the present study was performed in a very heterogeneous population with regard to overweight. Our aim was not to develop generally applicable prediction equations but to study the effect of body geometry on the relationship between R-values measured on different body parts. The magnitude of this effect can only become visible in a population with a wide range of overweight.

Comparison of the R-values measured revealed that $\mathrm{HH}$ and FF measurements can be used for calculating the corresponding R-value for a traditional HF measurement. This may be of value in cases where a hand or a foot is not accessible. Inclusion of the circumference of the limb which is not measured, and in the case of FF measurements the length of the trunk. increases the accuracy of this procedure. The HF measurement is aiso merely a measurement of a leg and arm as the trunk contributes approximately only $8 \%$ to the total measured resistance'. The part of the body with the smallest cross-sectional area contributes most to the total impedance measured ${ }^{15,16}$. The fact that lengths of the limbs did not significantly contribute to the prediction equations may be caused by the strong correlation found between $\mathrm{LI}$ and $\mathrm{La}(r=0.734, \mathrm{P}<0.01)$. As the correlation between the $\mathrm{Lt}$ and $\mathrm{L}$ was less strong $(r=0.399, \mathrm{P}<0.01)$ the significant contribution of $\mathrm{Lt}$ in $\mathrm{FF}$ measurement can be explained. 
Most researchers do not recommend the inclusion of anthropometric variables in prediction equations. This would reduce the ease of impedance measurements and in addition there is often no theoretical basis for their effect. In the present study the effect of some anthropometric variables is apparent and can be explained logically. In contrast to whole body measurements, for the alternative measurements studied inclusion of anthropometric variables of the body part which is not measured appears necessary and justified if predictions for total body fluid compartments are made.

Table 4. Prediction equations for TBW (deuterium dilution), ECW (Br dilution) and ICW based on $L^{2} / R 50, L^{2} / R e c w$ or $L^{2} / R i c w$ from the hand to foot $(\mathrm{HF})$, hand to hand $(\mathrm{HH})$ and foot to foot (FF) measurements with or without inclusion of body weight (W).

\begin{tabular}{|c|c|c|}
\hline Prediction equations & $r^{*}$ & SEE \\
\hline \multicolumn{3}{|l|}{ Without weight } \\
\hline $\mathrm{TBW}=0.647^{*} \mathrm{~L}^{2} / \mathrm{R} 5 \mathrm{OHF}+3.052$ & 0.927 & 2.67 \\
\hline $\mathrm{TBW}=0.633^{\circ} \mathrm{L}^{2} / \mathrm{RSOHH}+5.890$ & 0.926 & 2.67 \\
\hline$T B W=0.449^{\circ} L^{2} /$ RSOFF +9.808 & 0.804 & 4.22 \\
\hline$E C W=0.352^{\circ} L^{2} /$ RecwHF +2.386 & 0.839 & 1.81 \\
\hline$E C W=0.344^{\circ} L^{2} /$ RecwHH +3.603 & 0.833 & 1.86 \\
\hline$E C W=0.216^{\circ} L^{2} /$ RecWFF +7.025 & 0.705 & 2.29 \\
\hline$I C W=0.823^{\circ} L^{2} / R i c W H F+1.306$ & 0.789 & 2.54 \\
\hline$I C W=0.684^{*} L^{2} / R i c W H H+4.927$ & 0.784 & 2.65 \\
\hline ICW $=0.609^{*} L^{2} /$ RicWFF +5.247 & 0.721 & 2.58 \\
\hline
\end{tabular}

With inclusion of weight

\begin{tabular}{|c|c|c|}
\hline$T B W=0.519^{\circ} L^{2} / R 50 H F+0.0799^{\circ} W+2.076$ & 0.951 & 2.22 \\
\hline$T B W=0.502^{\circ} \mathrm{L}^{2} / R 50 \mathrm{HH}+0.091^{\circ} \mathrm{W}+3.515$ & 0.961 & 1.90 \\
\hline $\mathrm{TBW}=0.297^{\circ} \mathrm{L}^{2} / \mathrm{R} 50 \mathrm{FF}+0.121^{\circ} \mathrm{W}+7.44$ & 0.868 & 3.55 \\
\hline$E C W=0.294^{\circ} \mathrm{L}^{2} /$ RecwHF $+0.031^{\circ} \mathrm{W}+1.786$ & 0.863 & 1.68 \\
\hline$E C W=0.287^{\circ} L^{2} /$ RecWHH $+0.034^{\circ} W+2.709$ & 0.860 & 1.73 \\
\hline$E C W=0.164^{\circ} L^{2} /$ RecWFF $+0.045^{\circ} W+5.295$ & 0.766 & 2.10 \\
\hline$I C W=0.614^{\circ} L^{2} / R i c W H F+0.0545^{\circ} W+0.459$ & 0.833 & 32 \\
\hline$I C W=0.515^{\circ} \mathrm{L}^{2} /$ RicWHH $+0.0658^{\circ} \mathrm{W}+1.988$ & 0.851 & 2.27 \\
\hline$I C W=0.423^{\circ} \mathrm{L}^{2} / R i C W F F+0.0468^{\circ} \mathrm{W}+5.019$ & 0.752 & 2.48 \\
\hline
\end{tabular}

TBW is total body water (L), ECW extracellular water (L). R50 is the resistance (ohm) measured at $50 \mathrm{kHz}$. Recw and Ricw are the modelled R values of ECW and ICW. L is length $(\mathrm{cm}), W$ is weight (kg). W significantly contributed to all prediction equations $(P<0.01)$. * All correlation coefficients were statistically significant ( $P<0.0001)$.

In order to compare the alternative methods with the traditional method the first step was to compare measured $R$ values. The next step is to compare calculated fluid volumes from measured $R$ values. In the literature there is much debate concerning the best method to $u^{4} e^{4.5}$. Although the use of prediction equations based on single-frequency measurements has been questioned, this approach is still used very often in daily practice. Furthermore new impedance analysers are introduced which measure $R$ at $50 \mathrm{kHz}$ from foot to foot or from hand to hand. Comparison of the predictive capacities of equations based on linear regression with $L^{2} / R e c w, L^{2} / R i c w$ and $L^{2} / R 50$ for the three different methods is necessary for evaluating the applicability of the different methods. Volume calculations by the Xitron $4000 \mathrm{~B}$ 
software are not based on linear regression analysis but on the mixture model as described by de Lorenzo'. In the present study we did not use this model because for the alternative FF and $\mathrm{HH}$ measurements no equations bases on a mixture model have been developed yet.

Published data show that the standard error of estimation (SEE) for predicting TBW based on the regression approach ranges from 1.6 to $3.6 \mathrm{~L}$ and that correlation coefficients range from 0.927 to $0.975^{17,18}$. Results of the present study fall within this range for predictions based on R50 of $\mathrm{HH}$ and HF measurements. The same can be concluded for ECW predictions. This finding is promising for the use of these alternative measurements in subjects with less extreme deviations from a normal body composition. The ICW predictions were less accurate than the TBW and ECW predictions regardless of the type of measurement used. This may be caused by the fact that we did not measure ICW directly. ICW was calculated as the difference between TBW and ECW measured by the dilution methods. Because of error propagation ICW estimations are subject to larger errors than TBW or ECW. For ICW the correlation coefficients between methods and SEE found in the present study were in the same range as described by others ${ }^{10}$.

Predictions of fluid compartments based on FF measurements were systematically less precise than predictions based on $\mathrm{HF}$ or $\mathrm{HH}$ measurements. This can be explained by the significant influence of trunk length $(\mathrm{Lt})$ on the relationship between $\mathrm{R}$ values of $\mathrm{FF}$ and $\mathrm{HF}$ measurements. Inclusion of $\mathrm{Lt}$ in the regression would increase the accuracy of FF predictions.

In clinical situations the alternative measurements have some limitations but also possibilities. Fluid imbalance is an important contra indication for the use of impedance measurements based on regression equations developed in fluid stable subjects. Regional fluid accumulation influences the accuracy of the measurement dependent on the location of the fluid. Segmental BIS measurements have been proposed to overcome these problems ${ }^{20,21.22}$ Measuring a leg, arm and trunk separately can increase the accuracy of BIS for measuring changes in fluid volumes as shown in some studies ${ }^{20,21}$. The $\mathrm{HH}$ and FF measurements are in fact measurements of 2 arms or 2 legs. The contribution of the trunk to the measured $\mathrm{R}$ in these measurements is very small. The advantage of this approach is the ease of electrode location on the feet and the fact that 2 legs or 2 arms instead of one limb is measured, excluding the question which side of the body should be measured.

Recently new BIA devices have been introduced which measure impedance from foot-to-foot or from hand-to-hand with subjects in the standing position instead of in the supine position. In the case of FF measurements pressure contact footpad electrodes are used which are incorporated in a digital weighing scale. $\mathrm{HH}$ measurements are performed with a device consisting of two grasps in which metallic electrodes are present. Differences with the conventional measurements are not only the electric current path and the posture but also the type of electrodes, metallic pressure instead of gel electrodes, and the electrode location, foot sole and hand paim instead of upper part of hand and foot.

Several validation studies of a Tanita FF system have been published ${ }^{6.0 .9 .10}$. Nuñez found high correlations between $L^{2} / Z$ of the FF measurement, in which $Z$ is the measured impedance at $50 \mathrm{kHz}$, and TBW $(r=0.86)$ or FFM $(r=0.93)^{6}$. The SEE however was large, $5.45 \mathrm{~L}$ and $6.1 \mathrm{~kg}$ and was explained by the diverse nature of the large subject pool. These results were comparable with the traditional HF measurements that they performed.

In other studies the correlation between $L^{2} / Z$ and the reference method was less strong. Bell et $\mathrm{al}^{\mathrm{s}}$ reported a correlation with TBW of 0.66 and SEE of $4.6 \mathrm{~L}$ and Xie et $\mathrm{al}^{10}$ found a correlation with FFM of 0.66 and a SEE of $3.5 \mathrm{~kg}$. In the study of Utter et al the correlation between $L^{2} / Z$ and FFM was only 0.54 and the SEE $3.7 \mathrm{~kg}$. However, application of the prediction equations supplied by the manufacturer in which weight, age and $L^{2} / Z$ are included, resulted in an $r$ of 0.78 .

The results of the present study are promising compared with these studies. Despite the diversity in the study population the correlations between $L^{2} / R 50 F F$ or $L^{2} / R 50 H H$ and TBW were stronger than in most studies. Furthermore, our study demonstrates that $\mathrm{HH}$ 
measurements are even more strongly correlated with the reference methods and have smaller SEE than FF measurements.

Several differences between the gel-electrode FF impedance measurements and the Tanita system may be responsible for the difference in accuracy between studies. Not only the type of electrodes, but also the positioning of the electrodes may affect the measurements, because it is unknown if the skin resistances of the foot sole and hand palm are comparable with wrist and ankle skin resistance. Subject positioning may have effects on BIS measurements. The new FF devices measure subjects in a standing position. Besides the possible differences in the fluid distribution between legs and trunk ${ }^{23.24}$ the separation of legs may not be possible in obese subjects standing on a device as small as a weighing scale. Contact between thighs may affect the measured electrical path and result in measurement errors.

FF and $\mathrm{HH}$ measurements may be of value for monitoring the muscle mass of limbs. A decrease in the body cell mass is the main indicator of clinical depletion. This decrease is mostly caused by a decrease in skeletal muscle mass and not by a decrease in organ mass ${ }^{25}$. Exclusion of the effect of the trunk on BIS measurements by the use of alternative measurements like $\mathrm{FF}$ or $\mathrm{HH}$ may become valuable. In recent studies strong correlations between segmental multifrequency BIA measurements of arms or legs and muscle mass measured by DEXA were found ${ }^{26}$. Measurements of arms gave better results than measurements of legs. Also strong associations between the Tanita BIA measurements and the lower limb skeletal muscle mass have been published ${ }^{27}$. In these studies the regression approach was used for TBW or FFM predictions. However, in clinical practice ECW as well as ICW of the limbs should be evaluated in order to monitor changes in body cell mass. New algorithms based on physical models for FF and $\mathrm{HH}$ measurements could be of great value for the application of these alternative measurements in patients.

In conclusion, alternative BIS measurements from hand-to-hand and to a lesser extent from foot-to-foot can predict TBW, ECW and ICW with the same accuracy as the traditional HF measurements even in a heterogeneous population with regard to overweight. The relationship between resistance values of the alternative and conventional measurements is not influenced by the degree of overweight itself but by the relative circumferences of the limbs and the length of the trunk. In cases where the traditional HF measurements can not be performed, these alternatives may be of value. However, in patients with altered fluid distribution the use of these methods is not recommended because the specific resistivities of ECW and ICW may be affected. Research is warranted to study the potency of these methods to measure changes in body cell mass of the limbs as a suitable measure for nutritional assessment.

\section{References}

1. Lorenzo de A, Andreoli A, Matthie J, Whithers P. Predicting body cell mass with bioimpedance methods: a technical review. J Appl Physiol 1997; 82: 1542-1558.

2. Heitman B L. Impedance: a valid method in assessment of body composition ? Eur $\mathrm{J}$ Clin Nutr 1994: 48: 228-240.

3. Deurenberg P. Schouten F J M. Loss of total body water and extracellular water assessed by multifrequency impedance. Eur J Clin Nutr 1992; 46: 247-255.

4. Earthman C P. Matthie J R, Reid P M. Harper I T, Ravussin E, Howell W H. A comparison of bioimpedance methods for detection of body cell mass in HIV infection. J Appl Physiol 2000; 88: 944-956.

5. Gudivaka R, Schoeller D A, Kushner R F, Bolt M J. Single- and multifrequency models for bioelectrical impedance analysis of body water compartments. J Appl Physiol 1999; 87: 1097. 1096. 
6. Nuñez C, Gallagher D, Visser M, Pi-Sunyer F X, Wang Z, Heymsfield S B. Bioimpedance analysis: evaluation of leg-to-leg system based on pressure contact foot-pad electrodes. Med Sci Sports Exerc 1999; 29: 524-531.

7. Ghosh S, Meister D, Cowen S, Hannan W J, Ferguson A. Body composition at the bedside. Eur J Gastroenterol Hepatol 1997; 9: 783-788.

8. Bell N A, McClure P D, Hill R J, Davies P S W. Assessment of foot-to-foot bioelectrical impedance analysis for the prediction of total body water. Eur J Clin Nutr 1998; 52: 856-859.

9. Utter A C, Nieman D C, Ward A N, Butterworth D E. Use of the leg-to-leg bioelectrical impedance method in assessing body-composition change in women. Am J Clin Nutr 1999; 69: 603-607.

10. Xie X, Kolthoff N, Bärenholt $O$, Nielsen S P. Validation of a leg-to-leg bioimprdance analysis system in assessing body composition in postmenopausal women. Int J Obes 1999; 23: 1079 1084.

11. Lukaski H C, Johnson P E, Bolonchuk W W, Lykken G I. Assessment of fat free mass using bioelectrical impedance measurement of human body. Am J Clin Nutr 1985; 41: 810-817.

12. Westerterp K R, Wouters L, van Marken Lichtenbelt W D. The Maastricht protocol for the measurement of body composition and energy expenditure with labeled water. Obes Res 1995; 3 (Suppl 1): 49-57.

13. Wong W W. Sheng H P, Morkeberg J C, Kosanovich J L, Clarke L L, Klein P D. Measurement of extracellular water by bromide ion chromatography. Am J Clin Nutr 1989; 50: 1290-1294.

14. Organ L W, Bradham G B, Gore D T, Lozier L. Segmental bioelectrical impedance analysis: theory and application of a new technique. J Appl Physiol 1994; 77: 98-112.

15. Baumgartner R N. Chumlea W C, Roche A T: Estimation of body composition from segmental impedance. Am J Clin Nutr 1989; 50: 221-225.

16. Fuller N J, Elia M: Potential use of the bioelectrical impedance of the "whole body " and of body segments for the assessment of body composition: comparison with densitometry and anthropometry. Eur J Clin Nutr 1989; 43: 779-791.

17. Kushner R F. Bio-electrical impedance analysis: a review of principles and applications. J Am Col Nutr 1992: 11: 199-209.

18. Houtkooper L B, Lohman T G. Going S B. Howell W H. Why bioelctrical impedance analysis should be used for estimating adiposity. Am J Clin Nutr 1996; 64(Suppl 3):436S-448S.

19. Schwenk A, Escher W, Kremer G, Ward L C, Assessment of intracellular water by whole body bioelectrical impedance and total body potassium in HIV-positive patients. Clin Nutr 2000; 19: 109-113.

20. Zhu F, Schneditz D, Levin N W: Sum of segmental bioimpedance analysis during ultrafiltration and hemodialysis reduces sensitivity to changes in body composition. Kidney Int 1999; 56: 692-699.

21. Thomas B J. Cornish B H. Ward L C. Patterson M A. A comparison of segmental and wrist-toankle methodologies of bioimpedance analysis. Appl Radiat isot 1998; 49: 477-478.

22. Brocca D. Revelly J P, Berger M M. Chiolèro R L. Bedside determination of fluid accumulation after cardiac surgery using segmental bioelectrical impedance. Crit Care Med 1998; 26: 1065 1070.

23. Roos AN, Westendorp RGJ, Frolich M, Meinders A E. Tetrapolar body impedance as influenced by body posture and plasma sodium concentration. Eur J Clin Nutr 1992; 46: 53-60.

24. Scarfetter H, Monif M, Lászió Z, Lambauwer T. Hutten H. Hinghofer-Szalkay H. Effect of postural changes on the reliability of volume estimations from bioimpedance spectroscopy data. Kidney int 1997: 51 : 1078-1087.

25. Elia M: Tissue distribution and energetics in weight loss and undernutrition. In: Kinney J M, Tucker H N, Eds. Physiology, stress and mainutrition. Functional correlates, nutritional intervention. New York: Lippincott-Raven Publishers, 1997: 383-411.

26. Pietrobelli A, Morini P, Battistini N, Chiumello G, Nunez C, Heymsfield S B.: Appendicular skeletal muscle mass: prediction from multiple frequency segmental bioimpedance analysis. Eur J Clin Nutr 1998; 52: 507-511.

27. Nunez C, Gallagher D, Grammes J, Baumgartner R N, Ross R, Wang Z, Thornton J. Heymsfield S B. Bioimpedance analysis: Potential for measuring lower limb skeletal muscle mass. J Parent Enter Nutr 1999; 23: 96-103. 


\section{CHAPTER 7}

\section{Bio-electrical impedance spectroscopy and skinfold measurements for monitoring body composition in children with cystic fibrosis.}

PLM Cox-Reijven', JJE Hendrix ${ }^{2}$, PP Forget ${ }^{2}$, B van $\mathrm{Kreel}^{3}$, PB Soeters ${ }^{4}$

'Department of Dietetics, ${ }^{2}$ Department of Pediatrics, ${ }^{3}$ Department of Clinical Chemistry, ${ }^{4}$ Department of Surgery, University Hospital Maastricht, Netherlands.

Subrnitted 


\begin{abstract}
Introduction:

Malnutrition is common among children with cystic fibrosis (CF). Monitoring changes in body composition is important for evaluation of nutritional therapy. However, no suitable accurate methods are available at the moment. Bioelectrical impedance spectroscopy (BIS) may be of value, because it is a non-invasive, easy and quick method. The primary aim of the study was to assess the accuracy of BIS for measuring total water (TBW), extracellular water (ECW), fat free mass (FFM) and fat mass (FM) and for measuring changes in these compartments in children with CF. The secondary aim was to compare the accuracy of BIS with the accuracy of the traditionally used skinfold thickness measurements (SFT).

Methods:

In 13 children with CF (age $9 \pm 3 \mathrm{Y}$, weight $27 \pm 10 \mathrm{~kg}$ ) BIS measurements and SFT measurements were performed and repeated after 6 months and 1 year. Extrapolated resistance values of ECW (Re) and ICW (Ri) were used in equations based on emulsion sciences to predict TBWbis, ECWbis, FFMbis and FMbis. From the sum of 4 skinfold measurements FMsft and FFMsft were predicted. Reference methods for TBW and ECW were Deuterium (Deu)- and bromide (br) dilution, and for FFM and FM dual energy X-ray absorptiometry (DXA). Absolute values as well as changes in body compartments measured by different methods were compared. Also, the correlations between changes in resistance indexes $\left(L^{2} / R\right)$ at different frequencies and changes in body compartments were calculated.

Results:

BIS underestimated TBW by $2.9 \pm 2.1 \mathrm{~L}$ and FFM by $3.4 \pm 2.0 \mathrm{~kg}$ and overestimated FM by $4.3 \pm 1.9 \mathrm{~kg}$. SFT slightly overestimated FFM by $0.4 \pm 1.1 \mathrm{~kg}$ and FM by $0.5 \pm 0.9 \mathrm{~kg}$. Changes measured by BIS or SFT did not differ from the changes measured by the reference methods, but correlations between measured changes were not significant for TBWbis, ECWbis and FFMbis. However, changes in the resistance indexes at low frequencies, $L^{2} / R e$ and $L^{2} / R 50$, correlated with changes in FFMdxa. Changes in FFMsft and FMsft were significantly correlated with changes measured by DXA.

Conclusions:

The good results of SFT measurements compared with BIS can be explained by the contribution of weight in the equations to calculate FFMsft and FMsft, combined with the absence of fluid imbalance. For the pediatric population adjustments of the constants used in the mixture equations is needed to correct for the systematic error of BIS. The lack of a good agreement between BIS and the reference methods for measuring changes may be due to the fact that changes were relatively small and that disease specific alterations in membrane properties may be present.
\end{abstract}




\section{Introduction}

Poor growth is a chronic problem in cystic fibrosis (CF) patients, and improved nutrition has been identified as a major factor reducing morbidity and mortality'. The effects of malnutrition in CF include failure to grow, delay of puberty, increased susceptibility to infections and increased mortality ${ }^{2,3}$. The imbalance between energy and protein intake and requirements is caused by a variety of factors including increased energy expenditure. increased nutrient losses, decreased intake, and alterations in protein and fatty acid metabolism².

Current recommendations for nutritional assessment in these children rely heavily on anthropometry'. However, recent studies show that weight-based indicators are not sensitive indicators of sub-optimal nutritional status in CF. They significantly underestimate the extent of malnutrition ${ }^{4}$. Therefore, body composition techniques are essential for the measurement of nutritional status and the effectiveness of nutritional therapy.

Available methods for routine body composition measurements in children are bioelectric impedance analysis (BIA) and skinfold thickness (SFT) because they are well tolerated by children, are cheap and can be repeated regularly. Although the BIA method is quick and relatively simple to perform, it does have limitations with respect to the equations required to calculate fat free mass (FFM), because they are specific in age, gender, ethnicity and disease status ${ }^{5.6 .7}$. Skinfold thickness is the most widely available body composition technique. However, well-trained personnel is required to reduce error. Dual energy $X$-ray absorptiometry (DXA) is often used as reference method but is not well suited for routine clinical care because it is time consuming, costly and not portable.

Several BIA approaches are currently in use. With the traditional single frequency BIA (SFBIA) total body water (TBW) and fat free mass (FFM) are measured based on the resistance (R) index at $50 \mathrm{kHz}$ (length $/ \mathrm{R} 50$ ). However, multi-frequency BIA (MF-BIA) indicated that the used frequency is too low for full penetration of the current through cells ${ }^{b}$. It is advised to use SF-BIA only in the absence of fluid imbalance ${ }^{\circ}$. With the bioelectrical impedance spectroscopy (BIS) approach, intracellular (ICW) and extracellular water (ECW) can be measured separately. The clinical advantage of BIS over SF-BIA is that changes in the hydration status theoretically do not affect the accuracy of the method.

Although the last decade many validation studies of BIA in healthy children have been published $^{5,10-21}$, only few studies describe the accuracy of BIA in children with CF $^{22.23,24}$. Based on SF-BIA a number of population specific equations for children have been published which differ in the number of variables included and in the values of the constants used. This development makes the use of BIA complicated and the need for a universal applicable equation is growing. Because BIS is able to overcome the problems of SF-BIA associated with the hydration state of a subject, it seems logical to assume that in the clinical situation BIS is to be preferred. However, the advantage of BIS over SF-BIA has not yet been convincingly proven ${ }^{25.26 .27}$. The use of mixture equations, based on physical laws, could be a step towards the development of a universal equation. Until now few studies described the accuracy of BIS with mixture equations in a pediatric population ${ }^{21.28}$

The clinical usefulness of a method for measuring body composition depends on its accuracy for measuring clinically relevant changes. Therefore, in this study we performed serial BIA measurements and compared the results with reference methods.

The primary objective of the present study was to assess the validity of BIS, with use of mixture equations, for monitoring body composition in children with CF by comparing results with Deuterium -and bromide dilution techniques for the measurements of TBW and ECW and with DXA for the measurement of FFM and FM. Also the predictive capacity of changes in the resistance index of R50, R at infinite frequency (Rinf), R of ICW (RicW) and R of eCW (Recw) for changes in body compartments was tested in order to compare SF-BIA with MFBIA and BIS. 
The secondary aim was to compare BIS with SFT measurements for the measurement of absolute values of FFM and FM and for changes in these compartments by comparing both methods with DXA results.

\section{Materials and methods}

\section{Subjects}

The study included 13 children ( 8 male, 5 female; age 5-17) with cystic fibrosis (CF). Their body composition was monitored by different measures for 1 year. At the start and at the end of the study period their Z scores for height and weight for height was calculated. Z scores standardize height and weight for age and gender and are calculated by using the formula: $Z=$ observed value- Medial reference value)/ SD of the reference population. Reference values of the Dutch population were used ${ }^{20}$.

All measurements were performed on the same day in the morning after an overnight fast.

\section{Anthropometric measurements}

Anthropometric measurements were performed at the start of the study, after 6 months and after 12 months. All measurements were obtained with children wearing only underwear. Length was measured with a stadiometer to the nearest $0.1 \mathrm{~cm}$, body weight with a Seca scale to the nearest $0.1 \mathrm{~kg}$. Skinfold thickness (SFT) at the triceps, biceps, subscapular, and suprailiac sites were measured in triplicate by a Harpenden skinfold caliper, using standard methods ${ }^{30}$. The same trained dietician performed all SFT measurements. FFM and FM were computed from SFT measurements at 4 sites with the use of age- and sex-appropriate equations $^{31,32}$. The body density was calculated from the equations:

For boys Density $=1.1533-0.0643^{*} \log$ sum of the skinfold thicknesses $(\mathrm{mm})$ at 4 sites.

For girls Density $=1.1369-0.0598^{*} \log$ sum of the skinfold thicknesses $(\mathrm{mm})$ at 4 sites.

From body density body fat mass (FMsft) was calculated:

$\mathrm{FMsft}=[(4.95 /$ body density $)-4.5]{ }^{*}$ body weight $(\mathrm{kg})$.

Fat free mass (FFMsft) was calculated as the difference between body weight and FMsft.

\section{Bioelectrical impedance measurements}

Impedance measurements were performed at the start of the study, after 6 months and after 1 year. Subjects lay on a bed with legs separated and arms abducted from the body. Measurements were started after the subjects had voided and A tetra-polar electrode (3M red $\mathrm{Dot} \mathrm{Ag} / \mathrm{AgCl}$ ) arrangement as described by Lukaski et al was used ${ }^{33}$. Measurements were performed with a Xitron $4000 \mathrm{~B}$ bioelectrical impedance spectrometer (Xitron technologies, San Diego, California) using 48 frequencies ranging from 5 to $500 \mathrm{kHz}$. Measurements were done at the right and left side of the body. Mean values of resistances and fluid volumes were used for analysis of the data. From all 48 measured resistance and reactance values the resistance of the extracellular (Recw) and intracellular (Ricw) fluid was extrapolated by using the Xitron curve-fit software. All fits were classified as 'good' or 'excellent'. The resistance at $50 \mathrm{kHz}$ (R50) was recorded for comparison of BIS results with single-frequency BIA. Recw and Ricw were used in equations based on Hanai mixture theory for calculating body fluid compartments ${ }^{34}$. For a detailed description of the equations used we refer to the paper of De Lorenzo ${ }^{\circ}$. From the calculated intracellular (ICWbis) and extracellular water (ECWbis) total body water (TBWbis) is calculated by the Xitron software as ECW + ICW, and FFMbis as (Decw"ECWbis) + (Dicw"ICWbis) in which Decw and Dicw are the assumed densities of ECW and ICW (Decw. males: 1.45 females:1.48, DicW: 
males:1.31, females:1.23) and FMbis as body weight-FFMbis.

The resistance at infinite frequency (Rinf) was calculated as:

Rinf $=\left(\right.$ Ricw $^{*}$ Recw $) /($ Ricw + Recw $)$ and was used to study changes in the resistance index in relation to changes in body composition.

\section{Dual energy X-ray absorptiometry (DXA)}

Dexa measurements were performed at the start of the study, after 6 months and after 12 months.

Dexa was used for measurement of whole body fat mass (FMdxa), lean soft tissue (comprising muscle, inner organs and body water) and bone mineral density. Fat free mass (FFMdxa) was calculated as the sum of lean soft tissue and bone mineral content. The equipment used in this study was DPX-L (Lunar Radiation Corp., Madison, WI).

DXA measurements were performed in a standard manner while subjects were lying in a supine position on a table. From an $\mathrm{x}$-ray source and $\mathrm{K}$-edge filter below the patient, $\mathrm{x}$-ray beams of stable energy radiation of 38 and $70 \mathrm{KeV}$ were emitted. Attenuation of the $x$-rays was measured with a detector situated above the patient. Transverse scans, about 120 pixel elements with a size of approximately $5 \cdot 10 \mathrm{~mm}$ yield data on the attenuation ratio. Approximately 40 to $45 \%$ of the pixels over the body contain bone and soft tissue, and 55 to $60 \%$ contain soft tissue alone $e^{35}$. Bone mass was estimated from the ratio of the attenuation at low energy peaks relative to attenuation at high energy peaks through bone containing pixels after correction for the overlying soft tissue. The composition of the soft tissue was estimated by the ratio of beam attenuation at lower energy relative to the higher energy in soft tissue pixels; this ratio is inversely and linearly related to the percentage of $\mathrm{fat}^{36,36}$.

\section{Dilution techniques}

Total body water was measured by deuterium oxide dilution (TBWdeu) and extracellular water by $\mathrm{NaBr}$ dilution (ECWbr). Measurements were performed at the start of the study and after 12 months.

In the morning fasted patients drank a mixture of $10 \mathrm{ml}$ deuterium-labeled water $\left(\mathrm{D}_{2} \mathrm{O}: 99.84\right.$ atom percentage excess) and $10 \mathrm{ml} 150 \mathrm{mM} \mathrm{NaBr}$. Deuterium and bromide enrichment in body fluid after 4 hours was measured in serum. Deuterium was analyzed with isotope ratio mass spectroscopy ${ }^{37}$ and bromide with gas chromatography ${ }^{30}$. TBWdeu was calculated by correcting the Deu-dilution space with $4 \%$ for exchange of labile hydrogen ECWbr was calculated by correcting the $\mathrm{Br}$-dilution space with 0.90 for non-extracellular distribution of $\mathrm{Br}$ and with 0.95 for the Donnan equilibrium.

The $\mathrm{Br}$-dilution method for ECW is estimated to have an accuracy of $5 \%{ }^{30.30}$. The accuracy of TBW measurements by Deu-dilution has been reported to be $1.5 \%{ }^{30,40}$.

\section{Statistical analysis}

At each of the three time points body composition measures obtained by BIS and SFT were compared with the reference methods by paired Student T-tests. For an overall comparison of body composition measures, Bland and Altman analysis ${ }^{41}$ was performed on data pooled over the different time points.

Changes in body compartments measured by the different methods over three different time intervals ( $0-6$ months; $0-12$ months; 6 months - 12 months) were compared between methods by paired student T-test. Pearson correlation coefficients were calculated for the pooled data of all changes measured by BIS or SFT with those measured by the reference methods, and for changes in resistance indexes with changes in FFM and FM measured by DXA.

Linear regression analysis with changes measured by DXA as dependent variable and changes measured by BIS or SFT as independent variable was performed. 


\section{Results}

Characteristics of the study population are presented in table 1. During the study period body weight and length significantly increased by a mean of $2.9 \mathrm{~kg}$ and $5.1 \mathrm{~cm}$ respectively. At the start of the study the Z-score of length for age was below -1 , indicating that the length of the children was below the 15 percentile of the Dutch reference population. During the study period of one year this did not improve. Deviation of weight was less extreme, the mean $\mathrm{Z}$ score of weight for length was -0.6 at the start and stayed constant. These data indicate the presence of growth retardation without development of major underweight.

Table 1. Subject characteristics at the start and end of the study period (mean (SD)).

\begin{tabular}{lcccc}
\multicolumn{2}{c}{ Start } & \multicolumn{3}{c}{ End } \\
\hline & Mean & SD & Mean & SD \\
\hline Number (M/F) & $13(8 / 5)$ & & $13(8 / 5)$ & \\
Age (years) & 9.7 & 3.5 & 10.7 & 3.5 \\
Length (cm) & 133.0 & 16.9 & $138.1 \cdots$ & 15.3 \\
Weight (kg) & 27.2 & 10.1 & $30.1 \cdots$ & 10.0 \\
Z score Length & -1.29 & 0.70 & -1.20 & 0.87 \\
Z score Weight for length & -0.60 & 1.28 & -0.62 & 1.37 \\
\hline
\end{tabular}

Paired T-test: " $P<0.05$, " $p<0.005$

BIS significantly underestimated TBW and FFM compared with TBWdeu and FFMdxa, both at the start and at the end of the study (table 2). The FMbis was significantly larger than FMdxa at all three time points. Absolute ECWbis values were not significantly different from ECWbr values. Compared with DXA values, skinfold measurements overestimated FFM at 12 months and overestimated FM at the start of the study.

Bland and Altman analysis (table 3) of all measurements showed strong correlations between methods. BIS estimates of fluid compartments correlated less well with the dilution methods than estimates of FFMbis and FMbis with DXA measures. The correlations of SFT measures with DXA were in the same range as the correlation between BIS and DXA. However, a bias for TBWbis, FFMbis and FMbis was found. BIS underestimated TBW by $2.89 \mathrm{~L}$, FFM by $3.36 \mathrm{~kg}$ and overestimated FM by $4.26 \mathrm{~kg}$ compared with the reference methods. The bias of SFT measures were smaller, both FFMsft and FMsft were overestimated by 0.41 and $0.46 \mathrm{~kg}$ respectively. The $95 \%$ confidence intervals for FFMbis and FMbis were wide, $7.84 \mathrm{~kg}$ and $7.48 \mathrm{~kg}$ respectively, while for SFT measurements these values were 4.24 and $3.68 \mathrm{~kg}$. Significant correlations found between the difference and mean of the methods indicate that deviations from the reference method are influenced by the size of the FFM or FM. Comparison of BIS with SFT revealed the same results as comparison between BIS and DXA due to the fact that SFT measures agreed more with DXA than BIS. 
Table 2. Comparison of body composition measures (mean (SD)) at different time points during the study in 13 CF patients.

\begin{tabular}{llll}
\hline & start & 6 months & 12 months \\
\hline TBWdeu (L) & $16.75(4.04)$ & & $18.31(4.69)$ \\
TBWbis (L) & $14.36(4.83)^{* *}$ & $15.12(4.48)$ & $16.05(3.90)^{* *}$ \\
ECWbr (L) & $8.06(3.01)$ & & $8.37(1.61)$ \\
ECWbis (L) & $8.47(2.76)$ & $8.73(2.53)$ & $9.02(2.44)$ \\
FFMdexa (kg) & $22.86(7.26)$ & $23.22(5.98)$ & $24.71(6.82)$ \\
FFMskinfolds (kg) & $22.82(7.13)$ & $23.98(6.79)$ & $25.21(6.21)^{*}$ \\
FFMbis (kg) & $19.17(6.40)^{* *}$ & $20.26(5.89)^{* *}$ & $22.12(5.31)^{* *}$ \\
FMdexa (kg) & $3.46(3.01)$ & $4.46(4.10)^{*}$ & $4.56(3.64)$ \\
FMskinfolds (kg) & $4.35(3.18)^{*}$ & $4.70(3.31)$ & $4.84(3.26)$ \\
FMbis (kg) & $7.99(3.81)^{* *}$ & $8.42(4.04)^{* *}$ & $7.93(5.13)^{* *}$ \\
\hline
\end{tabular}

Comparison with reference method (TBWdeu, ECWbr or FFMdxa, FMdxa) paired T-test P values * P<0.05, *p<0.005

Table 3. Bland and Altman analysis of TBW, ECW, FFM and FM measured by different methods. The difference between methods was calculated as: reference method - BIS, or as DXA - SFT values.

$\begin{array}{llll}\begin{array}{l}\text { correlation } \\ \text { coefficient }\end{array} & \begin{array}{l}\text { difference } \\ \text { mean (SD) }\end{array} & \begin{array}{l}95 \% \text { limits } \\ \text { of agreement }\end{array} & \begin{array}{l}\text { correlation } \\ \text { mean and difference } \\ \text { of methods }\end{array}\end{array}$

\begin{tabular}{|c|c|c|c|c|}
\hline TBWdeu vs TBWbis (L) & $0.888 \cdots$ & $2.89(2.08)^{\wedge A}$ & {$[-1.27 ; 7.05]$} & 0.011 \\
\hline ECWbr vs ECWbis (L) & $0.854^{* *}$ & $-0.28(1.36)$ & {$[-3.00 ; 2.43]$} & -0.190 \\
\hline FFMdxa vs FFMbis (kg) & $0.958 \cdots$ & $3.36(1.96)^{\mathrm{AM}}$ & {$[-0.56 ; 7.28]$} & $0.399^{*}$ \\
\hline FFMsft vs FFMbis (kg) & $0.974 \cdots$ & $3.79(1.78) \wedge$ & {$[0.23 ; 7.35]$} & $0.588 *$ \\
\hline FFMdxa vs FFMsft (kg) & $0.988 \cdots$ & $-0.41(1.06)^{\wedge}$ & {$[-2.53 ; 1.71]$} & -0.249 \\
\hline FMdxa vs FMbis (kg) & $0.898 \cdots$ & $-4.26(1.87)^{M}$ & {$[-8.00 ;-0.52]$} & $-0.354 \cdot$ \\
\hline FMsft vs FMbis (kg) & $0.923 \cdots$ & $-3.80(1.78)^{M}$ & {$[-7.36 ;-0.24]$} & $-0.595^{*}$ \\
\hline FMdxa vs FMsft (kg) & $0.969 \cdots$ & $-0.46(0.92)^{M A}$ & {$[-2.30 ; 1.38]$} & $0.414^{\cdots}$ \\
\hline
\end{tabular}

Significant correlation: ${ }^{*} \mathrm{P}<0.05,{ }^{*} \mathrm{P}<0.005$.

Significant different from zero, paired T-test, two-tailed $P$ values: $\wedge P<0.05$, $\wedge p<0.005$

Changes in body composition over the three periods are presented in table 4. Over each period significant increases in length and weight were measured. In one year TBWdeu increased $1.85 \mathrm{~L}$ while the ECWbr increase was not significant. BIS measured changes in both TBW and ECW over each period. The changes in fluid volumes measured by BIS over one year did not differ from the dilution methods. Also, the measured increases in FFM and FM over the periods did not differ between methods. In one year FFMdxa increased $1.82 \mathrm{~kg}$ and FMdxa $1.09 \mathrm{~kg}$.

Correlations between methods for measured changes were compared. Measured changes in TBWdeu and ECWbr did not correlate with changes measured by BIS and changes in FFMbis did not correlate with changes in FFMdxa (fig. 1), while changes in FM measured by the two methods were significantly correlated (fig. 2). However, in cases where BIS measured FM losses of up to $5 \mathrm{~kg}$. DXA measured no change in FM. Comparing the 
changes measured by SFT revealed that both FFM $(r=0.665, P<0.0001)$ and FM $(r=0.808$, $\mathrm{P}<0.0001)$ changes were correlated with changes measured by DXA. The changes in FM measured by SFT were small

Table 4. Changes in body composition measures in children with CF over three periods.

\begin{tabular}{|c|c|c|c|}
\hline & 0 to 6 months & 6 to 12 months & 0 to 12 months \\
\hline $\begin{array}{l}\text { length }(\mathrm{cm}) \\
\text { weight }(\mathrm{kg})\end{array}$ & $\begin{array}{l}2.57(1.06)^{* *} \\
1.50(0.49)^{* *}\end{array}$ & $\begin{array}{l}2.46(1.32)^{* *} \\
1.36(1.24)^{* *}\end{array}$ & $\begin{array}{l}5.05(2.23)^{* *} \\
2.87(1.65)^{* *}\end{array}$ \\
\hline TBWdeu (L) & - & - & $1.85(2.39)^{*}$ \\
\hline TBWbis (L) & $0.81(0.68)^{* *}$ & $0.92(1.08)^{*}$ & $1.68(1.54)^{* *}$ \\
\hline ECWbr (L) & - & - & $0.31(2.27)$ \\
\hline ECWbis (L) & $0.30(0.41)^{*}$ & $0.29(0.41)^{\circ}$ & $0.55(0.58)^{\circ}$ \\
\hline FFMdxa (kg) & $0.36(1.76)$ & $1.58(1.13)^{* *}$ & $1.82(1.19)^{* *}$ \\
\hline FFMsft $\left(\mathrm{kg}_{\mathrm{g}}\right)$ & $1.16(1.06)^{* *}$ & $1.23(0.73)^{* *}$ & $2.39(1.26)^{* *}$ \\
\hline FFMbis (kg) & $1.08(0.92)^{* *}$ & $1.23(1.38)^{* *}$ & $2.24(1.97)^{* *}$ \\
\hline FMdxa (kg) & $1.00(1.46)^{\circ}$ & $0.09(0.91)$ & $1.09(1.2)^{* *}$ \\
\hline FMst (kg) & $0.34(0.68)$ & $0.14(0.62)$ & $0.48(0.55)^{* *}$ \\
\hline FMbis $(\mathrm{kg})$ & $0.43(1.22)$ & $0.21(1.71)$ & $0.63(2.38)$ \\
\hline
\end{tabular}

The significance of the changes were tested by paired T-test (two-tailed $P$ values: $" P<0.05, * P, 0.005$ ). No significant difference between methods for the measured changes was found. TBW is total body water, ECW is extracellular water, FFM is fat free mass, FM is fat mass, deu is deuterium oxide dilution, br is bromide dilution, dxa is dual energy X-ray absorptiometry, sft is skinfold thickness, bis is bioelectrical impedance spectroscopy.

In order to elucidate if the regression approach of BIA would be able to detect changes better than the mixture approach, the correlation between changes in resistance indexes and changes in FFM and FM measured by DXA were studied. Both absolute and relative changes in body compartments and resistance indexes were compared. While changes in $L^{2} / R i$ and $L^{2} / R i n f$ did not correlate with changes in FFM or FM, changes in $L^{2} / R e$ and $L^{2} / R 50$ were both significantly and to the same degree correlated with changes in FFMdxa (table 5). Relative changes in these indexes and relative changes in FFMdxa were stronger correlated than absolute changes. Regression analysis of changes in $L^{2} / R 50$ with changes in FFMdxa as dependent variable showed that changes in FFM could be predicted with an SEE of 1.32 kg (fig 3.)

\section{Discussion}

Body composition assessment of children with CF is important in the evaluation and monitoring of their nutritional status. We tested the validity of BIS for monitoring body composition in children with CF and for detecting changes in body composition and compared results with SFT measurements and SF-BIA. 
Table 5.Correlations between absolute and relative changes in resistance index and absolute and relative changes in FFM and FM measured by DXA.

\begin{tabular}{llllll}
\hline & \multicolumn{2}{l}{ Absolute changes } & \multicolumn{2}{l}{ Relative changes } \\
\hline & $\Delta$ FFMdxa & $\Delta$ FMdica & & $\% \Delta F F M d x a$ & $\% \Delta F M d x a$ \\
$\Delta\left(\mathrm{L}^{2} /\right.$ Recw $)$ & $0.525 *$ & 0.021 & $\% \Delta\left(\mathrm{L}^{2} /\right.$ Recw $)$ & $0.617^{* *}$ & $0.380^{*}$ \\
$\Delta\left(\mathrm{L}^{2} /\right.$ Ricw $)$ & -0.110 & -0.230 & $\% \Delta\left(\mathrm{L}^{2} /\right.$ Ricw $)$ & -0.118 & -0.176 \\
$\Delta\left(\mathrm{L}^{2} /\right.$ Rinf $)$ & 0.046 & -0.211 & $\% \Delta\left(\mathrm{L}^{2} /\right.$ Rinf $)$ & 0.014 & -0.088 \\
$\Delta\left(\mathrm{L}^{2} / \mathrm{R} 50\right)$ & $0.551^{*}$ & 0.113 & $\% \Delta\left(\mathrm{L}^{2} / \mathrm{R} 50\right)$ & $0.629^{* *}$ & $0.499^{* *}$ \\
\hline
\end{tabular}

Recw, Ricw, Rinf and R50 are resistance vlues (ohm) of extracellular water, intracellular water and extrapolated resistance at infinite frequency and resistance at $50 \mathrm{kHz}$ respectively. $\mathrm{L}$ is length (cm). FFMdxa is fat free mass measured by dual energy $\mathrm{X}$-ray absorptiometry. FMdxa is fat mass measured by dual energy $\mathrm{X}$-ray absorptiometry Significant correlation: $" \mathrm{p}<0.05, \cdots p<0.005$.

FFM changes (kg) DXA against BIS

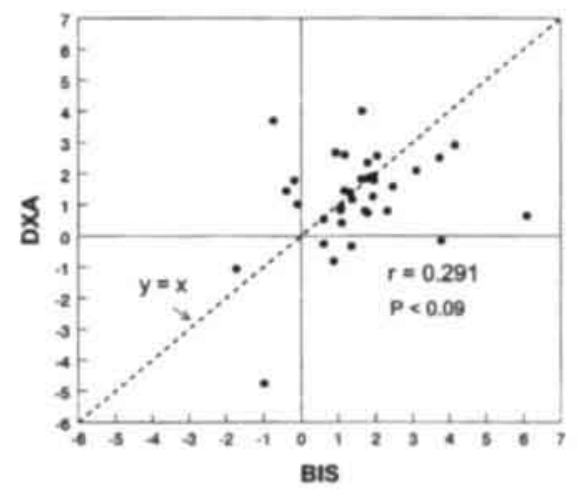

FFM changes (kg) DXA against skinfolds

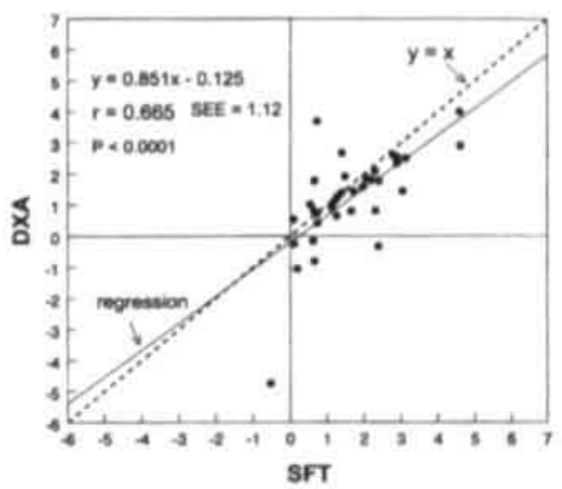

Figure 1. Changes in fat free mass (FFM) measured by dual energy $X$-ray absorptiometry (DXA) against changes measured by bioelectrical impedance spectroscopy (BIS) (left) and against changes measured by skinfold thickness (SFT) (right).

\section{Possible causes for the systematic difference between BIS and reference methods}

In the present study Xitron equations systematically underestimated TBW and FFM. This bias is caused by the values of the constants used. Ellis et al $^{27}$ showed in a large pediatric population that adjustment of these constants for children reduced the difference between BIS and the reference method ${ }^{21}$. These constants act as scalers and their values were originally derived from measurements in adults ${ }^{\circ}$. The constant used for calculating ECW, Kecw is composed of body density, body geometry and the specific resistivity of ECW. Age dependent changes in body density and body geometry during growth justify adjustment of this constant. The value of the constants has no effect on the correlation between methods and on the standard error of estimate $(\text { SEE) })^{8}$. Measured changes in body compartments are 
less affected by the absolute values of the constants than the calculated absolute size of the body compartments. Bland Altman analysis revealed a correlation between the difference and mean of FFM and FM measured by DXA and BIS. This implies that the size of the compartment measured affects the deviation of BIS from DXA. The taller children with larger FFM were older children. The age of the children included in the study varied from 4 to 17 years. This large age range, associated with age specific alterations in body density and body geometry, and thus probably in the values of 'constants', may be responsible for this finding. Simple replacement of a constant by a new constant for the total study population will not eliminate this effect because then age dependent alterations are not taken into account. Age-dependent values appear to be necessary. Although these adjustments complicate the use of BIS, the assumptions in the mixture equations of BIS theory are not violated because changes in the body density and geometry with growth are well documented. Age-dependent adjustment of the constants is merely a refinement of the method. However, more studies in large pediatric populations of different ages are needed for this refinement.

FM changes (kg) DXA against BIS

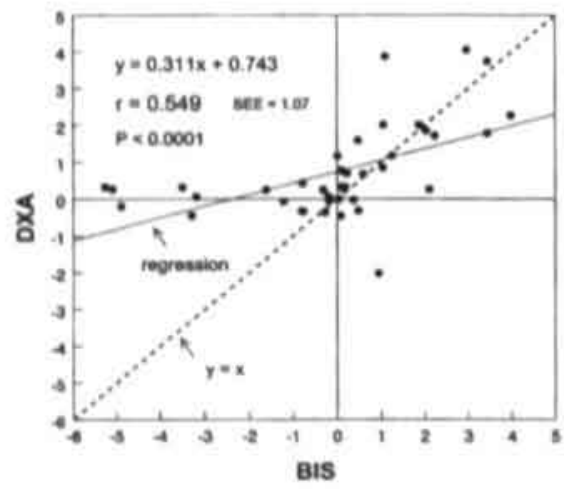

FM changes (kg) DXA against skinfolds

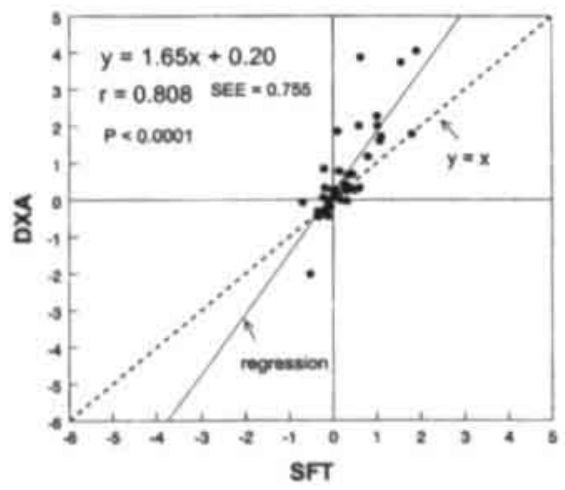

Figure 2. Changes in fat mass (FM) measured by dual energy $X$-ray absorptiometry (DXA) against changes measured by bioelectrical impedance spectroscopy (BIS) (left) and against changes measured by skinfold thickness (SFT) (right).

\section{The accuracy of BIS for measuring changes in ECW and TBW}

Although mean changes measured by BIS did not differ from changes measured by the reference methods, further analysis of these changes showed no significant correlations between changes in TBW, ECW and FFM measured by BIS and changes measured by the dilution methods and DXA. Based on the precision of Deu and $\mathrm{Br}$ dilution of $1.5 \%$ and $5 \%$ respectively and the mean TBW and ECW values measured at the start of the study (17 L and $8 \mathrm{~L}$ ), in absolute terms this would be 0.26 and $0.4 \mathrm{~L}$. For measured changes these values would be $0.37 \mathrm{~L}$ TBW $(0.26 \times \sqrt{2})$ and $0.57 \mathrm{~L} \mathrm{ECW}(0.4 \times \sqrt{2})$. Because ECW changes over one year were smaller than the minimal required change for $\mathrm{Br}$-dilution to be detected, the lack of correlation between methods is explainable. As TBW changes were large enough to be detected by Deu-dilution, it can be concluded that BIS is not sensitive enough for measuring relevant changes in this population. Because TBW is calculated by the mixture 
equations as the sum of ECW and ICW which are related to RecW and Ricw values, the accuracy of measurements at low as well as at high frequency ranges influences the measured TBW values, whereas ECW values are mainly influenced by the impedance at low frequencies. At high frequencies the capacitive property of cell membranes is lost and current will be conducted by ECW as well as by ICW. The specific effects of disease on these physical properties is not described yet, but theoretically BIS measurements in CF patients may differ from those measured in normal individuals. The altered sodium excretion of the sweat glands and increased transepithelial membrane potential difference may affect skin impedance, and the increased bioelectric potential difference across some epithelial membranes may affect the reactance of electric current in the bodies of patients with $\mathrm{CF}^{22}$.

\section{FFM changes $(\mathrm{kg})$ DXA as function of change in ( $\left.\mathrm{L}^{*} \mathrm{~L}\right) / \mathrm{R} 50$}

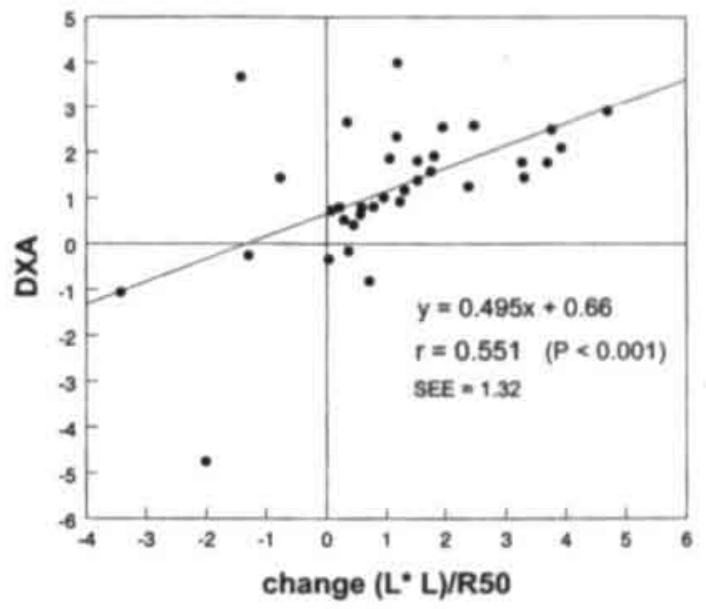

Figure 3. Changes in fat free mass (FFM) measured by dual energy $\mathrm{X}$-ray absotrptiometry against changes in the resistance index at $50 \mathrm{kHz}$

The contribution of the factor weight to the apparent accuracy of SFT measures

Both absolute values of FFM and FM and changes in these compartments derived from skinfold measurements agreed better with DXA than BIS. While BIS measures primarily fluid volumes from which FM and FFM are derived, SFT measures subcutaneous fat from which body density and subsequently body FM and FFM are calculated. For the conversion of density values to absolute values of FFM or FM the factor body weight is used. Consequently, changes in body composition calculated by this method are directly related to changes in body weight. This large contribution of the factor weight explains the good agreement between SFT and DXA. In fact, the sum of skinfolds did not significantly change during the study period while the calculated change in FFMsft $(r=0.946, P<0.0001)$ and FMsft ( $r=0.794, P<0.0001)$ correlated very strongly with changes in body weight. In the mixture equations body weight is also included, but its contribution to calculated fluid 
volumes is only proportional to $W^{1 / 3}$. For the development of these equations an approximation of the total body volume is necessary and provided by W/D. The good agreement between DXA and SFT will be lost if weight changes are caused by selective alterations in specific body compartments. A relatively constant contribution of FM to the weight gain during growth in the CF children in the present study may be responsible for the good results of SFT measurements. Although during the study children did not show visible signs of fluid imbalance, in clinical situations this may often be present which will limit the applicability of SFT measurements because over- as well as under-hydration directly affects the thickness of skinfolds. Based on these considerations, we do not advise SFT as the preferred method for monitoring changes in body composition despite the good results obtained in our study.

\section{The predictive capacity of changes in the resistance index at different frequencies}

Only few studies describe the validity of single frequency BIA at $50 \mathrm{kHz}$ in patients with $\mathrm{CF}^{22,23.24}$ and studies using multifrequency BIA or BIS in this population have not yet been published. Borowitz concluded from a comparison between adult CF patients and a control group that CF specific regression equations will need to be developed ${ }^{22}$. Lands et al concluded that serial SF-BIA measurement in CF children with the use of non-specific prediction equations based on impedance, length, weight and age, did not result in accurate estimates of FFM compared with DXA ${ }^{24}$. In another study the R50 values of serial SF-BIA measurements in CF children were compared with changes in total body potassium (TBK) ${ }^{23}$. A correlation between $\Delta\left(L^{2} / R 50\right)$ and $\triangle T B K$ of 0.69 was found ${ }^{23}$. In our study changes in the resistance index of Recw and of R50 correlated with changes in FFMdxa, while FFMbis did not, suggesting that SF-BIA is more sensitive than BIS for measuring changes. The strong relationship between ECW and FFM during normal hydration states can explain the predictive capacity of changes in $L^{2} / R e$ or $L^{2} / R 50$ for changes in FFM. It is recognized that $\mathrm{R} 50$ is merely a measure of ECW because at this frequency current is mainly conducted by ECW. Consequently, both R50 and Recw are measures of the same fluid compartment. Despite the fact that the measured FFM changes during growth most likely reflect changes in body cell mass and thus in ICW, changes in the resistance indexes of Rinf and RicW did not show correlations with changes in FFM mass. As outlined above, changes in membrane properties may influence the accuracy of impedance measurements at the high frequency range. If indeed disease specific effects of CF on impedance measurements are present, the usefulness of BIA in clinical settings would be limited. However, as stated by a panel of experts, the effects of alterations in physical, chemical and metabolic characteristics of the body on its biological properties remain unknown and have not received sufficient scientific study?

From the results of this study we conclude that BIS employing non population specific mixture equations is not sensitive enough for monitoring body composition in children with CF. Adjustment of the constants used in these equations for the pediatric population may improve the accuracy of BIS. Resistance changes in the low frequency range are more sensitive for changes in body composition than resistance changes at high frequencies. More research is needed to elucidate the effect of disease on the bioelectrical properties of the body.

\section{References}

1. Ramsey BW, Farrell PM, Pencharz P. Nutritional assessment and management in cystic fibrosis: a consensus report. The Consensus Committee. Am J Clin Nutr 1992;55:108-116.

2. Shepherd RW, Cleghom G, Ward LC, Wall CR, Holt TL. Nutrition in cystic fibrosis. Nutr Res Rev 1991:4:51-67.

3. Roulet M. Protein-energy malnutrition in cystic fibrosis patients. Acta Pediatr 1994;395(suppl):4348. 
4. McNaughton SA, Shepherd RW, Greer RG, Cleghorn GJ Thomas BJ. Nutritional status of children with cystic fibrosis measured by total potassium as a marker of body cell mass: Lack of sensitivity of anthropometric measures. J Pediatr 2000;136:188-194.

5. Kushner RF. Bioelectrical impedance analysis: a review of principles and applications J Am Coll Nutr 1992;1!:199-209.

6. Azcue M, Fried M, Pencharz PB. Use of bioelectrical impedance analysis to measure total body water in patients with cystic fibrosis. J Pediatr Gastroenterol Nutr 1993;16:440-445.

7. Quirk P. Ward LC. Thomas BJ, Holt TL, Shepherd RW, Cornish BH. Multiple frequency bioelectrical impedance for the prediction of total body potassium in cystic fibrosis. Clin Nutr 1995:14:348-353.

8. De Lorenzo A, Andreoli A, Matthie J, Whiters P. Predicting body cell mass with bioimpedance by using theoretical methods: a technological review. J Appl Physiol 1997; 85:1542-1558.

9. Ellis KJ, Bell SJ, Chertow GM, Chumlea WC, Knox TA, Kotler DP, Lukaski HC, Schoeller DA. Bioelectrical impedance methods in clinical research: a follow-up to the NIH technology assessment conference. Nutrition 1999; 15: 874-880.

10. Ellis KJ. Measuring of body fatness in children and young adults: comparison of bioelectric impedance analysis,total body electrical conductivity, and dual-energy $\mathrm{X}$-ray absorptipmetry. Int $\mathrm{J}$ Obes 20:866-873.

11. Wu YT, Nieisen DH, Cassady SL, Cook JS, Janz KF, Hansen JR. Cross-validation of bioelectrical impedance analysis of body composition in children and adolescents. Phys Ther 1993:73:320328.

12. Hammond J, Rona RJ, Chinn S. Estimation in community surveys of total body fat of children using bioelectrical impedance or skinfold thickness measurements. Eur J Clin Nutr 1994;48:164171.

13. De Lorenzo A, Sorge SP, iacopino L, Andreoli A, Petrone de Luca P, Sasso GF. Fat free mass by bioelectrical impedance Vs dual-energy X-ray absorptiometry (DXA). Appl Radiat Isot 1998 49:739-741.

14. Boot AM, Bouquet J, de Ridder MAJ, Krenning EP, de Muinck Keizer-Schrama SMPF. Determinants of body composition measured by dual-energy $\mathrm{X}$-ray absorptiometry in Dutch children and adolescents. Am J Clin Nutr 1997 66:232-238.

15. Schaefer F. Wuhl E, Feneberg R, Mehis O, Scharer K. Assessment of body composition in children with chronic renal failure. Pediatr Nephrol 2000 14:673-678.

16. Stefanidis C, Siapera D, Papadopoulou A, Michelis K. Body composition of children on CAPD. Perit Dial Intern 1996; 16(Suppl1):S561-S566.

17. Gutin B, Litaker M, Isiam S, Manos T, Smith C. Treiber F. Body-composition measurement in 911-y-old children by dual-energy $X$-ray absorptiometry, skinfold thickness measurements and bioimpedance analysis. Am J Clin Nutr 1996;63:287-92.

18. Houtkooper LB, Lohman TG, Going SB, Hall MC. Validity of bioelectric impedance for body composition assessment in children. J Appl Physiol 1989;66:814-821.

19. Michener J, Lam S, Kolesnik S, Thornton JC, Wang J, Pierson RN. Skinfolds versus bioimpedance analysis for predicting fat free mass. Ann N Y Acad Sci 2000:904:339-341

20. Okasora K, Takaya R, Tokuda M, Fukunaga $Y$, Oguni T, Tanaka H, Konishi K, Tamai H Comparison of bioelectrical impedance analysis and dual energy $\mathrm{X}$-ray absorptiometry for assessment of body composition in children. Pediatr int 1999:41:121-125.

21. Ellis KJ, Shypailo RJ, Wong WW. Measurement of body water by multifrequency bioelectrical impedance spectroscopy in a multiethnic pediatric population. Am J Clin Nutr 1999;70:847-853.

22. Borowitz D. Conboy K. Are bioelectric impedance measurements valid in patients with cystic fibrosis? J Pediat Gastroenterol Nutr 1994 18:453-456

23. Quirk PC, Ward LC. Thomas BJ, Holt TL, Shepherd RW, Comish BH. Evaluation of bioelectrical impedance for prospective nutritional assessment in cystic fibrosis. Nutrition 1997;13:412-416

24. Lands LC, Gordon C, Bar-Or O, Blimkie LJ. Hanning M, Jones NL, Moss LA, Webber CE, Wilson WM. Heigenhauser GJF. Comparison of three techniques for body composition analysis in cystic fibrosis. J Appl Physiol 1993 75:162-166

25. Hannan WJ, Cowen SJ, Plester CE, Faeron KC, de Beau A. Comparison of bioempedance spectroscopy and multi-frequency bio-impedance analysis for the assessment of extracellular and total body water in surgical patients. Clin Sci 1995 89:651-658.

26. Lehnert ME, Clarke DD, Gibbons JG. Ward LC, Golding SM, Shepherd RW. Comish BH, Crawford DHG. Estimation of body water compartments in cirrhosis by multiple-frequency bioelectrical impedance analysis. nutrition 2001:17:31-34 
27. Patel PV, Peterson EL, Silverman N, Zarowitz BJ. Estimation of total body and extracellular water in post-coronary artery bypass graftsurgical patients using single and multiple frequency bioimpedance. Crit Care Med 1996; 24:1824-1828

28. Beerterna W, van Hezewijk M, Kester A, Forget PP, van Kreel B. Measurement of total body water in children using bioelectrical imoedance: A comparison of several prediction equations. JPGN 2000;31:428-432.

29. Gerver WJM, De Bruin R. Paediatric Morphometrics. A reference Manual.1996. Wetenschappelijke uitgeverij Bunge, Utrecht, The Netherlands.

30. Frisancho AR in: Anthropometric standards for the assessment of growth and nutritional status. 1993. The university of Michigan Press. Ann Arbor.

31. Durnin JVGA, Rahaman MM. The assessment of the amount of fat in the human body from measurements of skinfold thickness. Br J Nutr 1967;21:681-689.

32. Brook CGD. Determination of body composition of children from skinfold measurements. Arch Dis Child 1971:46:182-184.

33. Lukaski HC, Johnson PE, Bolonchuk WW, Lykken GI. Assessment of fat free mass using bioelctrical impedance measurement of human body. Am J Clin Nutr 1985; 41:810-817.

34. Hanai T. Electrical properties of emulsions. In: Sherman PH (ed). Emulsion science. Academic: London 1968, pp354-477.

35. Mazess RB, Barden HS, Bisek JP. Hanson J. Dual-energy x-ray absorptiometry for total body and regional bone-mineral and soft-tissue composition. Am J Clin Nutr 1990, 51:1106-1112.

36. Lohman TG. Dual energy $x$-ray absorptiometry. In: Human body composition, 1st Ed., edited by Roche AF, Heymsfield SB, Lohman TG, Champaign, IL, Human Kinetics, 1996, pp 63-78.

37. Van Kreel, Van der Vegt F. Meers M. Determination of total body water by a simple and rapid mass spectrometric method. J Mass Spectrom 1996, 31:108-111.

38. Van Kreel BK. An improved bromide assay for the estimation of extracellular water volume by capillary gas chromatography. Clin Chim Acta 1994: 231:117-128.

39. Gudivaka R, Schoeller DA, Kushner RF, Bolt MJG. Single- and multifrequency models for bioelectrical impedance analysis of body water compartments. J Appl Physiol 1999; 87:10871096.

40. Ho LT, Kushner RF, Schoeller DA, Gudivaka R, Spiegel DM. Bioimpedance analysis of total body water in hemodialysis patients. Kidney Int 1994 46:1438-1442.

41. Bland JM, Altman DG. Statistical methods for assessing agreement between two methods of clinical measurement. Lancet 1986;1: 307-310. 


\section{CHAPTER 8}

Bio-electrical impedance measurements in patients with gastrointestinal disease. Validation of the spectrum approach and a comparison of different methods for screening nutritional depletion.

PLM Cox-Reijven', B v. Kreel ${ }^{2}$, PB Soeters ${ }^{3}$ ${ }^{1}$ Department of Dietetics, ${ }^{2}$ Department of Clinical Chemistry. ${ }^{3}$ Department of surgery. University Hospital Maastricht, The Netherlands

Submitted 


\begin{abstract}
Background:

Identifying patients with clinical depletion requires simple non-invasive body composition measurements. Bio-electrical impedance spectroscopy (BIS) may be of value.

Objective: The primary aim of the study was to assess the validity of BIS in patients with gastrointestinal (GI) disease. The secondary aim was to compare different screening methods for identifying depleted patients based on measured resistance $(R)$ values.

Design:

In $70 \mathrm{GI}$ patients BIS measurements were performed and fluid compartments were calculated from extrapolated $R$ values of extracellular (Recw) and intracellular (Ricw) water based on Hanai mixture equations. Results were compared with total body water (TBW) and ECW measured by dilution methods. Patients were classified as depleted if their actual fat free mass (FFM) was smaller than $90 \%$ of their ideal FFM (iFFM). Different screening approaches for depletion were compared:

-the impedance vector method based on $\mathrm{R}$ and reactance measured at $50 \mathrm{kHz}$ normalized for height.

-the value of the ratio (length ${ }^{2} / R$ ) / iFFM at $R_{50}$. Ricw and $R$ at infinite frequency (Rinf).

Results:

TBW and ICW were largely underestimated $(4 \mathrm{~L})$ in the non-depleted patients, but not in depleted patients. In both groups ECW was slightly overestimated (0,6 to $0,7 \mathrm{~L})$. In depleted patients the critical frequency was $60 \%$ higher and the membrane capacitance $40 \%$ lower than in non-depleted patients. The impedance vector method failed to identify depleted patients while the proposed ratio at $R_{50}$ and Rinf resulted in comparable sensitivity ( $86 \%$ ) and specificity $(73-80 \%)$.

\section{Conclusion:}

BIS measures of body fluids in patients are influenced by the presence of depletion probably due to alterations of electrical properties of the body at the cellular level. However, for screening purposes use of the ratio $\left(\mathrm{L}^{2} / \mathrm{R}\right) / \mathrm{iFFM}$ at $\mathrm{R}_{\mathrm{s}_{0}}$ and $\mathrm{Rinf}$ may be of value.
\end{abstract}




\section{Introduction}

Malnutrition is often present in patients with gastrointestinal disease and has adverse effects on recovery as it increases morbidity and mortality'. Measuring body composition is essential for the assessment of nutritional status because body weight alone gives no information about the loss of body cell mass in depleted patients. Unfortunately, most body composition methods are not suited for routine clinical use. The need for a valid, accurate and convenient method for clinical use is growing.

Bioelectrical impedance analysis (BIA), based on measuring the impedance of the human body to an alternating current, may be of value. However, many different approaches are currently is use. The single frequency BIA (SF-BIA) measures the body impedance at one frequency, usually $50 \mathrm{kHz}$, from which total body water (TBW) is calculated based on regression equations with $L^{2} / R$ ( $L=$ body length, $R=$ measured resistance), weight, age, gender and sometimes other anthropometric measures as independent variables. It has been demonstrated that equations developed in normal weight individuals were not applicable in underweight patients as they overestimated TBW ${ }^{2,3,4}$. Consequently, equations specific for underweight and malnourished patients were published ${ }^{4}$. Population specific equations complicate the clinical use of SF-BIA because inevitably the question arises when to use which equation. Furthermore, it has been concluded that in cases of fluid imbalance, often present in patients, the SF-BIA is not valid ${ }^{5}$. Bioelectrical impedance spectroscopy (BIS) may overcome the limitations of SF-BIA as it measures the fluid compartments ECW and ICW separately. BIS measures the impedance at a range of frequencies from which the resistance of the extracellular (Recw) and intracellular (Ricw) fluid compartments are extrapolated. These R-values are used to calculate ECW and ICW separately. This approach also differs from SF-BIA by the fact that mixture equations based on physical models are often used instead of regression equations ${ }^{6}$. In view of the differences between the two approaches, BIS seems more appropriate for clinical applications than SF-BIA.

The resistance index $\left(L^{2} / R\right)$ without the use of population specific prediction equations may be of value for screening purposes because then the quantification of the body compartments is not necessary. Because the size of fluid compartments is proportional to $L^{2} / R$, comparison of the resistance index at different frequencies with normal values of fluid compartments may be able to identify depleted patients. The applicability of this ratio as a screening tool has not been studied yet.

The BIA vector method described by Piccoli is another approach not requiring prediction equations $\mathrm{s}^{7}$. This method uses the plot of the impedance vector components resistance (R) and reactance $(X c)$ measured at $50 \mathrm{kHz}$. $R$ and $X c$ standardized by the subject's height $(\mathrm{H})$ are plotted as bivariate vectors. Their confidence and tolerance intervals are ellipses on the R-Xc plane. Displacement of the vectors has been demonstrated in subjects with increased body mass due to fat or fluid overload ${ }^{8}$ and in dialysis patients undergoing fluid removal ${ }^{6}$. The advantages of this qualitative body composition assessment are that it does not require knowledge of body weight and that it does not rely on the assumptions and models, on which the traditional BIA is based. However, it is not clear if the method is clinically useful in discriminating between depleted and non-depleted patients, because no studies of this approach in patients with gastrointestinal diseases or in depleted patients have been published yet.

The primary aim of the present study was to assess the validity of BIS for measuring fluid volumes in patients with gastrointestinal disease by comparing BIS with dilution methods and to test the validity of BIS in the presence of weight loss and nutritional depletion.

The second aim was to assess the applicability of the resistance index $\left(L^{2} / R\right)$ and the impedance vector method as screening instruments for nutritional depletion by comparing the sensitivity and specificity of these approaches with results from BIS measurements and 
computation of the volume of body compartments.

\section{Subjects and methods}

\section{Patients}

Seventy patients (29 women, 41 men) with gastrointestinal disease admitted to the hospital were included in the study. Of these patients 53 were diagnosed with cancer of the esophagus, stomach, small intestine, caecum, colon, rectum or pancreas, and 17 had benign diseases including diverticulosis, pancreatitis, Crohn's disease, ulcerative colitis and benign stenoses of parts of the gastrointestinal tract. No patients had clinical signs of edema or dehydration and all patients were in a stable metabolic condition. Their mean BMI was $23.6(\mathrm{SD}=3.9) \mathrm{kg} / \mathrm{m}^{2}$. Written informed consent was obtained from all participants. The study was approved by the Medical Ethical Committee of the University Hospital Maastricht.

\section{Protocol}

All measurements were performed in the morning on the first day of admission. Patients were in an overnight fasted state. After voiding, bioelectrical impedance measurements were performed, followed by anthropometric measurements. Body weight was measured to the nearest $0,1 \mathrm{~kg}$. length to the nearest $0,1 \mathrm{~cm}$ and wrist circumference was measured with a metal tape to the nearest $0,1 \mathrm{~cm}$. Blood and saliva samples were taken followed by drinking an indicator dilution mixture of deuterium oxide and sodium bromide. Four hours after ingestion of the indicators again blood and saliva samples were taken. During the four-hour interval patients were not allowed to eat and drinking was limited to $200 \mathrm{ml}$ and only allowed during the first two hours.

Blood hematocrit and hemoglobin levels were analyzed according to routine hospital procedures.

Patients were interviewed regarding their usual weight and weight changes during the last year. Based on the degree of weight loss patients were divided in 3 groups. Based on the amount of FFM, measured with Deu-dilution, in relation to the ideal FFM, patients were divided in a 'depleted' and a 'not depleted' group.

\section{Dilution methods}

Total body water (TBW) was measured by deuterium oxide $\left(\mathrm{D}_{2} \mathrm{O}\right)$ dilution and extracellular water (ECW) by $\mathrm{NaBr}$ dilution. In the morning, post-absorptive patients drank a mixture of $20 \mathrm{~g}$ deuterium-labelled water $\left(\mathrm{D}_{2} \mathrm{O}: 99,84\right.$ atom percentage excess) and $30 \mathrm{ml} 150 \mathrm{mM} \mathrm{NaBr}$. Before and four hours after ingestion of the indicators, saliva and blood samples were obtained for deuterium and bromide analysis respectively. Deuterium was analyzed by a mass spectrometric method described by van Kreel ${ }^{10}$. Bromide was analyzed by ion chromatography as described by Wong". Plasma was not deproteinized by the use of a filter, but by acetonitrile. TBWdil was calculated by correcting the Deu-dilution space with $4 \%$ for exchange of labile hydrogen. ECWdil was calculated by correcting the Br-dilution space with 0.90 for nonextracellular distribution of $\mathrm{Br}$ and with 0.95 for the Donnan equilibrium.

Intracellular water (ICWdil) was calculated as TBWdil - ECWdil.

From TBWdil the FFM of patients was calculated by assuming a hydration factor of 73.2 : 


\section{Bio-electrical impedance spectroscopy (BIS)}

BIS measurements were performed just before subjects drank the indicator mixture. Subjects lay on a bed with legs separated and arms abducted from the body. A tetra-polar electrode (3M red Dot $\mathrm{Ag} / \mathrm{AgCl}$ ) arrangement as described by Lukaski et al was used ${ }^{12}$. Impedance was measured with a Xitron $4000 \mathrm{~B}$ bioelectrical impedance spectrometer (Xitron Technologies, San Diego, California) using 48 frequencies, ranging from 5 to $500 \mathrm{kHz}$. Measurements were done at the right and left side of the body. Mean values of resistances were used for analysis of the data. From all 48 measured resistance and reactance values the resistance of the extracellular (Recw) and intracellular (Ricw) fluid were extrapolated using the Xitron curve-fit software. All fits were classified as 'good' or 'excellent'. Recw and Ricw were used in Xitron equations based on Hanai mixture theory for calculating body fluid compartments ${ }^{6,13}$. The resistance at infinite frequency (Rinf) was calculated as:

Rinf $=($ Ricw $\cdot$ Recw $) /($ Ricw + Recw $)$.

The curve-fit software also provides values for the critical frequency ( $\mathrm{Fc}$ ) and the membrane capacitance $(\mathrm{Cm})$. Fc is the frequency at which the reactive component of the impedance reaches maximum values. $\mathrm{Cm}$ is a measure of the ability of membranes to store electrical charge. $\mathrm{Cm}$ of the whole body is determined by total cell surface area and membrane thickness and porosity. Furthermore, $\mathrm{Cm}$ is also affected by the aspect ratio (length to cross-sectional area) of the body's conductor. To study the effect of depletion on membrane properties we calculated the $\mathrm{Cm}$ index which removes the effect of the aspect ratio (by inclusion of length ${ }^{2}$ ) and of the total cell surface area (by inclusion of fat free mass measured by deuterium dilution):

$\mathrm{Cm}$ index $=\left(\right.$ length $\left.{ }^{2} \cdot \mathrm{Cm}\right) / \mathrm{FFMdil}$

\section{Calculations}

\section{Ideal body weight and ideal FFM}

Patients' wrist circumference was used to calculate frame size. Based on body length and frame size the ideal body weight was calculated according to tables published by the Metropolitan Life Insurance Company ${ }^{14}$. From the ideal body weight ideal FFM was calculated in $\mathrm{kg}$, using as reference values $80 \%$ of ideal body weight in men and $70 \%$ in women. If the FFM of patients, measured by the dilution method, was smaller than $90 \%$ of their ideal FFM they were classified as depleted.

\section{Weight loss categories}

Based on their usual weight and reported weight loss preceding the study, patients were divided into three categories. Patients with weight loss equal to or larger than $5 \%$ during 1 month or $10 \%$ during 6 months were classified as 'severe weight loss'. Patients with no weight loss were classified as 'no weight loss' and all others as "moderate weight loss'.

\section{Screening methods}

Three different screening methods were compared:

1. Screening based on BIS with mixture equations

Patients were classified as depleted by BIS if the FFMbis was smaller than $90 \%$ of the ideal FFM. 


\section{Screening based on BIA vector method}

The resistance $(R)$ and reactance $(X c)$ values of patients measured at $50 \mathrm{kHz}$ were recorded and normalized for height $(H)$. The gender specific bivariate normal distribution of $R / H$ and $X c / H$ published by De Palo ${ }^{13}$ and by Piccoli ${ }^{16}$ were used to assess the presence of depletion. For interpretation of the patient's vectors normalized for height, the graphical method was used. The sex-specific nomogram was divided into four sectors (fig. 5). Patients with vectors in the upper or lower right $95 \%$ tolerance ellipse, or outside the nomogram at the right side, were classified as depleted according to the instructions in the manual of the soft tissue analyzer of Akern Bioresearch.

\section{Screening based on resistivity index}

The resistivety index (RI) at different frequencies was calculated as Length ${ }^{2} / R$, in which $R$ represents the resistance measured at $50 \mathrm{kHz}(\mathrm{R} 50)$, or the resistance of ICW (RicW) or the resistance at infinite frequency (Rinf). To study the applicability of the RI as a screening tool for nutritional depletion, its' value in relation to the ideal FFM was assessed by the ratio RI/ideal FFM in both the depleted and non-depleted patients. The mean value and $95 \%$ confidence limits (mean $\pm 2 \mathrm{SE}$ ) of this ratio were calculated in both groups. If the confidence intervals did not overlap the mean distance between the upper limit in the depleted group and the lower limit of the non-depleted group was set as the threshold value. Screening was performed by comparing the value of Rl/ideal FFM of the patients with the threshold value. Patients were classified as non-depleted or depleted if this value was respectively higher or lower than the threshold value.

\section{Data analysis}

Fluid volumes measured by BIS were compared with values measured with the dilution methods by Bland Altman analysis ${ }^{17}$. The correlations between methods for TBW and ECW were calculated and a plot of the difference between methods and their mean value was made. A paired student T-test was used to calculate if the difference between methods was significant. To study if BIS prediction errors (dilution - BIS) were associated with the physical characteristics of subjects, the Pearson's correlation coefficients $r$ between the prediction error and age, length, weight, body mass index (BMI), ratio ECW/TBW, body fluid volumes and FFM measured by dilution methods were calculated.

The effect of weight loss on body composition. BIS variables and BIS prediction errors was tested by ANOVA. Differences between weight loss categories were tested by independent samples Student T-tests. To study the effect of depletion on these variables, differences between the depleted and not depleted group were tested by independent samples Student ttests.

To compare the ability of the different screening methods to identify patients with nutritional depletion, the sensitivity (percentage of depleted patients classified as depleted) and specificity (percentage of not depleted patients classified as not depleted) of the different approaches were calculated with the dilution method as the gold standard. For all tests $P$ values less than 0.05 were considered as significant.

\section{Results}

Subject characteristics are presented in table 1. The mean body weight was $2.5 \mathrm{~kg}$ above the ideal body weight and the mean BMI was $23.6 \mathrm{~kg} / \mathrm{m}^{2}$. Most of the patients $(47 \%) \mathrm{had}$ experienced severe weight loss. Only $28 \%$ had no weight loss and $24 \%$ had moderate weight loss. Classification based on the amount of FFM in relation to the ideal FFM resulted in $20 \%$ being classified as depleted and $80 \%$ as not depleted. 
For TBW and ECW the correlations between BIS and the dilution methods were comparable and significant, 0.861 and 0.865 respectively (fig.1). Bland Altman analysis revealed that BIS significantly underestimated TBW by $3.08 \mathrm{~L}$ while ECW was slightly but significantly overestimated by $0.64 \mathrm{~L}$ (fig. 2). BIS underestimated ICW by $3.72 \mathrm{~L}$. The $95 \%$ limits of agreement for TBW were very wide $[-4.4 ; 11.00]$ compared with those of ECW $[-4.76 ; 3.48]$

TBW (L)

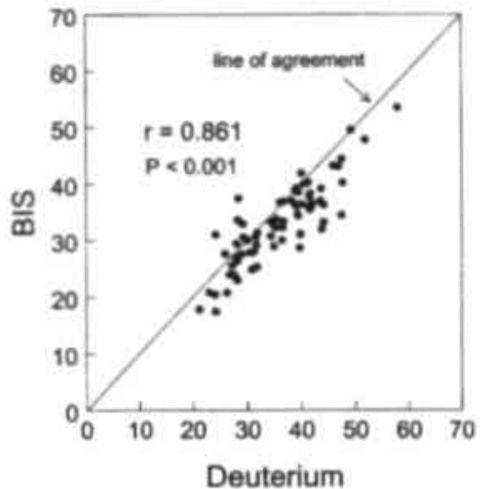

ECW (L)

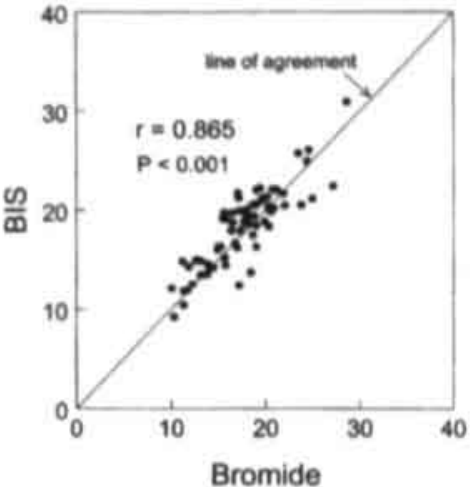

Figure 1. Correlations between BIS and the dilution method for total body water (TBW) and extracellular water (ECW).

TBW (L)

difference against mean of methods

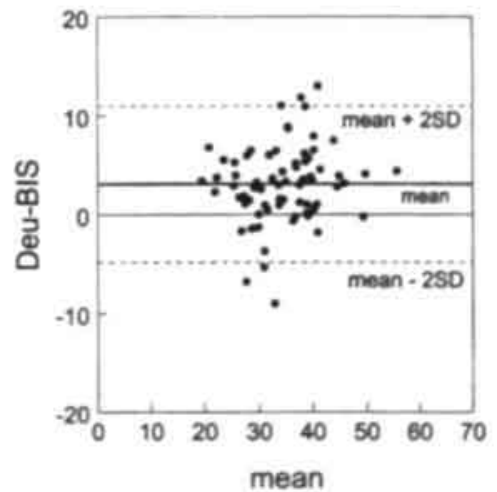

ECW (L)

difference against mean of methods

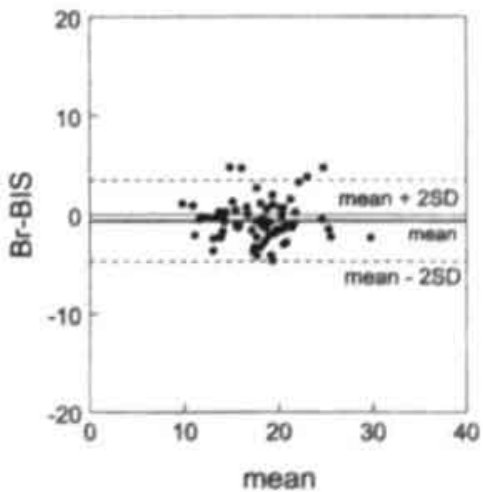

Figure 2. BIS prediction errors for TBW (TBWdil-TBWbis) against mean TBW values of BIS and dilution method and ECW prediction errors (ECWdil-ECWbis) against mean ECW values of BIS and dilution method 
Table 1. Subject characteristics. BIS variables and predlalon errors of EIS for the totai population and for two kinds of subgroups. Subdivision was either besed on the degree of whight loss (no, moderale or severe loss) or on the absence or presence of clinical depletion. Values are presented as mean (SO).

\begin{tabular}{|c|c|c|c|c|c|c|}
\hline & \multirow[b]{2}{*}{ All patients } & \multicolumn{3}{|c|}{ Weight loss categories } & \multicolumn{2}{|c|}{ Clinical depletion } \\
\hline & & no loss & moderate & severe & no & yos \\
\hline Number (M/F) & $70(41 / 29)$ & $20(12 / 8)$ & $17(10 / 7)$ & $33(19 / 44)$ & $56(33 / 23)$ & $14(8 / 6)$ \\
\hline Age (Years) & $02.3(12.2)$ & $622(10.3)$ & $623(76)$ & $62.3(152)$ & $61.4(121)$ & $66.1(12.5)$ \\
\hline Welght (kg) & $67.81(13.33)$ & $73.18(11.29)$ & $73.42(1359)$ & $3180(11.89)^{\circ-0}$ & $70.25(1212)$ & $58.03(13.90)^{4}$ \\
\hline Ideal woight (kg) & $6528(6.97)$ & $6547(3.57)^{\circ}$ & ES $8.2(7.18)$ & $6438(7.97)$ & $65.84(706)$ & $6305(0.42)$ \\
\hline Longth $(\mathrm{cm})$ & $169.4(10.5)$ & $168.5(8.6)$ & $170.5(108)$ & $1693(10.5)$ & $170.3(10.5)$ & $165.7(10.1)$ \\
\hline BMI (kolm2) & $23.6(39)$ & $25.7(3.3)$ & $252(3.5)$ & $21.5(3.5)^{n+1}$ & $242(36)$ & $210(44)^{n}$ \\
\hline Hemetocrit & $0.30(0.08)$ & $0.37(0.06)$ & $0.36(0.06)$ & $0.36(0.07)$ & $0.37(0.06)$ & $0.33(0.08)^{4}$ \\
\hline Homoglobin (g/dl) & $7.59(1.43)$ & $7.8(1.3)$ & $74(1.4)$ & $75(15)$ & $78(0.06)$ & $68(1.7)^{a}$ \\
\hline TEWdil (L) & $3607(7.72)$ & $3678(6.51)$ & $3746(8.62)$ & $34.92(7.98)$ & $38.01(7.14)$ & $28.30(4.40)^{n A}$ \\
\hline ECWdil (L) & $17.51(3.96)$ & $18.24(342)$ & $18.19(4.16)$ & $1672(414)$ & $18.22(3.94)$ & $1469(3.66)^{\wedge A}$ \\
\hline ICWdil (L) & $1856(4.87)$ & $18.53(4.40)$ & $1827(5.42)$ & $1820(487)$ & $19.79(4.51)$ & $1361(2.71)^{\mathrm{ma}}$ \\
\hline ECW/TBWdII & $0.49(0.06)$ & $0.49(0.06)$ & $0.49(0.06)$ & $048(0.06)$ & $048(006)$ & $0.52(0.06)^{4}$ \\
\hline Recw (onm) & $657(108)$ & $641(100)$ & $630(87)$ & $681(119)$ & $638(96)$ & $735(113)^{\wedge A}$ \\
\hline Ricw (ohm) & $1324(317)$ & $128 \div(265)$ & $1347(232)$ & $1468(365)^{\circ}$ & $1346(274)$ & $1536(429)$ \\
\hline $\mathrm{Cm}(\mathrm{nF})$ & $125(060)$ & $154(0.69)$ & $1.37(0.53)$ & $1.01(0.5)^{20}$ & $137(0.60)$ & $0.78(0.37)^{\mathrm{MA}}$ \\
\hline $\mathrm{Cm}$ Index $\left(\mathrm{cm}^{2} \mathrm{nF} \mathrm{kg}^{-1}\right)$ & $718(294)$ & $859(323)$ & $774(241)$ & 603 (260) & $756(284)$ & $563(294)^{\lambda}$ \\
\hline Fc (kHz) & $112(70)$ & $90(34)$ & $95(42)$ & $135(89)^{\circ}$ & $101(63)$ & $159(81)^{n}$ \\
\hline TBWbls (L) & $32.98(7.11)$ & $34.89(8.74)$ & $3463(7.64)$ & $30.99(8.72)^{\circ}$ & $3415(6.89)$ & $28.34(6.20)^{A .4}$ \\
\hline ECWbls (L) & $18.15(396)$ & 1888 (3 57) & 19 i8 $(442)$ & $18.18\{3.81\}$ & $18.84(3.78)$ & $15.40(3.54)^{\wedge .4}$ \\
\hline ICWbis (L) & $1484(366)$ & $1601(3.62)$ & $1544(3.73)$ & $13.81(3.50)^{\circ}$ & $15.31(361)$ & $1204(3.44)^{\wedge}$ \\
\hline ECW/TBWbis & $0.55(004)$ & $054(0.03)$ & $0.55(0.04)$ & $0.55(0.05)$ & $0.55(0.04)$ & $0.55(0.06)$ \\
\hline \multicolumn{7}{|l|}{ Erron Bls: } \\
\hline TEWdil-TEWbls & $3.08(398)^{\square}$ & $189(364)$ & $283(3.84)$ & $393(410)$ & $388(3.46)$ & $-0.04(4.40)^{4 A}$ \\
\hline ECWdilECWbls & $-084(206)^{2}$ & $-0.63(2.25)$ & $-0.99(1.79)$ & $.0 .46(209)$ & $.0 .62(2.70)$ & $-071(1.38)$ \\
\hline ICWdIItCWbls & $372(422)^{10}$ & $252(384)$ & $382(442)$ & $439(431)$ & $448(3.89)$ & $0.67(4.25)^{\wedge}$ \\
\hline
\end{tabular}

Differences between the dilution method (dil) and BIS were tested by paired-Samples Student T-test : $z(P<0,05), z Z$ ( $P<0$ 01)

Differences in variables between categories were tested by independent-Samples Student T-test Significantly different from group with no weight loss. - $(P<0.05)$ $(P<0.01)$ Significantly different irom group with moderate weight loss. " $(P<0,05)$ E $(P<0,01)$. No significant differences were found becween the groups with moderate weight loss and no weight loss. Significantly different from group with no depletion. $N(P<O, 05)$, M $(P<0,01)$. 
While age, length, weight and BMI were not associated with the BIS prediction errors, the size of the fluid compartments measured by the dilution methods did (table 2). Both TBWdil and ICWdil correlated significantly with the TBW and ICW prediction errors of BIS. The same applied to ECWdil and ECW measured by BIS although this correlation was less significant. Between the ECW and TBW prediction errors no correlation was found. The \%FFM, calculated from TBWdil and body weight, strongly correlated with BIS prediction errors of TBW and ICW. but not with ECW prediction errors.

A strong correlation between the relative size of the fluid compartments, expressed as the ratio ECW/TBW, and the prediction errors was found. TBW and ICW errors were negatively correlated with this ratio and ECW errors positively (fig 3 ). While during normal hydration BIS underestimates TBW, this changes in overestimation up till $10 \mathrm{~L}$ during overhydration. The opposite was found for ECW prediction errors, a small overestimation during normal hydration and an underestimation up till $4.5 \mathrm{~L}$ during overhydration.

The ratio ECWdil/TBWdil did not correlate with ECWbis/TBWbis.

Table 2. Correlation coefficients between the BIS prediction errors of total body water (TBW), extracellular water (ECW) and intracellular water (ICW) and subject characteristics $(\mathrm{N}=70)$.

\begin{tabular}{llll}
\hline & TBWdil-TBWbis & ECWdil-ECWbis & ICWdil-ICWbis \\
\hline Age (year) & -0.039 & 0.02 & -0.047 \\
Length $(\mathrm{cm})$ & 0.124 & -0.101 & 0.165 \\
Weight $(\mathrm{kg})$ & -0.088 & -0.160 & -0.005 \\
BMI $(\mathrm{kg} / \mathrm{m} 2)$ & -0.197 & -0.114 & -0.129 \\
ECW/TBWdil & $-0.473^{* *}$ & $0.633^{* *}$ & $-0.751^{* *}$ \\
TBWdil (L) & $0.404^{* *}$ & -0.098 & $0.426^{* *}$ \\
ECWdil (L) & 0.128 & $0.263^{*}$ & -0.008 \\
ICWdil (L) & $0.536^{* *}$ & $-0.370^{* *}$ & $0.682^{* *}$ \\
\%FFM & $0.695^{* *}$ & 0.061 & $0.621^{* *}$ \\
\hline
\end{tabular}

TBWdil is TBW measured by deuterium dilution, ECWdil is ECW measured by bromide dilution, ICWdil is intracellular water calculated from TBWdil and ECWdil. TBWbis, ECWbis and ICWbis are fluid volumes measured by BIS.

Significant correlation: * (P<0.01), * $(P<0.05)$

The effect of weight loss

Patients with severe weight loss had lower body weight and BMI than patients with no weight loss, but no significant differences in the size of the fluid compartments measured with the dilution methods were found (table 1). BIS however measured significantly lower TBW and ICW in the group with severe weight loss compared with the no weight loss group. Other BIS variables were also different between the groups. Compared with the group without weight loss, the $\mathrm{Fc}$ was $45 \mathrm{kHz}$ higher and the $\mathrm{Cm} 0.53 \mathrm{nF}$ lower (table 1). In the group with severe weight loss the $\mathrm{Cm}$ index was significantly lower than in the groups with moderate or no weight loss. The BIS prediction errors were not affected by weight loss.

The effect of depletion

Of the 70 patients 14 were classified as depleted based on their FFM in relation to their ideal FFM. This group had significant lower body weight, BMI, TBW, ECW and ICW, and had a 
higher ECW/TBW ratio as measured by the dilution methods (table 1). Blood hemoglobin levels and hematocrit were lower in depleted patients. BIS also measured significantly lower TBW, ECW and ICW in this group compared with the not depleted patients. The FC was $60 \mathrm{kHz}$ higher in the depleted patients, and the $\mathrm{Cm}$ was $0,59 \mathrm{nF}$ lower. The $\mathrm{Cm}$ index also showed a significant decrease in the depleted group. The BIS prediction errors were different in the two groups. Compared with the patients without depletion in which BIS underestimated TBW and ICW and overestimated ECW, in the depleted patients BIS prediction errors were significantly smaller for TBW and ICW.

TBW prediction error (L) against ECW/TBW

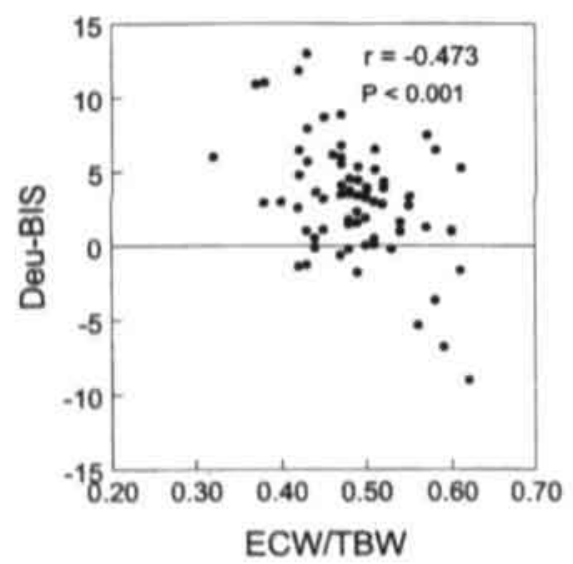

ECW prediction error (L) against ECW/TBW

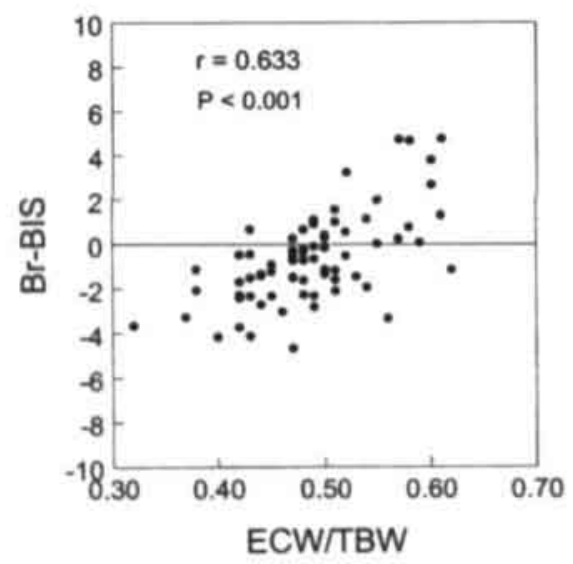

Figure 3. Correlation between the BIS prediction error of fluid compartments (TBW and ECW) and the ratio ECW/TBW.

\section{Comparison of screening methods}

Individual values of the ratio RI/(ideal FFM) for $\mathrm{R}_{\text {so. }}$ Ricw and Rinf in the depleted and nondepleted group are shown in fig.4. The confidence intervals for the ratio of Ricw of the two groups overiapped, and therefore the ratio ( $\mathrm{L}^{2} /$ Ricw)/ideal FFM was not used for further analysis. The ratios at $50 \mathrm{kHz}$ and at infinite frequency were significantly lower in the depleted than in the non-depleted group and threshold values were 1.02 and 1.29 respectively (fig 4). Application of these values for screening of the total population resulted in sensitivity values comparable with results obtained from screening based on FFM values measured by BIS with use of mixture equations (table 3 ). The specificity found for screening based on $R_{50}$ values was higher than for BIS or for screening based on Rinf.

According to the impedance vector approach only 7 patients were classified as depleted, 5 correctly and two incorrectly (fig 5). The sensitivity was low $(36 \%)$ but the specificity was very high $(96 \%)$ due to the fact that only 2 of the 56 not depleted patients were wrongly classified as depleted by this method (table 3 ). 
Resistance index at infinite frequenoy ideal FFM

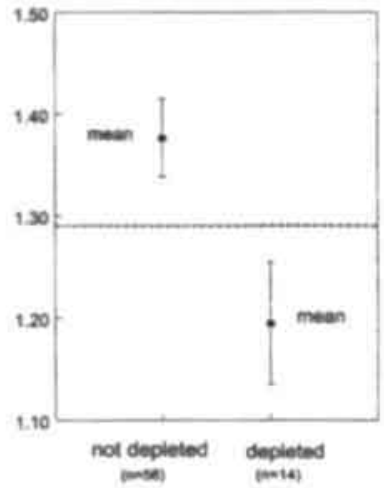

Resistance index at $50 \mathrm{kHz}$ ideal FFM

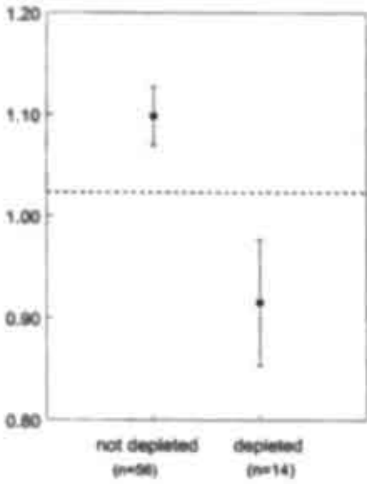

Resistance index of Ricw deal FFM

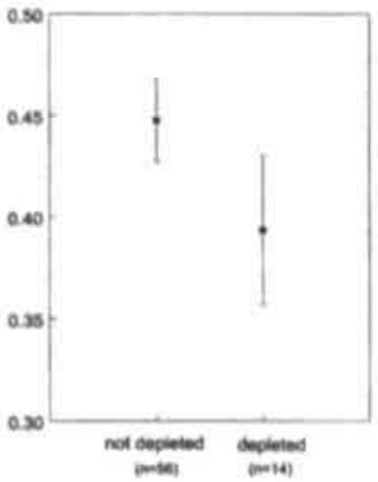

Figure 4. Mean and $95 \%$ confidence limits for the ratio: resistance index $\left(L^{2} / R\right.$ ) / ideal $F F M$ at different frequencies in depleted and not-depleted patients. The dotted lines indicate the values used as threshold values for screening of depletion based on this ratio.
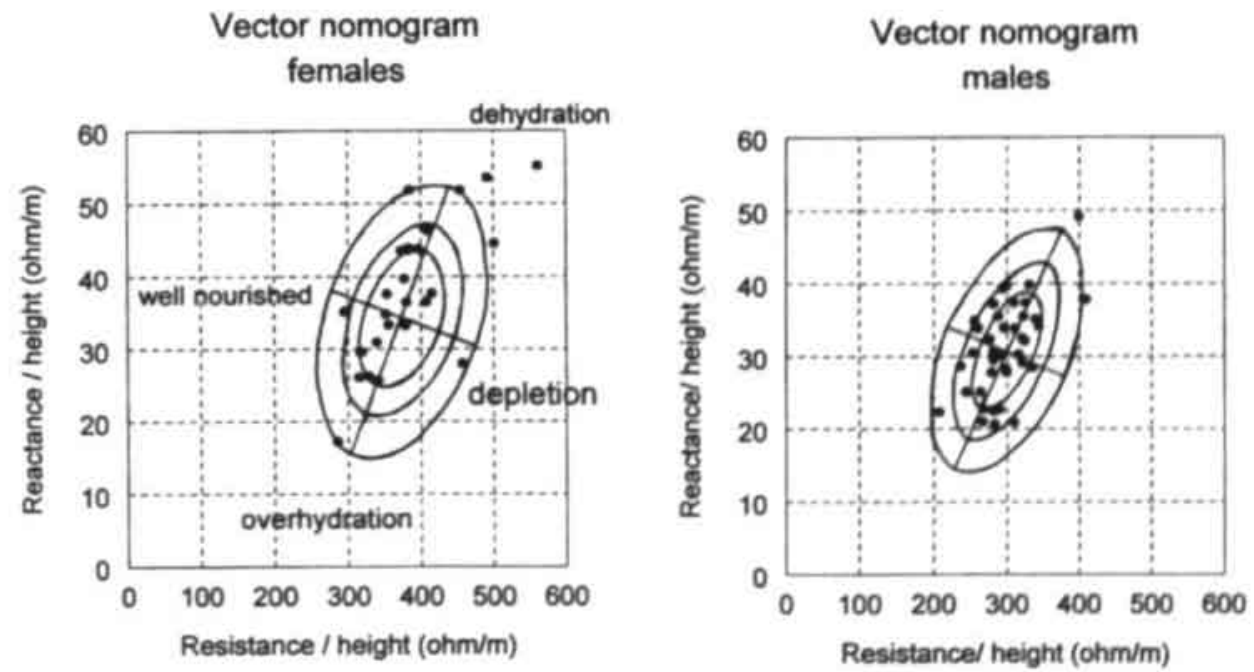

Figure 5. The impedance vector of patients plotted on the gender specific nomograms published by Piccolit 


\section{Discussion}

For the assessment and management of clinical depletion valid method to measure body composition are needed. We tested the validity of BIS with the use of mixture equations, for measuring body composition in patients with gastrointestinal disease, employing dilution methods as gold standard. For screening purposes, when quantification of measures is not necessary, other approaches based on measured resistance values without the use of complicated prediction equations may be of value. We tested the applicability of the impedance vector method for identifying depleted patients and compared this method with screening based on the resistance index at different frequencies normalized for the ideal FFM of the patient.

Table 3.Frequency tables for the assessment of the specificity and the sensitivity of BIS, the impedance vector nomograms and the ratio of the resistance index (RI)/ideal FFM at $50 \mathrm{kHz}$ and at infinite frequency for diagnosing clinical depletion with the ideal FFM calculated from the Deuterium dilution method as the criterium method*.

\begin{tabular}{l|l|l|l} 
& $\begin{array}{l}\text { Dilution } \\
\text { Depleted }\end{array}$ & $\begin{array}{l}\text { Dilution } \\
\text { Not depleted }\end{array}$ & Total \\
\hline $\begin{array}{l}\text { Bis } \\
\text { Depieted }\end{array}$ & 12 & 17 & 29 \\
\hline $\begin{array}{l}\text { Bis } \\
\text { Not depleted }\end{array}$ & 2 & 39 & 41 \\
\hline Total & 14 & 56 & 70
\end{tabular}

\begin{tabular}{l|l|l|l} 
& $\begin{array}{l}\text { Dilution } \\
\text { Depleted }\end{array}$ & $\begin{array}{l}\text { Ditution } \\
\text { Not depleted }\end{array}$ & Total \\
\hline $\begin{array}{l}\text { Imp. vector } \\
\text { Depleted }\end{array}$ & 5 & 2 & 7 \\
\hline $\begin{array}{l}\text { Imp. vector } \\
\text { Not depleted }\end{array}$ & 9 & 54 & 63 \\
\hline Total & 14 & 56 & 70
\end{tabular}

\begin{tabular}{l|l|l|l} 
& $\begin{array}{l}\text { Dilution } \\
\text { Depleted }\end{array}$ & $\begin{array}{l}\text { Dilution } \\
\text { Not depleted }\end{array}$ & Total \\
\hline $\begin{array}{l}\text { Riso / IFFM } \\
\text { Depleted }\end{array}$ & 12 & 11 & 23 \\
\hline $\begin{array}{l}\text { Riso / iFFM } \\
\text { Not depleted }\end{array}$ & 2 & 45 & 47 \\
\hline Total & 14 & 56 & 70
\end{tabular}

\begin{tabular}{l|l|l|l} 
& $\begin{array}{l}\text { Dilution } \\
\text { Depleted }\end{array}$ & $\begin{array}{l}\text { Dilution } \\
\text { Not depleted }\end{array}$ & Total \\
\hline $\begin{array}{l}\text { Rlint / iFFM } \\
\text { Depleted }\end{array}$ & 12 & 15 & 27 \\
\hline $\begin{array}{l}\text { Rtint / iFFM } \\
\text { Not depleted }\end{array}$ & 2 & 41 & 43 \\
\hline Total & 14 & 56 & 70
\end{tabular}

-Patients were classified as depleted according to the dilution method when their FFM, caiculated from TBWdil, was less than $90 \%$ of their ideal FFM. According to BIS they were classified as depleted when FFMbis < 90 ideal FFM. Riso : Resistance index at $50 \mathrm{kHz}\left(\mathrm{L}^{2} / \mathrm{Rso}\right)$; Rlint: Resistance index at infinite frequency $\left(\mathrm{L}^{2} / \mathrm{Rinf}\right) ;$ ifFM: ideal fat free mass. 
Results of the present study show that BIS employing mixture equations underestimated TBW and ICW, and only slightly overestimated ECW in patients with gastrointestinal disease. Although the errors in TBWbis were not associated with the degree of weight loss, they were smaller in depleted patients than in non-depleted patients. For ECW this effect was not found. Overall ECW predictions were accurate with acceptable standard errors of estimation (SEE) of $2 \mathrm{~L}$, comparable with results described by others ${ }^{6.1020}$ while SEE for TBW were $4 \mathrm{~L}$ Other studies confirm our finding that in patients BIS predicts ECW better than TBW. In severely ill patients impedance values at low frequencies provided reasonable measurements of $\mathrm{ECW}^{21,22}$ and in critically ill children changes in Recw were in agreement with changes in hydration but changes in other BIS variables (Ricw and $\mathrm{Cm}$ ) were not consistent and unstable ${ }^{2.24 .25}$ Our finding that TBW and ICW are largely underestimated in the non-depleted patients, but not in the depleted patients limits the clinical applicability of BIS. It can be argued that in the patients classified as depleted the severity of illness is higher than in non-depleted patients and that not depletion, but severity of illness is responsible for these findings. While a systematic over- or underestimation can be corrected by adjusting the 'constants' used in the mixture equations which act as scalars, selective bias is difficult to correct. Furthermore, such a correction seems only justified if the underlying physical causes are understood. For a systematic underestimation the expected Ricw in the depleted group should be higher than the actual measured Ricw

The degree of weight loss is often used as an indicator for the presence of depletion. Due to the catabolic effects of disease, a substantial loss of body mass during illness may be indicative for the loss of body cell mass. In the present study however, the patients with severe weight loss had substantial lower body weight, but not a significantly decreased TBW compared with patients without weight loss, indicating that the weight loss was mainly caused by fat losses. The classification of patients in depleted or non-depleted was based on the amount of FFM measured by Deu-dilution in relation to the ideal FFM of the patient. The two approaches obviously led to different classifications. In fact, of the patients with no weight loss 30 percent were classified as depleted, of those with moderate weight loss $53 \%$ and of patients with severe losses $54 \%$. The weight loss was calculated from the usual body weight as reported by the patient, which may be subject to considerable error, due to uncertainty of the patient regarding usual body weight and improper calibration of scales. Furthermore, weight loss may be masked by fluid accumulation. Therefore, weight loss alone is not a valid indicator for the presence of depletion in patients with gastrointestinal disease.

Depletion can be defined as a loss of body cell mass (BCM), the metabolically active part of the body, leading to impairment of physiological function. In this study we defined depletion as a condition in which patients have less than $90 \%$ of their ideal FFM. We are aware that this is not the most optimal approach, but within the frame of practical alternatives it is most likely the most reasonable one. BCM cannot be measured directly, ICW can be used as a measure of $B C M$, but it has to be calculated as the difference between TBW and ECW. Due to error propagation, ICW calculations are by definition less accurate than TBW or ECW measurements. Furthermore, no normal values for ICW specified for frame size are available at the moment. FFM is strongly related to BCM in cases of normal hydration and distribution of fluid between the intra- and the extracellular compartment. Patients measured in the present study did not exhibit clear physical signs of fluid imbaiance although there was a small but significant increase in the ECW/TBW ratio in depleted patients. This means that the FFM calculated from TBWdil contains relatively more ECW than in the non depleted patients. Consequently the BCM of these patients may be more depleted that values of FFM indicate. 
The finding that both ECW and TBW prediction errors of BIS are correlated with the absolute as well as with the relative size (expressed as ECW/TBW) of the fluid compartments has already been described in patients with altered fluid distribution ${ }^{26}$. Although in the present study depleted patients had only a slightly increased ECW/TBW ratio as measured by the dilution methods, especially in acute diseases clinical depletion is associated with ECW expansion in combination with ICW losses ${ }^{22.27}$. Because both ECW and TBW prediction errors of BIS are correlated with the true ECW/TBW ratio, but in opposite directions, BIS will be unable to detect an increase in this ratio. This finding seriously limits the clinical use of BIS.

Dehydration as well as overhydration may affect conductive properties of ECW as well as ICW, resulting in changes of the specific resistivity $(\rho)$ of these fluid compartments ${ }^{26.29}$. Changes in the composition of body fluids without changes in their volume may also affect $\rho$. In the Hanai based mixture equations these values are set as constants based on measurements in healthy humans ${ }^{6}$. For the clinical application of BIS additional information regarding electrical properties, electrolyte concentrations and osmolarity, appear to be necessary in order to adjust the used 'constants'.

The finding that TBW was less accurately measured by BIS than ECW, and the fact that TBW and ICW values, in contrast to ECW, were influenced by the presence of depletion indicate that factors related to measurements at high frequencies (used for measurement of TBW and ICW) are partly responsible for measurement errors. In several patients groups depression of the phase angle at $50 \mathrm{kHz}$ has been described ${ }^{30.31 .32}$. It has been hypothesized that alterations in the electrical properties of membranes are responsible. Impairment of membrane potential during iliness may cause a decrease in membrane capacitance $(\mathrm{Cm})$. In critically ill children, the reactance component of the impedance measured at different frequencies was significantly decreased $^{33}$. In our study the $\mathrm{Cm}$ calculated by the Xitron curve fitting software was on average lower than values measured in healthy individuals, 1,25 compared with $2,18 \mathrm{nF}$, and Fc values were higher, $112 \mathrm{kHz}$ compared with $60 \mathrm{kHz}^{6}$. Furthermore, $\mathrm{Cm}$ was decreased in depleted patients compared with non-depleted patients and in patients with severe weight loss compared with those without weight loss. In the same groups the critical frequency (Fc) was increased by $60 \%$. Because $\mathrm{Cm}$ is also a function of total cell surface area which is decreased in depleted patients due to loss of body cell mass, we calculated the $\mathrm{Cm}$ index. According to de Lorenzo et al this index is a measure of cell porosity and thickness ${ }^{6}$. Our results show that the $\mathrm{Cm}$ index is decreased in patients with severe weight loss and in depleted patients. At present it is not clear how the values of these parameters should physiologically be interpreted but they are indicative for changes at the level of the membranes of cells during illness. These changes have no effects on the resistances measured at low frequencies, but especially at frequencies above Fc, the resistances measured appear to be affected. It is likely that such changes are important in explaining the TBW and ICW prediction errors of BIS. Studying alterations in electrical properties of cells during illness is necessary for a complete evaluation of the clinical applicability of BIS.

\section{Screening methods}

It was impossible to accurately identify depleted patients with the vector method as described by Piccoli. Promising results with this method have been described for screening of fluid overioad or dehydration ${ }^{\mathrm{i} .34}$. The low sensitivity of the method in our study may be caused by the fact that only height was used to normalize the measured $R$ at $50 \mathrm{kHz}$. The use of the resistance index at $50 \mathrm{kHz}\left(\mathrm{L}^{2} / \mathrm{R}\right)$ divided by the ideal $\mathrm{FFM}$ appeared to be a screening instrument with high sensitivity and specificity. By assessing the ideal FFM, based on ideal body weight, the method is refined. The advantage of this screening method is that no population specific prediction equations or complicated mixture equations are needed. This simple procedure was superior compared with screening based on FFM values calculated from BIS and with the use of the same index calculated from $R$ at infinite frequency. Problems related to measurements in the high frequency range, as discussed above, may be responsible for the 
fact that $R 50$ values gave better results than $R$ at infinite frequency or the mixture derived FFM values. It can be argued that a frequency of $50 \mathrm{kHz}$ is too low for full penetration of the current through cells. Indeed, especially in depleted patients were the $\mathrm{Fc}$ was $159 \mathrm{kHz}$ this will be true. In fact, at this frequency probably only ECW plays part in current conduction. Due to the strong interrelationship between fluid compartments and the absence of severe fluid imbalance this ECW measure is strongly related to the amount of FFM and explains the good results.

In conclusion, BIS with use of mixture equations is able to measure accurately ECW in patients with gastrointestinal disease, but the accuracy of ICW and TBW measurements is lower and influenced by the presence of nutritional depletion. Alterations in the electric properties of the body due to changes at the cellular level may play a role. A better understanding of the underlying physical phenomena seems necessary, before widespread clinical use can be advocated.

The impedance vector approach is not sensitive enough for screening patients for clinical depletion. Screening based on the resistance index at $50 \mathrm{kHz}$ or based on $\mathrm{R}$ at infinite frequency in relation to ideal FFM has a high sensitivity and specificity and may be of value for clinical use in patients with normal distribution of fluid between the extracellular and intracellular space.

\section{References}

1. Berry JK, Braunschweig CA. Nutritional assessment of the critical ill patient. Crit Care Nurs Q 1998 21:22-46.

2. Simons JP. Schols AM, Westerterp KR, ten Velde GP, Wouters EF. The use of bioelectrical impedance analysis to predict total body water in patients with cancer cachexia. Am J Clin Nutr 1995 61:741-745.

3. Haderslev KV, Staun M. Comparison of dual-energy-X-ray absorptiometry to four other methods to determine body composition in underweight patients with gastrointestinal disease. Metabolism 2000 49:360-366.

4. Royall D , Greenberg GR, Allard JP. Baker JP, Harrison JE, Jeejeebhoy KN. Critical assessment of body-composition measurements in malnourished subjects with Crohn's disease: the role of bioelectric impedance analysis. Am J Clin Nutr 1994:59:325-330.

5. Ellis KJ, Bell SJ, Chertow GM, Chumiea WC, Knox TA, Kotier DP, Lukaski HC, Schoeller DA. Bioelectrical impedance methods in clinical research: a follow-up to the NIH technology assessment conference. Nutrition 1999;15:874-880.

6. Lorenzo de A, Andreoli A, Matthie J, Withers P. Predicting body cell mass with bioimpedance by using theoretical methods: a technological review. J Appl Physiol 1997 (82):1542-1558.

7. Piccoli A, Pillon L, Dumier F. Impedance vector distribution by sex, race, body mass index, and age in the United States : standard reference intervals as bivariate $Z$ scores. Nutrition 2002;18:153-167.

8. Piccoli A, Brunani A, Savia G, Pillon L, Favaro E, Berselli ME, Cavagnini F. Discriminating between body fat and fluid changes in the obese adult using bioimpedance vector analysis. Int J Obes 1998 22:97-104.

9. Piccoli A. Identification of operational clues to dry weight prescription in hemodialysis using bioimpedance vector analysis. Kidney Int 1998;53:1036-1043.

10. Kreel van BK, Van der Vegt F, Meers M, Wagenmakers T, Westerterp K, Coward A. Determination of total body water by a simple and rapid mass spectrometric method. J mass Spectr 1996;31:108-111.

11. Wong WW. Sheng HP, Morkeberg JC, Kosanovich JL, Clarke LLKlein PD. Measurement of extracellular water volume by bromide ion chromatograghy. Am J Clin Nutr 1989;50:1290-1294.

12. Lukaski HC, Johnson PE, Bolonchuk WW. Lykken GI. Assessment of fat free mass using bioelectrical impedance measurement of human body. Am J Clin Nutr 1985;41:810-817.

13. Hanai T. Electric properties of emulsions. In: Sherman PH (ed). Emulsion science. Academic:London, 1968, pp 354-477.

14. 1983 Metropolitan height and weight tables. Stat Bull Metrop Life Found 1983; 64:3-9.

15. De Pola T, Messina G. Edefonti A, Perfumo F, Pisanello L, Di lorio B, Mignozzi M, Vienna A, Conti G. Penza R, Piccoli A. Normal values of the bioelectrical impedance vector in childhood and puberty. Nutrition 2000;16:417-424. 
16. Piccoli A, Nigrelli S, Caberlotto A, Bottazzo S, Rossi B, Pillon L, Maggiore Q. Bivariate normal values of the bioelectrical impedance vector in adult and elderly populations. Am J Clin Nutr 1995;61:269270.

17. Bland JM, Altman DG. Statistical methods for assessing agreement between two methods of clinical measurements. Lancet 1986; 1:307-310.

18. Plank LD, Monk DN, Woollard GA, Hill GL. Evaluation of multifrequency bioimpedance spectroscopy for measurement of the extracellular space in critically ill patients. Appl Radiat Isot 1998; 49:481-483.

19. Patel RV, Matthie JR, Withers PO, Peterson EL, Zarowitz BJ. Estimation of total and extracellular water using single- and multiple-frequency bioimpedance. Ann Pharmacother 1994;28:565-569.

20. Baarends EM, Van Marken Lichtenbelt WC, Wouter EFM, Schols AMWJ. Body-water compartments measured by bioelectrical impedance spectroscopy in patients with chronic obstructive pulmonary disease. Eur J Clin Nutr 1998; 17:15-22.

21. Marx G, Vangerow B, Burczyk C, Gratz KF, Maassen N, Cobas Meyer M, Leuwer M, Kuse E, Rueckholdt $H$. Evaluation of non-invasive determinants for capillary leakage syndrome in septic shock patients. Intensive Care Med 2000;26:1252-1258.

22. Finn PJ, Plank LD, Clark MA, Connolly AB, Hill G. Progressive dehydration and proteolysis in critically ill patients. Lancet 1996; 437:654-656.

23. Meyer A, Mazariegos M, Solomons NW, Furst P. The use of bioimpedance spectroscopy to monitor water changes induced by dehydration in young children with abnormal water distribution associated with diarrheal disease. Appl Radiat Isot 1998; 49:607-610.

24. Pithan C, Mazariegos M. Solomons NW, Furst P. Monitoring of fluid changes in hospitalized, malnourished, Guatemalian children using bioelectrical impedance spectroscopy (BIS) Appl Radiat Isot 1998 49:615-617.

25. Mazariegos M, Pithan C, Meyer A, Mendoza I, Furst P, Solomons NW. Bioelectrical impedance spectroscopy (BIS) in young children with acute and semi-acute hydration disorder: problems and limitations. Appl Radiat Isot 1998 49:611-614.

26. Cox-Reijven, PL, Kooman JP, Soeters PB, van der Sande FM, Leunissen KM. Role of bioimpedance spectroscopy in assessment of body water compartments in hemodialysis patients. Am J Kidney Dis $200138: 832-838$.

27. Plank LD. Hill GL. Similarity of changes in body composition in intensive care patients following severe sepsis or major blunt injury. Ann N Y Acad Sci. 2000; 904:592-602.

28. Asselin MC, Kriemler S, Chettle DR, Webber CE, Bar-Or O, Mcneill FE. Hydration status assessed by multi-frequency bioimpedance analysis. Appl Radiat isot $1998 ; 49: 495-497$.

29. Bemeis K, Keller U. Bioelectrical impedance analysis during acute changes of extracellular osmolality in man. Clin Nutr 2000 19:361-366.

30. Scheltinga M, Jorna E, Chandi D, Wust M, Grep E, Compas D, Wesdorp R. Multiple frequency impedance measurements in critically ill patients. Clin Nutr 1995 14:42-44.

31. Ott M, Fischer H, Polat H, Helm EB, Frenz M. Caspary WF, Lembcke B. Bioelectrical impedance analysis as a predictor of survival in patients with human immunodeficiency virus infection. J Acquir Immune Defic Syndr Hum Retrovirol 1995 9:20-25.

32. Schwenk A, Beisenherz A, Romer K, Kremer G. Salzberger B, Elia M. Phase angle from bioelectrical impedance analysis remains an independent predictive marker in HIV-infected patients in the era of highly active antiretrovioral treatment. Am J Clin Nutr 2000;72:496-501.

33. Kreel van BK. Multi-frequency bioimpedance measurements of children in intensive care. Med Biol Eng Comput 2001: 39: 551-557.

34. Picolli A, Pittoni G, Facco E, Favaro E, Pillon L. Relationship between central venous pressure and bioimpedance vector analysis in critically ill patient. Crit Care Med 2000; 28:132-137. 


\section{CHAPTER 9}

General discussion 


\section{Chapter 9}

\section{Introduction}

In order to study the clinical applicability of BIS for measuring ECW and TBW the validity of the method was tested in different groups of patients by comparing the results with indicator dilution methods. The ideal method should be universally applicable and should yield comparable results in populations differing in specific body compartments. While the regression approach is by definition population specific, mixture equations based on physical laws derived from emulsion sciences should theoretically be universally applicable. The studies presented in this thesis describe the results of BIS in obese subjects, in dialysis patients, in children with cystic fibrosis and in patients with gastrointestinal disease.

\section{Review of the findings}

The bias of BIS, or the mean difference between the dilution methods and BIS, was different for the studied groups (table 1). While on average TBW was underestimated, ECW was slightly overestimated except in dialysis patients. The degree of TBW underestimation was smallest in obese patients and largest in dialysis patients. Especially in dialysis patients results were disappointing. with the weakest correlation between methods, the largest bias and the widest limits of agreement. Calibration of BIS to the gold standard appears to be necessary, but would result in population specific values for the 'constants' used in the model. This procedure seems only justified if the physical causes of deviations in the values of these constants are understood. Furthermore, the standard error of estimation (SEE) and the correlation with the gold standard will not improve by this adjustment. The specific resistivity of the fluid compartments is the main factor determining the values of these constants. Several published studies of BIS concluded that agreement between BIS and the dilution methods can be achieved only when the tissue resistivity values are recalculated for each specific population ${ }^{1-6}$. This will complicate the use of BIS for clinical applications severely.

The studies presented in this thesis identified some of the factors affecting the accuracy of BIS. The degree of overweight, body geometry, the relative size of the fluid compartments and the presence of clinical depletion affected the accuracy of BIS.

\section{Overweight}

In Chapter 2 the effect of obesity on BIS calculations of ECW and TBW was described. The difference between the dilution methods and BIS was found to correlate with the BMI used as a measure for the degree of overweight. With the assumption that the mixture equations are valid the specific resistivities of ECW and ICW were recalculated. The values were strongly correlated with the degree of overweight. It could not be elucidated if this was a true effect of obesity on the specific resistivities or if other confounders account for this effect. It is known that the electrolyte content, the osmolarity and the viscosity of the body fluids determine the overall resistivity'. However, it seems unlikely that the presence of overweight would influence the composition of the body fluids to such an extent that this would explain the discrepancies described.

Studying the changes in body composition during weight loss (chapter 3 and 4 ) shed a different light on the possible causes of the effect of overweight. Although the extrapolated Recw and Ricw changed less than they should for an ideal agreement between BIS and the dilution methods for measuring changes, the calculated changes in TBW and ECW were largely overestimated by use of mixture equations. It was concluded that the factor weight in the prediction equations, used to determine the conductive body volume, was responsible. It was hypothesized that the large amount of subcutaneous fat, largely responsible for the overweight, contributes only little to the actual conductive volume of the body. This fat mass 
actually may form an insulating layer around the conductive mass of skeletal muscles and organs. The fact that relative changes in the resistance index $\left(\mathrm{L}^{2} / \mathrm{R}\right)$ were more in agreement with the changes in TBW and ECW and ICW (chapter 4) supported this hypothesis.

Table 1 Comparison between BIS and dilution methods for measuring total body water (TBW) and extracellular water (ECW) in different populations.

\begin{tabular}{|c|c|c|c|c|c|c|c|c|}
\hline & \multicolumn{2}{|c|}{$\begin{array}{l}\text { Obese } \\
\text { subjects }\end{array}$} & \multicolumn{2}{|c|}{$\begin{array}{l}\text { Dialysis } \\
\text { patients }\end{array}$} & \multicolumn{2}{|c|}{$\begin{array}{l}\text { Children with } \\
\text { cystic fibrosis }\end{array}$} & \multicolumn{2}{|c|}{$\begin{array}{l}\text { Patients with } \\
\text { gastrointestinal } \\
\text { disease }\end{array}$} \\
\hline & ECW & TBW & ECW & TBW & ECW & TBW & ECW & TBW \\
\hline $\begin{array}{l}\text { Correlation coefficient } \\
\text { between methods }(r)\end{array}$ & 0.86 & 0.94 & 0.71 & 0.71 & 0.85 & 0.89 & 0.86 & 0.86 \\
\hline $\begin{array}{l}\text { Mean difference between } \\
\text { methods (dilution- BIS) (L) }\end{array}$ & -1.8 & 0.5 & 2.3 & 6.9 & -0.28 & 2.89 & -0.64 & 3.08 \\
\hline SD of the difference & 1.8 & 2.3 & 2.9 & 5.8 & 1.4 & 2.1 & 2.1 & 3.9 \\
\hline
\end{tabular}

\section{Geometry}

Impedance measurements from hand to foot are relatively insensitive for the composition of the trunk due to the small contribution of the trunk to total measured impedance". Individual differences in geometry may contribute to the errors of BIS in all groups studied. Refinement of the method is theoretically possible by correcting for individual differences in geometry. However, a large number of anthropometric measurements have to be included and calculations become very complicated. Such a procedure would seriously decrease the attractiveness of BIS. In the mixture equations the effect of geometry on impedance is corrected by inclusion of a constant $(\mathrm{Kb})$ derived in adults. In a pediatric population this factor will be different. Adjustment of the model for the geometric differences between children and adults seems justified. This procedure may reduce the bias of BIS in children with cystic fibrosis.

Due to the geometric influence the accuracy of BIS for measuring changes in body composition is largely determined by the localization of the change. While fluid overload in the extremities will result in a detectable decrease of Recw, ascites only marginally affects RecW of whole body BIS ${ }^{0.10}$. Segmental BIS measurements, measuring an arm, a leg and the trunk separately, can theoretically overcome these limitations. Improvement of BIS by the use of the segmental approach has been described during acute changes in body fluid distributions ${ }^{11-13}$. This approach, like the inclusion of anthropometric data, is far more complicated than the standard BIS method. Furthermore, measurements of the trunk have practical as well technical limitations. Due to the absence of easily accessible landmarks on the trunk, a correct and reproducible placement of electrodes is difficult. The composition of the trunk is less homogeneous compared with the limbs. Because of the anisotropic nature of the trunk BIS data may not fit accurately to the Cole-Cole model ${ }^{14}$. Preliminary results in peritoneal dialysis patients showed that trunk measurements were often not in accordance with the used model and that no Recw and Ricw could be extrapolated.

The proposed alternative hand-hand and foot-foot measurements described in chapter 6 are merely measurements of the limbs. Although the $R$ values obtained by these measurements 
were closely related to the values from the traditional hand-foot measurements, they largely exclude the trunk. If measurement of skeletal muscle mass is the main goal of nutritional assessment, exclusion of the confounding effects of the trunk is warranted. Furthermore, the alternative measurements are more in accordance with the cylinder theory than the traditional measurements.

\section{Size of fluid compartments}

Bland and Altman analysis showed no correlation between the absolute size of the fluid compartments and the error of BIS in obese subjects, in children with CF and in patients with gastrointestinal disease. In contrast to this finding, measurements in dialysis patients showed a strong positive correlation between the TBW and ECW errors of BIS and the size of these fluid compartments. In this group the relative magnitude of ECW and TBW, expressed as fraction of the body weight, was also positively correlated with the errors. In patients with gastrointestinal disease the ECW/TBW ratio was positively correlated with the ECW error and negatively with the TBW error. In healthy subjects the distribution of body fluids between compartments is closely regulated. The results of our studies show that, in situations where this normal distribution is maintained, the BIS error is not affected by the size of the compartments over a wide range of TBW (15-65 L) and ECW (8-35 L) values measured. However, during illness associated with fluid imbalance, BIS like SF-BIA, is less accurate. Studies in renal patients showed reduced accuracy of bio-impedance methods compared with controls ${ }^{15-10}$. Plausible causes are alterations in the specific resistivity of ECW and $\mathrm{ICW}^{10.20}$ and the insensitivity of whole body BIS for the composition of the trunk ${ }^{13,21 \cdot 23}$.

\section{Clinical depletion}

In the subgroup of clinically depleted patients the BIS prediction errors of TBW and ICW differed from the values found in non-depleted patients with gastrointestinal disease. The underestimation found in the total group was not present in the depleted subgroup. Consequently, BIS classified more patients as depleted than the dilution method. The specificity of BIS with mixture equations for screening of clinical depletion was $70 \%$. No effect of depletion on calculated ECW was found. Alteration of the critical frequency (Fc) and membrane capacitance $(\mathrm{Cm})$ suggest that the effects of depletion might be caused by changes at a cellular level. It can not be distinguished if depletion itself or the severity of the underlying disease is the major cause. In dialysis patients isolated ultrafiltration resulted in a decrease of $\mathrm{Fc}$ and an increase of $\mathrm{Cm}$, possibly indicating normalization of cell volume or cell membrane characteristics. The fact that ECW prediction of BIS was not affected by the presence of depletion strongly suggests that indeed confounding effects are present at the high frequency range where both ECW and ICW conduction of the current takes place. Results of studies in critically ill patients confirm this hypothesis. In critically ill patients BIA measurements at low frequencies have been reported to provide reasonable measurements of $\mathrm{ECW}^{24.25}$. In malnourished children ${ }^{26}$ and in dehydrated children ${ }^{27}$ changes in Recw were in agreement with changes in the clinical condition during recovery, but other BIS variables, Ricw, $\mathrm{Cm}$ and $\mathrm{Fc}$ were less consistent. In septic patients changes in ECW measured with BIS were comparable with results from Bromide dilution ${ }^{20}$. Because TBW is calculated as the sum of ECW and ICW which are derived from Recw and Ricw, it seems likely that the mixture model is not optimally suited for measuring ICW in patients. Reported changes in physical properties of the cell membranes may be responsible.

The accuracy of BIS for measuring changes in fluid volumes was studied in obese subjects, in dialysis patients and in children with CF. The type of body composition alterations differs considerably between these groups. While during ultrafiltration acute fluid losses take place 
without changes in other body compartments or body geometry, during severe weight loss in obese subjects changes are associated with losses of fat mass and body cell mass resulting in large changes of geometry. In the children with CF long term changes during growth may include increase and decrease of body compartments depending on their clinical condition. Changes in body geometry in this group are largely determined by increase of the length of limbs and by changes in their circumferences. The type of changes affected the accuracy of BIS. During utrafiltration ECW changes agreed well with changes in $\mathrm{L}^{2} / \mathrm{RecW}$ and with $\mathrm{ECW}$ changes calculated by mixture equations. In contrast, BIS failed to monitor TBW changes by mixture equations or by changes in $L^{2} /$ Rinf. In obese subjects short term changes of ECW and TBW could reasonably well be predicted by mixture equations while long term changes associated with fat losses were overestimated by mixture equations. In this group changes in the resistance indices of Recw and Ricw were more in agreement with true fluid changes than mixture equations. In CF patients ECW changes were too small to be detected by bromide dilution and TBW changes, although large enough, were not accurately measured by BIS. Changes in the FFM measured by dual energy X-ray absorptiometry did correlate with changes in the resistance indices of $R_{50}$ and Recw, but not with changes in the resistance indices of Ricw and Rinf. These results indicate that BIS yields better results in healthy subjects than in sick persons. Especially the accuracy of ICW and TBW is affected by the presence of illness. It has been suggested that the increase in Fc affects the accuracy of the fit of the impedance data to the Cole-Cole plot because there are not enough data beyond this frequency $y^{20}$. Increasing the frequency range of the measurements can solve this problem. In patients Fc's above $500 \mathrm{kHz}$ have been described ${ }^{30-32}$. For clinical use an extension of the frequency range up to $1,3 \mathrm{MHz}$ appears to be necessary.

\section{Implications for the clinical use of BIS}

At present dozens of BIA machines are commercially available, each using different prediction equations for converting the impedance, resistance or reactance data to estimates of body composition. This development not only complicates a thorough comparison of results presented in the literature, but also confuses clinicians and dieticians who have to choose the most appropriate method. In normal weight healthy individuals single-frequency BIA has been proven to be sufficiently accurate for measuring TBW or fat free mass ${ }^{33}$. To assess ECW and ICW in clinical practice, SF-BIA is not well suited because a sound scientific foundation is lacking. Equations based on emulsion sciences are theoretically appealing, but the mixture equations tested in this thesis produced different biases in different populations. Calibration of the method would yield disease specific values of the used "constants". Although such procedures appear to be warranted, in clinical situations it is not practical because confounding factors like the degree of overweight, the degree of overor dehydration and the presence of depletion are not known beforehand. Furthermore, in an individual patients a combination of these factors and possibly others like an elevated body temperature ${ }^{34}$, altered skin resistance ${ }^{35}$ and changes in the composition of body fluids ${ }^{10.36}$ may be present. This problem becomes even more complex during the monitoring of body composition because the contribution of all the possible confounding factors may vary in time depending on the clinical condition of the patient. Therefore, it can be concluded that at present no universally applicable approach for the calculation of absolute body composition measures based on impedance measurements is available.

To overcome the limitations of prediction equations that inevitably introduce errors due to the underlying assumptions that may not hold for individual patients, evaluation of crude resistance values can provide information regarding changes in body composition. A thorough understanding of all other possible factors that may affect the measured resistance values besides the volumes of fluid compartments is necessary for such approach. The studies presented in this thesis indicate that $\mathrm{L}^{2} / R e c w$ and changes in this index may provide a reasonable estimate for the volume of ECW and for relative changes in ECW both in 
healthy and in sick persons. Because values of $L^{2} / R i c w$ and changes in this index were less consistent, the use of Ricw for the evaluation of the size of the ICW compartment during iliness is questionable. The effects of cell characteristics on Ricw have to be studied in more detail to elucidate if and when it can be used as a measure of ICW.

When the main goal of body composition measurements is to evaluate changes in skeletal muscle mass, segmental BIS or the alternative hand-hand and foot-foot measurements can be used. Such an approach, obliviating the use of prediction equations has several advantages. First, the geometry is less complex compared with whole body measurements and secondly, the unequivocal contribution of the trunk to the total measured impedance is minimized. Evaluation of the resistance indices of the limbs in combination with body weight changes and circumferences of trunk and limbs can provide an overall insight in relative changes in the composition of limbs and trunk. Successful diagnosis of postmastectomy lymphedema was described by BIS measurements of the arms by comparing Recw of the affected arm with the non-affected $\mathrm{arm}^{37}$.

For nutritional assessment evaluation of ICW or body cell mass is of vital importance. Due to an increase in $\mathrm{Fc}$ and a decrease in $\mathrm{Cm}$ in patients, the frequency range necessary for an accurate fit of the impedance data to the Cole-Cole plot should be larger than the usual 5 to $500 \mathrm{kHz}$ range. Increases up to $1,3 \mathrm{MHz}$ are advised.

\section{Directions for future research}

Because segmental impedance measurements can avoid artifacts due to geometric effects, segmental BIS measurements can be of value for measuring skeletal muscle mass. Regional SF-BIA ${ }^{38-40}$ as well as multi-frequency-BIA ${ }^{41}$ could accurately predict muscle mass of the leg. For nutritional assessment measuring total body composition has generally been aimed at. However, if an evaluation of BCM is the main purpose of nutritional assessment and if measurement of skeletal muscle mass, the main contributor to changes in BCM during clinical depletion, is less prone to artifacts, then segmental measurements should be preferred. Clinical studies should aim at testing the feasibility of this application of BIS. together with the development of reference values for skeletal muscle mass.

For a thorough evaluation of the use of BIS as a body composition measurement fundamental research regarding the influence of illness in general and cell characteristics in particular is needed. For a correct interpretation of the measured $\mathbf{R}$ values in patients, more information about the effect of the composition of body fluids is necessary. Future research should focus on the relationship between changes in BIS variables and hematocrit, electrolyte profile, albumin, viscosity and other blood chemistry values.

The phase angle calculated from SF-BIA and the membrane capacitance $(\mathrm{Cm})$ derived from BIS measurements are measures of the capacity to store an electrical charge. The effects of changes in $\mathrm{Cm}$ on values of Recw and Ricw have not been described yet. It is plausible that alterations in $\mathrm{Cm}$ violate assumptions underlying the Cole-Cole model and the mixture equations. The effect of changes in physical cell characteristics like $\mathrm{Cm}$ and $\mathrm{Fc}$ on resistance values and body composition estimates from mixture equations should be studied in more detail. Based on results in renal ${ }^{42.43}$, septic ${ }^{25.44}$ and HIV-infected patients ${ }^{45-47}$, it has been postulated that a low phase angle may be a global marker of cellular distress. In HIV-infected patients the phase angle was found to be a much stronger prognostic marker of clinical progression and survival than fluid compartments measured by SF-BIA ${ }^{46}$. Low Cm values were measured in critically ill patients ${ }^{25,44}$ and in dialysis patients ${ }^{30.42}$. In CAPD patients strong correlation between $\mathrm{Cm}$ and serum Albumin $(r=0.84)$ was found ${ }^{48}$ and in healthy persons between basal metabolic rate and $\mathrm{Cm}(r=0,99){ }^{40}$. More fundamental research is needed to assess the significance of these parameters for clinical application. Also, their relationship with morbidity and mortality should be studied. Studying cell physiology may become a new area for the application of BIS. 


\section{References}

1. De Lorenzo A, Andreoli A, Matthie J, Withers P. Predicting body cell mass with bioimpedance by using theoretical methods: a technological review. J Appl Physiol 1997;82:1542-1558.

2. Smye SW, Norwood HM, Buur T, Bradbury M, Brocklebank JT. Comparison of extra-cellular fluid volume measurement in children by 99Tcm-DPTA clearance and multi-frequency impedance techniques. Physiol Meas 1994;15:251-260.

3. Janssen YJ, Deurenberg P. Roelfsema $F$. Using dilution techniques and multifrequency bioelectrical impedance to assess both total body water and extracellular water at baseline and during recombinant human growth hormone $(\mathrm{GH})$ treatment in $\mathrm{GH}$-deficient adults. J Clin Endocrinol Metab 1997;82:3349-3355.

4. van Marken Lichtenbelt WD, Snel YE, Brummer RJ, Koppeschaar HP. Deuterium and bromide dilution, and bioimpedance spectrometry independently show that growth hormone-deficient aduits have an enlarged extracellular water compartment related to intracellular water. J Clin Endocrinol Metab 1997;82:907-911.

5. Ellis KJ, Shypailo RJ, Wong WW. Measurement of body water by multifrequency bioelectrical impedance spectroscopy in a multiethnic pediatric population. Am J Clin Nutr 1999;70:847-53.

6. Ellis KJ. Wong WW. Human hydrometry: comparison of multifrequency bioelectrical impedance with $2 \mathrm{H} 2 \mathrm{O}$ and bromine dilution. J Appl Physiol 1998;85:1056-1062.

7. Schoeller DA. Bioelectrical impedance analysis. What does it measure? Ann N Y Acad Sci 2000;904:159-162.

8. Heitmann BL. Impedance: a valid method in assessment of body composition? Eur J Clin Nutr 1994:48:228-240.

9. Sarhill N, Waish D, Neison K, Homsi J, Komurcu S. Bioelectrical impedance, cancer nutritional assessment, and ascites. Support Care Cancer 2000;8:341-343.

10. Schioerb PR, Forster J, Deicore R, Kindscher JD. Bioelectrical impedance in the clinical evaluation of liver disease. Am J Clin Nutr 1996;64(3 Suppl):510S-514S.

11. Bracco D, Berger MM, Revelly JP, Schutz Y, Frascarolo P, Chiolero R. Segmental bioelectrical impedance analysis to assess perioperative fluid changes. Crit Care Med 2000;28:2390-2396.

12. Wotton MJ, Trocki O, Thomas BJ, Hammond P, Shepherd RW, Lewindon PJ, Wilcox J, Murphy AJ. Cleghorn GJ. Changes in body composition in adolescents with anorexia nervosa. Comparison of bioelectrical impedance analysis and total body potassium. Ann N Y Acad Sci 2000;904:418-419.

13. Zhu F, Schneditz D, Kaufman AM, Levin NW. Estimation of body fluid changes during peritoneal dialysis by segmental bioimpedance analysis. Kidney Int 2000;57:299-306.

14. Chumlea WC. Baumgartner RN. Bioelectric impedance methods for the estimation of body composition. Can J Sport Sci 1990:15:172-179.

15. Arkouche W, Fouque D, Pachiaudi C, Normand S, Laville M, Delawari E, Riou JP. Traeger J, La Ville M. Total body water and body composition in chronic peritoneal dialysis patients. J Am Soc Nephrol 1997;8:1906-1914.

16. Woodrow G, Oidroyd B. Turney JH, Davies PS, Day JM, Smith MA. Measurement of total body water by bioelectrical impedance in chronic renal failure. Eur J Clin Nutr 1996;50:676-681.

17. Pupim LB, Kent P. Ikizler TA. Bioelectrical impedance analysis in dialysis patients. Miner Electrolyte Metab $1999 ; 25: 400-406$.

18. Dumler F. Use of bioelectric impedance analysis and dual-energy $X$-ray absorptiometry for monitoring the nutritional status of dialysis patients. ASAIO J 1997;43:256-60.

19. Rees AE. Ward LC. Cornish BH. Thomas BJ. Sensitivity of multiple frequency bioelectrical impedance analysis to changes in ion status. Physiol Meas 1999;20:349-362.

20. Ward LC, Elia M, Cornish B. Potential errors in the application of mixture theory to multifrequency bioelectrical impedance analysis. Physiol Meas 1998;19:53-60.

21. Than N, Woodrow G, Oldroyd B, Gonzalez C. Turney JH, Brownjohn AM. Effect of peritoneal fluid on whole body and segmental multiple frequency bioelectrical impedance in patients on peritoneal dialysis. Eur J Clin Nutr $2000 ; 54: 450-451$.

22. Thomas BJ, Cornish BH, Ward LC, Patterson MA. A comparison of segmental and wrist-to-ankie methodologies of bioimpedance analysis. Appl Radiat isot 1998:49:477-478.

23. Valentinuzzi ME, Morucci JP, Felice CJ. Bioelectrical impedance techniques in medicine. Part II: Monitoring of physiological events by impedance. Crit Rev Biomed Eng 1996:24:353-466.

24. Roos AN, Westendorp RG, Frolich M, Meinders AE. Tetrapolar body impedance is influenced by body posture and plasma sodium concentration. Eur J Clin Nutr 1992;46:53-60. 
25. Marx G, Vangerow B, Burczyk C, Gratz KF, Maassen N. Cobas Meyer M, Leuwer M, Kuse E, Rueckholdt. Evaluation of noninvasive determinants for capillary leakage syndrome in septic shock patients. Intensive Care Med 2000;26:1252-1258.

26. Pithan C, Mazariegos M, Solomons NW, Furst P. Monitoring of fluid changes in hospitalized, Malnourished, Guatemalan children using bioelectrical impedance spectroscopy (BIS). Appl Radiat Isot 1998 May-Jun; 49(5-6):615-7

27. Meyer A, Mazariegos M, Solomons NW, Furst P. The use of bioimpedance spectroscopy to monitor water changes induced by rehydration in young children with abnormal water disturbances associated with diarrheal disease. Appl Radiat isot 1998;49:607-610.

28. Finn PJ, Plank LD, Clark MA, Connolly AB, Hill GL. Progressive cellular dehydration and proteolysis in critically ill patients. Lancet. 1996;347:654-656.

29. Zarowitz BJ, Matthie JR. Bioimpedance and the estimation of net fluid balance in critical care patients: problems and possibilities. Crit Care Med 1999;27:1655-1657.

30. Hannan WJ, Cowen SJ, Plester C, Fearon KC. Proximal and distal measurements of extracellular and total body water by multi-frequency bio-impedance analysis in surgical patients. Appl Radiat Isot 1998;49:621-622.

31. Van Kreel BK. Multi-frequency bioimpedance measurements of children in intensive care. Med Biol Eng Comput 2001;39:551-557.

32. Mazariegos M, Pithan C, Meyer A, Mendoza I, Furst P, Solomons NW. Bioelectrical impedance spectroscopy (BIS) in young children with acute and semi-acute hydration disorders: potentials and limitations. Appl Radiat isot 1998;49:611-614.

33. Ellis KJ, Bell SJ, Chertow GM, Chumlea WC, Knox TA, Kotier DP, Lukaski HC, Schoeller DA. Bioelectrical impedance methods in clinical research: a follow-up to the NIH technology assessment conference. Nutrition $1999: 15: 874-880$.

34. Asselin MC, Kriemler S, Chettle DR, Webber CE, Bar-Or O, Mcneill FE. Hydration status assessed by multi-frequency bioimpedance analysis. Appl Radiat Isot 1998;49:495-497.

35. Cornish BH. Thomas BJ, Ward LC. Effect of temperature and sweating on bioimpedance measurements. Appl Radiat Isot 1998;49:475-476.

36. Berneis $\mathrm{K}$, Keller $\mathrm{U}$. Bioelectrical impedance analysis during acute changes of extracellular osmolality in man. Clin Nutr $2000: 19: 361-366$.

37. Cornish BH, Chapman M, Thomas BJ, Ward LC, Bunce IH, Hirst C. Early diagnosis of lymphedema in postsurgery breast cancer patients. Ann N Y Acad Sci 2000;904:571-575.

38. Lukaski HC. Assessing regional muscle mass with segmental measurements of bioelectrical impedance in obese women during weight loss. Ann N Y Acad Sci. 2000;904:154-158.

39. Nunez C, Gallagher D, Grammes J, Baumgartner RN, Ross R, Wang Z. Thornton J, Heymsfield SB. Bioimpedance analysis: potential for measuring lower limb skeletal muscle mass. JPEN J Parenter Enteral Nutr 1999:23(2):96-103.

40. Salinari S, Bertuzzi A, Mingrone G, Capristo E, Pietrobelli A, Campioni P, Greco AV, Heymsfield SB. New bioimpedance model accurately predicts lower limb muscle volume: validation by magnetic resonance imaging. Am J Physiol Endocrinol Metab 2002;282(4):E960-E966.

41. Pietrobelli A, Morini P, Battistini N, Chiumello G, Nunez C. Heymsfieid SB. Appendicular skeletal muscle mass: prediction from multiple frequency segmental bioimpedance analysis. Eur $\mathrm{J}$ Clin Nutr 1998;52(7):507-511.

42. Scanferta F, Landini S, Fracasso A, Morachiello P. Righetto F. Toffoletto PP, Bazzato G. On-line bioelectric impedance during haemodialysis: monitoring of body fluids and cell membrane status. Nephrol Dial Transplant 1990:5 Suppl 1:167-170.

43. Passadakis P, Sud K, Dutta A, Singhal M, Pettit J, Chatalalsingh C, Thodis E, Vargemezis V. Oreopoulos D. Bioelectrical impedance analysis in the evaluation of the nutritional status of continuous ambulatory peritoneal dialysis patients. Adv Perit Dial 1999;15:147-152.

44. Mattar JA. Application of total body bioimpedance to the critically ill patient. Brazilian Group for Bioimpedance Study. New Horiz 1996;4:493-503.

45. Schwenk A, Beisenherz A, Kremer G, Diehl V, Salzberger B, Fatkenheuer G. Bioelectrical impedance analysis in HIV-infected patients treated with triple antiretroviral treatment. Am J Clin Nutr 1999;70(5):867-873.

46. Schwenk A, Beisenherz A, Romer K, Kremer G. Salzberger B, Elia M. Phase angle from bioelectrical impedance analysis remains an independent predictive marker in HIV-infected patients in the era of highly active antiretroviral treatment. Am J Clin Nutr 2000;72:496-501.

47. Shah S, Whalen C. Kotler DP, Mayanja H, Namale A, Melikian G, Mugerwa R, Semba RD. Severity of human immunodeficiency vinus infection is associated with decreased phase angle, fat 
mass and body cell mass in adults with pulmonary tuberculosis infection in Uganda. $J$ Nutr 2001;131:2843-2847.

48. Domoto DT, Weindel ME. Bioimpedance analysis of fluid compartments in female CAPD patients. Adv Perit Dial 1998;14:220-222.

49. De Lorenzo A, Candeloro N, Bertini I, Talluri T, Pierangeli L. Total body capacity correlated with basal metabolic rate. Appl Radiat isot 1998;49:493-494. 
Chapter 9 


\section{Summary}




\section{Introduction}

Nutritional assessment is an essential part of clinical care. Because clinical depletion has adverse effects on recovery and increases complication rates and mortality, early diagnosis as well as monitoring of the nutritional status of patients is important. In clinically depleted patients the body cell mass, the metabolic active part of the body, is decreased. Body composition measurements are necessary to quantify this loss. At present no suitable methods for routine clinical use are available. Most methods are too expensive, too cumbersome or not reliable in patients. Bio-electrical impedance analysis (BIA) is a cheap, portable method suited for repeated body composition measurements that may be of value for clinical application. BIA is based on measuring the resistance of an alternating current in the body. The current will flow mainly through the electrolyte rich fluid compartments of the body whereas bone and fat only marginally contribute to the conduction due to their high resistance. The lower the resistance the larger the electrolyte rich fluid compartment. This bio-electrical characteristic serves as the basis for computing body compartments.

There are different approaches in use for calculating body composition based on BIA measurements. Single-frequency BIA (SF-BIA) measures resistance (R) at one frequency $(50 \mathrm{kHz})$ and regression equations based on the resistance index $\left(\mathrm{L}^{2} / \mathrm{R}\right)$ are used to calculate total hody water (TRW) or fat free mase (FFM). Thie approsoch has an acooptablo acouracy in healthy persons but in sick people, in which fluid imbalance is often present, the method is less accurate. Furthermore, SF-BIA is not able to measure intracellular (ICW) and extracellular water (ECW) separately. Because clinical depletion is characterized by a decrease in ICW often accompanied by ECW expansion, TBW values are unable to assess the loss of body cell mass. For nutritional assessment in clinical settings both fluid compartments have to be quantified.

Multifrequency BIA (MF-BIA) measures impedance at different frequencies. At low frequency the current will only pass through the ECW because cell membranes and tissue interfaces act as capacitors. At high frequencies this capacitive property is lost and current passes through both ECW and ICW. Resistance values measured at low and at high frequencies are used to predict ECW and TBW based on the resistance index at the specific frequencies. Bioelectrical impedance spectroscopy (BIS) measures impedance at a range of frequencies (usually 50) and data are fit to a theoretical model, the Cole-Cole model from which the resistance at zero and infinite frequency (Rinf) are extrapolated. This procedure provides resistance values of ICW (RicW) and of ECW (RecW). These R-values can be used to calculate fluid volumes based on regression equations or by use of equations based on physical laws, the mixture equations. Theoretically the mixture approach should be less population specific than the regression approach. For clinical use this approach is very attractive. However, at present it is unclear if the mixture approach is universally applicable.

The aim of the studies presented in this thesis was to assess the validity of BIS, with and without employing mixture equations, for measuring TBW and ECW in different patient groups and for measuring changes in these fluid compartments. TBW and ECW measured by BIS were compared with results from gold standard methods, the deuterium- and bromide dilution methods respectively. The secondary aim was to identify confounding factors. Patients deviating in body composition from normal subjects were included, obese patients with excess fat mass, dialysis patients with ECW expansion, children with cystic fibrosis and patients with gastrointestinal disease with decreased body cell mass.

\section{Obesity}

In a population differing in the degree of overweight the regression and mixture approach were compared (Chapter 2). While the regression approach underestimated both TBW and ECW by $1.1 \mathrm{~L}$, the mixture approach only underestimated ECW by $0.8 \mathrm{~L}$. The correlations 
with the dilution methods and the standard errors of estimation (SEEs) for TBW and ECW were comparable for the two approaches. Further analysis of the mixture approach revealed that prediction errors for TBW and ECW correlated with the body mass index (BMI). Recalculation of the constants used in the model showed that Kecw, a constant used in the equations to calculate ECW, and the specific resistivities of ECW (pecW) and ICW (picw) also correlated with BMI. From this study it was concluded that the mixture approach was slightly more accurate than the regression approach, but not sensitive enough for clinical use. The finding that the constants used in the mixture model varied with the degree of overweight should be studied further in order to optimise the model.

\section{Morbid Obesity}

In morbidly obese subjects who underwent gastric reduction surgery the accuracy of BIS to measure changes in body composition during severe weight loss was tested (Chapter 3 ). Patients were measured before operation and 2 weeks, 3 months and 1 year after operation. After one year the mean weight loss was $53 \mathrm{~kg}$, of which $12 \mathrm{~kg}$ was fat free mass and $41 \mathrm{~kg}$ fat mass. TBW loss was $8.7 \mathrm{~L}$ and ECW loss $4.3 \mathrm{~L}$. Comparison of BIS, with application of mixture equations, with the reference methods for measuring all possible changes over 6 time intervals revealed a mean overestimation of TBW $(2.4 \mathrm{~L}, \mathrm{SD}=2.9)$ and $\mathrm{ECW}(0.74 \mathrm{~L}$, $\mathrm{SD}=2.6$ ) losses by BIS. The degree of overestimation correlated with the change in body weight and with the relative loss of fat mass, expressed as percentage fat of the weight loss or as change in triceps skinfold. This finding could explain why short-term losses were measured more accurately by BIS than long-term losses associated with large fat losses. For an ideal agreement between BIS and the golden standard, the values of the resistance of ECW and ICW and changes in these values were calculated and compared with the measured values. Measured changes in Recw and Ricw were smaller than expected changes. The factor weight in the mixture equations, used to estimate total body volume, might be responsible for these findings. It was hypothesized that the actual conducting body volume in obese subjects is overestimated by mixture equations.

Comparison of the regression and the mixture approach for measuring changes in body composition during severe weight loss revealed that relative changes in the resistance index of Recw, Ricw and Rinf were in the same order as relative changes in ECW, ICW and TBW, while mixture equations systematically overestimated long-term losses of the fluid compartments (Chapter 4 ). These results confirmed the hypothesis that mixture equations overestimate the change in conducting body volume during severe weight loss.

\section{Hemodialysis patients}

In hemodialysis patients BIS with use of mixture equations underestimated TBW by $6.9 \mathrm{~L}$ and ECW by $2.3 \mathrm{~L}$ and limits of agreement were very wide (Chapter 5 ). The error of BIS was significantly correlated with the relative magnitude of TBW and ECW compartments, expressed as TBW:body weight and ECW:body weight. In contrast to the low agreement between absolute fluid volumes measured by BIS and the dilution methods, changes in ECW measured by BIS were significantly correlated with changes in body weight both during isolated ultrafiltration $(r=0.83)$ and hemodialysis $(r=0.76)$. This correlation was not found for TBW changes.

\section{Segmental measurements}

In Chapter 6 results of the traditional hand-to-foot measurements were compared with handto-hand and foot-to-foot measurements as alternatives for clinical use. Measurements were performed in a population with different degrees of overweight to study the influence of body 
geometry. Recw, Ricw and R50 values of the hand-to-foot measurements could be accurately described as a function of Recw. Ricw and R50 values of the two alternative measurements. The degree of overweight did not affect this relationship. However, the relative circumferences of arms and legs (expressed as the ratio circumference arm / circumference leg) and the length of the trunk influenced the relationship between $R$ values of the three different measurements. The precision of TBW, ECW and ICW predictions based on the resistance index of $R$ values from hand-to-hand measurements were comparable with the traditional hand-to-foot measurements. The foot-to-foot measurements gave slightly less accurate results.

\section{Cystic fibrosis}

In children with cystic fibrosis the validity of BIS with mixture equations for monitoring body composition was compared with the dilution methods, with dual energy $\mathrm{X}$-ray absorptiometry (DXA) and the skinfold method (Chapter 7). Children were measured three times with intervals of 6 months. BIS with mixture equation underestimated TBW by $2.9 \mathrm{~L}$, fat free mass by $3.4 \mathrm{~kg}$ and overestimated fat mass by $4.3 \mathrm{~kg}$. Results of the skinfold method were more in agreement with DXA results than BIS. Changes in body compartments measured with BIS or with the skinfold method did not differ from the changes measured with the reference methods. However, for BIS TBW, ECW and FFM changes calculated with mixture equations were not significantly correlated with changes measured by the dilution methods and DXA. In contrast, changes in the resistance index at low frequencies, $L^{2} / R e c w$ and $L^{2} / R 50$. correlated with changes in FFM measured by DXA. It was argued that the good results of the skinfold method compared with BIS could be explained by the contribution of the factor weight in the equations converting skinfold thicknesses to fat - and fat free masses. As the sum of skinfolds did not significantly change during the study period, calculated changes in fat- and fat free mass were due to weight changes. The lack of good agreement between BIS and the reference methods for measuring changes may be due to the fact that changes were relatively small and that disease specific alterations in electrophysical membrane properties may be present.

\section{Gastrointestinal disease}

In patients with gastrointestinal disease (Chapter 8) BIS underestimated TBW (3.1 L) and ICW (3.7 L) and overestimated ECW (0.6 L). Dividing the group in depleted and nondepleted patients revealed that TBW and ICW underestimation was only present in the nondepleted group. Other BIS variables were also different between the two groups. In depleted patients the critical frequency was $60 \%$ higher and the membrane capacitance $40 \%$ lower than in the non-depleted patients.

This study also includes a comparison of different screening methods, based on impedance measurements, for identifying depleted patients. The impedance vector method described in the literature, which compares the resistance and reactance at $50 \mathrm{kHz}$ normalized for height $(R / H$ and $X c / H)$ with reference values, failed to identify depleted patients. The ratio of the resistance index and the ideal fat free mass (iFFM) at R50, Ricw and Rinf (e.g. (L ${ }^{2} /$ Rinf ) / iFFM ) was proposed as an alternative screening tool. Application of this method resulted for R50 and Rinf in comparable sensitivity $(86 \%)$ and specificity $(73-80 \%)$. The ratio of Ricw failed to distinguish between depleted and non-depleted patients. It was concluded that BIS measures of body fluids in patients are influenced by the presence of depletion probably due to alterations of electrical properties of the body at the cellular level. However, for screening purposes use of the proposed ratio may be of value. 


\section{Conclusions}

Reviewing the results of the studies described in this thesis leads to the conclusion that BIS with use of mixture equations is not a universally applicable approach for measuring body composition (Chapter 9). The underlying physical laws may not be valid during changes in nutritional status and during disease. Besides the volumes of fluid compartments the composition of the fluids and the electro-physical properties of membranes affect the measured R-values. The applied algorithm may only be valid in healthy persons, but not in situations where changes in membrane properties are likely as during inflammation or nutritional depletion. In Chapter 9 the impact of confounding factors is described as well as possibilities and limitations of BIS for clinical use. 
Summary 


\section{Samenvatting}




\section{Inleiding}

Meting van de voedingstoestand is een essentieel onderdeel van de klinische zorg. Omdat klinische depletie een negatief effect heeft op het herstel en de kans op complicaties en mortaliteit doet toenemen, is het belangrijk dat de diagnose vroeg gesteld wordt en dat de voedingstoestand van patiënten nauwkeurig wordt gevolgd. In klinisch deplete patiënten is de lichaamscelmassa, het metabool actieve gedeelte van het lichaam, afgenomen. Meting van de lichaamssamenstelling is nodig om dit verlies te kunnen kwantificeren. Op het moment zijn er geen geschikte methodes beschikbaar voor routinematig klinisch gebruik. De meeste methodes zijn te duur, te omslachtig of geven geen betrouwbare resultaten in patienten. Bioelectrische impedantie analyse (BIA) is een goedkope methode geschikt voor het herhaaldelijk meten van de lichaamssamenstelling aan het bed. BIA zou van waarde kunnen zijn voor klinische toepassing. De methode is gebaseerd op het meten van de weerstand die een wisselstroom in het lichaam ondervindt. Stroomgeleiding vindt voornamelijk plaats door vochtcompartimenten rijk aan elektrolyten, terwijl bot en vet als gevolg van hun hoge weerstand slechts marginaal bijdragen aan de geleiding. De elektrische weerstand van het lichaam is derhalve de basis voor berekening van de lichaamssamenstelling.

Voor het berekenen van de lichaamssamenstelling op basis van BIA metingen zijn verschillende benaderingen in gebruik. "Single-frequency" BIA (SF-BIA) meet de weerstand (R) bij één frequentie $(50 \mathrm{kHz})$ en met regressievergelijkingen gebaseerd op de weerstand index $\left(\mathrm{L}^{2} / \mathrm{R}\right)$ worden totaal lichaamswater (TBW) of vetvrije massa (FFM) berekend.

Deze benadering heeft een acceptabele nauwkeurigheid in gezonde personen, maar voor zieke mensen, vooral als er sprake is van verschuivingen tussen lichaamscompartimenten, wordt deze benadering onnauwkeurig. Bovendien is SF-BIA niet in staat intracellulair (ICW) en extracellulair water (ECW) apart te meten. Omdat klinische depletie gekarakteriseerd wordt door een afname van ICW, vaak in combinatie met ECW expansie, zijn TBW waardes niet in staat het verlies van lichaamscelmassa vast te stellen. Nutritional assessment in een klinische setting vereist bepaling van de grootte van beide vochtcompartimenten.

"Multifrequency" BIA (MF-BIA) meet de impedantie bij verschillende frequenties. Bij lage frequenties wordt de stroom alleen door ECW geleid omdat celmembranen en contactoppervlaktes tussen weefsels zich gedragen als condensatoren. Bij hoge frequenties gaat deze eigenschap verloren en vindt er geleiding door zowel ECW als ICW plaats. Weerstanden gemeten bij lage en hoge frequenties worden gebruikt om ECW en TBW te berekenen gebaseerd op de weerstand index bij de specifieke frequenties. Bioelectrische impedantie spectroscopie (BIS) meet de impedantie bij een reeks van frequenties (meestal 50) en de data worden toegepast op een theoretisch model, het Cole-Cole model, waardoor de weerstand bij een frequentie van 0 en oneindig (Rinf) kan worden geëxtrapoleerd. Deze methode geeft weerstandwaardes voor ICW (Ricw) en ECW (Recw). Deze R-waardes kunnen worden gebruikt om vochtcompartimenten te berekenen gebaseerd op regressievergelijkingen of door gebruik te maken van vergelijkingen gebaseerd op natuurkundige wetten, de mixture vergelijkingen. Theoretisch zou deze mixture benadering minder populatie specifiek zijn dan de regressie benadering. Voor klinisch gebruik is deze methode zeer aantrekkelijk. Op dit moment is het echter onduidelijk of de mixture benadering universeel toepasbaar is.

De doelstelling van de studies gepresenteerd in dit proefschrift was de validiteit van BIS vast te stellen, met en zonder toepassing van mixture vergelijkingen, voor het meten van TBW en ECW in verschillende groepen van patiênten en voor het meten van veranderingen in deze vochtcompartimenten. TBW en ECW gemeten met BIS werden vergeleken met resultaten van gouden standaard methodes, respectievelijk de deuterium- en broom verdunnings methode. Een secundaire doelstelling was het identificeren van verstorende factoren. 
Patiênten met een lichaamssamenstelling afwijkend van normaal werden geincludeerd, obese patiènten met een overmatige vetmassa, dialyse patiēnten met toename van ECW, kinderen met cystic fibrosis en patiënten met maag-darmaandoeningen met afname van de lichaamscelmassa.

\section{Obesitas}

In een populatie met een variērend overgewicht werden de regressie en mixture benadering vergeleken (Hoofdstuk 2). Terwill de regressie methode zowel TBW als ECW onderschatte met $1.1 \mathrm{~L}$ onderschatte de mixture approach alleen ECW met $0.8 \mathrm{~L}$. De correlaties met de verdunningsmethodes en de standaard meetfouten (SEEs) voor TBW en ECW waren vergelijkbaar voor de twee benaderingen. Verdere analyse van de mixture benadering toonde aan dat meetfouten van TBW en ECW correleerden met de Quetelet index. Herberekening van de constanten gebruikt in het model toonde aan dat Kecw, een constante in de vergelijking waarmee ECW wordt berekend, en de specifieke weerstand van ECW ( $\rho$ ecw) en ICW ( $\mathrm{picw}$ ) ook correleerden met de Quetelet index. Geconcludeerd werd dat de mixture benadering iets nauwkeuriger was dat de regressie benadering, maar niet gevoelig genoeg voor klinisch gebruik in de individuele patiênt. De bevinding dat de constanten gebruikt in de mixture vergelijkingen variëren met de mate van overgewicht dient verder bestudeerd te worden om het model te optimaliseren.

\section{Morbide Obesitas}

In patiënten met morbide obesitas die een maagverkleiningsoperatie ondergingen werd de nauwkeurigheid van BIS voor het meten van veranderingen in lichaamssamenstelling tijdens gewichtsverlies getest. (Hoofdstuk 3). Patiènten werden gemeten voor de operatie en 2 weken, 3 maanden en een jaar na operatie. Het gemiddelde gewichtsverlies na een jaar bedroeg $53 \mathrm{~kg}$, waarvan $12 \mathrm{~kg}$ vet vrije massa was en $41 \mathrm{~kg}$ vetmassa. Het TBW verlies bedroeg $8.7 \mathrm{~L}$ en ECW verlies $4.3 \mathrm{~L}$. Vergelijking van BIS met toepassing van mixture equations met de referentiemethode voor het meten van alle veranderingen over de 6 mogelijke tijdsintervallen toonde een gemiddelde overschatting van TBW en ECW verliezen $(2.4 \mathrm{~L}, \mathrm{SD}=2.9 ; 0.74 \mathrm{~L}, \mathrm{SD}=2.6$ ) door BIS aan. De mate van overschatting correleerde met veranderingen in lichaamsgewicht en met het relatieve verlies van vetmassa, uitgedrukt ais vetpercentage van het gewichtsverlies of als verandering in de triceps huidplooi. Deze bevinding kon verklaren waarom korte-termijn verliezen nauwkeuriger worden gemeten door BIS dan lange-termijn verliezen die samengaan met grote verliezen van vet. De waarden die de weerstanden van ECW en ICW zouden moeten hebben voor een ideale overeenkomst tussen BIS en de gouden standaard en de veranderingen in deze waarden werden berekend en vergeleken met de werkelijk gemeten waarden. De gemeten veranderingen van Recw en Ricw waren kleiner dat de verwachte veranderingen. De factor lichaamsgewicht in de mixture vergelijkingen, die gebruikt wordt om het totaal lichaamsvolume te berekenen, zou verantwoordelijk kunnen zijn voor deze bevindingen. Als mogelijke verklaring werd geopperd dat het werkelijk geleidend lichaamsvolume in obese personen overschat wordt door mixture vergelijkingen.

Vergelijking tussen de regressie en de mixture benadering voor het meten van veranderingen in lichaamssamenstelling tijdens grote gewichtsverliezen toonde aan dat relatieve veranderingen in de weerstand index van Recw, Ricw en Rinf in dezelfde orde van grootte waren als relatieve veranderingen in ECW. ICW en TBW, terwijl de mixture vergelijkingen systematisch lange-termijn verliezen in vochtcompartimenten overschatten (Hoofdstuk 4). Deze resultaten bevestigen de veronderstelling dat mixture vergelijkingen de veranderingen in geleidend lichaamsvolume overschatten tijdens grote gewichtsverliezen. 


\section{Hemodialyse patiënten}

In hemodialyse patiënten onderschatte BIS met gebruik van mixture vergelijkingen TBW met $6.9 \mathrm{~L}$ en ECW met $2.3 \mathrm{~L}$ (Hoofdstuk 5). Bovendien waren betrouwbaarheidsintervallen erg groot. De meetfout van BIS correleerde significant met de relatieve grootte van de TBW en ECW compartimenten, uitgedrukt als TBW:lichaamsgewicht en ECW:lichaamsgewicht. In tegenstelling tot de slechte overeenkomst tussen absolute vochtvolumes gemeten met BIS en de dilutie-methode correleerden veranderingen in ECW gemeten met BIS significant met veranderingen in lichaamsgewicht zowel tijdens geïsoleerde ultrafiltratie $(r=0.83)$ als tijdens hemodialyse $(r=0.76)$. Deze correlatie werd echter niet gevonden voor TBW veranderingen.

\section{Segmentele metingen}

In Hoofdstuk 6 werden resultaten van de traditionele hand-voet metingen vergeleken met hand-hand en voet-voet metingen als alternatieve metingen voor klinisch gebruik. Om het effect van de lichaamsvorm te kunnen bestuderen werden metingen verricht in een populatie variërend in mate van overgewicht. Recw, Ricw en R50 waardes van de hand-voet metingen konden nauwkeurig worden beschreven als functie van Recw, Ricw en R50 waardes van de twee alternatieve metingen. De mate van overgewicht had geen invloed op deze relatie. Echter, de relatieve omtrek van armen en benen (uitgedrukt als de ratio omtrek arm / omtrek been) en de lengte van de romp beīnvloedden de relatie tussen $R$-waardes van de verschillende metingen. De nauwkeurigheid van TBW. ECW en ICW voorspellingen gebaseerd op weerstand-indexen van $\mathrm{R}$-waardes afkomstig van hand-hand metingen was vergelijkbaar met de traditionele hand-voet metingen. De voet-voet metingen waren iets minder nauwkeurig.

\section{Cystic fibrosis}

In kinderen met cystic fibrosis werd de validiteit van BIS met mixture vergelijkingen voor het monitoren van de lichaamssamenstelling vergeleken met de dilutie methodes, met dual energy X-ray absorptiometry (DXA) en de huidplooi methode (Hoofdstuk 7). Kinderen werden drie keer gemeten met tussenposen van 6 maanden. BIS onderschatte TBW met 2.9 $\mathrm{L}$, vetvrije massa (FFM) met $3.4 \mathrm{~kg}$ en overschatte vetmassa (FM) met $4.3 \mathrm{~kg}$. Resultaten van de huidplooi methode waren meer in overeenstemming met DXA dat resultaten van BIS. Veranderingen in lichaamscompartimenten gemeten met BIS of de huidplooien verschilden niet van veranderingen gemeten met de referentie methodes. Veranderingen in TBW, ECW en FFM berekend met de mixture vergelijkingen waren echter niet significant gecorreleerd met veranderingen gemeten met de dilutie methoden en DXA. Veranderingen in de weerstand index bij lage frequenties, $L^{2} / R e c w$ en $L^{2} / R 50$, correleerden echter wel met veranderingen in FFM gemeten met DXA. Er werd verondersteld dat de goede resultaten van de huidplooi-methode vergeleken met BIS verklaard kunnen worden door de bijdrage van de factor gewicht in de vergelijkingen waarmee de som van de huidplooien wordt omgezet in vet- en vetvrije massa. Aangezien de som van de huidplooien niet veranderde tijdens de studieperiode waren de berekende veranderingen in FFM en FM veroorzaakt door gewichtsveranderingen. De slechte overeenkomst tussen BIS en de referentiemethodes voor het meten van veranderingen zou het gevolg kunnen zijn van het feit dat veranderingen relatief gezien erg klein waren of doordat er ziekte specifieke veranderingen in membraan eigenschappen optraden. 


\section{Maag Darmziekten}

In patiênten met maag-darmaandoeningen (Hoofdstuk 8) onderschatte BIS TBW $(3.1 \mathrm{~L}$ ) en ICW $(3.7 \mathrm{~L})$ en overschatte ECW $(0.6 \mathrm{~L})$. Opsplitsing van de groep in een deplete en nietdeplete groep bracht aan het licht dat TBW en ICW alleen in de niet deplete groep werden onderschat. Andere BIS variabelen waren ook verschillend tussen de twee groepen. In de deplete patiènten was de kritieke frequentie $60 \%$ hoger en de membraan capaciteit $40 \%$ lager dan in de niet-deplete patiènten.

In deze studie werden ook verschillende screenings-methoden, gebaseerd op impedantiemetingen, voor het identificeren van deplete patiênten getest. De in de literatuur beschreven impedantie vector methode, die de weerstand en reactantie (Xc) bij $50 \mathrm{kHz}$, genormaliseerd naar lengte $(\mathrm{R} / \mathrm{H}$ en $\mathrm{Xc} / \mathrm{H})$, vergelijkt met normaal waardes, was niet in staat deplete patienten te identificeren. De ratio van de weerstandsindex en de ideale vetvrije massa (iFFM) bij R50, Ricw en Rinf (bv ( $L^{2} / R$ inf) / iFFM) werd geintroduceerd als een alternatieve screeningsmethode. Toepassing van deze methode resulteerde voor R50 en Rinf in vergelijkbare sensitiviteit $(86 \%)$ en specificiteit $(73-80 \%)$. De ratio berekend met Ricw bleek ongeschikt voor het onderscheiden van deplete en niet deplete patiènten. $\mathrm{Er}$ werd geconcludeerd dat de waardes van vochtcompartimenten verkregen met BIS beìnvioed worden door de aanwezigheid van depletie, waarschijnlijk als gevolg van veranderingen in electrische eigenschappen van het lichaam op cellulair niveau. Voor screeningsdoeleinden kan de voorgestelde ratio echter wel van waarde zijn.

\section{Conclusies}

De resultaten van de studies gepresenteerd in dit proefschrift overziend concluderen we dat BIS met gebruik van mixture vergelijkingen geen universeel toepasbare methode voor het meten van de lichaamssamenstelling is (Hoofdstuk 9). De natuurkundige wetmatigheden waarop de methode gebaseerd is zijn waarschijnlijk niet geldig wanneer er veranderingen in de lichaamssamenstelling optreden en tijdens ziekte. Niet alleen de grootte van de vochtcompartimenten maar ook de samenstelling ervan en de electro-fysische eigenschappen van membranen hebben invloed op de waarde van de weerstand die gemeten wordt. Waarschijnlijk zijn de toegepaste vergelijkingen alleen geidig voor gezonde personen, maar niet in patiënten waar veranderingen in membraan eigenschappen waarschijnlijk zijn zoals tijdens sepsis en klinische depletie. De invloed van storende factoren, mogelijkheden en beperkingen van BIS voor klinisch gebruik worden beschreven in Hoofdstuk 9. 
Samenvatting 


\section{APPENDIX I}

\section{Standard measurement conditions}

Because a variety of factors influence impedance measurements, standardization of measurements is advised. In the studies presented in this thesis all BIS measurements were performed according to the following guidelines:

- Patients are fasted overnight and have empty bladders.

- Patients wear light clothing.

- All metal containing accessories, like watches, rings and bracelets are removed.

- Patients with implanted defibrillators, pacemakers, stents or with metal suture material in the heart or large vessels are not measured.

- BIS measurements are not performed in conjunction with other devices that inject a measurement current, including impedance cardiography instrumentation. Use of other devices in conjunction with the BIS device may cause the safe current limit to be exceeded.

- Subjects lay relaxed on a non-conducting surface in supine position with the arms comfortably abducted from the body 15 degrees, and the legs comfortably separated.

- Subjects should be in a supine position for at least 10 minutes because body posture affects measured impedance due to redistribution of fluid from limbs to trunk resulting in an increase of measured $R$ when subjects are lying down.

- It is recommended that the subject is not in contact with or in very close proximity to metal surfaces as this may significantly affect high frequency measurement results.

- After cleaning all skin contact areas with alcohol, aluminum foil spot electrodes are placed on the dorsal surface of the hands and feet at the distal metacarpals and metatarsals, respectively, and also between the distal prominences of the radius and ulna and between the medial and lateral malleoli at the ankle as shown in figure 1. It is highly recommended that distinct "physical landmarks" are used to determine electrode placement. Care should be taken to position the electrodes accurately. The accuracy of the measurements is predominantly determined by the position of the voltage sense electrodes

- Current-injector electrodes should always be placed distal to the voltage sense electrodes.

- The electrodes should have a contact area of $5 \mathrm{~cm}^{2}$ or more.

- Bio-impedance spectra can be obtained at different frequencies from $1 \mathrm{kHz}$ to $1 \mathrm{Mhz}$. In the present studies a range of 48 frequencies between 5 and $500 \mathrm{kHz}$ was used.

- The BIS Analyzer measured the $R$ and $X c$ at these logarithmically spaced frequencies. Data were fit to the equivalent Cole-Cole circuit model using curve-fitting procedures. The electrical model consists of an Recw (resistance of extracellular water) in parallel with a number of combinations of an Ricw (resistance of intracellular water) and a $\mathrm{Cm}$ (membrane capacitance).

- Total- (TBW), extracellular- (ECW) and intracellular water (ICW) were predicted using equations from mixture theory (Appendix III). 
Appendix

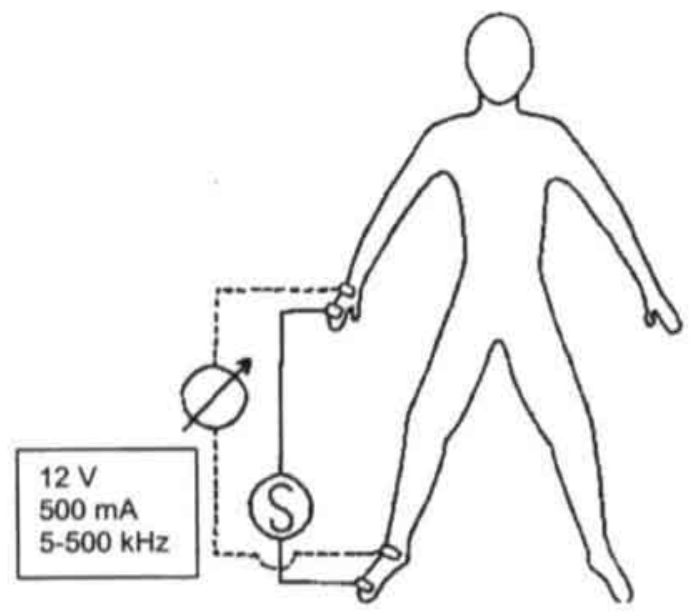

Figure 1. Subject positioning during a bioelectrical impedance measurement. 


\section{APPENDIX ॥}

\section{Theoretical description of BIS}

In biological structures, application of a constant low-level alternating current results in an impedance to the spread of the current that is frequency dependent. Impedance $(Z)$ is the frequency-dependent opposition of a conductor to the flow of an alternating electric current and is a function of resistance (R) and reactance (Xc), such that:

$$
\mathrm{Z}^{2}=\mathrm{R}^{2}+\mathrm{Xc^{2 }}
$$

$R$ is equal to the pure opposition to flow of an alternating current, $X c$ is the opposition to flow of electric current caused by capacitance, or the voltage stored by a condensor for a brief period of time, produced by tissue interfaces and cell membranes'. Capacitance causes the administered current to lag behind the voltage and creates a phase shift that is represented geometrically as the phase angle or the arc tangent of the ratio Xc/R.

If skeletal muscle tissue is measured the geometric relationships between impedance, resistance, reactance and phase angle depend on the frequency of the administered electrical current and are described as an impedance plot (fig 1).

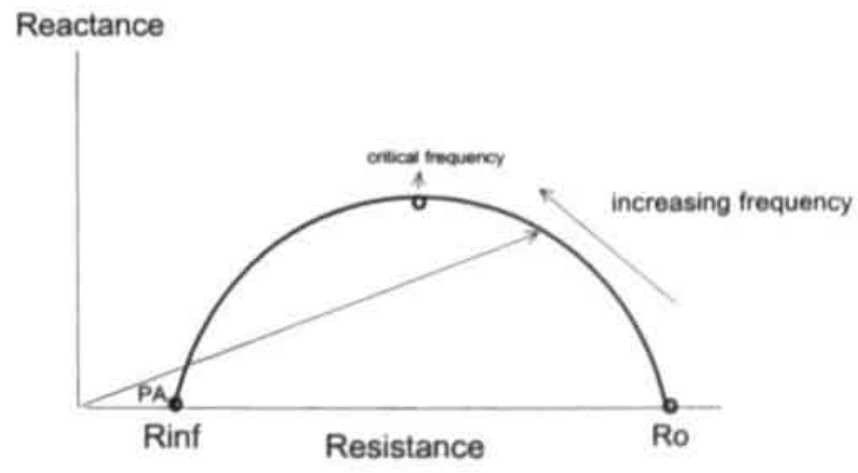

Fig. 1 The impedance plot. PA, phase angle, Ro resistance at zero frequency, Rinf resistance at infinite frequency.

In the low frequency range there is minimal conduction through the cells and conductivity is governed primarily by the properties of the extracellular water. At these frequencies the measured impedance is almost purely resistive. As the frequency increases the current penetrates the cell membranes and $X c$ increases. Because of the change in polarity with alternating current, the cell membrane charges and discharges the current at the rate of the applied frequency. The impedance decreases with increasing frequency because the amount of conducting volume is increasing. At the critical or characteristic frequency (Fc) the reactance is maximal. Above this frequency the reactance decreases as the cell membranes and tissue interfaces lose their capacitive properties. At very high frequencies the current flows through both the ECW and ICW compartments in properties dependent on their relative conductivity and volumes. Thus both at very high and very low frequencies the impedance is 
purely resistive and independent of the membrane capacitance, while at the critical frequency the effect of membrane capacitance on measured $Z$ is at a maximum ${ }^{2}$.

The basis for the application of impedance variables for the assessment of human body composition is a simple electrical circuit model (fig. 2).

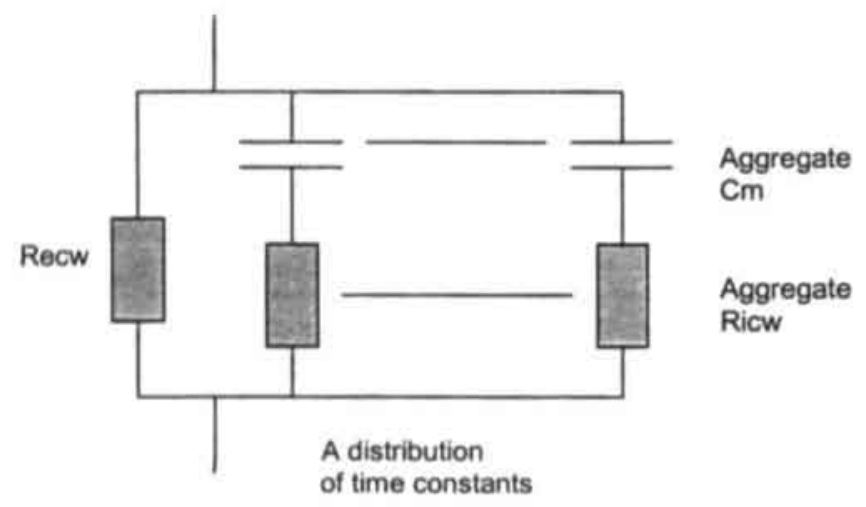

Figure 2. Equivalent electrical circuit analogous to Cole model. Recw is aggregate component value in ohms; Ricw is aggregate component in ohms; and membrane capacitance $(\mathrm{Cm})$ is aggregate value in farads.

The model includes a resistance attributable to an extracellular path, dependent on the amount and composition of extracellular fluid, and a complex intracellular path, including cell membrane capacitance and intracellular resistance.

The BIS approach is based on analyzing the multi-frequency impedance data by the theory developed by Cole ${ }^{3}$. The theory proposes that the variation in R and Xc of biological components of the body with frequency can be represented by the following general model:

$Z=\operatorname{Rinf}+\left(R_{0}-\operatorname{Rinf}\right) /\left[1+(w t)^{t a d}\right]$

Z: impedance

$\mathbf{R}_{0}$ : the resistance at zero frequency

Rinf: the resistance at infinite frequency

j. $\sqrt{ }(-1)$

w: frequency in radians/s

t: the time constant associated with the cell membrane

$\alpha$ : the distribution of the time constant'.

Because the extracellular conduction pathway is principally a resistive path, it is indicated as Recw. The intracellular pathway includes the capacitive influence of cell membranes $(\mathrm{Cm})$ and intracellular resistance (Recw). At low frequencies $R_{0}$ equals Recw. At an infinite 
frequency, the effects of $\mathrm{Cm}$ become negligible and the current passes through both Recw and Ricw in a parallel configuration so that $R$ Rinf $=($ Ricw $\cdot$ Recw $) /($ Ricw $+R e c w)$.

The original Cole model was extended to allow for the frequency invariant time delay (Td) caused by the speed at which electrical information is transferred trough a conductor. The overall modeled equation used in the Xitron curve fitting software is:

$z=\left[\frac{\text { Recw }}{\text { Recw + Ricw }}\right]\left[\operatorname{Ricw}+\frac{\text { Recw }}{1+[j w \text { Cm(Recw + Ricw })]}\right]\left(e^{-i w 1 d}\right)$

The values of Recw, Ricw, , Cm Td are calculated by iterative, nonlinear curve fitting. The value of the critical or characteristic frequency (Fc) is determined after the other model components have been determined ${ }^{2}$.

\section{References}

1. Lukaski HC. Biological indexes considered in the derivation of the bioelectrical impedance analysis. Am J Clin Nutr 1996 Sep;64(3 Suppl):397S-404S.

2. Lorenzo de A, Andreoli A, Matthie J, Withers P. Predicting body cell mass with bioimpedance by using theoretical methods: a technological review. J Appl Physiol 1997 (82):1542-1558.

3. Cole KS. Membranes, Ions and Impulses: A Chapter of Classical Biophysics. Berkeley, CA: Univ. of Calif. Press, 1972. 


\section{APPENDIX III}

\section{Volume equations}

The ECW and ICW volumes are predicted from the modeled RecW and Ricw by using equations presented in the Xitron manual. These equations are derived from Hanai's theory. This theory describes the effect that a concentration of nonconductive material has on the apparent resistivity $(\rho)$ of the surrounding conductive fluid:

$\rho=\frac{\rho_{0}}{(1-C)^{3 / 2}}$

$\rho$ : the apparent resistivity of a conductive material

$\rho_{0}: \quad$ the actual resistivity of a conductive material

C: volumetric concentration of the nonconductive material in the mixture.

Based on this equation and with the following assumptions volume equations were derived:

1. At low frequencies the volumetric concentration of nonconductive elements in the body is given by:

$$
1 \cdot \frac{\text { Vecw }}{V_{\text {tot }}}
$$

$V_{\text {tot }}$ : total body volume

2. At high frequencies the volumetric concentration of nonconductive elements in the body is given by

$$
1-\frac{V_{e c w}+V_{i c w}}{V_{\text {bot }}}
$$

3. The total body volume is $W / D_{b}$ in which $W$ is body weight and $D b$ is body density $(\mathrm{kg} / \mathrm{L})$

4. The total volume of a body fluid can be described by

$$
V_{F}=K_{B} \rho_{F} \frac{\mathrm{L}^{2}}{\mathrm{R}}
$$

$V_{F}$ : total volume of the fluid in the body

$\rho_{F}$ : the resistivity of the fluid

L: body height

$R$ : the measured resistance between wrist and ankle.

$K_{\mathrm{b}}$ : a factor relating the relative proportions of the leg, arm and torso to the total measured volume:

$$
K_{\mathrm{e}}=\left(1 \mathrm{~L}^{2}\right)\left[\left(L_{1} / C_{1}^{2}+L_{1} C_{1}^{2}+L_{2} / C_{2}{ }^{2}\right) \cdot\left(2 L_{0} C_{3}{ }^{2}+2 L_{1} C_{1}^{2}+L_{1} C_{1}^{2}\right)\right]
$$

$L_{1}, L_{1}, L_{2}$ : length of leg, trunk and arm

$\mathrm{C}_{\mathrm{b}}, \mathrm{C}_{\mathrm{b}}, \mathrm{C}_{\mathrm{a}}$ : circumference of leg, trunk and arm 
Appendix

5. The factors $D_{b}, K_{B}$ and $\rho_{F}$ can be considered roughly constant.

6. The Hanoi equation is applicable at high frequencies and low frequencies to mixtures in the human body.

The volume of the extracellular water can now be described as:

$$
\text { Vecw }=k e c w\left[\frac{L^{2} W_{t}}{R e c w}\right] \text { vs }
$$

The constant keck can be described as:

$$
\text { keck }=\frac{1}{1000}\left[\frac{\left(K_{b}\right)^{2}\left(\rho_{\text {eco }}\right)^{2}}{D_{b}}\right]^{13}
$$

$\rho_{\text {now }}$ : the resistivity of extracellular water $(\mathrm{ohm} \mathrm{cm}$ ).

The volume of intracellular water (View) is calculated from the equation:

$$
\begin{aligned}
& 1+\left[\frac{V_{i c w}}{V_{e c w}}\right]^{s / 2}=\left[\frac{\text { Rec + Rick }}{\text { Rick }}\right]\left[1+\frac{k p \text { View }}{V_{\text {eco }}}\right] \\
& \text { kp: Plow / pow }
\end{aligned}
$$

Total body water is calculated as Vtbw $=\mathrm{Vecw}+\mathrm{Vicw}$

143 
Appendix 


\section{Nawoord}

Toen ik 11 jaar geleden aan een parttime functie bij de afdeling Diettetiek begon was het niet de bedoeling om te promoveren. Mijn functie omhelsde meer dan alleen onderzoek. Het begeleiden van onderzoeksactiviteiten en het scholen van mensen vond ik een enorme uitdaging. Gedurende die 11 jaar was er steeds een spanningsveld tussen die twee taken, die ik beide wilde vervullen. Als enige onderzoeker van de afdeling was het moeilijk veranderingen tot stand te brengen omdat mijn invalshoek nogal eens verschilde met die van dieztisten. Gaandeweg werd het mij duidelijk dat het ook voor de afdeling belangrijk was mijn studies met de BIA in de vorm van een promotie af te ronden. Het onderzoek was een vrij solitaire aangelegenheid wat een aantal voordelen heeft maar ook ernstige nadelen. Bij een aantal mensen kon ik echter altijd aan de deur kloppen voor hulp. Zonder die hulp zou dit proefschrift niet tot stand gekomen zijn.

Allereerst wil ik Peter Soeters bedanken. Hij heeft me door zijn goede begeleiding doen inzien wat mijn sterke en minder sterke kanten zijn. Door zijn geloof in het tot stand komen van dit boekje voelde ik me gesterkt. Al de jaren dat ik Peter ken heeft hij zich hard gemaakt voor professionalisering van het vakgebied Diêtetiek. Zijn ideeên hierover spraken me erg aan. Het valideren van een meetinstrument is te zien als een kleine stap in die richting. Peter, bedankt voor je stimulerende begeleiding, je heldere kijk op zaken en de gezellige samenwerking.

Bernard van Kreel is de man naar wie ik toe kon gaan met vragen over de theoretische achtergrond van de BIA. Ondanks het feit dat zijn theoretische uitleg soms mijn petje te boven ging heb ik veel van hem geleerd. Zijn gedrevenheid om alle mogelijkheden van de BIA te bestuderen bewonder ik.

Zonder Phil Geertings had er op de afdeling Diêtetiek geen onderzoek verricht kunnen worden. Toen ze mij destijds als onderzoeker aanstelde was dat een nieuwe ontwikkeling. Diètetiekformatie werd ingeleverd voor een onderzoeker. Vanuit onze verschillende achtergronden keken we wel vaak verschillend tegen zaken aan. Dat maakte het voor ons beiden niet altijd even gemakkelijk. Vaak voelde ik me een vreemde eend in de bijt. Ik heb er echter veel van geleerd en wil haar daarvoor bedanken.

Ook alle afdelingsgenoten wil ik bedanken voor de interesse, het medeleven en vooral voor de gezelligheid. In de loop der jaren zijn meerdere afdelingsgenoten onderzoek gaan uitvoeren. Bij hen vond ik begrip voor de frustraties die daarmee soms gepaard gaan. Met name José en Marja wil ik bedanken voor hun luisterend oor, tips en aanmoedigingen.

Mia Meers wil ik hartelijk bedanken voor de deuterium analyses, Gabri. Jean en Hans voor de broom analyses.

Bij Lily Fredrix, die ik regelmatig in de trein tegenkwam, vond ik begrip voor de hectische omstandigheden waaronder er soms gewerkt moest worden doordat ik de zorg voor 3 kinderen moest zien te combineren met het schrijven van een proefschrift. In 10 minuten tijd kletsten we helemaal bij en had ik altijd het gevoel niet alleen te staan in deze voortdurende onrust.

In de loop der jaren heb ik diverse kamergenoten gehad. Samen met Bernadette van Acker betrok ik de ruimte op niveau 2. Er volgde een gezellige tijd waarin we veel lief en leed met elkaar deelden. Ook inhoudelijk kon ik goed met haar overleggen. Bernadette, ik heb veel steun aan je gehad, heel erg bedankt hiervoor. Daarna kwamen Jessica, Karel en Carolien. Ook met hen was het altijd heel gezellig.

Dankzij de hulp van Piet Claessens was elk technisch probleem met de apparatuur snel opgelost. De verpleging van de dialyse afdeling wil ik bedanken voor de medewerking aan het onderzoek op hun afdeling, want het betekent toch altijd weer extra werk.

De patienten die meededen aan het onderzoek wil ik speciaal bedanken, want ondanks het feit dat het hun niets daadwerkelijks oplevert, waren ze toch bereid mee te doen, ter wille van de vooruitgang. 
En dan is er natuurlijk nog het thuisfront, onze altijd pratende kinderen, die steeds het naadje van de kous willen weten en nooit moe lijken te worden. Vragen als: "Wat hebben patiënten nu aan dat onderzoek, worden ze er sneller beter door?" en " Kun je niet eens iets echt belangrijks uitvinden?" zorgden ervoor dat ik alle bezigheden vrij goed kon relativeren. Henk gaf me de rust die ik nodig had op dagen vol vertwijfeling. Bedankt voor de steun en het begrip.

Mijn ouders wil ik bijzonder bedanken. Dankzij hun inzet en steun heb ik immers altijd de vrijheid gehad datgene te doen wat ik belangrijk vond. 


\section{Curriculum Vitae}

Petronella Lucia Martha Cox-Reijven werd op 13 December 1959 geboren in Haler-Uffelse. In 1978 behaalde ze het WWO Atheneum-B diploma aan de "Philips van Horne Scholengemeenschap" in Weert. Aansluitend bezocht ze een jaar het Moller Instituut te Tilburg voor de vakken tekenen en handvaardigheid. Van 1979 tot 1986 studeerde ze aan de Landbouw Hogeschool Wageningen. Afstudeervakken waren Humane Voeding. Toxicologie en Onderwijskunde. Van 1986 tot 1987 werkte ze bij de afdeling fysiologie van het Nederlands Instituut voor Zuivelonderzoek (NIZO) in Ede waar ze onder leiding van Dr F de Waard onderzoek verrichtte naar de effecten van de samenstelling van een nieuw zuivelproduct op het stikstof, calcium, fosfor en magnesium metabolisme in ratten. Van 1987 tot 1989 werkte ze als AIO aan de Universiteit Maastricht bij de vakgroep algemene Heelkunde onder leiding van prof. PB Soeters en Dr. NEP Deutz waar ze onderzoek verrichtte naar het stikstofmetabolisme en met name het glutamine metabolisme van lever, darmen en skeletspier. In 1988 trouwde ze met Henk en in 1989 werd hun eerste zoon geboren. Van 1989 tot 1991 bleef ze op parttime basis als vrijwilliger verbonden aan het onderzoek op de afdeling Heelkunde. Na de geboorte van hun tweede zoon in 1991 werkte ze op freelance basis bij de Open Universiteit (OU) te Heerlen, afdeling Voedingswetenschappen, onder leiding van prof $\mathrm{J}$ de Vries, aan het ontwikkelen van de cursus Food Nutrition and Toxicity. Tevens startte ze in 1991 met haar huidige parttime functie als onderzoeker bij de afdeling Diêtetiek van het Academisch Ziekenhuis Maastricht met als hoofd P Geerlings. Centraal binnen deze functie staan het valideren van meetinstrumenten en het begeleiden van onderzoeksactiviteiten binnen de afdeling. In 1997 werd hun dochter geboren. Vanaf 1997 concentreerde ze haar activiteiten op het onderzoek beschreven in dit proefschrift dat werd uitgevoerd in samenwerking met de vakgroep Heelkunde onder begeleiding van PB Soeters. 
Curriculum vitae 


\section{Publications}

- van Kreel BK, Cox-Reyven N, Soeters P. Determination of total body water by multifrequency bio-electric impedance: development of several models. Med Biol Eng Comput 1998; 36:337-345.

- Cox-Reijven PL, Soeters PB. Validation of bio-impedance spectroscopy: effects of degree of obesity and ways of calculating volumes from measured resistance values. Int J Obes Relat Metab Disord 2000; 24:271-280. (Cox-Reijven N Erratum. Int J Obes Relat Metab Disord 2000; 24(9):1231).

- Kooman JP, Cox-Reijven PL, van der Sande FM, van den Ham EC, Leunissen KM. Assessment of body composition in ESRF. (Letter). Kidney Int 2001; 59:383-384.

- Cox-Reijven PL, Kooman JP. Soeters PB, van der Sande FM, Leunissen KM. Role of bioimpedance spectroscopy in assessment of body water compartments in hemodialysis patients. Am J Kidney Dis 2001; 38(4):832-838.

- Cox-Reijven PL, van Kreel B, Soeters PB. Bio-electrical impedance spectroscopy: Alternatives for the conventional hand-to-foot measurements. Clin Nutr 2002; 21:127133.

- Barendregt K, Cox-Reijven PL, Hogen E van den, Beijer S, Geerlings P, Soeters PB. Case study of the clinical usefulness of bioelectrical impedance spectroscopy in evaluating nutritional status.. J Hum Nutr Diet 2002; 15:189-192.

- Cox-Reijven PL, van Kreel B, Soeters PB. Accuracy of bioelectrical impedance spectroscopy in measuring changes in body composition during severe weight loss. JPEN J Parenter Enteral Nutr 2002; 26:120-127.

- Cox-Reijven PLM, van Kreel B, Soeters PB. Bioelectrical impedance analysis during severe weight loss. Comparison of the regression and mixture approach for measuring changes in body fluid compartments. Submitted to Clin Nutr

- Cox-Reijven PLM, Hendrix JJE, Forget PP, van Kreel B, Soeters PB. Bioelectrical impedance spectroscopy and skinfold measurements for monitoring body composition in children with cystic fibrosis. Submitted to Pediatrics.

- Cox-Reijven PLM, van Kreel B, Soeters PB. Bioelectrical impedance measurements in patients with gastrointestinal disease. Validation of the spectrum approach and a comparison of different methods for screening nutritional depletion. Submitted to Am J Clin Nutr. 
